UNIVERSIDADE DE BRASÍLIA

FACULDADE DE TECNOLOGIA

DEPARTAMENTO DE ENGENHARIA CIVIL E AMBIENTAL

\begin{abstract}
AVALIAÇÃO DOS EFEITOS DAS ALTERAÇÕES NA COBERTURA E USO DO SOLO SOBRE O REGIME DE VAZÕES VIA MODELAGEM HIDROLÓGICA CONSIDERANDO INCERTEZA PARAMÉTRICA
\end{abstract}

PLÁCIDO SOUSA BESERRA

ORIENTADOR: DIRCEU SILVEIRA REIS JUNIOR

DISSERTAÇÃO DE MESTRADO EM TECNOLOGIA AMBIENTAL E RECURSOS HÍDRICOS

PUBLICAÇÃO: PTARH.DM - 194/16

BRASÍLIA/DF: SETEMBRO - 2016 
UNIVERSIDADE DE BRASÍLIA

FACULDADE DE TECNOLOGIA

DEPARTAMENTO DE ENGENHARIA CIVIL E AMBIENTAL

\section{AVALIAÇÃO DOS EFEITOS DAS ALTERAÇÕES NA COBERTURA E USO DO SOLO SOBRE O REGIME DE VAZÕES VIA MODELAGEM HIDROLÓGICA CONSIDERANDO INCERTEZA PARAMÉTRICA}

\section{PLÁCIDO SOUSA BESERRA}

DISSERTAÇÃO SUBMETIDA AO DEPARTAMENTO DE ENGENHARIA CIVIL E AMBIENTAL DA FACULDADE DE TECNOLOGIA DA UNIVERSIDADE DE BRASÍLIA COMO PARTE DOS REQUISITOS NECESSÁRIOS PARA A OBTENÇÃO DO GRAU DE MESTRE EM TECNOLOGIA AMBIENTAL E RECURSOS HÍDRICOS.

APROVADA POR:

Prof. Dirceu Silveira Reis Junior, PhD (ENC-UnB)

(Orientador)

Prof. Sérgio Koide, PhD (ENC-UnB)

(Examinador Interno)

Prof. Daniel Andrés Rodriguez ( CSST-INPE)

(Examinador Externo) 


\section{FICHA CATALOGRÁFICA}

\begin{tabular}{|c|c|}
\hline BESERRA, PLÁ & \\
\hline $\begin{array}{r}\text { Avaliação dos ef } \\
\text { via mode } \\
2016 . \\
\text { xvii, } 128 \mathrm{p} ., 210 \\
\text { Hídricos, } \\
\text { de Tecno }\end{array}$ & $\begin{array}{l}\text { e uso do solo sobre o regime de vazões } \\
\text { ncerteza paramétrica. [Distrito Federal] } \\
\text { re, Tecnologia Ambiental e Recursos } \\
\text { - Universidade de Brasília. Faculdade } \\
\text { la Civil e Ambiental. }\end{array}$ \\
\hline 1.Uso do solo & 2. Modelagem hidrológica \\
\hline 3.Oeste Baiano & 4. Incertezas \\
\hline I. ENC/FT/UnB & II. Título (série) \\
\hline
\end{tabular}

\section{REFERÊNCIA BIBLIOGRÁFICA}

BESERRA, P.S. (2016). Avaliação dos efeitos das alterações na cobertura e uso do solo sobre o regime de vazões via modelagem hidrológica considerando incerteza paramétrica. Dissertação de Mestrado em Tecnologia Ambiental e Recursos Hídricos, Publicação PTARH.DM - 194/2016, Departamento de Engenharia Civil e Ambiental, Universidade de Brasília, Brasília, DF, 128p.

\section{CESSÃO DE DIREITOS}

AUTOR: Plácido Sousa Beserra.

TÍTULO: Avaliação dos efeitos das alterações na cobertura e uso do solo sobre o regime de vazões via modelagem hidrológica considerando incerteza paramétrica.

GRAU: Mestre ANO: 2016

É concedida à Universidade de Brasília permissão para reproduzir cópias desta dissertação de mestrado e para emprestar ou vender tais cópias somente para propósitos acadêmicos e científicos. $\mathrm{O}$ autor reserva outros direitos de publicação e nenhuma parte desta dissertação de mestrado pode ser reproduzida sem autorização por escrito do autor.

Plácido Sousa Beserra

Rua Imbuias, Casa 8, Condomínio Verde, Jardim Botânico

CEP: 71.680-608, Brasília - DF, Brasil 


\section{AGRADECIMENTOS}

À minha mãe Carmen, que além de ter me dado a vida me deu um grande exemplo de força e determinação e ao meu pai José Beserra por todas as oportunidades.

À Maura Martins, minha segunda mãe e seu esposo Tião Francelino, que me deram muito mais do que suporte material, mas uma extensão do meu lar.

À minha mulher Ana Carolina, uma companheira paciente, motivadora e inspiradora.

Ao meu orientador e professor Dirceu Reis Jr, meus agradecimentos pela paciência e valiosos conselhos.

A toda a equipe de professores do Programa de Pós-Graduação em tecnologia Ambiental e Recursos Hídricos por tantos ensinamentos.

Ao Dr. Edson Eyji Sano, que forneceu os dados de cobertura e uso do solo do Oeste Baiano.

À equipe do Grupo de Pesquisa de Hidrologia de Grandes Escala do Instituto de Pesquisas Hidráulicas - IPH-UFRGS, em especial a Fernando Fan, pela disponibilidade em sanar todas as dúvidas sobre o uso do modelo MGB-IPH.

À Dra. Maria Tereza Pantoja Gaspar, que contribuiu com este trabalho fornecendo os dados hidrogeológicos do aquífero Urucuia.

Ao Instituo de Meio Ambiente e Recursos Hídricos do Estado da Bahia pelo fornecimento dos dados de caracterização física da área de estudo.

À equipe do Departamento de Desenvolvimento e Cooperação Técnica da SNSA/MCIDADES, nas pessoas de Manoel Renato Filho e Hélio José Freitas, pelo apoio à realização deste trabalho.

À toda a turma de alunos do mestrado de 2014/1 do PTARH pelo companheirismo e amizade. 


\section{RESUMO}

Este estudo foi realizado na bacia do Rio Grande, afluente do Rio São Francisco, no Oeste Baiano, região que é a maior produtora de grãos do estado Bahia e uma das maiores do país. A área de estudo foi escolhida por ter tido ocupação recente, a partir da segunda metade dos anos 1970, quando já se tem a disponibilidade de imagens de satélite, que viabilizaram o histórico de evolução da cobertura e uso do solo. A avaliação dos efeitos das mudanças na cobertura e uso do solo sobre as vazões foi realizada com a utilização do modelo MGB-IPH. Na avaliação foram consideradas as incertezas do modelo e dos parâmetros, para isso, ao invés de se considerar que há um único conjunto de parâmetros que represente a bacia, foi considerado que diversos parâmetros podem representar a bacia. Foram avaliadas as mudanças nas vazões mensais, anuais e nas vazões mínimas, no período de 1969 a 2005, dividido em 3 períodos: P1, de 1969 a 1985, com o uso do solo de 1980; P2, de 1986 a 1995, com o uso do solo de 1990; e P3, de 1996 a 2005, com uso do solo 2000. A detecção de ocorrência de alterações nas vazões em função das mudanças no uso do solo foi realizada pela comparação dos resíduos entre as vazões observadas e simuladas obtidos do período de referência, anterior à mudança no uso do solo, e nos períodos posteriores. Também foram comparados os conjuntos de parâmetros obtidos de calibrações realizadas nos diferentes períodos e, por fim, foram comparadas as respostas da bacia aos diferentes conjuntos de parâmetros obtidos na calibração de cada período. $\mathrm{O}$ modelo se mostrou eficiente em representar a hidrologia da bacia e capaz de detectar efeitos da mudança no uso do solo sobre o escoamento superficial. Em todas as comparações, os resultados indicam que houve redução das vazões devido à substituição da vegetação natural por pastagem e culturas agrícolas. 


\begin{abstract}
This study is about the Rio Grande Basin, a São Franscisco River tributary, in the West of the State of Bahia, the region is the biggest grain producer of the State and one of the biggest of the country. This area was chosen for its recent occupation, starting from the latest 70's, when satellite images became available, which enable the register of land-use or land-cover - LULC. The evaluation of LULC changes effects on streamflow was made using the MGB-IPH model. This evaluation considered model and parameter uncertainty, for this instead of using one parameter set that represents the watershed, was considered that various parameter sets can represent the watershed. Effects on the monthly, annual and minimal streamflow was evaluated between 1969 and 2005, divided in three periods: P1, from 1969 to 1985, using LULC from 1980; P2, from 1986 to 1995, using LULC from 1990; and P3, from 1996 to 2005, using LULC from 2000. The changes detection in streamflow due to changes in LULC was performed by comparing the residuals between observed and simulated streamflow obtained from the reference period prior to the change in land-use, and in subsequent periods. The sets of calibration parameters obtained for each period was also compared, and finally, the simulations obtained with different parameter sets were compared between each other. The MGB-IPH was able to reproduce the watershed hydrology and to detect the LULC changes effects on the runoff. Results have indicated that there was streamflow decrease due to natural cover substitution for pasture and crops.
\end{abstract}




\section{SUMÁRIO}

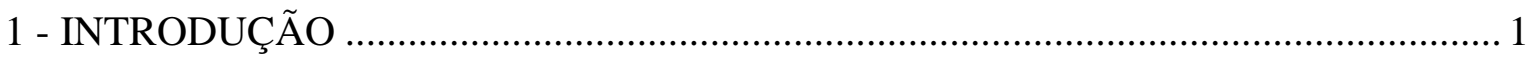

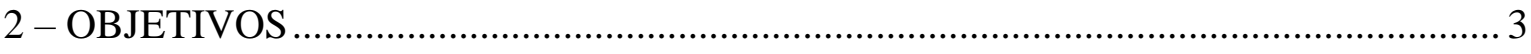

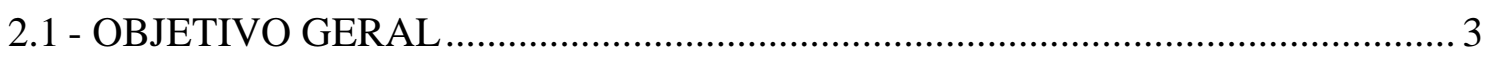

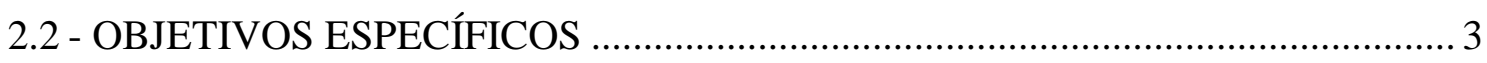

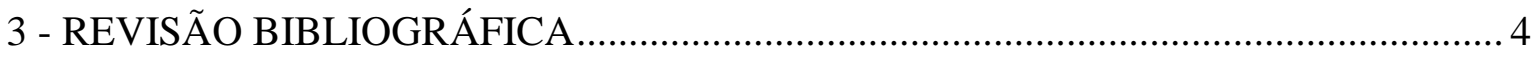

3.1 - O CICLO HIDROLÓGICO E O PAPEL DA VEGETAÇÃO ................................... 4

3.2 - METODOLOGIAS EXPERIMENTAIS DE AVALIAÇÃO DOS EFEITOS DA ALTERAÇÃO DA VEGETAÇÃO SOBRE O REGIME HIDROLÓGICO...................... 5

3.3 - IMPACTOS DAS MUDANÇAS NA COBERTURA E USO DO SOLO SOBRE AS COMPONENTES DO CICLO HIDROLÓGICO ...................................................... 8

3.3.1 - Precipitação …………………………………………………………….. 10

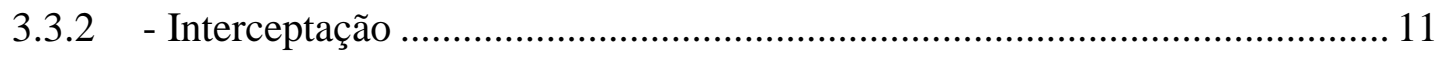

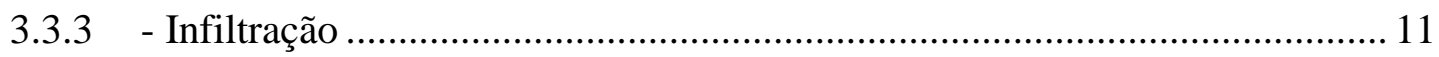

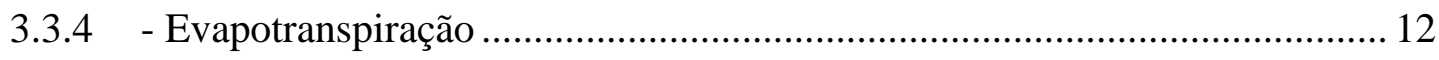

3.4 - IMPACTOS DAS MUDANÇAS NA COBERTURA VEGETAL SOBRE O ESCOAMENTO ………………………………………………………………. 14

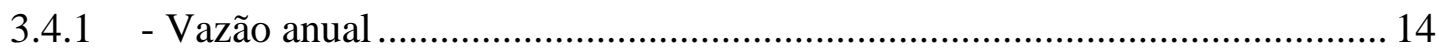

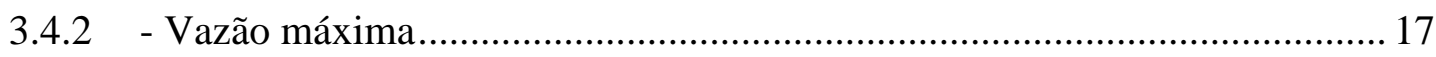

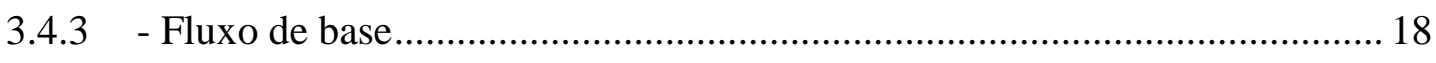

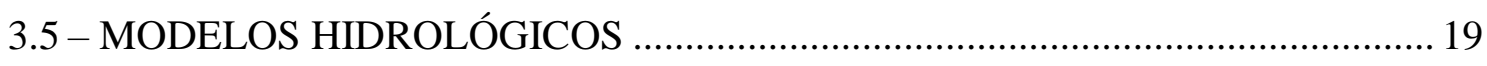

3.5.1 - Classificação dos modelos hidrológicos ........................................................ 20

3.5.2 - Evolução da modelagem hidrológica ............................................................... 22

3.5.3 - Visão geral dos principais modelos hidrológicos............................................ 24

3.6 - INCERTEZAS NA MODELAGEM HIDROLÓGICA ………………………..... 27

3.7 - APLICAÇÃO DE MODELOS HIDROLÓGICOS NA AVALIAÇÃO DOS EFEITOS DA ALTERAÇÃO DA COBERTURA VEGETAL SOBRE O REGIME DE VAZÕES 32 


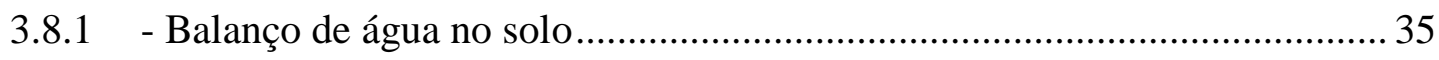

3.8 .2 - Interceptação ............................................................................... 38

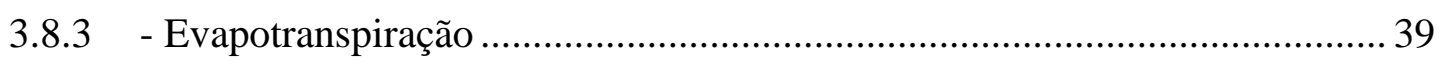

3.8.4 - Escoamento superficial, subsuperficial e subterrâneo............................... 42

3.8.5 - Escoamento na rede de drenagem ...................................................... 44

3.8.6 - Parâmetros do Modelo .............................................................................. 44

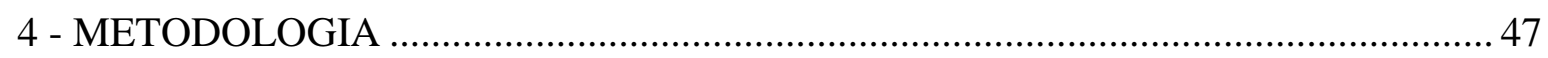

4.1 - DETECÇÃO DOS EFEITOS DAS MUDANÇAS NA COBERTURA E USO DO

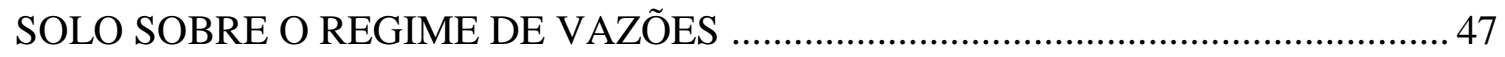

4.1.1 - Análise dos resíduos entre as vazões simuladas e observadas ....................48

4.1.2 - Comparação entre os conjuntos de parâmetros obtidos de diferentes calibrações

4.1.3 - Análise dos resíduos entre as simulações com parâmetros de diferentes calibrações

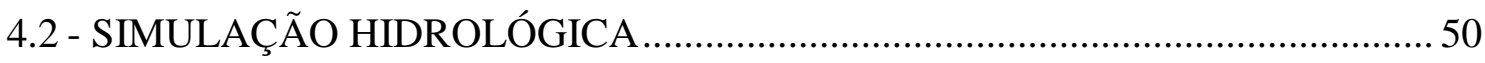

4.2.1 - Preparação dos dados de entrada no MGB-IPH........................................... 51

4.2.2 - Geração de base de dados para aplicação do sistema de informações geográficas .51

4.2.3 - Geração das Unidades de Resposta Hidrológica .........................................53

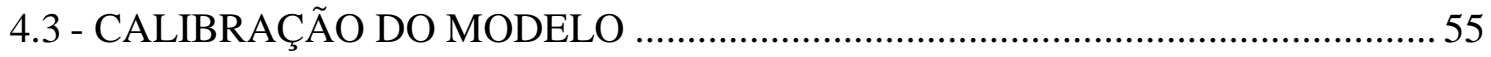

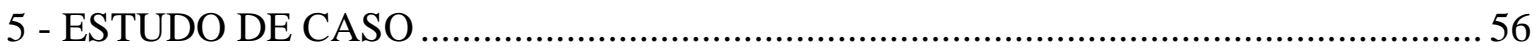

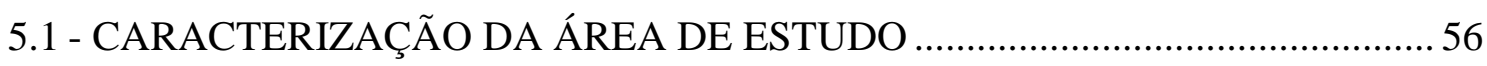

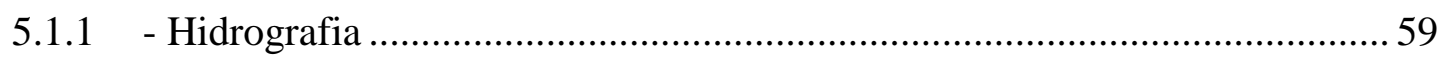

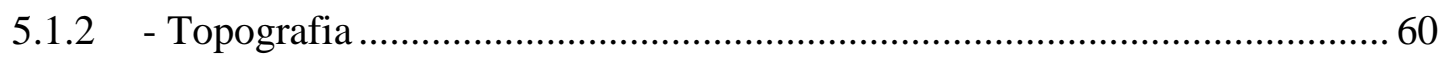

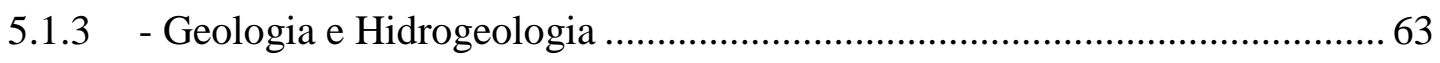

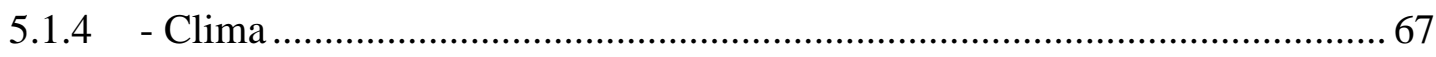

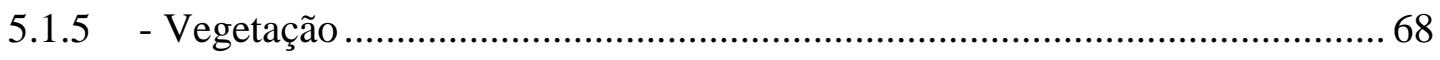

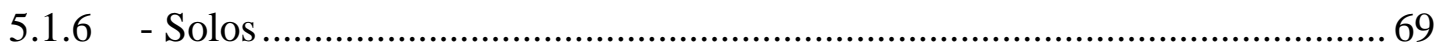




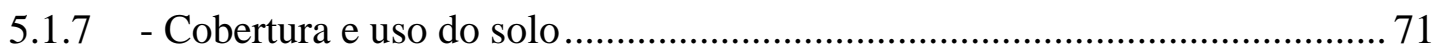

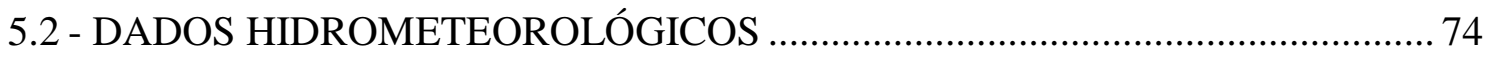

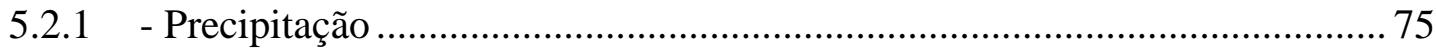

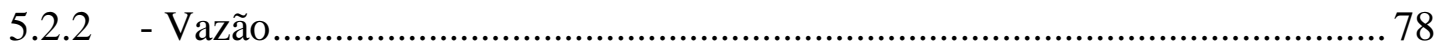

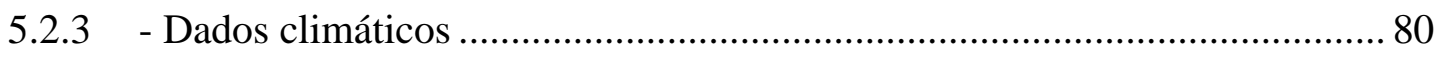

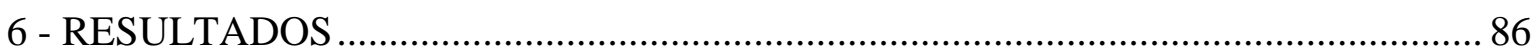

6.1 - BACIA A MONTANTE DO POSTO FLUVIOMÉTRICO NOVA VIDA-

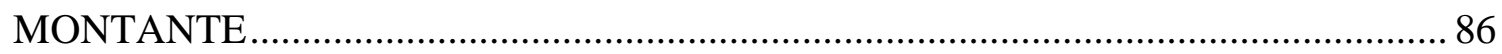

6.1.1 - Calibração do modelo na bacia a montante do posto Nova Vida-Montante87

6.1.2 - Comparação entre as vazões simuladas e as vazões observadas no posto Nova Vida - Montante

6.1.3 - Comparação dos parâmetros da bacia a montante do posto Nova VidaMontante 96

6.1.4 - Comparação entre as simulações com diferentes conjuntos de parâmetros da bacia a montante do posto Nova Vida-Montante .99

6.2 - BACIA A MONTANTE DO POSTO FLUVIOMÉTRICO BOQUEIRÃO ......... 102

6.2.1 - Calibração do modelo na bacia a montante do posto Boqueirão ............... 102

6.2.2 - Comparação entre as vazões simuladas e as vazões observadas no posto Boqueirão 107

6.2.3 - Comparação dos parâmetros obtidos em diferentes calibrações na bacia do Rio Grande 110

6.2.4 - Comparação entre as vazões simuladas com diferentes conjuntos de Parâmetros na bacia a montante do posto Boqueirão 113

7 - CONCLUSÃO E RECOMENDAÇÕES 116 REFERÊNCIAS BIBLIOGRÁFICAS 118 


\section{LISTA DE TABELAS}

Tabela 3.1 - Valores de IAF para diferentes tipos de vegetação (Collischonn, 2001)........ 38

Tabela 3.2 - Valores médios de albedo para diferentes coberturas de solo (Bayer, 2014).. 40

Tabela 3.3 - Resistência superficial mínima para diferentes tipos de cobertura vegetal (Collischonn, 2001).

Tabela 3.4 - Altura de diferentes tipos de cobertura vegetal (Collischonn, 2001). 42

Tabela 3.5 - Parâmetros do MGB-IPH (Collischonn, 2001). 44

Tabela 4.1 - Dados de entrada do modelo MGB-IPH 51

Tabela 5.1 - Evolução da produção de grãos da área de estudo (IBGE, 2016). 57

Tabela 5.2 - Caracterização geológica da Bacia (INEMA, 2014). 64

Tabela 5.3 - Resumo da evolução da cobertura e uso do solo na Bacia do Rio Grande. .... 74

Tabela 5.4 - Estações pluviométricas utilizadas no estudo .75

Tabela 5.5 - Estações fluviométricas da área de estudo. .78

Tabela 5.6 - Estações meteorológicas 80

Tabela 6.1 - Desempenho do modelo nos períodos calibrado e nos demais períodos na bacia a montante do posto Nova Vida-Montante

Tabela 6.2 - Valores das medianas e dos percentis de 10 e $90 \%$ dos resíduos e dos valores de $\mathrm{p}$ das vazões mensais no posto Nova Vida-Montante.

Tabela 6.3 - Valores das medianas e dos percentis de 10 e $90 \%$ dos resíduos e dos valores de $\mathrm{p}$ das vazões médias anuais no posto Nova Vida-Montante.

Tabela 6.4 - Valores das medianas e dos percentis de 10 e $90 \%$ dos resíduos e dos valores de $\mathrm{p}$ das vazões mínimas no posto Nova Vida-Montante. .95

Tabela 6.5 - Resultados do teste de Mann-Whitney para a comparação dos parâmetros obtidos na calibração de cada período na bacia a montante do posto Nova Vida-Montante.

Tabela 6.6 - Comparação dos resíduos entre as simulações obtidas com parâmetos calibrados nos períodos P1, P2 e P3.

Tabela 6.7 - Desempenho do modelo nos períodos calibrados e nos demais períodos da bacia a montante do posto Boqueirão 103

Tabela 6.8 - Valores das medianas e dos percentis de 10 e $90 \%$ dos resíduos e dos valores de $\mathrm{p}$ das vazões mensais no posto Boqueirão. 108

Tabela 6.9 - Valores das medianas e dos percentis de 10 e $90 \%$ dos resíduos e dos valores de $\mathrm{p}$ das vazões médias anuais no posto Boqueirão 109 
Tabela 6.10 - Valores das medianas e dos percentis de 10 e $90 \%$ dos resíduos e dos valores de $\mathrm{p}$ das vazões mínimas no posto Boqueirão................................................................... 110 Tabela 6.11 - Resultados do teste de Mann-Whitney para a comparação dos parâmetros

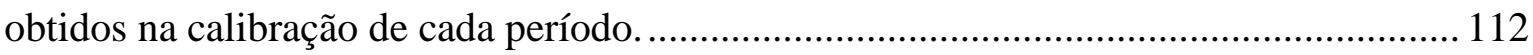
Tabela 6.12 - Comparação dos resíduos entre as simulações obtidas com parâmetos calibrados nos períodos P1, P2 e P3 na bacia a montante do posto Boqueirão. 113 


\section{LISTA DE FIGURAS}

Figura 3.1 - Princípio da metodologia das bacias pareadas: as bacias passam por uma fase de calibração (a) e (b) e em seguida é aplicado o tratamento (c) e (d) (Bayer, 2014)........... 7 Figura 3.2 - (a) apresenta a correlação entre as bacias no período de libração e em (b) a relação no período de tratamento (Bayer, 2014).

Figura 3.3 - Mudanças na vazão anual em função das mudanças da cobertura do solo para diferentes tipos de vegetação (Bosh e Hewlett, 1982 - modificado).

Figura 3.4 - Comparação da evolução da umidade do solo no período seco coberto por floresta e desmatado (Bruinjzeel e Critchley, 1994).

Figura 3.5 - Relação entre a cobertura do solo, a precipitação anual e a evapotranspiração anual (Zhang et al., 2001).

Figura 3.6 - Variação na vazão média anual em função da porcentagem de tratamento aplicado às bacias (Andréassian, 2004).

Figura 3.7 - Mudanças da vazão anual em função da alteração da cobertura vegetal (Bayer, 2014).

Figura 3.8 - Variação da vazão anual em função de diversos tratamentos (Hornbeck, 1993 citado por Brown, 2005).

Figura 3.9 - Variação das incertezas em função da definição da superfície de Pareto obtida após calibração multiobjetivo (Gupta et.al. 1998 - modificado). 30

Figura 3.10 - Balanço de água no solo em cada URH (Collischonn at al., 2007)............... 36

Figura 4.1 - Discretização de mini-bacias e sub-bacias da Bacia do Rio Grande. ............... 52

Figura 4.2 - Unidades de resposta hidrológicas da Bacia do Rio Grande - 1980 ............... 53

Figura 4.3 - Unidades de resposta hidrológicas da Bacia do Rio Grande - 1990. ............... 54

Figura 4.4 - Unidades de resposta hidrológica da Bacia do Rio Grande - 2000................. 54

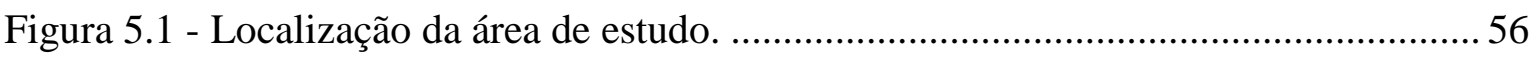

Figura 5.2 - Evolução do Produção de grãos nos municípios da área de estudo (IBGE,2016). .58

Figura 5.3 - Hidrografia da sub-bacia do Rio Grande (ANA, 2010). 60

Figura 5.4 - Modelo digital de elevação da sub-bacia do Rio Grande (Miranda, 2005)..... 61 Figura 5.5 - Curvas de nível com espaçamento vertical de 50 metros da sub-bacia do Rio Grande, obtido a partir do MDE. 61

Figura 5.6 - Mapa de declividades da sub-bacia do Rio Grande obtida a partir do MDE... 62 Figura 5.7 - Relevo da sub-bacia do Rio Grande ( INEMA, 2014). 
Figura 5.8 - Mapa geológico da sub-bacia do Rio Grande ( INEMA, 2014).

Figura 5.9 - Mapa hidrogeológico da sub-bacia do Rio Grande ( INEMA, 2014)

Figura 5.10 - Clima da sub-bacia do Rio Grande (IBGE, 2000). .68

Figura 5.11 - Vegetação da sub-bacia do Rio Grande (IBGE, 2000). 69

Figura 5.12 - Mapa de solos da área de estudo (INEMA, 2014). .71

Figura 5.13 - Mapa de cobertura e uso do solo da Bacia do Rio Grande em 1980 (Sano et. al, 2011).

Figura 5.14 - Mapa de cobertura e uso do solo da Bacia do Rio Grande em 1990 (Sano et. al, 2011). .73

Figura 5.15 - Mapa de cobertura e uso do solo da Bacia do Rio Grande em 2000 (Sano et. al, 2011). .73

Figura 5.16 - Evolução do uso do solo na Bacia do Rio Grande. .74

Figura 5.17 - Disponibilidade de dados de chuvas observados na área de estudo. .76

Figura 5.18 - Disposição espacial dos postos pluviométricos utilizados no estudo. .77

Figura 5.19 - Variações das precipitações anuais dos postos pluviométricos usados neste estudo (1969- 2005). .77

Figura 5.20 - Precipitações médias mensais dos postos pluviométricos utilizados neste estudo (1969-2005). .78

Figura 5.21 - Disponibilidade temporal dos dados de vazão dos postos fluviométricos operadas pela ANA (1969-2005) .79

Figura 5.22 - Localização das estações fluviométricas e suas respectivas áreas de drenagem. 80

Figura 5.23 - Localização das estações meteorológicas. .81

Figura 5.24 - Variação das temperaturas médias diárias do período entre 1969-2005....... 82

Figura 5.25 - Variação das temperaturas médias mensais do período entre 1969-2005..... 82

Figura 5.26 - Variação da umidade relativa do ar na área de estudo entre 1969-2005. ...... 82

Figura 5.27 - Variação mensal da umidade relativa do ar no período entre 1969-2005. .... 83

Figura 5.28 - Variação mensal média da velocidade do vento no período entre 1969-2005.

Figura 5.29 - Variação da pressão atmosférica no período entre 1969-2005. .84

Figura 5.30 - Variação das horas de insolação diárias entre o período de 1969-2005. ....... 84

Figura 5.31 - Variação mensal das horas de insolação diária no período entre 1969-2005.85 Figura 6.1 - Evolução da cobertura e uso do solo da Bacia a montante do posto fluviométrico Nova Vida -Montante. .87 
Figura 6.2 - Conjunto dos 30 melhores hidrogramas do posto Nova Vida-Montante calibração no período entre junho de 1976 e 1985

Figura 6.3 - Conjunto dos 30 melhores hidrogramas do posto Nova Vida-Montante calibração no período entre junho de 1986 e 1995

Figura 6.4 - Conjunto dos 30 melhores hidrogramas do posto Nova Vida-Montante calibração no período entre junho de 1996 e 2005.

Figura 6.5 - Resíduos das simulações realizadas com os parâmetros obtidos na calibração do primeiro período $-\mathrm{P} 1$.

Figura 6.6 - Resíduos das médias anuais das vazões simuladas com os parâmetros obtidos na calibração do primeiro período-P1.

Figura 6.7 - Resíduos das vazões mínimas simuladas com os parâmetros obtidos na calibração do primeiro período-P1

Figura 6.8 - Variabilidade de parâmetros Wm, b, Kbas e Kint obtidos nas calibrações de P1, P2 e P3, que se apresentam agrupados em cada URH.

Figura 6.9 - Variabilidade de parâmetros Wc, Cs, Ci e Cb obtidos nas calibrações de P1, P2 e P3, que se apresentam agrupados em cada URH

Figura 6.10 - Hidrogramas obtidos com parâmetros dos períodos P1, P2 e P3 no posto Nova Vida-Montante.

Figura 6.11 - Evolução da cobertura e uso do solo da Bacia a montante do posto fluviométrico Boqueirão. 102

Figura 6.12 - Conjunto dos 30 melhores hidrogramas do posto Boqueirão obtidos com os parâmetros do período $\mathrm{P} 1$ 104

Figura 6.13 - Conjunto dos 30 melhores hidrogramas do posto Boqueirão obtidos com parâmetros do período $\mathrm{P} 2$ 105

Figura 6.14 - Conjunto dos 30 melhores hidrogramas do posto Boqueirão obtidos com parâmetros do período $\mathrm{P} 3$ 106

Figura 6.15 - Resíduos das vazões mensais obtidas com parâmetros do período P1 107 Figura 6.16 - Resíduos das vazões médias anuais com parâmetros obtidos na calibração do período $\mathrm{P} 1$

Figura 6.17 - Resíduos das vazões mínimas simulas com parâmetros obtidos no período $\mathrm{P} 1$.

Figura 6.18 - Variação dos parâmetros obtidos em cada calibração

Figura 6.19 - Hidrogramas obtidos com parâmetros dos períodos P1, P2 e P3 no posto Boqueirão 114 


\section{LISTA DE SÍMBOLOS E ABREVIAÇÕES}
$\alpha$
Albedo
$\Delta$
Variação da pressão de saturação do vapor d'água
ANA
Agência Nacional de Águas
b
Parâmetro de não-uniformidade da capacidade de armazenamento do solo
CAP Máximo fluxo ascendente para o solo
CB Parâmetro de retardo do reservatório subterrâneo
CI Parâmetro de retardo do reservatório sub-superficial (CI)
CN Curva Número
$\mathrm{c}_{\mathrm{p}} \quad$ Calor específico do ar úmido
CS Parâmetro de retardo do reservatório superficial
D Resíduo do modelo
D bas Escoamento subterrâneo
DBHM Distributed Biosphere Hydrological Model
$\mathrm{D}_{\text {cap }} \quad$ Fluxo capilar de água no solo
DHI Danish Hydraulic Institute
$D_{\text {int }} \quad$ Escoamento sub-superficial
$\mathrm{D}_{\text {sup }} \quad$ Escoamento superficial
EMBRAPA Empresa Brasileira de Pesquisa Agropecuária
EPA US Environmental Protection Agency
e Pressão de saturação da água
$\mathrm{e}_{\mathrm{d}} \quad$ Pressão do vapor d'água
ET Evapotranspiração
G Fluxo de energia para o solo
h $\quad$ Altura das árvores
HBV Hydrologiska Byråns Vattenbalansavdelning
HEC Hydrologic Engineering Center
HEC-HMS Hydrologic Modeling System
HSPF Hydrological Simulation Program-Fortran
IAF Índice de Área Foliar
IBGE Instituto Brasileiro de Geografia e Estatística 
INEMA Instituto do Meio Ambiente e Recursos Hídricos da Bahia

INPE Instituto Nacional de Pesquisas Espaciais

k Constante de von Kármán

Kbas Parâmetro de escoamento subterrâneo

KINEROS Kinenmatic Runoff and Erosion Model

Kint Parâmetro de escoamento sub-superficial

MDE Modelo Digital de Elevação do Terreno

MGB-IPH Modelo de Grande Bacias

MIKE SHE European Hydrological System Model

MMS USGS Modular Modeling System

NAVMO Niederschlag, Abfluss, Verdunstungs Modell

NSE Coeficiente de Nash-Sutcliffe

NSElog Coeficiente de Nash-Sutcliffe do logarítmo

P Precipitação

$\mathrm{p} \quad$ Valor da estatística do teste de Mann-Whitney

PRMS Precipitation Runoff Modeling System

Q Vazão

$\mathrm{r}_{\mathrm{a}} \quad$ Resistência aerodinâmica

$\mathrm{R}_{\mathrm{L}} \quad$ Radiação líquida na superfície

$\mathrm{r}_{\mathrm{s}} \quad$ Resistência superficial

SCS Soil Conservation Service

SHE Systeme Hydrologique Europeen

SIL Capacidade do reservatório de interceptação

SMAP Soil Moisture Accounting Procedure

SRTM Shuttle Radar Topography Mission

SVAT Solo-Vegetação-Atmosfera

SWAT Soil and Water Assessment Tool

SWAT Soil and Water Assessment Tool

SWM Stanford Watershed Model

SWMM Storm Water Management Model

THMB Terrestrial Hydrology Model with Biogeochemistry

TKB Tempo de retardo do reservatório subterrâneo

TKI Tempo de retardo do reservatório sub-superficial 


$\begin{array}{ll}\text { TKS } & \text { Tempo de retardo do reservatório superficial } \\ \text { U } & \text { Velocidade do vento } \\ \text { URH } & \text { Unidade de Resposta Hidrológica } \\ \text { USGS } & \text { United States Geological Survey } \\ \text { V } & \text { Volume do reservatório } \\ \text { VIC } & \text { Variable Infiltration Capacity Macroscale Hydrologic Model } \\ \text { W } & \text { Armazenamento de água no solo } \\ \text { Wc } & \text { Limite de armazenamento no solo } \\ \text { WGS } & \text { World Geodetic System } \\ \text { Wm } & \text { Capacidade máxima de armazenamento de água no solo } \\ \text { XL } & \text { Índice de porosidade do solo } \\ \gamma & \text { Constante psicrométrica } \\ \delta & \text { Fator de distribuição da capacidade de armazenamento de água no solo } \\ \Delta V & \text { Relação entre os volumes observados e simulados } \\ \lambda & \text { Calor latente de vaporização } \\ \rho_{\mathrm{A}} & \text { Massa específica do ar } \\ \rho \mathrm{W} & \text { Massa específica da água }\end{array}$




\section{1- INTRODUÇÃO}

Ao longo da história tem-se verificado que a expansão da ocupação humana se dá pela transformação do meio ambiente na busca por recursos naturais, um exemplo claro deste poder de transformação é a ocupação do território brasileiro, onde houve intensa alteração da paisagem, partindo-se do litoral para o interior do país. Toda essa alteração causa impactos no meio ambiente como um todo e com o ciclo hidrológico não seria diferente.

Os impactos das alterações de cobertura e uso do solo sobre o ciclo hidrológico são observados desde o século XV, quando os navegadores perceberam que nas ilhas da América Central havia redução das chuvas nas áreas onde a vegetação natural havia sido desmatada (Shukla e Mintz, 1982). Mesmo que seja antigo o entendimento de que as mudanças na cobertura e uso do solo causam alterações no regime hidrológico, os primeiros estudos científicos foram realizados somente no início do século $\mathrm{XX}$ (McCulloch e Robinson, 1993), quando se proliferaram os estudos em bacias experimentais, pequenas bacias intensamente monitoradas, ao redor do mundo e foi desenvolvida a metodologia de bacias pareadas, que é considerada a mais adequada para avaliar os impactos das alterações de cobertura e uso do solo sobre o regime hídrico, na qual as bacias passam por um período de calibração, seguido da remoção ou implantação de cobertura vegetal em uma delas, enquanto a outra serve de bacia de controle.

Os estudos com bacia experimentais permitiram chegar a algumas conclusões sobre os efeitos do desmatamento e reflorestamento sobre o comportamento da bacia. Os estudos comprovam que, de modo geral, a remoção de cobertura vegetal causa aumento nas vazões, que nem sempre são previsíveis (Hibbert, 1967). Embora esses estudos experimentais tenham de popularizado e já exista uma vasta quantidade ao redor do mundo, esses estudos são limitados pela escala de abordagem do assunto, uma vez que a área das bacias experimentais gira em torno de $1 \mathrm{~km}^{2}$ e as conclusões obtidas não devem ser aplicadas diretamente às grandes bacias por conta da heterogeneidade de suas características.

Outro ponto de destaque é que os estudos bacias experimentais se concentram nos países desenvolvidos, onde predominam as florestas temperadas, quando fora dessa região, os demais estudos são em regiões de floresta tropical, havendo uma grave escassez desses estudos no cerrado brasileiro. 
Tendo em vista a dificuldade da realização de estudos experimentais em grandes bacias, a aplicação de modelos hidrológicos se mostra uma ferramenta de grande auxílio nesta tarefa. Muitas metodologias vêm sendo adotadas para prever os efeitos das mudanças na cobertura e uso do solo sobre os mecanismos de escoamento, no entanto ainda não há uma metodologia definitiva (Hundecha e Bárdossy, 2003).

Este trabalho apresenta a aplicação da metodologia proposta por Seibert e McDonnell (2010), que avalia os efeitos das mudanças no uso do solo considerando as incertezas dos parâmetros. É considerado que não há apenas um único conjunto de parâmetros que represente a bacia, mas um conjunto de parâmetros que podem igualmente representar a bacia e os efeitos da mudança no uso do solo sobre as vazões é realizada com essa consideração.

A área de estudo é a sub-bacia do Rio Grande, afluente do Rio São Francisco, localizada no Oeste Baiano, que se caracteriza por ter se tornado um dos principais polos da produção de grãos no Brasil, sendo em 2013, responsável por $48 \%$ da produção de grãos do estado da Bahia (IBGE, 2016). Esta área foi escolhida porque a intensificação de sua ocupação ocorreu a partir da década de 1980, período quando também passou a ser disponibilizadas as imagens do satélite LandSat 5, que possibilitaram a identificação da evolução das alterações na cobertura e uso do solo.

As simulações serão realizadas por meio do modelo hidrológico MGB-IPH, por se tratar de um modelo distribuído conceitual, com representação física de parte dos processos hidrológicos, capaz de representar a distribuição espacial dos processos hidrológicos e representar os efeitos da vegetação sobre a bacia.

Este estudo se torna importante devido à necessidade de se expandir os conhecimentos sobre comportamento das vazões diante das mudanças na cobertura e uso do solo de modo a subsidiar a gestão dos recursos hídricos, promovendo a alocação dos recursos hídricos compatibilizando as ofertas e as demandas e por ser realizado no bioma Cerrado, que é o segundo maior bioma do país e carece de mais estudo sobre o seu comportamento hidrológico. 


\section{2- OBJETIVOS}

\section{1 - OBJETIVO GERAL}

Avaliar uma metodologia de detecção dos impactos da mudança no uso do solo sobre o regime de vazões com uso de modelagem hidrológica considerando as incertezas dos parâmetros e do modelo.

\section{2 - OBJETIVOS ESPECÍFICOS}

- Ajustar o modelo hidrológico distribuído MGB-IPH para simular as vazões na bacia do Rio Grande no Oeste Baiano;

- Avaliar a capacidade do modelo MGB-IPH detectar efeitos da cobertura e uso do solo sobre as vazões;

- Aplicar conceitos de incertas na análise dos efeitos das mudanças na cobertura e uso do solo;

- Avaliar os impactos das mudanças na cobertura e uso do solo na Bacia do Rio Grande sobre as vazões mensais, anuais e mínimas anuais. 


\section{3 - REVISÃO BIBLIOGRÁFICA}

Quando ocorrem cheias ou secas extremas, o público em geral relaciona imediatamente estas ocorrências às alterações sobre a vegetação natural, o que fez com que o papel da vegetação sobre os processos hidrológicos se tornasse objeto de discussão científica ao longo dos dois últimos séculos (Andréassian, 2004), por isso muitos estudos têm sido realizados para compreender esta relação, com alguns pontos sendo elucidados, enquanto outros ainda continuam sem conclusão.

\section{1 - O CICLO HIDROLÓGICO E O PAPEL DA VEGETAÇÃO}

Durante a precipitação numa bacia, apenas uma parte atinge a superfície do solo, pois uma fração considerável da mesma será retida pela vegetação ou pela serapilheira e evaporada durante ou logo após a precipitação (Bruijnzeel, 1990). A evapotranspiração real engloba a transpiração e a evaporação (pelas plantas, serapilheira e solo), definida como o processo de transferência de água da superfície do solo e da cobertura vegetal para a atmosfera. A evapotranspiração sob diferentes coberturas vegetais não depende apenas do tipo de vegetação, mas também do solo e do clima da bacia. Mudanças da evapotranspiração devido a mudanças na cobertura vegetal tem um grande impacto no balanço hídrico (Best et al., 2007)

O escoamento pode se dar pela superfície (fluxo superficial), pela subsuperficie (fluxos subsuperficiais) ou pelo fluxo de base. Os dois primeiros são responsáveis pelo fluxo rápido e o último pelo fluxo lento, de modo geral, todas estas formas de escoamento ocorrem simultaneamente na bacia.

Quando a intensidade da precipitação excede a capacidade de infiltração no solo tem-se a ocorrência do escoamento superficial hortoniano, que tem sua ocorrência restrita a áreas com solos muito rasos, com baixa taxa de infiltração, ou regiões desérticas ou semi-áridas (Brutsaert, 2005). Quando o solo é saturado pela ascensão do lençol freático até a superfície tem-se o escoamento por excesso de saturação (Dunne e Black, 1970), que é a forma de escoamento superficial predominante. 
Solos sob vegetação natural densa, como florestas, se caracterizam por apresentar uma camada de resíduos vegetais (serapilheira) e por um horizonte A rico em matéria orgânica. A matéria orgânica é comprovadamente eficiente em manter os agregados do solo, preservando sua porosidade (Bertoni e Lombardi Netto,1993). Portanto, solos sob vegetação normalmente apresentam significativa porosidade, especialmente macroporosidade, proporcionada por raízes mortas e cavidades de animais. Solos com cobertura vegetal desenvolvem uma camada de matéria orgânica superficial e por isso tem maior capacidade de infiltração.

No caso de solos sob o cerrado, a serapilheira se apresenta de forma dispersa e não exerce influência sobre a capacidade de infiltração do solo, sendo que as alterações nas características do solo, tais como densidade e macroporosidade, são decorrentes das práticas de manejo agrícola (Carneiro et al., 2009)

\section{2 - METODOLOGIAS EXPERIMENTAIS DE AVALIAÇÃO DOS EFEITOS DA ALTERAÇÃO DA VEGETAÇÃO SOBRE O REGIME HIDROLÓGICO}

De acordo com Andréassian (2004), o primeiro estudo para avaliar o impacto das mudanças da vegetação sobre o regime hidrológico foi realizado por Belgrand de 1850 a 1852, no qual comparou o comportamento hidrológico de 3 bacias na França, uma totalmente coberta por florestas, outra totalmente desmatada e uma parcialmente desmatada, chegando à conclusão de que não havia evidências de que a cobertura vegetal exercesse alguma influência no comportamento hidrológico. No entanto, por realizar o estudo um período mais longo, McCulloch e Robinson (1993) consideram que o primeiro estudo de fato, foi realizado por Engler, publicado em 1919, que realizou medições em duas bacias com diferentes níveis de cobertura vegetal por mais de 15 anos na Suíça e verificou que a bacia com maior cobertura florestal apresentava vazão menor do que a predominantemente coberta por pastagem. Estes estudos, porém, foram realizados em bacias diferentes e nenhum deles apresentou resultados definitivos sobre os efeitos da vegetação sobre regime hidrológico.

Ao longo da primeira metade do século XX, novas metodologias para avaliar os efeitos da vegetação sobre o regime hidrológico em bacias experimentais foram desenvolvidas, 
podendo-se agrupá-las em três grupos: estudos de correlação, estudos de bacia única e estudo de bacias pareadas (McCulloch e Robinson 1993).

Nos estudos de correlação, o comportamento hidrológico é comparado entre diferentes bacias, que se diferenciam apenas no atributo de interesse, no caso, a vegetação. Como na prática isto é quase impossível devido à heterogeneidade do meio ambiente, há a opção de monitorar diversas bacias simultaneamente, averiguando-se as possíveis variações de condições naturais (geologia, geomorfologia, solos e clima). Os dados hidrológicos obtidos são então analisados estatisticamente por meio de equações de regressões múltiplas, obtendo-se, como produto final, equações empíricas que relacionam as vazões com as variáveis independentes (ex.: Lacey e Grayson, 1998); estas variáveis, não chegam a ser de fato independentes, o que pode levar a conclusões equivocadas, como no caso dos estudos realizados na Rússia, que chegaram à conclusão de que a silvicultura aumentava a vazão dos rios (McCulloch e Robinson 1993).

Em estudos de bacia única, o comportamento hidrológico de uma bacia é estabelecido após alguns anos de monitoramento. Posteriormente, a bacia é tratada (desmatada ou reflorestada) e continua-se o monitoramento por alguns anos até se estabelecer a influência do tratamento no regime hidrológico. Isto resolve o problema das diferenças físicas das bacias, mas não é capaz de evitar os problemas de variação climática, pois o clima do período de calibração pode ser mais seco ou mais úmido que o período de tratamento (McCulloch e Robinson 1993).

Os estudos com bacias pareadas, considerada a metodologia mais adequada de avaliação do impacto das formas de uso e ocupação no regime hidrológico, é realizado em bacias com características muito similares, sendo preferível que as bacias pareadas se localizem o mais próximo possível, de forma a exibir características semelhantes quanto aos aspectos físicos, climáticos, de tipo de vegetação e formas de uso e ocupação. As bacias devem ser monitoradas por alguns anos para caracterizar adequadamente seu comportamento, o que é chamado de período de calibração. Completada a calibração, uma das bacias é tratada (altera-se a sua cobertura vegetal), enquanto a outra, que é a bacia de controle, permanece inalterada, evitando conclusões equivocadas decorrentes da variação climática, a figura 3.1 e 3.2 apresentam um resumo desta metodologia. A análise estatística por regressão linear dos dados de vazão das bacias de controle e tratada possibilita a determinação do impacto do tratamento. Para tanto, comparam-se os dados reais com os obtidos com a equação de 
regressão caso não houvesse tratamento (Best et al. 2003). Há também outras formas de análise de dados, como a construção de curvas de permanência, que permitem analisar não só os fluxos anuais, como também as variações sazonais (Best et al. 2003).

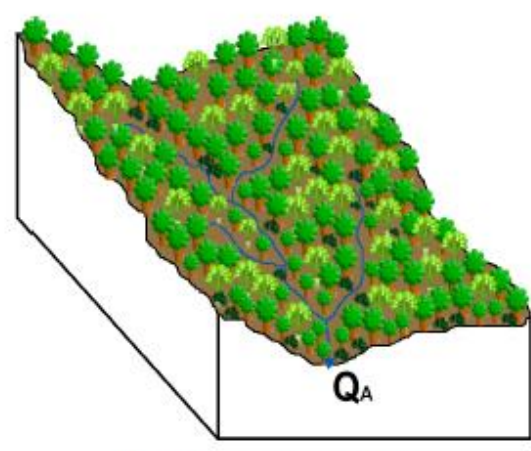

(a) Bacia A - Fase de calibração

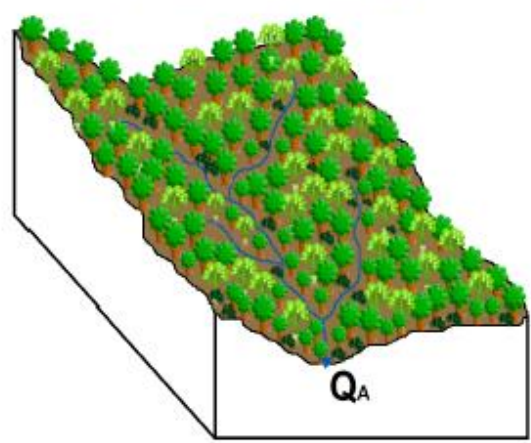

(c) Bacia A - Fase de tratamento

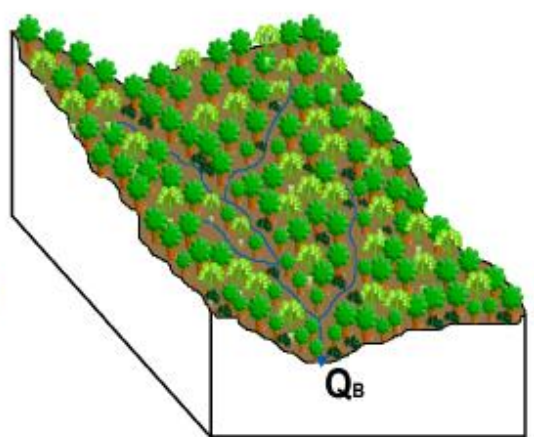

(b) Bacia B - Fase de calibraçåo

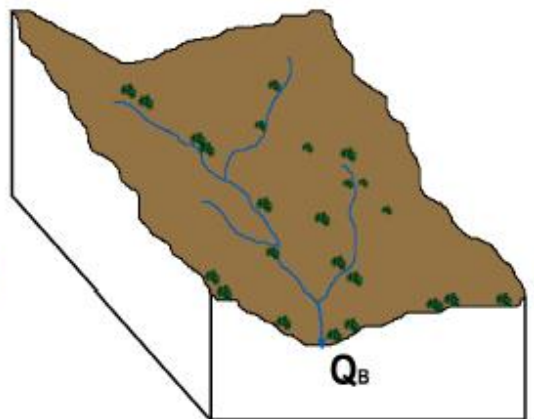

(d) Bacia B - Fase de tratamento

Figura 3.1 - Princípio da metodologia das bacias pareadas: as bacias passam por uma fase de calibração (a) e (b) e em seguida é aplicado o tratamento (c) e (d) (Bayer, 2014).

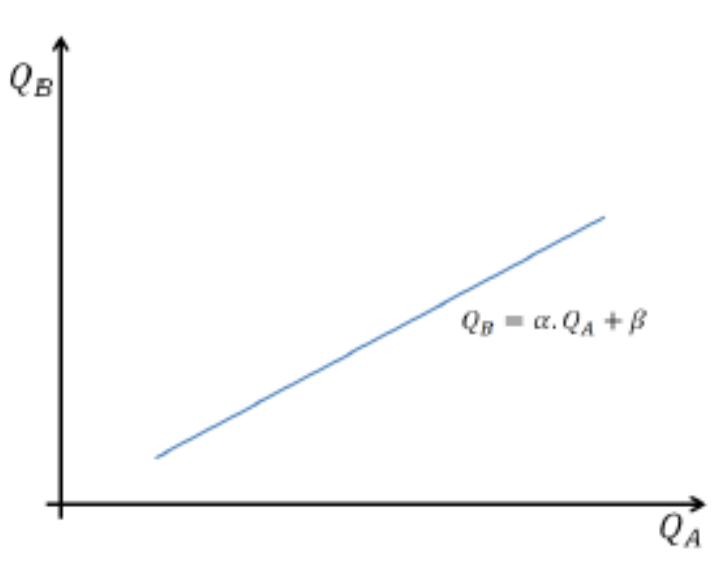

(a) Fase de Calibraçã̃o

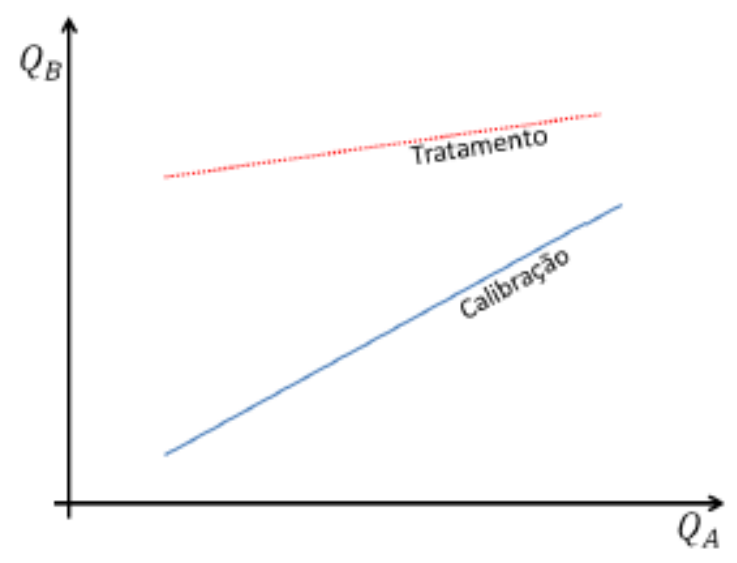

(b) Fase de Tratamento

Figura 3.2 - (a) apresenta a correlação entre as bacias no período de libração e em (b) a relação no período de tratamento (Bayer, 2014). 


\section{3 - IMPACTOS DAS MUDANÇAS NA COBERTURA E USO DO SOLO SOBRE AS COMPONENTES DO CICLO HIDROLÓGICO}

Ainda no século XIX, o desempenho da vegetação sobre o regime hidrológico já era objeto de discussão (Andréassian, 2004). Por um lado, existiam os partidários de uma visão mais científica, com argumentos embasados em dados hidrológicos e meteorológicos; por outro, havia os denominados florestais, que consideravam que as florestas influenciavam o regime hidrológico dos rios diminuindo o escoamento superficial, causando aumento do fluxo de base, aumentando a precipitação local e melhorando a qualidade da água (Calder, 1998).

As controvérsias sobre os efeitos da vegetação começaram a ser desfeitas com a realização dos primeiros estudos com bacias pareadas, que foram realizadas em bacias no estado do Colorado, EUA. Tais experimentos permitiram superar as hipóteses defendidas pelos florestais sobre o papel das florestas nos rios (Andréassian, 2004), a partir de então estudos usando a metodologia das bacias pareadas se proliferaram.

Hibbert (1967) realizou a primeira compilação de estudos com bacias pareadas sobre os efeitos da mudança de vegetação sobre o regime hidrológico, na qual foram analisadas 39 bacias, de regiões de clima temperado e florestas tropicais, e chegou às seguintes conclusões:

- A redução da cobertura vegetal florestal aumenta a produção de água;

- A introdução de florestas reduz a produção de água;

- As respostas das bacias às mudanças na cobertura vegetal são altamente variáveis, o que inviabiliza a realização de previsões.

Bosch e Hewlett (1982) atualizaram o trabalho de Hibbert e incluíram mais experimentos de reflorestamento em sua análise, num total de 94 . Além de reforçar as duas primeiras conclusões de Hibbert, os pesquisadores chegaram às seguintes conclusões:

- Alterações de vegetação inferiores a $20 \%$ não são detectáveis;

- Após os primeiros $20 \%$ de alteração, a cada mudança de $10 \%$ na cobertura de coníferas e eucalipto causa uma mudança da ordem de $40 \mathrm{~mm} \cdot \mathrm{ano}^{-1}$, enquanto que para floresta decídua essa mudança é de $25 \mathrm{~mm}_{\text {.ano }}{ }^{-1}$. Para vegetação arbustiva e pastagem este efeito é da ordem de $10 \mathrm{~mm} . \mathrm{ano}^{-1}$, na figura 3.3 é 
apresentado como as vazões anuais são alteradas pela remoção de diferentes tipos de vegetação;

- Nas respostas das bacias ao desmatamento dependem tanto da precipitação média anual, quanto da precipitação no ano em que o desmatamento ocorreu.

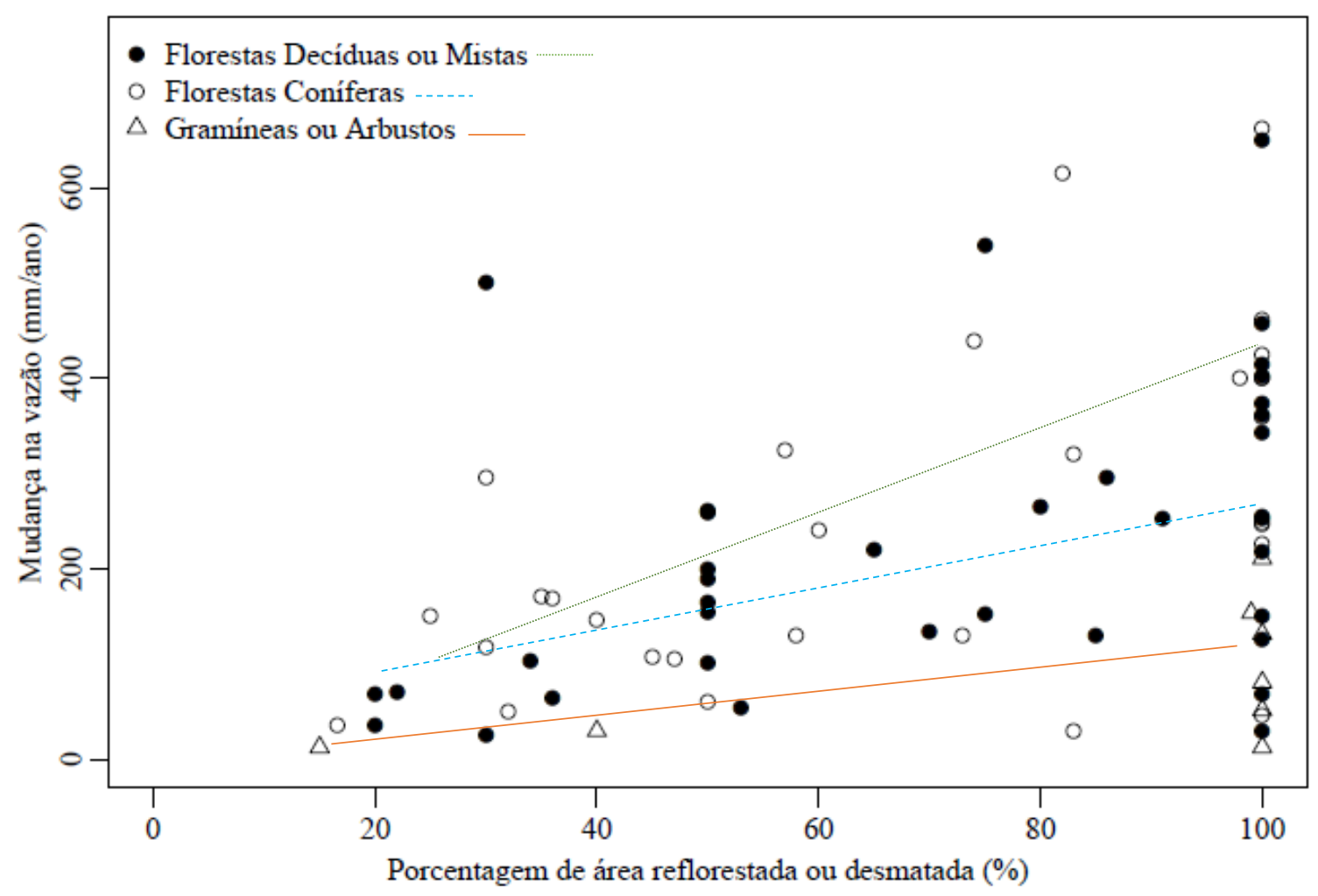

Figura 3.3 - Mudanças na vazão anual em função das mudanças da cobertura do solo para diferentes tipos de vegetação (Bosh e Hewlett, 1982 - modificado).

Outros trabalhos subsequentes (Bruijnzeel, 1990, McCulloch e Robinson, 1993, Sahin e Hall, 1996, Best et al., 2003, Andréassian ,2004, Brown et al. 2005) confirmam de forma geral as conclusões de Bosch e Hewlett (1982), embora existam situações pontuais, normalmente justificadas por características locais das bacias ou então por peculiaridades quanto à forma de tratamento (Buinjnzeel, 1990, Andréassian 2004).

As mudanças do uso do solo em uma bacia podem conduzir mudanças nas componentes de seu balanço hídrico. O tempo de resposta da vazão é geralmente determinado pelo clima (principalmente pela chuva), características da vegetação, características fisiográficas da bacia e pelas práticas de manejo da vegetação. Respostas de vazão serão mais lentas quando seguidas de reflorestamento, quando comparado com desmatamento, uma vez que leva um determinado tempo até o estabelecimento de um novo equilíbrio. Compreender o tempo de resposta é de suma importância para a política de alocação de recursos hídricos e para o planejamento regional (Brow et al.,2005). 
A natureza dinâmica e transitória e as inter-relações dos processos hidrológicos na natureza constituem, seguramente, um complicador para a geração de modelos preditivos do comportamento. Por tais razões, novos estudos têm sido desenvolvidos para compreender como os tratamentos afetam em termos físicos a magnitude e a frequência dos processos hidrológicos em uma bacia. Estes estudos envolvem o emprego de dados hidroquímicos, traçadores e datações, que são usualmente empregados para avaliar e quantificar as eventuais alterações no regime hidrológico em decorrência dos tratamentos nas bacias. Tais informações possibilitam compreender melhor as relações de causa e efeito de cada componente do ciclo hidrológico (Buinjnzeel, 1990).

A seguir é apresentado como as alterações na cobertura e uso do solo impacta o comportamento de cada componente do ciclo hidrológico.

\subsection{1 - Precipitação}

Havia o entendimento de que as florestas teriam a capacidade de atrair chuva, pois era considerado que devido à maior evapotranspiração da vegetação seria suficiente para aumentar a umidade atmosférica e, consequentemente, as precipitações locais (Andréassian, 2004). Estudos utilizando modelos de circulação convergem para este entendimento apenas no caso de florestas de grande extensão, como a floresta Amazônica, mas para coberturas menores e descontínuas este fator tem-se mostrado desprezível, pois a maior parte da água das chuvas é proveniente dos oceanos (Bruijnzeel 1990).

A hipótese de aumento da chuva em áreas com floresta partiu de estudos que provavelmente desconsideravam o efeito da turbulência atmosférica, que é menos significativo nas clareiras onde são instalados os pluviômetros, e desta forma tendem a registrar maior volume de chuva (McCulloch e Robinson, 1993). Mesmo os eventuais aumentos de precipitação local devido ao efeito orográfico exercido por árvores muito altas teriam efeito desprezível no regime hidrológico (Zhang et al., 1999). 


\subsection{2 - Interceptação}

A interceptação da precipitação pela cobertura vegetal, neste texto entendida como a parcela da precipitação que fica retida pela vegetação, é uma componente do ciclo hidrológico de difícil mensuração, por ser função do potencial de evaporação, da capacidade de armazenamento de água, que são fatores dependentes da área ocupada pela copa e das características das folhas (Zhang et al., 1999; Best et al., 2003), e das características da chuva (intensidade e duração). As árvores interceptam mais que outros tipos de vegetação de menor porte, como gramíneas e grande parte das culturas agrícolas, por possuírem maior rugosidade aerodinâmica e índice de área foliar superior (Zhang et al. 1999, Best et al. 2003). Porém, os dados de interceptação disponíveis na literatura são extremamente variáveis, até para um mesmo gênero de vegetação (Bruijnzeel, 1990).

A interceptação pela vegetação é normalmente uma componente menor do ciclo hidrológico, em especial quando se compara com a evapotranspiração. As florestas tropicais, por exemplo, interceptam em média apenas $13 \%$ da precipitação anual (Bruijnzeel 1990).

\subsection{3 - Infiltração}

A capacidade de infiltração depende do tipo de cobertura e uso do solo. Solos cobertos por florestas normalmente apresentam alta capacidade de infiltração, o que diminui a produção de escoamento superficial. Para solos que sofrem compactação, a capacidade de infiltração pode diminuir consideravelmente, resultando em maior escoamento superficial (Tucci e Clarke, 1997). A substituição da cobertura de cerrado por culturas agrícolas ou pastagens é responsável por reduções da capacidade de infiltração de água na camada superior do solo (Hunkle et al., 2015).

Mapa (1995) apresentou estudo demonstrando que solos compactados de áreas agrícolas e pastagens exibem um rápido desenvolvimento de macro e microporosidade, em função da maior incorporação de matéria orgânica ao longo de alguns anos após o reflorestamento.

A capacidade de infiltração é maior quando o solo está seco, devido à ação das forças capilares, e diminui progressivamente com o umedecimento. Solos sob floresta mostram-se 
em média menos umedecidos (Sharma et al.1987), em face do maior potencial de transpiração das árvores de grande porte. Consequentemente, a taxa média de infiltração tende a ser maior nas florestas, pelo efeito combinado de maior permeabilidade e menor umidade antecedente (Best et al. 2003). Na figura 3.4 é apresentado como a umidade a diferentes profundidades varia após o tratamento da bacia em diferentes tipos de vegetação.

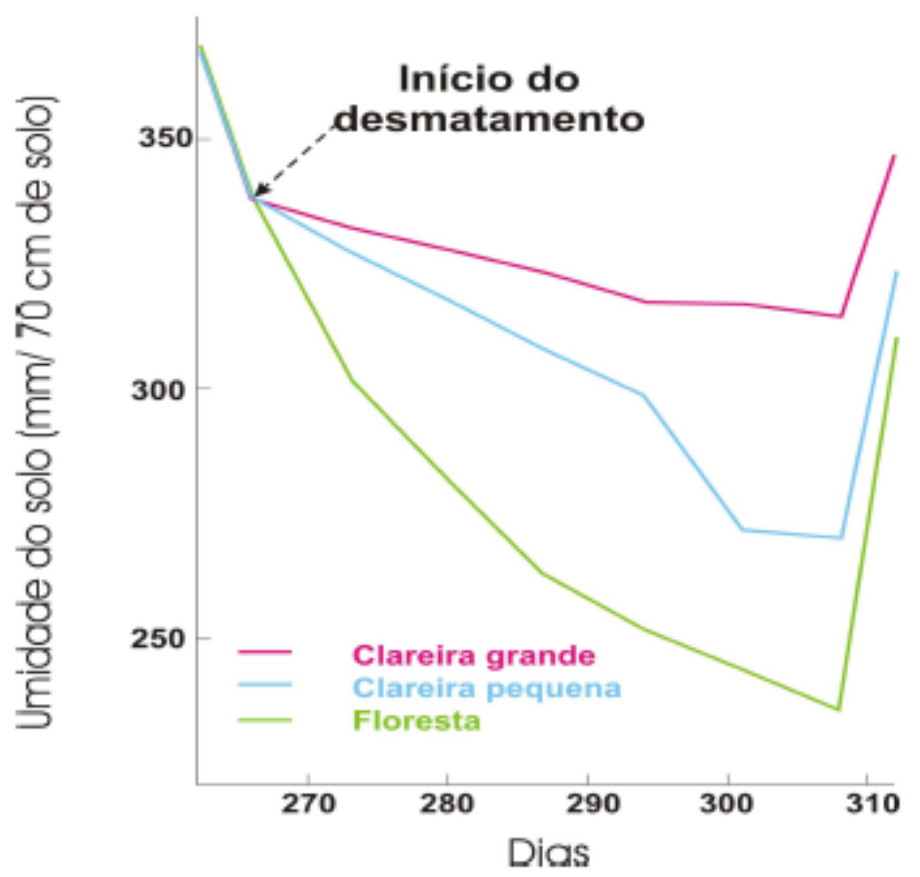

Figura 3.4 - Comparação da evolução da umidade do solo no período seco coberto por floresta e desmatado (Bruinjzeel e Critchley, 1994).

\subsection{4 - Evapotranspiração}

A evapotranspiração é composta por dois processos, a evaporação e a transpiração. A evaporação é o processo no qual a água na fase líquida é convertida em vapor d'água e transferida para a atmosfera a partir de superfícies tais como lagos, rios, solos e a partir da água interceptada na vegetação pelas folhas e pela liteira. A transpiração consiste da vaporização da água utilizada nos processos fisiológicos das plantas e é controlada pela abertura dos estômatos (Allen et al., 1998) e pela capacidade do sistema radicular de captar água do solo (Best et al., 2007). Por isso a evapotranspiração é a componente do ciclo hidrológico mais diretamente influenciada pela cobertura vegetal. 
A evapotranspiração é a componente mais importante do ciclo hidrológico, pois sua magnitude normalmente supera em muito a de outros componentes, como recarga, escoamento superficial e variação da umidade do solo chegando a $70 \%$ do total precipitado (Brutsaert, 2005). Desta forma, o principal processo responsável pelas mudanças hidrológicas decorrentes de alteração da vegetação em escala anual é a evapotranspiração (Zhang et al., 2001).

O clima afeta a evapotranspiração ao facilitar tanto a evaporação como a transpiração. Quanto maior a radiação solar líquida, expressada principalmente pelo albedo, maior a transpiração. Quanto maiores os processos de advecção e mais turbulento o fluxo atmosférico, maior será a evapotranspiração. Zhang et al. (2001) apresentam a diferença de evapotranspiração entre os diferentes tipos de vegetação para diferentes níveis de precipitação, demonstrando como a evapotranspiração está relacionada à precipitação.

Em climas áridos, a evapotranspiração é regulada principalmente pela disponibilidade de água no solo, que é função da precipitação e da capacidade de armazenamento no perfil de solo. Em climas úmidos a evapotranspiração é regulada pela energia líquida disponível e pela advecção (Zhang et al., 2001).

As características mais importantes da planta em relação à evapotranspiração são a área foliar e a profundidade das raízes, que representam a capacidade de a planta obter e se desfazer de água. Também são importantes as técnicas de manejo do solo e da vegetação (Allen et al., 1998). A evapotranspiração nas florestas costuma ser superior à da vegetação de menor porte, como apresentado na figura 3.5, pois nas estações úmidas há maior transporte de vapor d'água devido à superfície aerodinamicamente mais rugosa de suas copas; nas estações secas a maior capacidade de evaporação das florestas é devido ao sistema radicular maior e mais desenvolvido (Calder, 1998). A diferença entre a evapotranspiração de áreas com gramíneas e floresta cresce com o índice pluviométrico, como indicado na figura 3.5. 


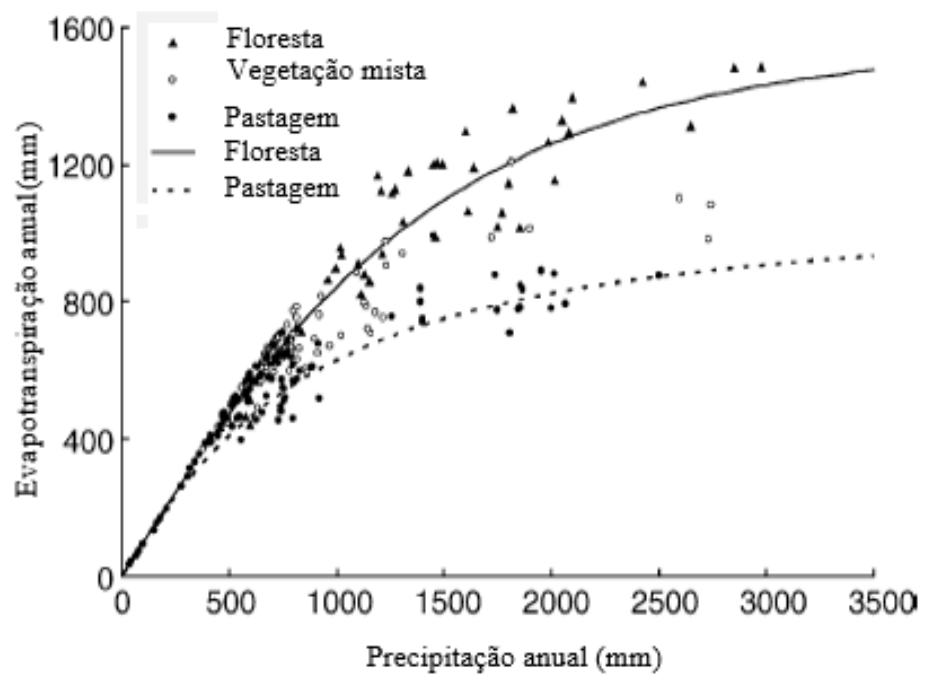

Figura 3.5 - Relação entre a cobertura do solo, a precipitação anual e a evapotranspiração anual (Zhang et al., 2001).

A maior capacidade de infiltração de água em solos cobertos por florestas é largamente superada pelo maior potencial de evapotranspiração, que atinge $1415 \mathrm{~mm}$ em média, no caso de florestas tropicais sem déficit hídrico (Bruijnzeel, 1990). Portanto, o desmatamento tende a aumentar o volume de água disponível nas bacias hidrográficas, aumentando as vazões anuais dos rios.

\section{4 - IMPACTOS DAS MUDANÇAS NA COBERTURA VEGETAL SOBRE O ESCOAMENTO}

\subsection{1 - Vazão anual}

Os estudos realizados em bacias experimentais são consensuais quanto ao fato de que introdução ou a retirada da vegetação arbórea de uma bacia causam, respectivamente a redução e o aumento da vazão média anual (Bosch e Hewlett, 1982; Best et al., 1999; Brown et al., 2005; Andréassian, 2004). A figura 3.6 apresenta as variações na vazão média anual para 137 bacias ao redor do mundo para diferentes níveis de ambos os tratamentos, reflorestamento e desmatamento (Andréassian, 2004). 


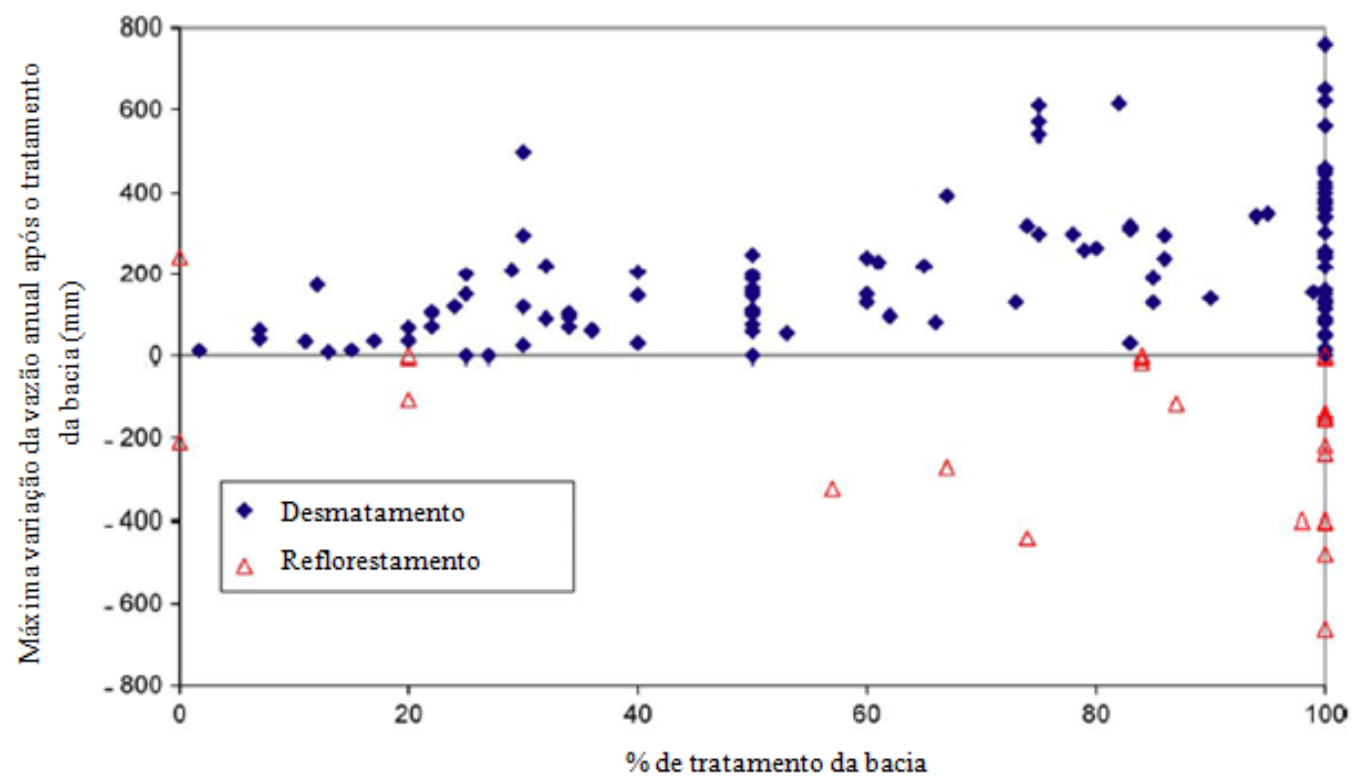

Figura 3.6 - Variação na vazão média anual em função da porcentagem de tratamento aplicado às bacias (Andréassian, 2004).

Como mostrado na figura 3.6 e também registrado por Bosch e Hewlett (1982), as variações nas vazões médias anuais são mais significativas quando o tratamento é realizado em mais de $20 \%$ da área da bacia. Trimble et al. (1987) propuseram uma equação através de uma análise de regressão com coeficiente de determinação $\left(\mathbf{r}^{2}\right)$ de 0,5 e erro padrão de $89 \mathrm{~mm}$.

$$
y=3,26 x
$$

Nesta equação, $y$ é o aumento ou a redução da vazão média anual em mm.ano ${ }^{-1}$ e $x$ é o percentual de área tratada. A equação permite estimar preliminarmente o aumento ou a redução da vazão anual em uma bacia que teve sua vegetação alterada, a figura 3.7 apresenta os dados utilizados por Trimble et al., (1987) e os apresentados por Bosh e Hewlett, (1982). 


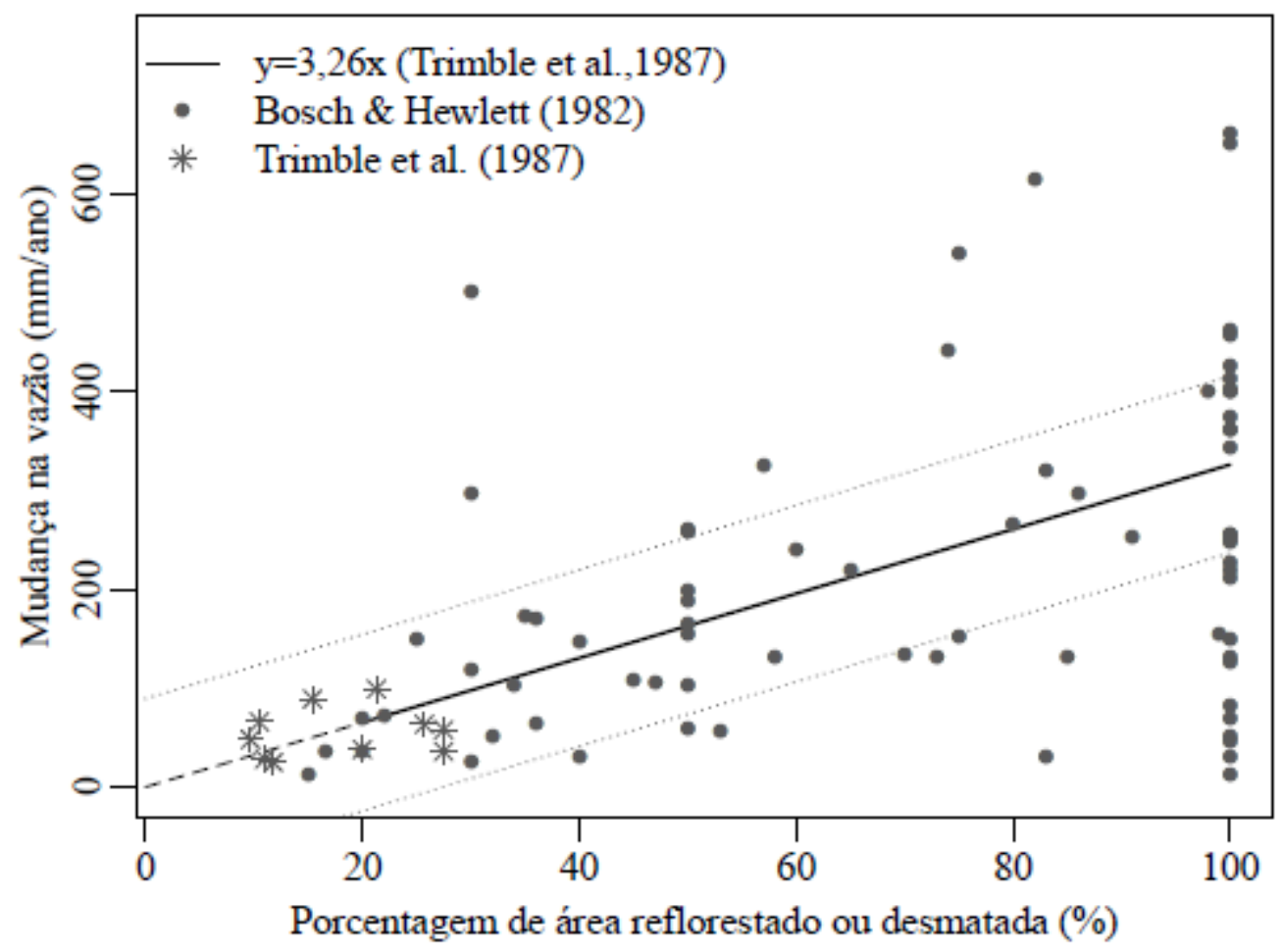

Figura 3.7 - Mudanças da vazão anual em função da alteração da cobertura vegetal (Bayer, 2014).

Ao analisar as variações de vazão é importante conhecer o período desde o último tratamento na bacia, pois se, subsequentemente a um desmatamento, a regeneração for permitida, a vazão decrescerá progressivamente. Hornbeck et al. (1993) analisaram os efeitos de mudanças da cobertura do solo no balanço hídrico em diversos tipos de clima nos Estados Unidos e chegaram às conclusões de que ocorre aumento de vazão imediatamente após a remoção da vegetação e que o aumento de vazão é mantido quando a rebrota da vegetação florestal é impedida, efeito semelhante quando é substituída por pastagem e que quando a rebrota é permitida, há a diminuição da vazão rapidamente, por volta de 3 a 10 anos. A figura 3.8 apresenta o comportamento da vazão ao longo do tempo diante de diversos tratamentos. Na bacia 1 ocorreu $100 \%$ de desmatamento no ano zero; na bacia 2 houve desmatamento parcial no ano zero e no ano 4 com lançamento de herbicida entre 5-7 anos; na bacia 3 ocorreu desmatamento parcial nos anos zero, 4-5 e 8-9 e aplicação parcial de herbicida no ano 7 e desmatamento total no ano 10, sendo permitida a rebrota nos anos seguintes; na bacia 4 houve desmatamento total no ano zero e aplicação de herbicida em toda bacia entre 2-4 anos (Hornbeck et al. 1993). Pode-se verificar que o desmatamento ou a aplicação de herbicidas resultam no aumento de vazões. 


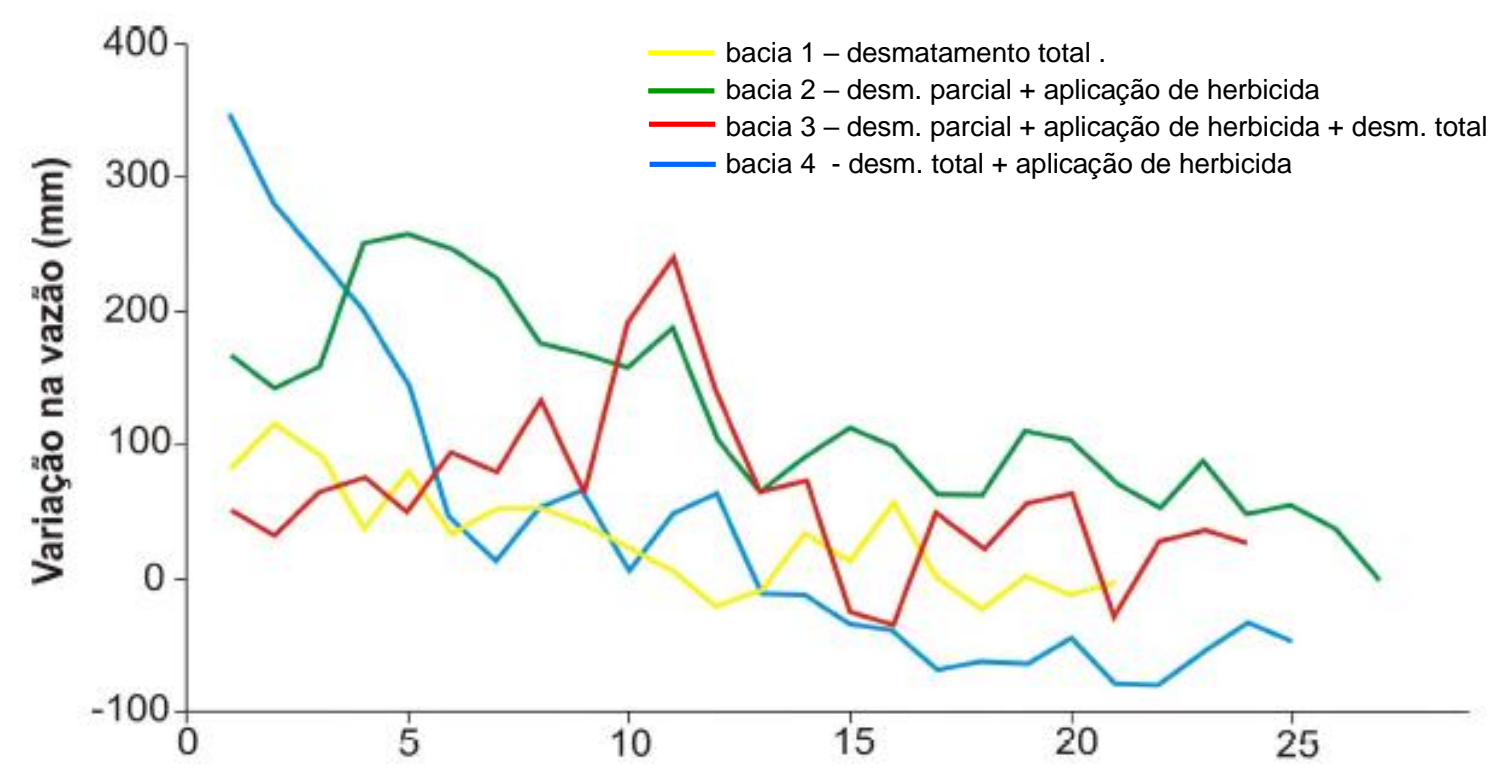

Anos após tratamento

Figura 3.8 - Variação da vazão anual em função de tratamentos diversos. (Hornbeck, 1993 citado por Brown, 2005).

O decréscimo da vazão nos anos após o desmatamento é decorrente da rebrota da vegetação que apresenta maior capacidade de evapotranspiração em relação à vegetação anterior, que estava em uma fase mais senil.

\subsection{2 - Vazão máxima}

Embora os picos de cheia sejam maiores quando a bacia é coberta por pastagens ou culturas agrícolas, vazões maiores são mais dependentes das condições anteriores de umidade do solo e de chuvas extremas do que da cobertura vegetal. A presença de vegetação florestal tem menor importância (Buijnzeel, 1990). Os efeitos do desmatamento sobre as vazões máximas podem ser minimizados quando determinados cuidados de manejo são realizados (Bruinjzeel e Critchley 1994).

A redução nas vazões máximas se baseia no fato de que a parte da chuva é retida pela copa e pela serrapilheria é maior em florestas que em pastagens ou culturas agrícolas, o que contribui para retardar a resposta da bacia. Aliado a isto, a maior capacidade de captar água pelas raízes e assim apresentar maior capacidade de evapotranspiração, o que torna menor o teor de umidade no solo, o que deixa menos água disponível para o escoamento. A cobertura vegetal de maior porte é capaz de reduzir pequenos picos de cheia, mas 
geralmente não tem efeito sobre eventos extremos. O efeito depende da altura e do grau de desenvolvimento das árvores e principalmente do manejo (McCulloch e Robinson, 1993).

O efeito da vegetação sobre as vazões máximas nem sempre é observado, Best et al. (2007) apresentou estudos em que 50\% das bacias não tiveram alteração em suas vazões máxima após o reflorestamento, mas $100 \%$ das bacias que foram desmatadas apresentaram aumento das vazões máximas para pequenos eventos.

McGuinness and Harrold (1971) realizaram estudos sobre as cheias em pequenas bacias na Alemanha antes e depois do reflorestamento e chegaram à conclusão de que para eventos extremos, o impacto do reflorestamento era desprezível. Robinson et al. (1991) consideraram que para eventos com tempo de recorrência superiores a 5 anos, os efeitos do reflorestamento eram menores do que as incertezas de medição.

\subsection{3 - Fluxo de base}

A maioria dos estudos realizados em bacias experimentais indicam que o fluxo de base aumenta com a remoção da cobertura vegetal (Hornbeck et al., 1993; Bruinjzeel e Critchley, 1994; Best et al.,2003); em florestas tropicais o aumento pode ser superior a 110 mm.ano-1 (Bruijnzeel 1990). Este aumento é devido à menor evapotranspiração observada após a remoção da vegetação de maior porte, o que permite a manutenção da umidade do solo durante a estação seca (Calder, 1998).

Pode ocorrer, no entanto, de a perda de água ocasionada pelo aumento da evapotranspiração, associado com a substituição de vegetação com raízes rasas por vegetação de maior porte, seja superado pela maior capacidade de infiltração do solo após o reflorestamento, o que implicaria em maior fluxo de base com o estabelecimento de florestas (Buijnzeel, 1990). Essas diferenças regionais concorrem com os efeitos das mudanças de vegetação, por exemplo, quando as características de infiltração do solo são alteradas após o desmatamento, devido à compactação causada pelo maquinário utilizado ou mesmo pela queda das gotas de chuva sob o solo exposto, o que aumenta o escoamento superficial e reduz a alimentação do aquífero (Tucci e Clarke, 1997).

Devido à complexidade dos diversos componentes do ciclo hidrológico, o fluxo de base pode aumentar ou diminuir com o desmatamento ou reflorestamento, pois a resposta do 
fluxo de base é muito dependente das características especificas da localização da bacia (Calder, 1998).

Cabe destacar, que embora a substituição da cobertura vegetal natural por pastagens ou culturas agrícolas aumente a oferta de água, isso não pode ser considerado um benefício ambiental, haja vista a importância das vegetações naturais para a manutenção da biodiversidade, manutenção da qualidade da água e proteção do solo contra a erosão e o transporte de sedimentos (Buinjnzeel, 1990).

\section{5 - MODELOS HIDROLÓGICOS}

Um modelo é uma representação simplificada do mundo real. Modelos são utilizados para a previsão do comportamento de sistemas e a compreensão dos processos hidrológicos. Um modelo consiste dos diversos parâmetros que definem as características do modelo. Modelo chuva-vazão pode ser definido como um conjunto de equações que estimam o escoamento em função dos parâmetros que descrevem a bacia hidrográfica (Devi et al., 2015).

Os modelos hidrológicos são aplicados no entendimento da dinâmica das interações entre e clima e a superfície terrestre (Kavvas et al. 1998). Os modelos são utilizados para fins variados, em escala local, são aplicados no planejamento e concepção de práticas de conservação do solo, projetos de drenagem urbana, manejo de água para irrigação, recuperação de áreas degradadas, gestão de reservatórios e gestão do lençol freático; em grande escala, modelos são utilizados para projetos de proteção de inundações, reabilitação de represas, gestão de áreas alagáveis e avaliação da qualidade da água e previsão de abastecimento de água.

Com o aumento da demanda por recursos hídricos, também tem aumentado a necessidade de a modelagem hidrológica otimizar o planejamento e a execução de projetos. Ao mesmo tempo, estudos de recursos hídricos tem se tornado mais preocupados com os efeitos da mudança do uso do solo relacionado com práticas agrícolas e florestais, os riscos de poluição e de eliminação de resíduos tóxicos e problemas gerais decorrentes dos usos múltiplos da água. Modelos convencionais de precipitação/escoamento são frequentemente inapropriados para tais problemas e uma nova geração de modelos hidrológicos se tornou 
necessária, o que estimulou o desenvolvimento de modelos de base física (Abbott et al., 1986).

\subsection{1 - Classificação dos modelos hidrológicos}

Os Modelos hidrológicos são classificados de acordo com as entradas e parâmetros e com a extensão dos princípios físicos empregados em sua estrutura, podendo ser concentrados ou distribuídos, estocásticos ou determinísticos, empíricos, conceituais ou de base física e estáticos ou dinâmicos.

Podem ser classificados como concentrados ou distribuídos de acordo com o fato de os parâmetros serem ou não função do espaço e do tempo, de acordo com Moradkhani e Sorooshian et al. (2008). Modelos concentrados tratam a bacia hidrográfica como unidade única, onde as variáveis de estado representam as médias sobre a área da bacia hidrográfica. Nos modelos distribuídos, a bacia é dividida em unidades menores com características distintas que variam com a localização, as características são distribuídas no espaço, com variáveis de estado locais, dividindo a bacia hidrográfica em um grande número de elementos e resolvendo as equações para as variações de estado associadas em cada elemento de discretização. Valores de parâmetros também devem ser especificados para cada elemento de um modelo distribuído (Beven, 2011).

Uma segunda classificação é entre modelos determinísticos e estocásticos. Modelos determinísticos permitem somente uma saída para um conjunto de entradas e valores de parâmetros. Modelos estocásticos permitem certa aleatoriedade e incerteza nos possíveis dados de saída devido às incertezas nas variáveis de entrada, condições de contorno e parâmetros do modelo. A grande maioria dos modelos chuva-vazão são utilizados de forma determinística, apesar de a distinção não ser clara já que tem exemplos de modelos que incluem um modelo de erro estocástico para as previsões determinísticas do modelo hidrológico e tem modelos que usam uma função de distribuição probabilística nas variáveis de estado, mas fazem a simulação de forma determinística. Uma regra válida é que se as variáveis de saída de um modelo são associadas com alguma variação ou outra medida de dispersão da previsão o modelo pode ser considerado estocástico; se os valores de saída são valores únicos em qualquer passo de tempo, o modelo pode ser considerado determinístico, independente da natureza dos cálculos subjacentes (Beven, 2011). 
Outra classificação é baseada no fator tempo, quando o tempo não é relevante, o modelo é considerado estático, quando há variação com o tempo o modelo é considerado dinâmico. Sorooshian et al. (2008) também classificam os modelos em baseados em eventos e contínuos, o primeiro apresenta resultados apenas para um determinado evento, enquanto o segundo oferece resultados contínuos (Devi et al., 2015). Uma das classificações mais importantes é entre modelos empíricos, conceituais e físicos.

Modelos empíricos, são os modelos baseados em observações, que levam em consideração apenas os dados entrada sem considerar os processos hidrológicos envolvidos, envolvem equações matemáticas derivadas dos dados de entrada e de saída observadas e não dos processos físicos que ocorrem na bacia e são válidos apenas para dentro dos intervalos dos dados observados. O hidrograma unitário é um exemplo deste método. Os modelos usam métodos estatísticos de correlação e regressão para estabelecer uma relação entre as entradas e as saídas. Redes neurais e regressão fuzzy são alguns exemplos destes tipos de modelos (Devi et al., 2015).

Modelos conceituais são modelos que descrevem todos os componentes do ciclo hidrológico, consistem de reservatórios interconectados que representam os componentes físicos do ciclo hidrológico que são alimentados pela chuva, infiltração e percolação e são esvaziados pela evaporação, escoamento superficial e drenagem. Equações semi-empíricas são usadas nesse método e os parâmetros do modelo são obtidos não somente pelas medições de campo, mas também por meio de calibração. Um grande número de dados hidrológicos e climáticos são necessários para a calibração. A calibração envolve o ajuste dos hidrogramas simulados e observados, o que pode ser dificultado quando há mudanças na cobertura e uso do solo não prevista na estrutura do modelo. O modelo Stanford Watershed Model IV (Crawford e Linsley, 1966) foi o primeiro modelo conceitual importante.

Modelos de base física são os que representam os fenômenos hidrológicos a partir dos processos físicos reais. São usados dados que podem ser medidos e que são funções do tempo e espaço e não necessitam de longas séries de históricas de vazão e precipitação para sua calibração. Os processos hidrológicos são representados por equações diferenciais (Abbott et al., 1986). 


\subsection{2 - Evolução da modelagem hidrológica}

O primeiro esforço de estabelecer um modelo hidrológico foi o desenvolvimento do método racional por Mulvany em 1850, para relacionar o pico de escoamento de chuva com a intensidade da precipitação. Em 1932, Sherman introduziu o conceito de hidrograma unitário para relacionar a resposta do escoamento direto ao excesso de precipitação, na mesma época, Horton em 1933 desenvolveu uma teoria de infiltração para estimar o excesso de chuva e aperfeiçoar as técnicas de separação do hidrograma. Keulegan em 1944 fez uma investigação teórica sobre escoamento superficial e sugeriu que simplificar a equação do que hoje é chamada de onda cinemática seria apropriado (Singh e Woolhiser, 2002).

Concorrente com o trabalho de Horton, Lowdermilk em 1934, Hursh em 1936 e Hursh e Brater em 1944 observaram que o fluxo sub-superficial constitui um componente importante dos hidrogramas de cheia em regiões úmidas. Posteriormente, Hoover e Hursh em 1943 relataram a importância da dinâmica do fluxo sub-superficial nos hidrogramas de cheia. Roessel em 1950 observou a dinâmica do fluxo subterrâneo. Desde os anos 1940 esses estudos trouxeram conhecimentos sobre os mecanismos de fluxo sub-superficial e proporcionou maior compreensão do sobre a geração do escoamento superficial e a teoria de Horton passou a ser considerado um caso à parte (Singh e Woolhiser, 2002).

Uma das primeiras tentativas de desenvolver uma teoria sobre a infiltração foi o trabalho de Green e Ampt em 1911 que usaram um princípio físico simplificado da taxa de capacidade de infiltração que ainda se mantem bastante popular. Os primeiros trabalhos descrevendo o processo de evaporação em lagos foi realizado por Richardson em 1931 e Cummings em 1935, enquanto Thornthwaite em 1948 e Penman em 1948 fizeram importantes contribuições para os modelos de evapotranspiração (Singh e Woolhiser, 2002).

Houve tentativas de quantificar outras abstrações, tais como interceptação, e detenções nas depressões do terreno. Horton em 1919 desenvolveu uma série de equações empíricas para determinar a interceptação em diversos tipos de cobertura vegetal. O então Serviço de Conservação do Solo (SCS), atualmente Serviço de Conservação do Recursos Naturais, do Departamento de Agricultura dos Estados Unidos desenvolveu o método da Curva-Número para considerar as abstrações na geração do escoamento superficial. Embora tenha sido 
desenvolvido para determinar os efeitos da cobertura e uso do solo sobre o escoamento superficial, este método tem sido usado tanto em modelos de infiltração como para simulação de escoamento superficial (Singh e Woolhiser, 2002).

A fase subterrânea do ciclo hidrológico foi estudada por Fair e Hatch em 1933 que desenvolveram uma forma de determinar a permeabilidade do solo. Theis em 1935 combinou a Lei de Darcy com a equação da continuidade para estabelecer uma relação entre a superfície piezométrica e a duração do fluxo superficial, este trabalhou lançou as bases para o desenvolvimento da hidrologia das águas subterrâneas (Singh e Woolhiser, 2002).

O Corpo de Engenheiros do Exército Americano, desenvolveu um método para propagação de cheia até os reservatórios, considerando que as relações entre armazenamento e vazões são constantes e ignorando a variação da propagação de cheia, posteriormente foi desenvolvido o método de Muskingum de propagação de cheia, que é muito usado em diversos modelos hidrológicos (Singh e Woolhiser. 2002).

Nos meados da década de 1950 o desenvolvimento de modelos foi retomado. O maior emprego da teoria de sistemas lineares conduziu ao desenvolvimento da teoria do hidrograma unitário instantâneo e à teoria generalizada do hidrograma unitário. Lighthill e Whithan, em 1955, desenvolveram a teoria da onda cinemática para a propagação de cheia em rios, esta teoria é aceita como uma ferramenta padrão para a modelagem de escoamento superficial.

O desenvolvimento de modelos tem andado de mãos dadas com a evolução dos computadores. Enquanto modelos baseados em eventos surgiram na década de 1930 e podiam ser resolvidos manualmente, os primeiros modelos hidrológicos para simulação de todo o ciclo hidrológico de forma contínua surgiram na década de 1960, quando os computadores se tornaram capazes de representar todo o processo de uma forma simplificada (Wheater, 2008). O Stanford Watershed Model (SWM) (Crawford e Linsley, 1966), atualmente HSPF, foi o primeiro modelo a simular todos os processos hidrológicos simultaneamente e foi sucedido pelo desenvolvimento de outros modelos como HEC-1 (Hydrologic Engineering Center, 1968) e os modelos de tanque.

Posteriormente, nas décadas de 1970 e 1980, o aumento da capacidade dos computadores viabilizou o surgimento de modelos hidrológicos de base física, resolvendo um conjunto acoplado de equações diferenciais parciais para representar fluxos e processos de 
transporte superficiais, subterrâneos e a propagação da cheia no leito do rio, juntamente com a evaporação. Atualmente, modelos climáticos globais são capazes de representar o ciclo hidrológico global com modelos de base física. Em paralelo, desenvolvimentos recentes no poder computacional proporcionam a capacidade de utilização de métodos cada vez mais poderosos para a análise do desempenho do modelo e para especificar as incertezas associadas à simulação hidrológica, tendo resultado no desenvolvimento da compreensão dos pontos fortes e das limitações da modelagem (Wheater, 2008).

O relacionamento entre modelos e dados é fundamental na tarefa de modelagem. Tecnologias atuais e o poder computacional podem fornecer poderosos pré e pósprocessadores para modelos hidrológicos através de Sistemas de Informação Geográfica, ligando os conjuntos de dados digitais para fornecer um ambiente de modelagem de fácil utilização. Estas tecnologias são importantes para ambientes de dados esparsos, e para lugares onde a disponibilidade de dados é de difícil obtenção. Desenvolvimento global em sensoriamento remoto, acoplado a assimilação de dados e modelagem, está fornecendo novas fontes de informação, (Sorooshian et al., 2008).

\subsection{3 - Visão geral dos principais modelos hidrológicos}

Depois do SWM houve a proliferação de modelos com ênfase na base física, como por exemplo SWMM (Metcalf e Eddy et al., 1971), PRMS (Leavesley et al.,1983), SHE Systeme Hydrologique Europeen (Abbott et al., 1986), entre outros. Todos estes modelos passaram por melhorias desde então, o SWM, agora chamado HSPF, é muito mais abrangente do que sua versão original. SHE foi estendido para incluir o transporte de sedimentos e é aplicável à diferentes escalas de bacias hidrográficas. O TOPMODEL foi modificado para ampliar as informações sobre a bacia hidrográfica, implementou mais processo de base física e melhorou estimativa de parâmetros.

Existem diversos modelos hidrológicos ao redor do mundo. Estes modelos variam significativamente em sua estrutura, em parte porque esses modelos têm diferentes fins. HEC-HMS é considerado o modelo padrão no setor privado nos Estados Unidos para a concepção de sistemas de drenagem e determinação do efeito da mudança do uso da terra sobre as inundações. HSPF e seu módulo de qualidade da água é o modelo adotado pela Agência de Proteção Ambiental dos Estados Unidos (EPA). O modelo MMS do USGS 
(Serviço Geológico dos Estados Unidos) é o modelo padrão para a gestão recursos hídricos e de obras. O WATFLOOD é popular no Canadá. TOPMODEL e SHE são os modelos padrão para análise hidrológica em muitos países europeus. O modelo HBV é o modelo padrão para previsão de fluxo em países escandinavos. Os modelos de tanque são populares no Japão e o modelo Xinanjiang é comumente utilizado na China (Singh e Woolhiser., 2002).

A seguir é apresentada uma visão geral sobre os principais modelos em uso atualmente.

O Stanford Watershed Model (SWM) (Crawford e Linsley,1966) foi o primeiro modelo a simular todo o ciclo hidrológico simultaneamente, em sua evolução incluiu um módulo de qualidade da água e passou a se chamar HSPF (Hydrological Simulation Program-Fortran) e tem aderido diversas aplicações desenvolvidas pelo Serviço Geológico dos Estados Unidos (USGS) e é o modelo padrão para cálculo de poluição não pontual adotado pela Agência de Proteção Ambiental dos Estados Unidos (EPA).

O SMAP (Soil Moisture Accounting Procedure) (Lopes et al., 1981) é um modelo concentrado, conceitual e determinístico, que considera que a bacia é composta por três reservatórios, superficial, zona aerada do solo e subeterrâneo. O escoamento superficial é separado baseado no método CN (Lopes, 1999).

SWMM (Storm Water Management Model) (Metcalf e Eddy, 1971) é um modelo chuvavazão dinâmico, que pode ser voltado a eventos ou de simulação contínua, que simula a geração de escoamento superficial e a qualidade da água, é usado principalmente em áreas urbanas. O SWMM simula a quantidade e qualidade do escoamento gerado em cada subbacia e a qualidade da água em cada canal ou tubo durante o período de simulação (Rossman e Huber, 2016).

O PRMS (Precipitation-Runoff Modeling System) está na sua quarta versão, é um modelo determinístico, com parâmetros distribuídos, com processos hidrológicos descrito com base física, usado para simular as respostas da bacia combinando o clima e o uso do solo. Tem sido usado recentemente para avaliar os efeitos das mudanças climáticas sobre os processos hidrológicos, posteriormente o PRMS foi incorporado ao MMS (USGS Modular Modeling System) (Markstrom et al., 2015).

O MIKE SHE (European Hydrological System Model) (DHI, 2012), foi desenvolvido a partir do SHE, foi desenvolvido por um consórcio entre três organizações europeias, o 
Instituto de Hidrologia do Reino Unido, a empresa de consultoria SOGREAH de França e DHI (Instituto de Hidráulica da Dinamarca). Trata-se de um modelo distribuído, determinístico e de base física. Os processos hidrológicos são representados por equações diferenciais, que descrevem o fluxo de massa e a transferência de momento, os parâmetros podem ser obtidos por medições em campo. Por ser um modelo estritamente de base física requer a uma grande quantidade de dados de entrada e aquisição destes dados tem alto custo, outro ponto também é a complexidade de resolução das equações diferenciais, que demandam muito tempo de processamento, essas características tornam difícil a aplicação do modelo em grandes bacias. O MIKE SHE é usado para planejamento e gestão de pequenas bacias, abastecimento de água, projetos de drenagem e irrigação, avaliação de impactos ambientais, etc. (DHI, 2012)

O TOPMODEL (Beven e Kirby, 1979) é um modelo semi-distribuído que leva em consideração as informações topográficas para a geração de escoamento. Por seus parâmetros serem teoricamente mensuráveis, seus autores o consideram um modelo de base física, mas pode ser definido como um modelo conceitual com área de contribuição variável. A partir das informações topográficas e da condutividade do solo é calculado o déficit de água no solo ou a profundidade do lençol freático em qualquer local, o modelo usa método de Green-Ampt para o cálculo de infiltração (Devi et al., 2015).

O HEC-HMS (Modeling System Hidrológico), desenvolvido pelo Corpo de Engenheiros dos Estados Unidos, foi concebido para simular os processos hidrológicos da bacia hidrográfica, é um modelo conceitual semi-distribuído. O modelo permite o acoplamento de modelos de transporte de sedimentos e qualidade da água e também a análise de incertezas (US Army Corps of Engineers, 2013).

O KINEROS (Kinenmatic Runoff and Erosion Model) (Woolhisher et al., 1990) é um modelo físico orientado a eventos. A bacia é representada em plano e canais, equações diferenciais descrevem o escoamento, a erosão e o transporte de sedimentos e são resolvidas por diferenças finitas. O KINEROS é usado para avaliação dos efeitos do desenvolvimento urbano sobre as bacias hidrográficas.

O SWAT (Soil and Water Assessment Tool) foi desenvolvido do Departamaneto de Agricultura do Estados Unidos para realizar previsão e avaliação dos impactos das práticas agrícolas sobre a produção de sedimentos, e poluições não pontuais em grandes bacias não 
monitoradas. É um modelo conceitual, determinístico e contínuo, operando em passo de tempo diário (Borah e Bera, 2004).

VIC (Variable Infiltration Capacity Macroscale Hydrologic Model) (Liang et al., 1994) é um modelo semi-distribuído aplicado a grandes bacias hidrográficas ao redor do mundo e pode ser acoplado a modelos de circulação global. O escoamento superficial é gerado pelo excesso de infiltração e excesso de saturação escoamento (fluxo Dunniano).

O THMB (Terrestrial Hydrology Model with Biogeochemistry) (Coe, 2000), atualmente chamado HYDRA, é um modelo conceitual, determinístico, semi-distribuído, com células com resolução de 5'x5', é aplicado a grandes bacias, o modelo e baseado no conceito de tanques lineares, tem sido usado para avaliar os efeitos das mudanças no uso do solo sobre a bacia hidrográfica.

O DBHM (Distributed Biosphere Hydrological Model) (Tang et al., 2006) é um modelo de base física, distribuído, determinístico e contínuo, que integra um sofisticado mecanismo de transferência solo-vegetação-atmosfera (SVAT) a um modelo hidrológico distribuído que representa os efeitos da topografia sobre a geração de escoamento e os efeitos da vegetação nos fluxos turbulentos à superfície, na escala de grandes bacias.

\section{6 - INCERTEZAS NA MODELAGEM HIDROLÓGICA}

Nenhum modelo constitui uma representação perfeita do mundo real, e as divergências entre o modelo e a realidade por ele representada não são necessariamente decorrentes de erros, mas também de incertezas produzidas pela falta de conhecimento de todas as condições a que a realidade está submetida (Beven, 2011).

As incertezas não devem ser confundidas com erros, que se referem à diferença entre o valor simulado e o valor observado, enquanto que incerteza se refere à diferença entre as estatísticas da amostra e da população. As incertezas em modelagem hidrológica são provenientes dos dados de entrada, da estrutura do modelo e da estimativa dos parâmetros (Tucci, 1998).

As incertezas em modelagem hidrológica têm diversas causas, pois a observação de alguns parâmetros é problemática já que as medições podem ser escassas ou realizadas por diferentes técnicas que podem apresentar diferentes resultados. Além disso, a 
regionalização dos valores medidos é difícil por conta da variabilidade natural das características da bacia em decorrência de diferenças de clima, solo, vegetação e estágio do desenvolvimento ecológico. Ainda, até se estas variações fossem perfeitamente medidas e suas causas fossem perfeitamente dimensionadas, alguma informação seria perdida quando o estabelecimento do modelo tiver a necessidade de agregar as informações das características da vegetação pelas sub-unidades espaciais do modelo. (Eckhardt et al., 2003).

As simplificações assumidas na modelagem, entre elas as agregações de espaço, aliadas à ausência de pleno conhecimento na estimativa dos parâmetros e da qualidade dos dados de entrada no modelo, implicam em incertezas nos resultados que são produzidos. Por esse motivo a confiabilidade nas previsões do modelo é um aspecto relevante para sua aplicação como ferramenta de suporte à tomada de decisão. O grau de confiabilidade de um modelo hidrológico pode ser investigado por meio das técnicas de análise de incertezas e de sensibilidade que permitem quantificar e representar um intervalo possível de valores de parâmetros que caracterizam o fenômeno modelado e os potenciais modelos que representam o evento hidrológico estudado (Sarmento, 2010).

De acordo com Beven (1993), o conceito de que há um conjunto ótimo de parâmetros é falho de várias maneiras, a mais importante delas é que esse pensamento desencoraja a consideração das incertezas na definição dos parâmetros e dos valores simulados. O que pode ser demonstrado, é que se for realizada a calibração para dois períodos distintos, ou mesmo quando a calibração é realizada por pessoas diferentes, dois conjuntos diferentes de parâmetros "ótimos" serão produzidos. A multiplicidade de períodos de dados disponível ou as diferentes expertises dos modeladores vai gerar uma multiplicidade de conjunto de parâmetros "ótimos".

A diversidade de conjuntos ótimos de parâmetros pode refletir as incertezas da definição dos parâmetros e da interação entre os parâmetros que resultam nas vazões simuladas. Múltiplos conjuntos de parâmetros para uma única calibração também são possíveis, particularmente para modelos distribuídos conceituais e de base física que são desenvolvidos para refletir diferentes tipos de resposta e permitir um grande número de valores de parâmetros, o que também pode se refletir nas incertezas nas respostas da bacia. Beven e Binley (1992) apresentaram o conceito de equifinalidade, no qual existem várias combinações de parâmetros que apresentam resultados semelhantes entre si e relativamente 
próximos aos dados observados, Entre estes conjuntos é praticamente impossível definir qual é o mais adequado.

A calibração multiobjetivo, conforme proposta de Yapo et al. (1998), por viabilizar a obtenção de diversos conjuntos de parâmetros que podem ser considerados como ótimos, permite a possibilidade de avaliar as incertezas associadas aos parâmetros calibrados (Collischonn e Tucci, 2003). A calibração multiobjetivo, não busca uma única solução, mas um conjunto das melhores soluções que formam a superfície de Pareto, que é formada pelo conjunto de soluções não-dominadas. Na superfície de Pareto a melhora de uma das funções objetivos implica na degradação de outra, sendo que os elementos desta superfície correspondem aos melhores valores globalmente, segundo as funções objetivo escolhidas.

Gupta et al. (1998) apresenta uma ilustração de como os resultados da calibração multiobjetivo podem reduzir as incertezas na determinação dos parâmetros e nas respostas da bacia. Na figura 3.9 (a) toda a faixa de possíveis valores que podem ser assumidos pelos parâmetros representa a incerteza inicial, $\mathrm{U}^{\circ}(\theta)$, que causam as incertezas das respostas da bacia, representada por $\mathrm{U}^{\circ}(\mathrm{Q})$ na figura 3.9 (b), correspondente à área cinza claro. A região $\mathrm{U}^{\circ}(\theta)$ pode ser adequadamente restringida com o conhecimento de uma combinação de parâmetros que gerem respostas razoáveis da bacia, que podem ser obtidos na calibração multiobjetivo, o que reduz a incerteza na definição dos parâmetros, obtendo-se a superfcíe $\mathrm{U}^{\mathrm{f}}(\theta)$, e consequentemente a incerteza da resposta da bacia $\mathrm{U}^{\mathrm{f}}(\mathrm{Q})$, que são representadas pela área cinza escuro das figura 3.9 (a) e 3.9 (b). As incertezas nas respostas da bacia deveriam ser anuladas pela definição das incertezas dos parâmetros, no entanto, por causa da existência de erros na estrutura do modelo, o valor mínimo das incertezas dos parâmetros $\left(\mathrm{U}^{\mathrm{f}}(\theta)\right)$, que é a superfície de Pareto $\mathrm{P}(\theta)$ determina a mínima incerteza na resposta da bacia, $\mathrm{U}^{\mathrm{f}}(\mathrm{Q})$.

Há diversas metodologias de análise de incertezas, das quais pode se destacar o método de simulação de Monte Carlo (Vrugt et al.,, 2000), o método do hipercubo latino (van Griensven et al., 2006), Teorema de Bayes (Balakrishnam et al., 2003), método do segundo momento de primeira ordem - FOSM, o método do valor médio do segundo momento de primeira ordem avançado - AFOSM e o método de estimativa generalizada de incerteza- GLUE (Beven e Binley, 1992). São técnicas robustas que requerem detalhamento dos dados observados e da estrutura do modelo (Batista, 2006). 
Xavier (2002) utilizou a técnica GLUE para avaliar as incertezas associadas à simulação hidrológica na bacia do Rio Iguaçu, no estado do Rio de Janeiro, com uso do modelo distribuído Topmodel e verificou a importância que a representação imperfeita da precipitação exerce sobre as incertezas na modelagem hidrológica.

a) Variabilidade dos parâmetros inicial e final

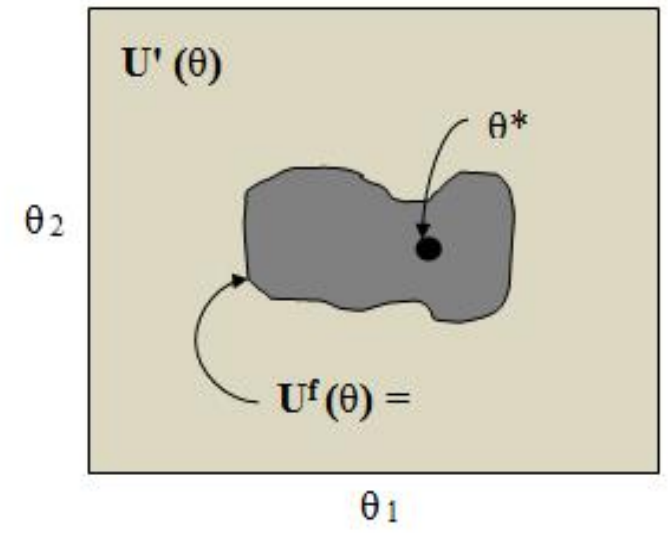

b) Incerteza hidrológica inicial e final

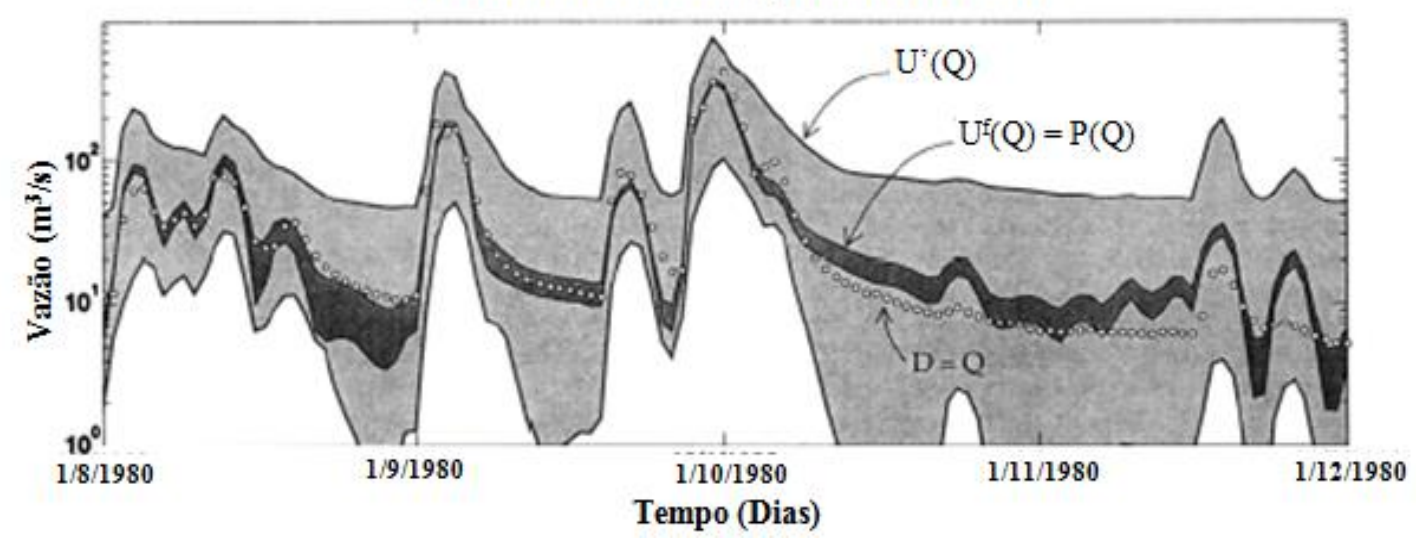

Figura 3.9 - Variação das incertezas em função da definição da superfície de Pareto obtida após calibração multiobjetivo (Gupta et.al. 1998 - modificado).

Batista (2006) estudou as incertezas baseadas na variação das características estatísticas das séries simuladas em bacias da região do alto Rio Paraíba, no estado de mesmo nome, com o modelo distribuído NAVMO, considerando diferentes estatísticas da bacia. As características estatísticas analisadas foram coeficiente de determinação, somatório das vazões anuais, teste de dupla massa, somatório do quadrado das diferenças, testes paramétricos da média e variância, o teste não-paramétrico de Wilcoxon e distribuições de probabilidade. Foi verificado que as incertezas são reduzidas quando se aumenta o número de divisões da bacia e melhora-se a base de dados de precipitação. 
Sarmento (2010), com uso do modelo SWAT, realizou a modelagem hidrológica da bacia do rio Descoberto, no Distrito Federal. A análise de incertezas foi realizada utilizando um conjunto de parâmetros obtidos pelo método do hipercubo latino, que permitiu o estabelecimento intervalos de confiança do desempenho do modelo.

Estudando os efeitos das mudanças na cobertura e uso do solo, Eckardt (2003) desenvolveu um método para levar em consideração as incertezas decorrentes da modelagem hidrológica, o método desenvolvido torna possível determinar se uma diferença na parametrização de duas simulações diferentes resultará numa diferença significativa nas respostas do modelo.

O método primeiramente realiza simulações de Monte Carlo independentes para cada tipo de cobertura de solo levando-se em conta todos os possíveis valores dos parâmetros e sua distribuição de frequência, apresentando as incertezas de saída do modelo. Estas distribuições de frequências são comparadas e então é realizado um teste estatístico não dimensional para expressar a probabilidade de as duas simulações com diferentes coberturas de solo produzirem os mesmos resultados. Quando o teste estatístico for superior ao limite estabelecido, as duas coberturas de solo são avaliadas como tendo produzido respostas significativamente diferentes do modelo. As mudanças na resposta da bacia só são consideradas se as simulações atenderem a estas condições. O principal objetivo não é calcular as incertezas absolutas dos valores simulados, mas avaliar a significância dos resultados das simulações.

Para a análise dos efeitos das mudanças do uso do solo sobre as vazões, Seibert et al. (2010) e Gebrehiwot et al. (2013) adotaram os conceitos de incertezas baseados em simulações de Monte Carlo usando modelo HBV, no qual um conjunto dos melhores sets de parâmetros foram utilizados para se estimar as respostas das bacias. Os efeitos das mudanças na cobertura e uso do solo sobre os picos de vazão foram detectados de três formas: (a) comparando-se as vazões observadas com as vazões simuladas com parâmetros obtidos da calibração em um período de referência; (b) comparando os valores dos parâmetros calibrados com diferentes tipos de cobertura da terra; e (c) comparando as simulações com diferentes conjuntos de parâmetros, obtidos de diferentes coberturas e uso do solo. A comparação foi realizada por meio do teste não paramétrico de Wilcoxon (Teste de Mann-Whitney) para confirmar se os valores comparados eram estatisticamente diferentes entre si. 


\section{7 - APLICAÇÃO DE MODELOS HIDROLÓGICOS NA AVALIAÇÃO DOS EFEITOS DA ALTERAÇÃO DA COBERTURA VEGETAL SOBRE O REGIME DE VAZÕES}

Os estudos experimentais com bacias pareadas para avaliar os impactos das alterações na cobertura vegetal sobre o regime hidrológico foram realizados predominantemente em bacias pequenas onde os processos de hidrológicos e os efeitos das mudanças na cobertura e uso do solo são mais súbitos. Em grandes bacias, no entanto, as respostas da bacia às mudanças levam maior tempo para serem percebidas, o que se alia à maior heterogeneidade para tornar difícil a aplicação dos conceitos observados em bacias experimentais às bacias de grande escala (Rodriguez et al. (2010). Para bacias de grande escala, é conveniente recorrer à utilização de modelos hidrológicos (Bultot et al., 1990).

No contexto dos efeitos das mudanças na cobertura e uso do solo, a modelagem hidrológica é aplicada de duas maneiras gerais. Os modelos podem ser aplicados para detectar mudanças nas respostas hidrológicas observadas, aumentando a compreensão dos fatores que causam essas mudanças e podem também ser aplicados para a previsão de respostas possíveis sob cenários futuros de uso da terra (McIntyre et al. 2014).

Para a previsão de respostas hidrológicas em cenários futuros há necessidade de um modelo de base física, pois por representar a complexidade dos processos hidrológicos representados, esse tipo de modelo pode ser parametrizado para as condições futuras de uso do solo. Para a detecção de alterações, por outro lado, é necessário um modelo que reproduza fielmente as séries de vazões, sendo capaz de informar as vazões que teriam sido observadas se não tivesse ocorrido nenhuma mudança, neste caso, os modelos conceituais são a escolha adequada, pois tem sido demonstrado que para situações com calibração, estes modelos funcionam tão bem ou mesmo melhor do que os modelos mais complexos, além do que, para os modelos conceituais, é possível obter os parâmetros do modelo por calibração, e estes parâmetros podem também ser utilizados para investigar as mudanças hidrológicas (Gebrehiwot et al., 2013).

A seguir serão apresentadas algumas aplicações de modelos hidrológicos para determinação dos impactos das alterações na cobertura e uso do solo sobre o regime hidrológico em diferentes tipos de clima e vegetação. 
Hernandes et al. (2000) aplicaram dois modelos hidrológicos na Bacia do Rio San Pedro, no norte do México e Sudeste do Arizona nos Estados Unidos, região de clima semi-árido. O modelo Kineros (Kinematic Runoff and Erosion) foi utilizado para avaliar as respostas da bacia para eventos de cheia e o resultado obtido foi semelhante aos observados em estudos experimentais, com o maior aumento de vazão sendo correspondente a áreas urbanizadas ou solo desnudo e os menores valores para vegetação florestal. Utilizando o SWAT para avaliar a variação da vazão anual para diferentes cenários de cobertura do solo os resultados foram semelhantes, com a diferenças de vazão chegando a $59 \mathrm{~mm} \cdot \mathrm{ano}^{-1}$.

Em duas grandes bacias do oeste africano de clima tropical, Li et al. (2007) utilizaram o modelo THMB (Terrestrial Hydrology Model with Biogeochemistry) para simular os efeitos das alterações do uso do solo sobre a vazão e seus estudos revelaram que quando a vegetação é totalmente removida há um aumento de vazão entre 33 e $91 \%$ e que os efeitos da alteração da vegetação são perceptíveis apenas quando o desmatamento ocorre em mais de $50 \%$ da área, limite a partir do qual a alteração é drástica, não sendo observado linearidade na resposta das bacias. As alterações no regime hidrológico são atribuídas às mudanças na evapotranspiração.

Tatsch (2011) utilizou o modelo DBHM para simular o comportamento hidrológico da bacia do Rio Mogi-Guaçu em São Paulo para diferentes cenários de cobertura e uso do solo. A bacia estudada encontrava-se altamente antropizada com intenso uso agrícola, principalmente cultivo de cana-de-açúcar. O estudo apresentou resultados semelhantes aos de estudos experimentais, com exceção de uma das sub-bacias, na qual o cenário com cobertura por vegetação nativa apresentou a maior vazão na estação seca entre os demais cenários comparados. De modo geral, as maiores vazões foram obtidas quando a cobertura predominante era agricultura, seguida de vegetação nativa e reflorestamento.

Utilizando o modelo hidrológico de base física MIKE-SHE (DHI, 2007) e o modelo de simulação da dinâmica do uso do solo chamado CA - Cellular Automata (White and Engelen, 2000), Wijesekara et al. (2012) avaliaram os efeitos das mudanças do uso do solo sobre as vazões da Bacia do Rio Elbow $\left(1258 \mathrm{Km}^{2}\right)$ no Canadá. Neste estudo os pesquisadores compararam as vazões anuais e a evapotranspiração observados nas condições de uso do solo em 2001 com as simulações de vazão e evapotranspiração para o cenário também simulado de uso do solo em 2031. A simulação da dinâmica de alteração do uso do solo entre 2002 e 2031 apresentou aumento de 25\% das áreas urbanas (5\% da 
área total), um aumento de $41 \%$ em áreas de pastagens (8\% da área total), um aumento de $33 \%$ em áreas agrícolas (20\% da área total), uma redução de $42 \%$ nas áreas de florestas decíduas (19\% da área total), e uma redução de 13,5\% em áreas de florestas verdes (47\% do total da área) com estas alterações no uso do solo, as simulações apontaram que o impacto sobre o regime hidrológico da bacia seria um aumento de 7,3\% no escoamento superficial, redução de $1 \%$ na evapotranspiração, redução de $13 \%$ no escoamento de base e redução de $2,3 \%$ na infiltração.

O VIC - Variable Infiltration Capacity (Liang, et al., 1994) foi utilizado para avaliar os efeitos das mudanças na cobertura e uso da terra na bacia do Rio Dongjiang na China (25,3 mil km²). Neste estudo, Niu e Sivakumar (2014) simularam as vazões no período de 1952 a 2000 para 4 cenários de cobertura e uso do solo comparando seus resultados com as vazões observadas no período e a situação de cobertura e uso do solo do ano 2001. Os resultados foram de aumentos da vazão média anual quando as florestas eram substituídas por pastagens e de redução quando pastagens ou culturas agrícolas eram substituídas por vegetação florestal, estas alterações variaram de 1,35 a 13,9\%.

O MGB-IPH foi utilizado por Caram (2010) para avaliar os efeitos das mudanças na cobertura e uso do solo sobre o comportamento hidrológico da bacia do Rio Piracicaba com diferentes cenários de cobertura e uso do solo, obtendo resultados divergentes dos obtidos em estudos experimentais, com aumento de vazão no cenário em que $100 \%$ da bacia era coberta por florestas. De todo modo o cenário de maior impacto na vazão foi com $100 \%$ de cobertura por agricultura. O aumento de vazão devido a cobertura por florestas

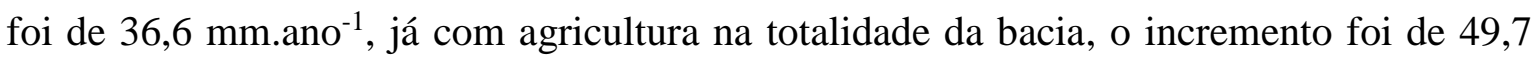
mm.ano ${ }^{-1}$. Nesse estudo a maior redução na vazão ocorreu com a conversão de agricultura em pastagem, onde o decréscimo foi de 11,5 mm.ano ${ }^{-1}$.

Também utilizando o MGB-IPH, Bayer (2014) realizou um estudo sobre os impactos das alterações na cobertura e uso do solo na bacia do Rio Paraná $\left(827.155 \mathrm{~km}^{2}\right)$, no qual não foram utilizados cenários, mas acompanhado o desenvolvimento das mudanças no uso do solo no período entre 1940 e 1999. Comparando as simulações com as variações na cobertura do solo ao longo do período, foi verificado que houve aumento de $62,8 \mathrm{~mm}$.ano ${ }^{-1}$ na vazão média devido ao desmatamento de $42,3 \%$ observado ao longo do período. 


\section{8 - MODELO DE GRANDES BACIAS - MGB-IPH}

O modelo de grandes bacias (MGB-IPH) foi desenvolvido para simular o processo de transformação da chuva em vazão em grandes bacias hidrográficas (Collischonn, 2001) e é composto de módulos para o cálculo do balanço de água no solo, interceptação, evapotranspiração, propagação do escoamento na rede de drenagem e escoamentos superficial, subsuperficial e subterrâneo em cada mini-bacia. A bacia é discretizada espacialmente em mini-bacias e cada mini-bacia é dividida em unidades de resposta hidrológica (URHs), que são áreas com o mesmo tipo de solo e vegetação (Fan, 2011), em cada mini-bacia são atribuídas informações como precipitação, temperatura do ar, umidade relativa, velocidade do vento, insolação e pressão atmosférica. Este modelo foi escolhido por ser um modelo distribuído, conceitual, com parte dos processos descritos com base física e com capacidade de representar as alterações na cobertura vegetal e também não exigir uma grande quantidade de parâmetros se comparado a modelos de base física. A seguir é apresentada uma descrição do modelo

\subsection{1 - Balanço de água no solo}

O balanço de água no solo é realizado de maneira independente para cada URH, utilizando as características e os parâmetros da URH. A Equação 3.2 descreve o balanço na camada de solo, representado na figura 3.9.

$$
W_{i+1}=W_{i}+P-E T-D_{\text {sup }}-D_{\text {int }}-D_{\text {bas }}-D_{\text {cap }}
$$

onde: $W_{i+1}(\mathrm{~mm})$ é o armazenamento na camada de solo ao final do intervalo de tempo; $W_{i}$ (mm) é o armazenamento na camada de solo ao início do intervalo de tempo; $P[\mathrm{~mm}]$ é a precipitação incidente ao longo do intervalo de tempo; ET (mm) é a evapotranspiração da água da camada de solo ao longo do intervalo de tempo; $D_{\text {sup }}(\mathrm{mm})$ é o escoamento superficial ao longo do intervalo de tempo (drenagem rápida); $D_{i n t}(\mathrm{~mm})$ é o escoamento subsuperficial ao longo do intervalo de tempo (drenagem lenta); $D_{b a s}(\mathrm{~mm})$ escoamento subterrâneo ao longo do intervalo de tempo (drenagem muito lenta); $D_{c a p}(\mathrm{~mm})$ é o fluxo do reservatório subterrâneo para a camada superficial do solo. O intervalo de tempo considerado é de 1 dia. 


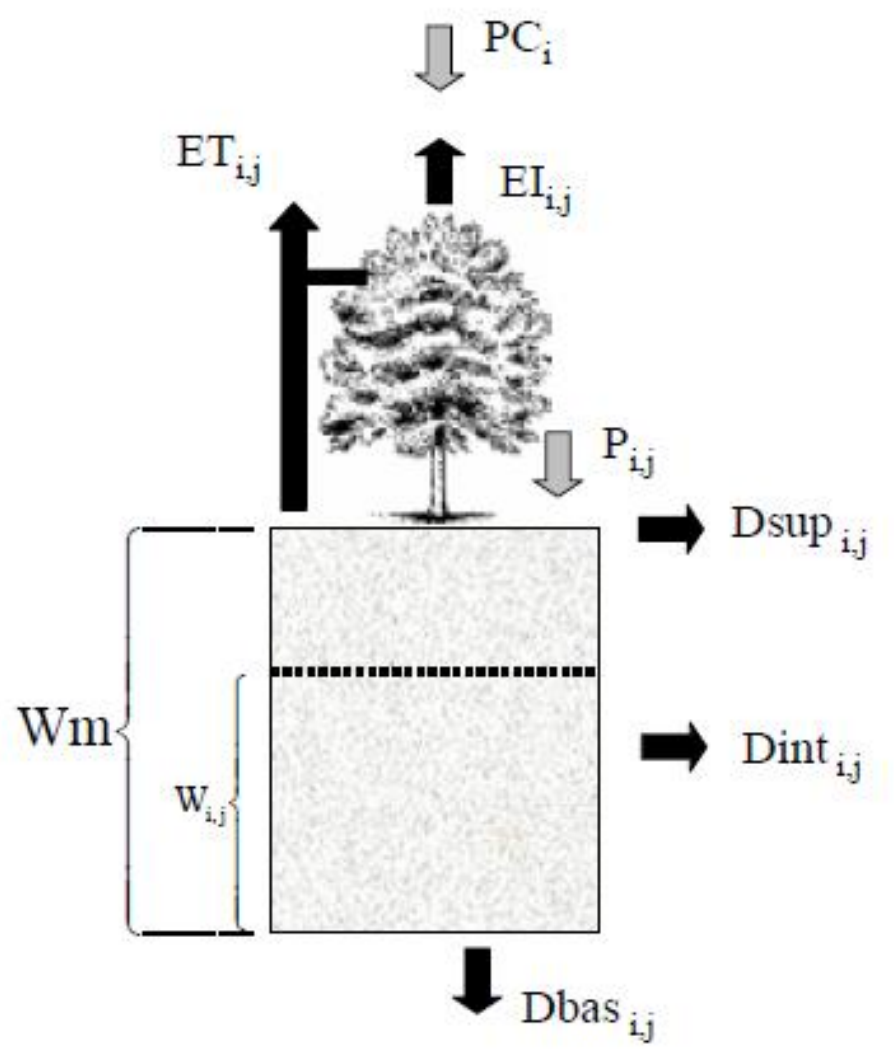

Figura 3.10 - Balanço de água no solo em cada URH (Collischonn at al., 2007).

O termo $\mathrm{D}_{\text {sup }}$, que representa o escoamento superficial, é calculado considerando que toda a chuva que cair sobre uma porção de solo já saturada de umidade irá gerar escoamento superficial. O modelo considera que existe uma relação entre $\mathrm{W}$, que é o estado de armazenamento atual da camada de solo, e a porcentagem de área saturada. $\mathrm{O}$ escoamento superficial, é calculado por:

$$
D_{\text {sup }}=P-(W m-W)
$$

Quando $\delta \leq 0$ e por:

$$
D_{\text {sup }}=P-(W m-W)+W m \times(\delta)^{b+1}
$$

Onde

$$
\delta=\left[\left(1-\frac{W}{W m}\right)^{\frac{b}{b+1}}-\frac{P}{(b+1) \times W m}\right]
$$

Onde: W (mm) é o armazenamento na camada do solo; Wm (mm) é o armazenamento máximo na camada do solo; b é um parâmetro adimensional que representa a não- 
uniformidade da capacidade de armazenamento do solo na URH; P (mm) é a precipitação menos a interceptação e $\mathrm{D}_{\text {sup }}(\mathrm{mm})$ é o escoamento superficial.

O escoamento sub-superficial é obtido por uma relação não linear com o armazenamento na camada de solo, baseada na equação da condutividade hidráulica do solo de Brooks e Corey, dada pela equação 3.6.

$$
D_{i n t}=K i n t \times\left(\frac{W-W_{z}}{W m-W_{z}}\right)^{\left(\frac{3+2}{X L}\right)}
$$

Onde: $\mathrm{D}_{\text {int }}(\mathrm{mm})$ é o escoamento sub-superficial; $\mathrm{W}_{\mathrm{z}}(\mathrm{mm})$ é o limite de armazenamento para haver escoamento sub-superficial; Kint (mm) é o parâmetro de escoamento subsuperficial e XL é o índice de porosidade do solo. O parâmetro Kint é calibrado e o índice XL é fixado em 0,67 .

O escoamento subterrâneo é calculado por uma equação simples, linear com relação ao armazenamento no solo.

$$
D_{b a s}=K b a s \times \frac{W-W c}{W m-W c}
$$

Onde: $D_{\text {bas }}(\mathrm{mm})$ é o escoamento subterrâneo; Kbas $(\mathrm{mm})$ é o parâmetro de escoamento subterrâneo e Wc (mm) é o limite de armazenamento no solo para haver escoamento subterrâneo.

Em alguns casos, quando o armazenamento do solo é baixo, pode ocorrer a transferência de água do reservatório subterrâneo para a camada de solo. Esta possibilidade visa permitir ao modelo simular situações em que as águas subterrâneas voltem a ser disponibilizadas para a evapotranspiração. A Equação 3.8 descreve o fluxo ascendente.

$$
D_{\text {cap }}=\frac{W c-W}{W c} \times C A P
$$

Onde: $\mathrm{D}_{\text {cap }}(\mathrm{mm})$ é fluxo ascendente; Wc $[\mathrm{mm}]$ é o limite de armazenamento para haver fluxo ascendente e CAP $(\mathrm{mm})$ máximo fluxo ascendente para o solo (parâmetro do modelo). 


\subsection{2 - Interceptação}

O MGB-IPH considera que há um reservatório para a interceptação que, quando excedido pela precipitação, passa diretamente para a superfície do solo. A capacidade deste reservatório é altamente dependente da densidade da cobertura vegetal, que é representada pelo índice de área foliar (IAF). A capacidade de interceptação e expressa pela equação 3.9

$$
S I L_{j}=\propto \times I A F_{j}
$$

Onde: $S I L_{j}(\mathrm{~mm})$ é a capacidade do reservatório de interceptação da URH j de qualquer mini-bacia; $\propto(\mathrm{mm})$ é o parâmetro de lâmina de interceptação, que o modelo adota com o valor fixo de $0,2 \mathrm{~mm}$; IAF é o índice de área foliar. A tabela 3.1 apresenta alguns valores típicos de IAF.

Tabela 3.1 - Valores de IAF para diferentes tipos de vegetação (Collischonn, 2001).

\begin{tabular}{cc}
\hline Tipo de cobertura & IAF \\
\hline Coníferas & 6 \\
Floresta decídua & 6 \\
Soja irrigada & 7,5 \\
Soja não irrigada & 6,0 \\
Floresta amazônica & 6 a 9,6 \\
Pastagem amazônica (estação seca) & 0,5 \\
Pastagem amazônica (estação chuvosa) & 3,9 \\
Cerrado (estação seca) & 0,4 \\
Cerrado (estação chuvosa) & 1,0 \\
\hline
\end{tabular}

As equações a seguir descrevem o processo de enchimento e esvaziamento do reservatório de interceptação. Quando a o reservatório está cheio, a precipitação passa integralmente para a camada superficial do solo, quando isso não ocorre o reservatório é esvaziado pela evaporação.

$$
\begin{gathered}
S F_{i, j}^{k}=S F_{i, j}^{k-1}+P C_{i} \text { quando } S F_{i, j}^{k-1}+P C_{i} \leq S I L_{j} \\
S F_{i, j}^{k}=S I L_{j} \text { quando } S F_{i, j}^{k-1}+P C_{i} \geq S I L_{j} \\
P_{i, j}=P C_{i, j}-\left(S F_{i, j}^{k}-S F_{i, j}^{k-1}\right)
\end{gathered}
$$


onde $S F_{i, j}^{k}(\mathrm{~mm})$, é a lâmina interceptada ao final do intervalo de tempo na URH j da minibacia i; $S I L_{j}(\mathrm{~mm})$ é a capacidade do reservatório de interceptação da URH j de qualquer

mini-bacia; $S F_{i, j}^{k-1}(\mathrm{~mm})$ é a lâmina interceptada ao final do passo de tempo anterior na URH j da mini-bacia i; $P C_{i}(\mathrm{~mm} /$ dia $)$ é a precipitação incidente sobre a cobertura vegetal sobre a mini-bacia i; $P_{i, j}(\mathrm{~mm} / \mathrm{dia})$ é a precipitação sobre a superfície do solo na URH j da mini-bacia i.

A evapotranspiração é aplicada de modo diferente para a lâmina interceptada e a água na superfície do solo.

\subsection{3 - Evapotranspiração}

O MGB-IPH estima a evapotranspiração utilizando a equação de Penman-Monteith, que é dada por:

$$
E=\left(\frac{\Delta \times\left(R_{L}-G\right)+\rho_{A} \times c_{p} \times \frac{\left(e_{s}-e_{d}\right)}{r_{a}}}{\Delta+\gamma \times\left(1+\frac{r_{s}}{r_{a}}\right)}\right) \times\left(\frac{1}{\lambda \times \rho_{w}}\right)
$$

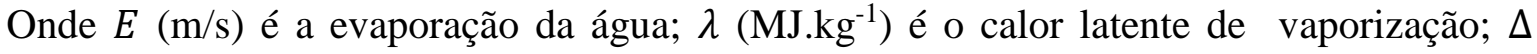
$\left(\mathrm{kPa} .{ }^{\circ} \mathrm{C}^{-1}\right)$ é a variação da pressão de saturação do vapor d'água; $R_{L}\left(\mathrm{MJ} \cdot \mathrm{m}^{-2} \cdot \mathrm{s}^{-1}\right)$ é a radiação líquida na superfície; $G\left(\mathrm{MJ} . \mathrm{m}^{-2} \cdot \mathrm{s}^{-1}\right)$ é o fluxo de energia para o solo; $\rho_{A}\left(\mathrm{~kg} . \mathrm{m}^{-3}\right)$ é a massa específica do ar; $\rho_{w}\left(\mathrm{~kg} \cdot \mathrm{m}^{-3}\right)$ é a massa específica da água; $c_{p}\left(\mathrm{MJ} \mathrm{kg}^{-1} \cdot{ }^{\circ} \mathrm{C}^{-1}\right)$ é o calor específico do ar úmido $\left(c_{p}=1,013 \cdot 10^{-3} \mathrm{MJ} \cdot \mathrm{kg}^{-1} \cdot{ }^{\circ} \mathrm{C}^{-1}\right) ; e_{s}(\mathrm{kPa})$ é pressão de saturação do vapor d'água; $e_{d}(\mathrm{kPa})$ é a pressão do vapor d'água; $\gamma\left(\mathrm{kPa} .{ }^{\circ} \mathrm{C}^{-1}\right)$ é a constante psicrométrica $(\gamma=0,66) ; r_{s}\left(\mathrm{~s} . \mathrm{m}^{-1}\right)$ é a resistência superficial da vegetação e $r_{a}\left(\mathrm{~s} . \mathrm{m}^{-1}\right)$ é a resistência aerodinâmica.

A equação 3.13 considera que há uma rede de resistências, superficial e aerodinâmica onde toda a radiação líquida está disponível às plantas para evapotranspiração. A radiação líquida que o modelo utiliza é obtida pela seguinte relação:

$$
R_{L}=S_{\text {sup }} \times(1-\propto)
$$

Onde $S_{\text {sup }}\left(\mathrm{MJ} \cdot \mathrm{m}^{-2} \cdot \mathrm{s}^{-1}\right)$ é radiação que atinge a superfície e $\propto$ (adimensional) é o albedo. 
A radiação que atinge a superfície pode ser calculada a partir da quantidade de horas de insolação, que é um dos dados de entrada no modelo, conforme descrito por Shuttleworth (1993).

O albedo é dado pela relação entre o fluxo radiação de ondas curtas refletidas pela superfície e a radiação global incidente (Brutsaert, 2005). É um parâmetro diretamente relacionado com as mudanças de cobertura e uso do solo. $\mathrm{O}$ desmatamento causa aumento do valor do albedo, uma vez que o albedo das florestas é mais baixo de que a maioria dos outros tipos de cobertura. Com o aumento do albedo há menos energia disponível para a evapotranspiração desta forma o desmatamento tende a reduzir a evapotranspiração.

A tabela 3.2 apresenta alguns valores típicos de albedo para diferentes tipos de cobertura do solo.

Tabela 3.2 - Valores médios de albedo para diferentes coberturas de solo (Bayer, 2014).

\begin{tabular}{|c|c|c|}
\hline \multicolumn{2}{|c|}{ Tipo de cobertura } & \multirow{2}{*}{$\begin{array}{c}\text { Albedo } \\
0,08\end{array}$} \\
\hline Água & & \\
\hline \multirow[t]{5}{*}{ Florestas } & Altas & $0,11-0,16$ \\
\hline & Amazônica & 0,134 \\
\hline & Coníferas & $0,05-0,10$ \\
\hline & Mistas & $0,10-0,15$ \\
\hline & $\begin{array}{c}\text { Temperadas (madeira-de- } \\
\text { lei }\end{array}$ & $0,15-0,20$ \\
\hline \multirow[t]{3}{*}{ Cultivos agrícolas } & & $0,20-0,26$ \\
\hline & Altos (ex. cana-de-açúcar) & $0,15-0,2$ \\
\hline & Baixos (ex. soja, trigo) & $0,20-0,26$ \\
\hline \multirow[t]{4}{*}{ Pastagens ou gramíneas } & & $0,20-0,26$ \\
\hline & Tropicais (amazônica) & 0,18 \\
\hline & Gramíneas altas & $0,15-0,20$ \\
\hline & Gramíneas baixas & $0,15-0,25$ \\
\hline \multirow[t]{2}{*}{ Cerrado brasileiro } & Época úmida & 0,13 \\
\hline & Época seca & 0,18 \\
\hline \multirow[t]{4}{*}{ Solo } & Exposto úmido & 0,10 \\
\hline & Exposto seco & 0,35 \\
\hline & Argiloso & $0,20-0,35$ \\
\hline & Arenoso & $0,25-45$ \\
\hline
\end{tabular}


Quanto à resistência superficial, trata-se da resistência ao fluxo de umidade do solo para a atmosfera através da planta. Este fluxo, que é a transpiração, é controlado pela abertura e fechamento dos estômatos das plantas (Calder, 1993). No MGB -IPH, a $r_{s}$ depende do teor de umidade do solo, de acordo com a seguinte equação (Wigmosta, 1994):

$$
r_{s}=f \times r_{\text {smin }}
$$

Onde $r_{\text {smin }}\left(\mathrm{s} . \mathrm{m}^{-1}\right)$ é a resistência superficial mínima, que ocorre quando não há escassez de água no solo, e $f$ é uma função que corrige a resistência em termos de déficit de umidade no solo, dada por:

$$
\begin{gathered}
\frac{1}{f}=1 \quad \text { se } \quad W_{L, i, j} \leq W_{i, j} \\
\frac{1}{f}=\frac{\left(W_{i, j}^{t}-W_{P M i, j}\right)}{\left(W_{L i, j}^{t}-W_{P M i, j}\right)} \quad \text { se } \quad W_{L, i j}>W_{i, j}
\end{gathered}
$$

Onde $W_{i, j}(\mathrm{~mm})$ é o conteúdo de água no solo; $W_{L, i, j}(\mathrm{~mm})$ é o mínimo de umidade do solo que não causa restrições à evapotranspiração, no MGB-IPH é definido como sendo $50 \%$ da capacidade de armazenamento de água no solo $(W m(\mathrm{~mm}))$ e $W_{P M i, j}(\mathrm{~mm})$ é o ponto de murcha, considerada no modelo como $10 \%$ do $\mathrm{Wm}$. A tabela 3.3 apresenta alguns valores típicos que resistência superficial mínima para diferentes tipos de cobertura vegetal.

Tabela 3.3 - Resistência superficial mínima para diferentes tipos de cobertura vegetal (Collischonn, 2001).

\begin{tabular}{cc}
\hline Cobertura vegetal & Resistência superficial mínima $\left(\mathrm{s} . \mathrm{m}^{-1}\right)$ \\
\hline Floresta & 100 \\
Cerrado & $100-200$ \\
Culturas agrícolas & 40 \\
Trigo & 40 \\
Campo & $40-80$ \\
Grama & $69-71$ \\
Savana africana & 60 \\
Savana com arbustos & 98
\end{tabular}


A resistência aerodinâmica controla a taxa de transferência do vapor d'água da superfície do solo, que ocorre por difusão turbulenta. A resistência superficial no MGB-IPH é calculada pela seguinte expressão:

$$
r_{a i, j}=\frac{\ln \frac{\left(z_{u}-d\right)}{0,123 \times h} \times \ln \frac{\left(z_{e}-d\right)}{0,123 \times h}}{k^{2} \times U}
$$

Onde $z_{u}(\mathrm{~m})$ é a altura em que são realizadas as medições de velocidade do vento; $z_{e}(\mathrm{~m})$ é a altura em que são realizadas as medições de umidade relativa do $\operatorname{ar} ; \quad U\left(\mathrm{~m} . \mathrm{s}^{-1}\right)$ é a velocidade do vento na altura $z_{u}, k$ é a constante de von Kármán que é igual a 0,$41 ; h(\mathrm{~m})$ é a altura média da cobertura vegetal e $d$ um fator de correção em relação à altura da cobertura vegetal dado por $d=0,67 \times h$. A tabela 3.4 apresenta a altura média de algumas coberturas vegetais.

Tabela 3.4 - Altura de diferentes tipos de cobertura vegetal (Collischonn, 2001).

\begin{tabular}{cc}
\hline Cobertura vegetal & Altura média $(\mathrm{m})$ \\
\hline Floresta & 10 \\
Cerrado & 5 \\
Campo, pastagem & 0,5 \\
Agricultura & 0,5 \\
Pastagem amazônica & 0,53 \\
Floresta amazônica & 30 \\
\hline
\end{tabular}

\subsection{4 - Escoamento superficial, subsuperficial e subterrâneo}

Os escoamentos superficial, subsuperficial e subterrâneo são representados no MGB-IPH, como apresentado na figura 3.9, por $\mathrm{D}_{\text {sup } \mathrm{i}, \mathrm{j}}, \mathrm{D}_{\text {int } \mathrm{i}, \mathrm{j}}$ e $\mathrm{D}_{\text {bas }}$ respectivamente. Este escoamento que deixa cada fração da mini-bacia não atinge instantaneamente a rede de drenagem, mas sofre retardo e amortecimento ainda no interior da de cada fração da mini-bacia. Este efeito é dado pela passagem do escoamento por reservatórios lineares, cujos coeficientes de amortecimento e retardo são parâmetros calibráveis do modelo. O escoamento superficial vai para o reservatório superficial, o escoamento subsuperficial vai para o reservatório subsuperficial e o escoamento subterrâneo vai para o reservatório subterrâneo. Nestes reservatórios, os escoamentos de cada URH são somados, conforme as seguintes equações: 


$$
\begin{gathered}
V_{\sup i}^{k \prime}=V_{\sup i}^{k-1}+\Delta t \times\left(\sum_{j=1}^{n b} D_{\sup i, j}\right) \\
V_{\text {int } i}^{k^{\prime}}=V_{\operatorname{int} i}^{k-1}+\Delta t \times\left(\sum_{j=1}^{n b} D_{\operatorname{int} i, j}\right) \\
V_{\text {bas } i}^{k \prime}=V_{\text {bas } i}^{k-1}+\Delta t \times\left(\sum_{j=1}^{n b} D_{\text {bas } i, j}\right)
\end{gathered}
$$

Onde $V_{\text {sup } i}^{k-1}\left(\mathrm{~m}^{3}\right)$ é o volume do reservatório superficial da mini-bacia no início do passo de tempo; $V_{\operatorname{int} i}^{k-1}\left(\mathrm{~m}^{3}\right)$ é o volume do reservatório subsuperficial da mini-bacia no início do passo de tempo; $V_{\text {basi }}^{k-1}\left(\mathrm{~m}^{3}\right)$ é volume do reservatório subterrâneo da mini-bacia no início do passo de tempo; $V_{\sup i}^{k \prime}\left(\mathrm{m}^{3}\right)$ é volume do reservatório superficial da mini-bacia após a entrada do escoamento superficial; $V_{\mathrm{int} i}^{k \prime}\left(\mathrm{m}^{3}\right)$ é volume do reservatório subsuperficial da mini-bacia após a entrada do escoamento subsuperficial; $V_{\text {bas } i}^{k \prime}\left(\mathrm{m}^{3}\right)$ é volume do reservatório subterrâneo da mini-bacia após a entrada do escoamento subterrâneo; j é o índice da URH; nb é o número de URHs em que a mini-bacia é dividida.

Cada reservatório é representado matematicamente por uma equação de reservatório linear simples.

$$
\begin{gathered}
Q_{\mathrm{sup} i}=\frac{1}{T K S_{i}} \times V_{\mathrm{sup} i}^{k^{\prime}} \\
Q_{\mathrm{int} i}=\frac{1}{T K I_{i}} \times V_{\mathrm{int} i}^{k^{\prime}} \\
Q_{\mathrm{bas} i}=\frac{1}{T K B_{i}} \times V_{\mathrm{bas} i}^{k^{\prime}}
\end{gathered}
$$

Onde $Q_{\sup i}\left(\mathrm{~m}^{3} \cdot \mathrm{s}^{-1}\right)$ é vazão de saída do reservatório superficial; $Q_{\operatorname{int} i}\left(\mathrm{~m}^{3} \cdot \mathrm{s}^{-1}\right)$ é vazão de saída do reservatório subsuperficial; $Q_{\text {bas } i}\left(\mathrm{~m}^{3} \cdot \mathrm{s}^{-1}\right)$ é vazão de saída do reservatório subterrâneo; $T K S_{i}$ (s) é o tempo de retardo do reservatório superficial; $T K I_{i}$ (s) é o tempo de retardo do reservatório sub-superficial e $T K B_{i}$ (s) é o tempo de retardo do reservatório subterrâneo.

A vazão de cada mini-bacia é dado pela soma das vazões de cada reservatório

$$
Q_{i}=Q_{\text {sup } i}+Q_{\text {int } i}+Q_{\text {bas } i}
$$

Onde $Q_{i}\left(\mathrm{~m}^{3} \cdot \mathrm{s}^{-1}\right)$ é a vazão de saída da mini-bacia; $Q_{\text {sup } i}\left(\mathrm{~m}^{3} \cdot \mathrm{s}^{-1}\right)$ é a vazão de saída do reservatório superficial; $Q_{\text {int } i}\left(\mathrm{~m}^{3} \cdot \mathrm{s}^{-1}\right)$ é a vazão de saída do reservatório subsuperficial e $Q_{\text {bas } i}\left(\mathrm{~m}^{3} \cdot \mathrm{s}^{-1}\right)$ é a vazão de saída do reservatório subterrâneo. 


\subsection{5 - Escoamento na rede de drenagem}

O MGB-IPH realiza a propagação do escoamento na rede de drenagem utilizando o método de Muskingum-Cunge, que relaciona a vazão de saída de um trecho de rio em um intervalo de tempo qualquer, às vazões de entrada e saída no intervalo de tempo anterior e à vazão de entrada no intervalo atual.

Os parâmetros do método de Muskingum-Cunge são calculados com base nos dados de comprimento, declividade, rugosidade e largura média dos trechos de rio. O comprimento e a declividade são obtidos de mapas topográficos. A largura é obtida com base em uma relação com a área de drenagem válida para a bacia e a rugosidade é estimada com base em observações locais, fotografias e informações sobre material do leito.

O intervalo de tempo diário utilizado no modelo é sub-dividido em intervalos menores durante a propagação por Muskingun-Cunge na rede de drenagem, considerando o intervalo de tempo ideal para a propagação apresentar precisão no tempo de viagem e no amortecimento do hidrograma.

\subsection{6 - Parâmetros do modelo}

O MGB-IPH tem um total de 14 parâmetros, que se dividem em parâmetros fixos e parâmetros calibráveis. Os parâmetros fixos são os relacionados à vegetação e são definidos para cada tipo de URH.

Os parâmetros calibráveis, por outro lado, são determinantes para um bom ajuste entre os dados de vazão observados e calculados. Os parâmetros calibráveis podem estar associados às URHs ou a cada sub-bacia, onde se tem dados observados de modo a orientar a calibração do modelo. A tabela 3.5 apresenta os parâmetros do MGB-IPH.

Tabela 3.5 - Parâmetros do MGB-IPH (Collischonn, 2001).

\begin{tabular}{ccc}
\hline Parâmetro & Tipo & Associação \\
\hline Capacidade de armazenamento de água no solo $(\mathrm{Wm})$ & Calibrável & URH/sub-bacia \\
Parâmetro de não-uniformidade da capacidade de & Calibrável & URH/sub-bacia \\
armazenamento do solo (b) & Calibrável & URH/sub-bacia \\
Limite de armazenamento no solo (Wc) & Calibrável & URH/sub-bacia \\
Parâmetro de drenagem subterrânea (Kbas) & & \\
\hline
\end{tabular}




\begin{tabular}{ccc}
\hline Parâmetro & Tipo & Associação \\
\hline Parâmetro de drenagem sub-superficial (Kint) & Calibrável & URH/sub-bacia \\
Parâmetro de fluxo ascendente (CAP) & Calibrável & URH/sub-bacia \\
Parâmetro de retardo do reservatório superficial (CS) & Calibrável & Sub-bacia \\
Parâmetro de retardo do reservatório sub-superficial & Calibrável & Sub-bacia \\
$($ CI $)$ & Calibrável & Sub-bacia \\
Parâmetro de retardo do reservatório subterrâneo (CB) & Calibrável & Sub-bacia \\
Vazão de referência & Fixo & URH/mês \\
Albedo & Fixo & URH/mês \\
Índice de área foliar & Fixo & URH/mês \\
Altura média das árvores & Fixo & URH/mês \\
Resistência Superficial & &
\end{tabular}

\subsection{7 - Calibração automática do modelo}

A calibração automática no MGB-IPH é realizada pelo algoritmo de calibração multiobjetivo MOCOM-UA (Multiple-Objective Complex Evolution - Universidade do Arizona) (Yapo et al., 1998), que utiliza princípios do algoritmo de busca global SCE-UA (Shuffle Complex Evolution - Universidade de o Arizona) (Duan et al., 1992). Aos parâmetros obtidos na calibração manual, foram permitidos que variassem de 0,3 a 1,8 vezes na calibração automática. A calibração de cada bacia foi realizada com população de 200 indivíduos e até 1000 gerações.

As funções objetivo utilizadas na calibração são o coeficiente de Nash-Sutcliffe das vazões (NSE), que favorece as vazões de pico; o mesmo coeficiente para os logaritmos das vazões (NSElog), que favorece as vazões mínimas e a relação entre volumes calculados e observados $(\Delta \mathrm{V})$. As equações abaixo apresentam a definição destas funções:

$$
\begin{gathered}
N S E=1-\frac{\sum\left(Q_{o b s}(t)-Q_{s i m}(t)\right)^{2}}{\sum\left(Q_{o b s}(t)-\bar{Q}_{o b s}(t)\right)^{2}} \\
N S E \log =1-\frac{\sum\left(\log Q_{o b s}(t)-\log Q_{\text {sim }}(t)\right)^{2}}{\sum\left(\log Q_{o b s}(t)-\log \bar{Q}_{o b s}(t)\right)^{2}}
\end{gathered}
$$




$$
\Delta V=\frac{\sum\left(Q_{s i m}(t)\right)-\sum\left(Q_{o b s}(t)\right)}{\sum\left(Q_{o b s}(t)\right)}
$$

Onde: $Q_{o b s}(t)$ é a vazão observada no intervalo de tempo t (dias); $Q_{s i m}$ é a vazão simulada pelo modelo no intervalo de tempo t (dias). 


\section{4 - METODOLOGIA}

\section{1 - DETECÇÃO DOS EFEITOS DAS MUDANÇAS NA COBERTURA E USO DO SOLO SOBRE O REGIME DE VAZÕES}

Para a avaliação dos efeitos das alterações do uso do solo sobre o regime de vazões, foi adotada uma metodologia alternativa à das bacias pareadas, ao invés de se ter uma bacia de controle, tem-se uma calibração de controle, que é a calibração obtida com o uso do solo durante um período de referência, que neste trabalho é o período com mínima alteração da vegetação natural.

O período de estudo foi determinado de acordo com a disponibilidade de dados hidrológicos e dados de cobertura e uso do solo. O período de estudo é de 1969 a 2005 e foi dividido em 3 períodos. O período P1 vai de 1969 a 1985 considera o uso do solo em 1980; o período P2 vai de 1986 a 1995 considera o uso do solo em 1990 e o período P3 vai de 1996 a 2005 considera o uso do solo em 2000.

Para se considerar as incertezas envolvidas na modelagem hidrológica, as análises foram realizadas não com apenas uma simulação, mas com as 30 melhores simulações obtidas a partir da superfície de Pareto fornecida pela calibração automática do modelo e nos casos de haver mais que 30 conjuntos na superfície de Pareto foram priorizados os conjuntos que apresentaram maior valor para a função NSElog, por favorecerem o ajuste das vazões mínimas.

As variáveis hidrológicas que foram avaliadas se sofreram alteração por causa das mudanças na cobertura do solo, foram as vazões mensais, vazões anuais e vazões mínimas. São consideradas vazões mínimas a menor vazão média de 7 dias consecutivos em cada ano hidrológico. As vazões anuais referem-se à vazão média anual considerando o ano hidrológico se iniciando no dia primeiro de outubro.

$\mathrm{Na}$ análise dos efeitos das alterações da cobertura e uso do solo sobre as vazões foi adotada a metodologia proposta por Seibert e McDonnelll (2010), com a diferença de que serão utilizados os conjuntos de parâmetros da superfície de Pareto ao invés de simulações de Monte Carlo como naquele trabalho. 
São usadas três diferentes abordagens para detectar as alterações nas vazões causadas pelas mudanças no uso do solo, conforme segue:

- Avaliação dos resíduos do modelo, o que é uma comparação das simulações com parâmetros calibrados no período de referência (P1) com as vazões observadas nos períodos que sofreram mudanças (P2 e P3);

- Comparação dos valores dos conjuntos de parâmetros obtidos em cada período de análise;

- Avaliação dos resíduos entre as diferentes respostas da bacia aos conjuntos de parâmetros das calibrações realizadas em cada período.

\subsection{1 - Análise dos resíduos entre as vazões simuladas e observadas}

Ao relacionar o escoamento observado ao escoamento simulado com o conjunto de parâmetros válidos para o período de referência, as influências climáticas no escoamento podem ser filtradas. Parte-se do pressuposto de que o modelo com os parâmetros do período de referência pode ser usado para reconstruir as séries de vazões dos períodos posteriores, gerando as vazões que deveriam ter sido geradas caso a bacia não tivesse sofrido alterações na cobertura do solo. Os resíduos são dados pela equação 4.1.

$$
D_{i}=\frac{Q_{o b s, i}-Q_{s i m, i}}{Q_{o b s, i}}
$$

Onde: $\mathrm{D}_{\mathrm{i}}$ é o resíduo do modelo no instante $\mathrm{i}$; $\mathrm{Q}_{\mathrm{obs}, \mathrm{i}}$ é a vazão observada $\left(\mathrm{m}^{3} / \mathrm{s}\right)$ e $\mathrm{Q}_{\text {sim,i }}$ é a vazão simulada $\left(\mathrm{m}^{3} / \mathrm{s}\right)$. Resíduos próximos de zero indicam que não houve mudança nas vazões, valores negativos indicam que as vazões sofreram redução e valores positivos indicam que houve aumento das vazões.

Para testar se houve mudanças nas vazões, parte-se da hipótese nula $\mathrm{H}_{\mathrm{o}}$ de que os resíduos são iguais entre os dois períodos analisados, então é realizado o teste de Mann-Whitney conforme descrito por Naghettini e Pinto (2007). Trata-se de um teste não-paramétrico de homogeneidade, que tem como princípio a consideração de que se as amostras não forem homogêneas, os elementos de uma amostra apresentarão ordens de classificação consistentemente diferentes da outra amostra. O teste foi realizado com significância de $5 \%$. 
Para evitar a ocorrência de falsas detecções de mudanças, o teste também foi realizado para os conjuntos de resíduos gerados pelos mesmos conjuntos de parâmetros para verificar se mesmo estes também rejeitam a hipótese nula, situação que põe em dúvida as constatações de mudança. Neste caso, o período de referência foi dividido ao meio e o teste foi realizado entre cada metade como se se tratassem de períodos distintos.

\subsection{2 - Comparação entre os conjuntos de parâmetros obtidos de diferentes calibrações}

A comparação dos parâmetros obtidos em diferentes períodos, permite avaliar quais características da bacia foram mais impactadas pelas mudanças no uso do solo.

Os parâmetros do modelo podem apresentar mudanças quando o modelo é calibrado para diferentes períodos. O que é esperado quando há mudança no uso do solo. A análise das diferenças nos valores dos parâmetros não é simples, uma vez que vários conjuntos de parâmetros podem gerar vazões equivalentes, consequentemente, os valores diferentes para um determinado parâmetro podem ser encontrados não só para diferentes períodos de tempo, mas também para o mesmo período, para contornar este problema de incertezas nos parâmetros os vários conjuntos de parâmetros gerados em cada período são comparados entre si. Para confirmar se ocorreram mudanças significativas entre os diferentes conjuntos de parâmetros, é realizado o teste de Mann-Whitney com nível de significância de $5 \%$. O teste é realizado para cada parâmetro calibrado em cada URH.

Para verificar a ocorrência de falsas detecções de mudanças, a amostra dos 30 conjuntos de parâmetros, obtidos da calibração no período de referência, é dividida em duas e tratadas como se fossem obtidas das calibrações de períodos distintos.

\subsection{3 - Análise dos resíduos entre as simulações com parâmetros de diferentes calibrações}

Mais importante que comparar os conjuntos de parâmetros, é comparar as respostas da bacia a esses diferentes conjuntos de parâmetros. Para isso, foram comparadas as simulações com cada conjunto de parâmetros obtidos das calibrações realizadas em cada 
período de análise, por meio da análise dos resíduos entre as simulações, dados pela equação 4.2 .

$$
D_{i}=\frac{Q_{\operatorname{sim} A, i}-Q_{\operatorname{sim} B, i}}{\left(Q_{\operatorname{sim} A, i}+Q_{\operatorname{sim} B, i}\right) / 2}
$$

Onde: $\mathrm{D}_{\mathrm{i}}$ é o resíduo entre as simulações $\mathrm{A}$ e $\mathrm{B}$ no instante i.

As incertezas do modelo estão representadas pelas 30 simulações, obtidas da calibração de cada período, e os resíduos são calculados para todas as combinações possíveis entre cada conjunto de simulações, ou seja, tem-se um total de 900 séries de resíduos. É considerado que houve diferença significativa entre as respostas da bacia quando a mediana dos resíduos é superior a $10 \%$ ou quando os percentis de 10 e $90 \%$ tem o mesmo sinal.

Comparar as simulações obtidas com diferentes conjuntos de parâmetros é uma maneira de contornar os problemas das interações de parâmetros. Em vez de se concentrar nos valores dos parâmetros individuais, o comportamento da bacia é investigado de forma integrada. Em contraste com a análise de resíduos das vazões observadas, a comparação entre simulações é menos sensível aos eventuais erros nos dados de precipitação ou de vazão (Seibert e McDonnell, 2010).

\section{2- SIMULAÇÃO HIDROLÓGICA}

A avaliação dos efeitos das alterações no uso do solo sobre o regime hidrológico foi realizada com uso do modelo MGB-IPH, que é um modelo distribuído conceitual com alguns processos com representação de base física. Este modelo foi escolhido por não demandar quantidade de elevada de dados de entrada, ao contrário do MIKE-SHE e por ter a possibilidade de se realizar a calibração multiobjetivo dos parâmetros. Outra razão para escolha do MGB-IPH é que este modelo já foi utilizado com sucesso na Bacia do Rio São Francisco (Silva et al., 2004) e por ser capaz de representar alterações na cobertura e uso do solo (Collischonn, 2001). 


\subsection{1 - Preparação dos dados de entrada no MGB-IPH}

Para aplicar o modelo MGB-IPH, implementou-se as seguintes etapas (Collischonn et al., 2010):

1- Definição da bacia;

2- Obtenção dos dados hidrológicos;

3- Geração de base de dados para aplicação do sistema de informações geográficas;

4- Discretização da bacia;

5- Criação do mapa de Unidades de Resposta Hidrológica.

\subsection{2- Geração de base de dados para aplicação do sistema de informações geográficas}

O primeiro dado espacial utilizado foi o modelo digital de elevação do terreno, obtido a partir dos dados gerados pelo projeto SRTM (em inglês, Shuttle Radar Topography Mission), cujo processamento digital das imagens foi realizado pela EMBRAPAMonitoramento por Satélite (Miranda,2005). Este MDE tem resolução espacial de 90 metros e foi utilizado no formato GEOTIFF de 16 bits no Datum WGS 1984, que é o único admitido para entrada no MGB-IPH e todas as outras informações espaciais foram geradas com essa resolução espacial e esse Datum (Collischonn, et. al, 2010-2). A tabela 4.1 apresenta um resumo dos dados que serão utilizados para formar a base de dados necessária para a realização das simulações com modelo MGB-IPH.

Tabela 4.1 - Dados de entrada do modelo MGB-IPH

\begin{tabular}{ccc}
\hline Dado & Formato & Fonte \\
\hline MDE & Imagem/Raster & SRTM/EMBRAPA \\
Hidrografia & Vetor & ANA \\
Postos pluviométricos & Vetor/Tabular & ANA \\
Postos fluviométricos & Vetor/Tabular & ANA \\
Postos meteorológicos & Vetor/Tabular & ANA \\
\hline
\end{tabular}




\begin{tabular}{ccc}
\hline Dado & Formato & Fonte \\
\hline Mapas de uso do solo & Raster & Imagens Landsat/INPE \\
Mapa de solos & Raster & INEMA \\
\hline
\end{tabular}

A partir do MDE foram geradas as mini-bacias, que correspondem à área de drenagem de cada trecho de rio. De acordo com a disponibilidade de dados fluviométricos foram definidos os postos de medição que foram usados neste trabalho, a área conta com 17 postos, no entanto, em seis deles, os dados de vazão só estão disponíveis para o último período de análise, inviabilizando, portanto, a realização de comparações. Dessa forma, foram utilizados os dados fluviométricos de 11 estações fluviométricas, e a partir destas estações foram geradas as sub-bacias pelo conjunto de mini-bacias à montante destes postos. Na figura 4.1 é apresentado o mapa com as sub-bacias da área de estudo.

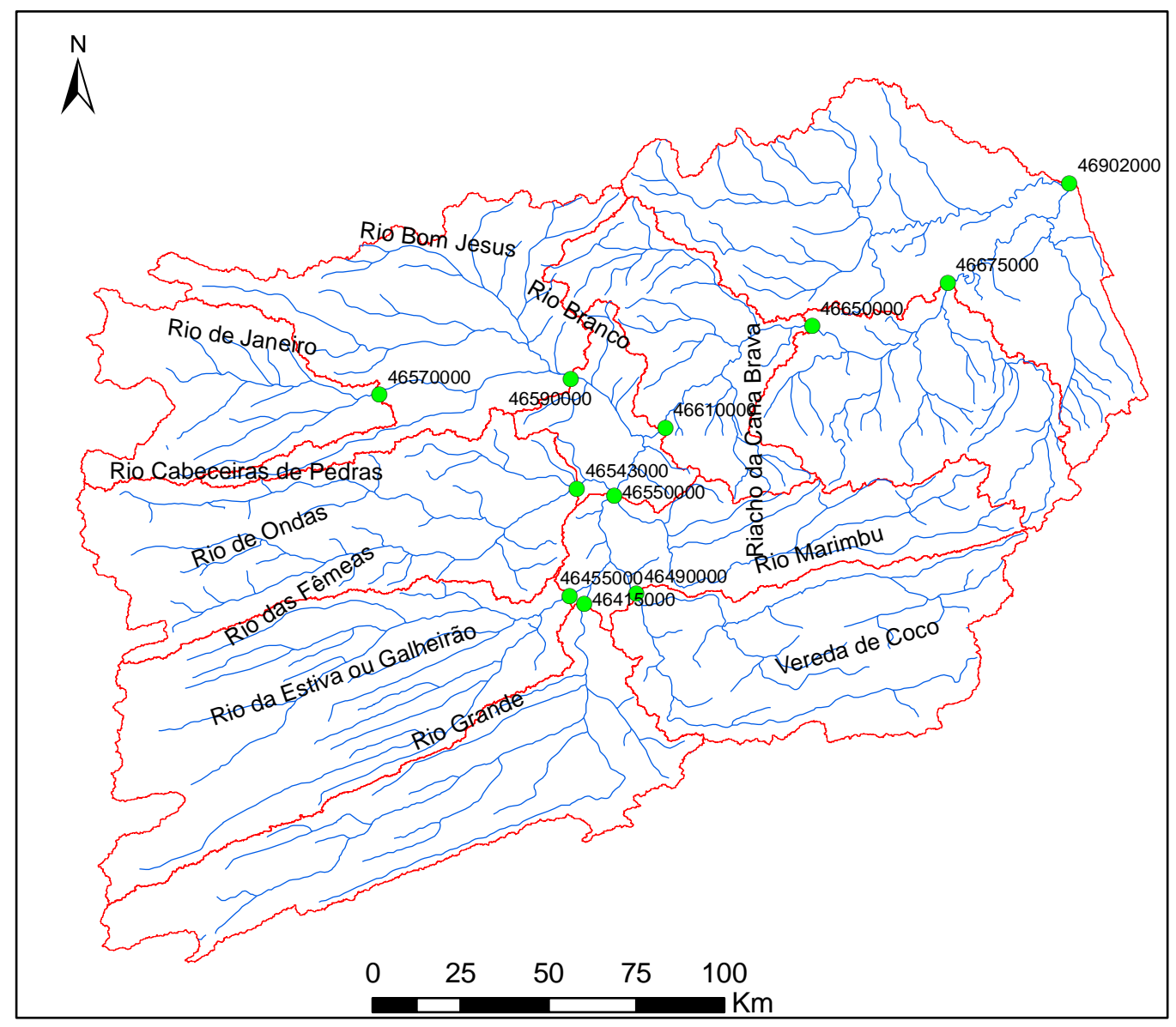

Figura 4.1 - Discretização de mini-bacias e sub-bacias da Bacia do Rio Grande. 


\subsection{3 - Geração das Unidades de Resposta Hidrológica}

As unidades de resposta hidrológicas foram obtidas da sobreposição do mapa de cobertura e uso do solo com o mapa de solos. O MGB-IPH aceita no máximo 12 URHs e recomenda que sejam usadas apenas 5 (Fan et.al,2010). Como se tem uma considerável quantidade de solos diferentes na área de estudo, foi feita uma reclassificação dos solos quanto à sua capacidade de produzir escoamento superficial (alto ou baixo) (NRCS, 2009; Sartori et al., 2005). As figuras 4.2, 4.3 e 4.4 apresentam as URHs nos anos de 1980, 1990 e 2000.

A bacia do Rio Grande, como será apresentado no item 5.1.3 tem parte de sua bacia hidrogeológica divergente da bacia hidrográfica, pois tem sentido oeste ao invés de leste (Gaspar, 2006), dessa forma, as águas subterrâneas dessa área de divergência, que corresponde a aproximadamente $2,3 \%$ da área total da bacia, não contribuem para a vazão do Rio Grande, por isso também foram criadas URHs para esta região, nas quais, para parâmetros referentes ao escoamento subterrâneo foram atribuídos valores nulos, de modo a não ser produzido escoamento de base nessa área.

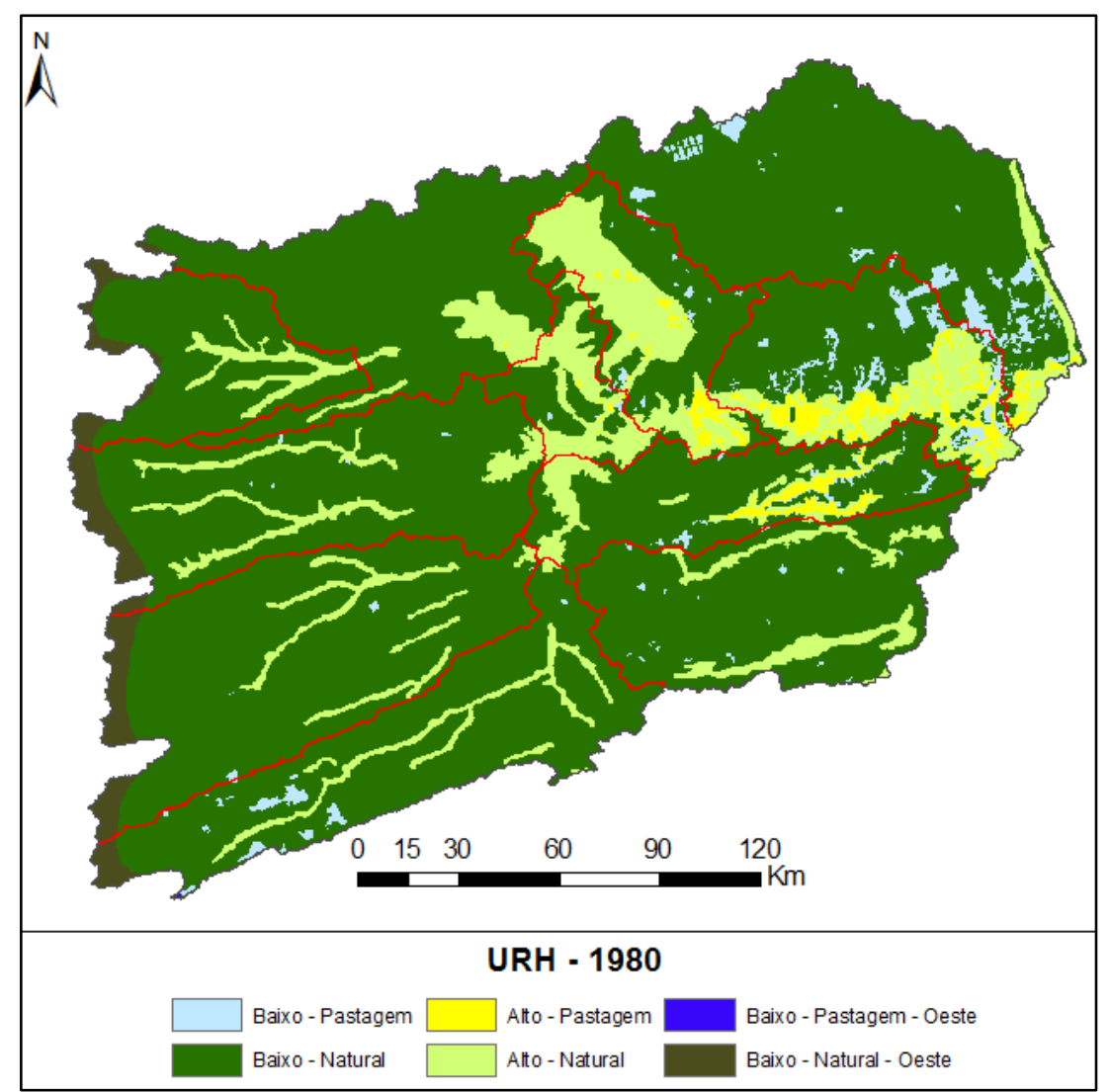

Figura 4.2 - Unidades de resposta hidrológicas da Bacia do Rio Grande - 1980. 


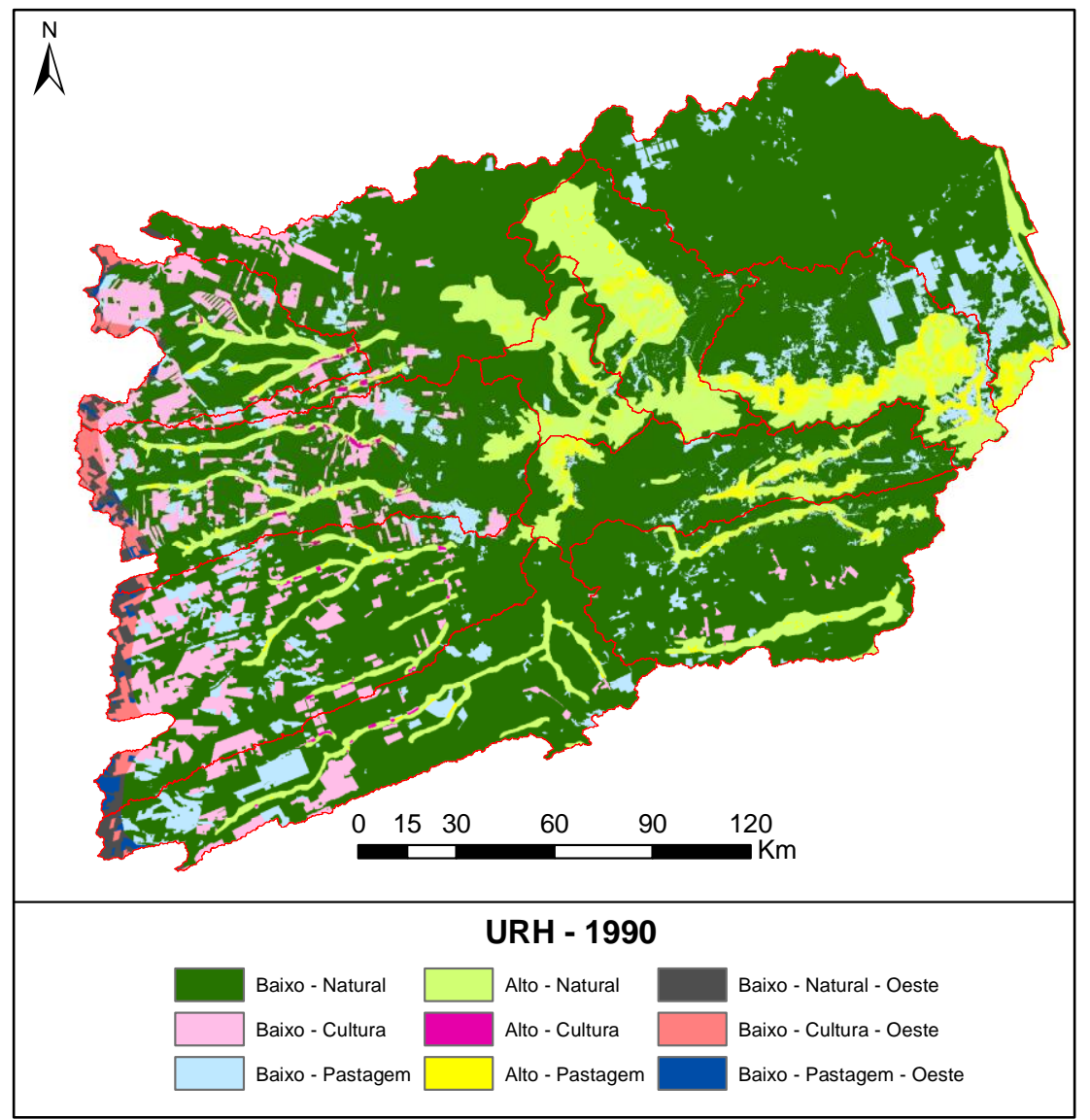

Figura 4.3 - Unidades de resposta hidrológicas da Bacia do Rio Grande - 1990.

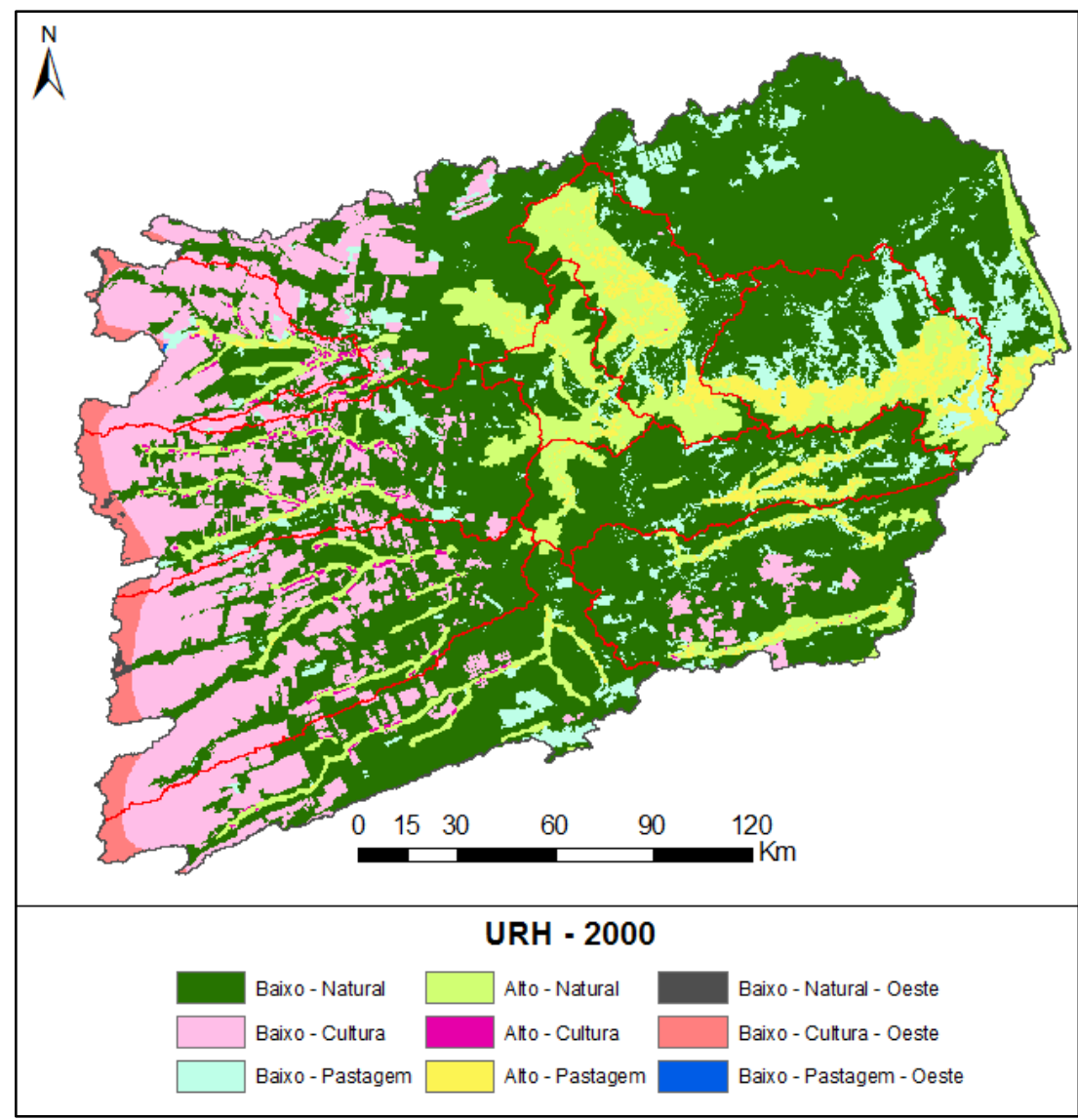

Figura 4.4 - Unidades de resposta hidrológica da Bacia do Rio Grande - 2000.. 


\section{3 - CALIBRAÇÃO DO MODELO}

O modelo foi calibrado para três períodos distintos, o período P1, que vai de 1969 a 1985 , que considerou as condições de cobertura e uso do solo de 1980. Este é o período em que a cobertura vegetal tinha menor alteração e por isso foi considerado como período de referência. $\mathrm{O}$ período $\mathrm{P} 2$, que é o período intermediário, considera as condições de cobertura e uso do solo de 1990. O período P3, que é o período final, tem as condições de cobertura e uso do solo de 2000.

Nas URHs referentes às áreas em que a bacia hidrogeológica é divergente da bacia hidrográfica, foram atribuídos os mesmos parâmetros das URHs com tipos de solo e vegetação iguais, diferenciando-se apenas nos parâmetros referentes ao fluxo de águas subterrâneas.

A calibração foi iniciada pelas sub-bacias mais a montante, sendo cada sub-bacia calibrada individualmente. Inicialmente foi realizada a calibração manual do modelo, considerando a análise de sensibilidade realizada por Bayer e Collischonn (2013) e então se seguiu à calibração automática.

Na calibração automática foi estabelecido que os parâmetros obtidos na calibração manual poderiam variar de 0,3 a 1,8 vezes de seu valor. A calibração de cada bacia foi realizada com população de 200 indivíduos e até 1000 gerações. 


\section{5 - ESTUDO DE CASO}

A avaliação dos efeitos das alterações na cobertura e uso dos solos sobre o regime de vazões foi realizada a partir de um estudo de caso. A área escolhida para este estudo de caso foi a bacia do Rio Grande a montante do posto fluviométrico Boqueirão. Esta área de estudo foi escolhida por ter tido ocupação recente, a partir da segunda metade dos anos 1970, quando já se tem a disponibilidade de imagens de satélite, que viabilizaram o levantamento do histórico de evolução da cobertura e uso do solo.

\section{1 - CARACTERIZAÇÃO DA ÁREA DE ESTUDO}

A bacia de estudo é parte de sub-bacia do Rio Grande, afluente do Rio São Francisco, no Oeste Baiano, se estendendo desde a nascente até a estação fluviométrica Boqueirão, nas coordenadas $11^{\circ} 21^{\prime} 22^{\prime \prime} \mathrm{S}$ e 4350’36" O, com área de drenagem de $46.734 \mathrm{~km}^{2}$ (ANA, 2010), abrangendo os municípios de São Desidério, Catolândia, Baianópolis, Cristópolis, Barreiras, Wanderley, Luís Eduardo Magalhães, Cotegipe, Angical e Riachão das Neves, conforme a figura 5.1 .

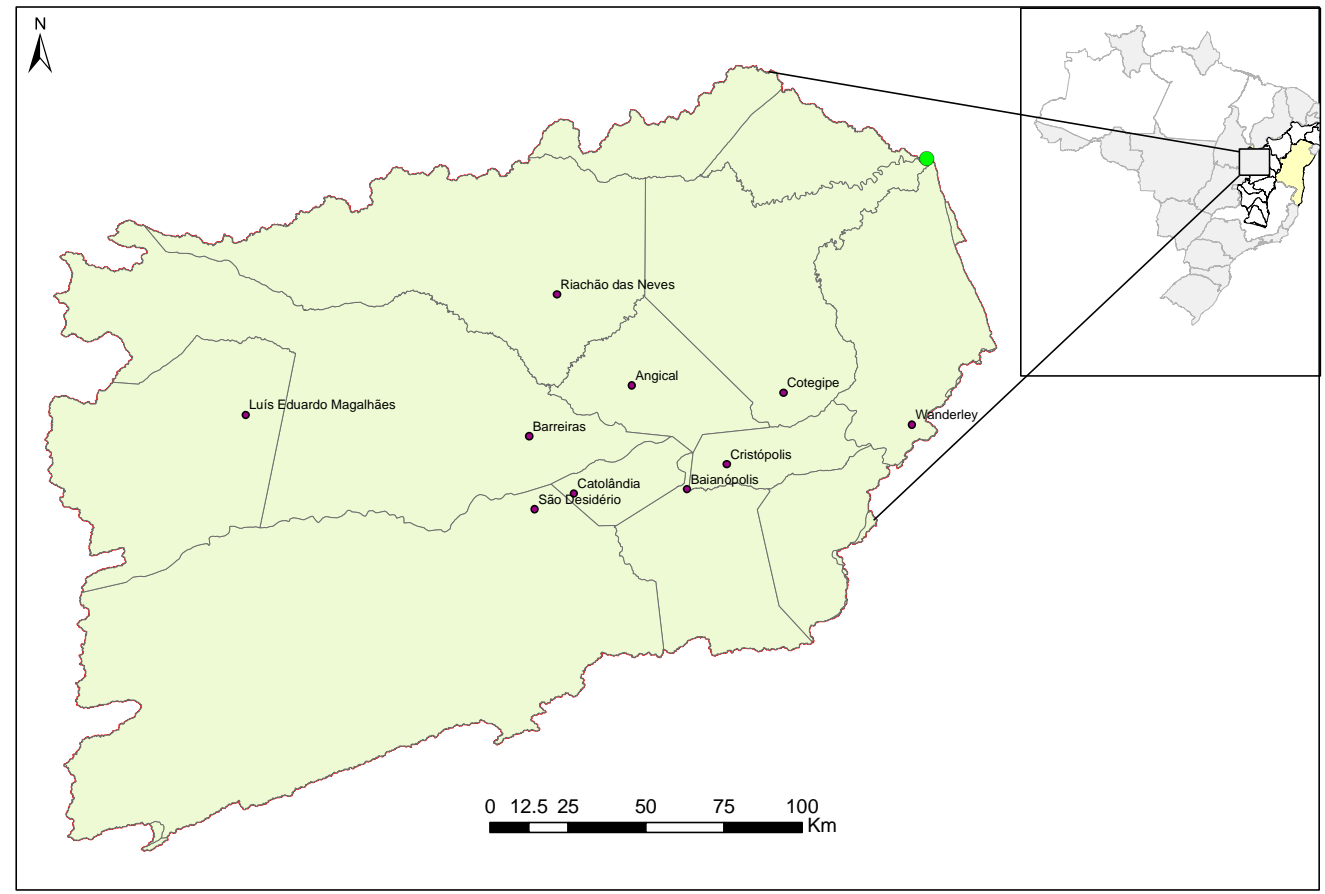

Figura 5.1 - Localização da área de estudo. 
O Cerrado brasileiro teve sua ocupação e consolidação econômica decorrentes dos seguintes fatores (Menke, 2009):

- Disponibilidade de terras com relativa proximidade dos centros econômicos do país (regiões Sul e Sudeste);

- Competitividade nacional no mercado externo, principalmente na produção de grãos;

- Fortalecimento do capital financeiro privado com a reestruturação interna da produção e o estabelecimento do agronegócio;

- Inovação tecnológica proveniente de uma política de ciência e tecnologia coordenada pela EMBRAPA.

Neste contexto, a área de estudo está inserida na Mesorregião do Oeste Baiano, cujo crescimento da área de produção agrícola foi iniciado na década de 1970 e se caracterizou por uma ampla reconfiguração espacial, traduzida na mudança do uso da terra especialmente na década de 90, quando o aumento da produção se deu tanto pelo crescimento da área plantada, como também à maior eficiência e produtividade agrícola oriundas do aprimoramento tecnológico (Pimentel et. al, 2011). O Oeste Baiano é uma das últimas fronteiras agrícolas do Brasil e a principal produtora de grãos do estado da Bahia. A região é caracterizada pelo vertiginoso desenvolvimento econômico a partir da década de 1980 devido à expansão do agronegócio na região, o que pode ser exemplificado pelo crescimento da produção de soja no município de Barreiras entre 1980 e 1986, que cresceu 146 vezes no período (Flores, 2011). A tabela 5.1 e a figura 5.2 apresentam a evolução da produção de grãos dos municípios que fazem parte da bacia de acordo com os dados da pesquisa sobre a produção agrícola municipal realizada pelo IBGE a partir de 1990.

Tabela 5.1 - Evolução da produção de grãos da área de estudo (IBGE, 2016).

\begin{tabular}{ccccccc}
\hline \multirow{2}{*}{ Município } & \multicolumn{5}{c}{ Produção anual de grãos (t) } \\
& \multicolumn{7}{c}{ Soja } \\
\hline & 1990 & 2000 & 2010 & 1990 & 2000 & 2010 \\
São Desidério & 91.999 & 428.872 & 738.990 & 10.960 & 244.908 & 438245 \\
Catolândia & - & - & - & 384 & 780 & 783 \\
Baianópolis & 1.679 & 24.570 & 21.420 & 1.470 & 8.622 & 11.578 \\
Cristópolis & - & - & - & 384 & 960 & 726 \\
Barreiras & 49.935 & 567.804 & 352.206 & 5.025 & 261.282 & 212.239 \\
Wanderley & - & - & - & 390 & 13.980 & 23.400
\end{tabular}




\begin{tabular}{|c|c|c|c|c|c|c|}
\hline \multirow{2}{*}{ Município } & \multicolumn{6}{|c|}{ Produção anual de grãos (t) } \\
\hline & & Soja & & & Milho & \\
\hline $\begin{array}{c}\text { Luís Eduardo } \\
\text { Magalhães }\end{array}$ & - & - & 400.554 & - & - & 132.748 \\
\hline Cotegipe & - & - & - & 162 & 1.080 & 1.056 \\
\hline Angical & - & - & - & 1.234 & 3.000 & 7.215 \\
\hline Riachão das Neves & 10.852 & 120.606 & 196.434 & 1.691 & 27.672 & 68.839 \\
\hline Total & 154.465 & 1.141 .852 & 1.709 .604 & 21.700 & 562.284 & 896.829 \\
\hline Bahia & 220.416 & 1.508 .115 & 3.112 .929 & 127.041 & 1.321 .569 & 2.223 .302 \\
\hline
\end{tabular}

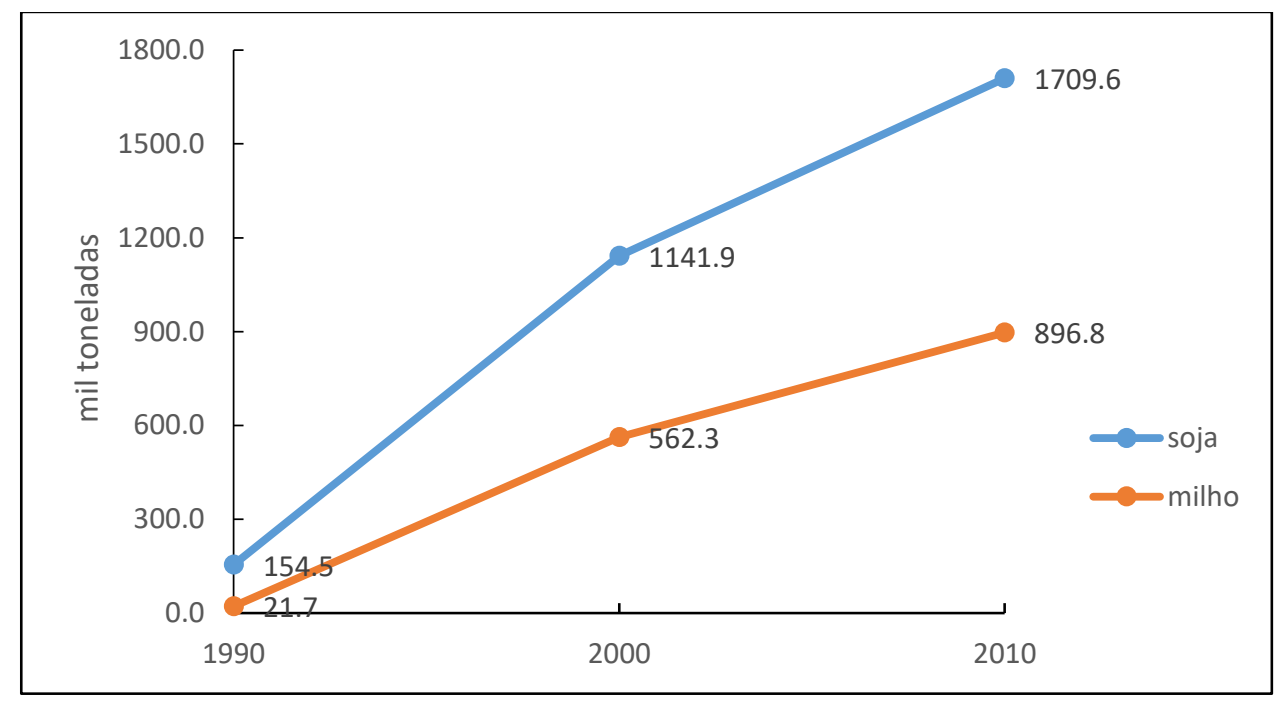

Figura 5.2 - Evolução do Produção de grãos nos municípios da área de estudo (IBGE,2016).

Esta bacia foi escolhida por ter registrado uma grande alteração na cobertura e uso do solo nas últimas décadas. A bacia se localiza no oeste baiano e representa uma região típica de Cerrado em termos de produção de grãos com alta produtividade e intensa mecanização. Sano et al. (2011) realizaram um estudo nessa região considerando os aspectos temporais e ambientais de sua ocupação e verificaram que no período de 1985 a 2005, houve um acréscimo de $352 \%$ na área plantada com culturas agrícolas, principalmente soja e milho.

No Oeste Baiano a taxa média de crescimento das áreas utilizadas para agricultura foi da ordem de 79,3 mil hectares por ano entre 1985 e 2005, que corresponde a um crescimento linear de $18 \%$, enquanto as áreas plantadas com pastagens cultivadas e reflorestamento mantiveram-se aproximadamente constantes ao longo do referido período, com 1,3 milhões de hectares de pastagens cultivadas e 170 mil hectares de reflorestamento. Até o início dos anos 1980, a ocupação agrícola na região era incipiente (Sano et al.,2011). 
As culturas agrícolas têm-se desenvolvido predominantemente na porção oeste da região onde predominam a topografia plana e os índices de precipitação são mais altos. Por outro lado, as pastagens cultivadas são mais comuns na porção leste da mesorregião, onde predominam topografia mais acidentada e índices pluviométricos menores em relação à porção oeste.

\subsection{1 - Hidrografia}

A bacia tem como rio principal o Rio Grande, que tem sua nascente nas proximidades da divisa entre Bahia e Tocantins. As cabeceiras do Rio Grande e de seus afluentes da margem esquerda encontram-se em região com chuvas abundantes, que mantém a perenidade dos rios. Na parte média e oriental da bacia onde as chuvas são mais escassas e pouco contribuem para os deflúvios do Rio Grande, sendo sua maioria de rios não perenes. Os afluentes situados na margem esquerda do Rio Grande apresentam maior disponibilidade hídrica que os da direita porque a concentração de chuvas é maior nesta região e devido à alimentação que recebem dos aquíferos da área, especialmente o arenito Urucuia, que mantém os rios perenes durante todo o tempo (Moreira e Silva, 2010). O Rio Grande corre em geral na direção SO-NE, seus principais tributários pela margem esquerda são os rios: das Fêmeas, de Ondas e Branco; pela margem direita, os principais afluentes são os rios São Desidério, Boa Sorte e Tamanduá. A figura 5.3 apresenta a hidrografia da área de estudo.

O padrão de drenagem é dendrítico, de modo geral, mas com predomínio do padrão paralelo no quadrante sudoeste da bacia. O padrão dentrítico é típico de áreas cobertas por rochas horizontais não fraturadas e isotrópicas em relação à erosão, trata-se de um padrão onde os talvegues têm comprimentos variados e não possuem nenhuma orientação preferencial, o que é comum em rochas sedimentares horizontais. O padrão paralelo é caracterizado quando os talvegues são paralelos a subparalelos entre si, típico de camadas sedimentares levemente inclinadas em regiões de topografia suave, onde os contatos geológicos se apresentam mais ou menos retilíneos. 


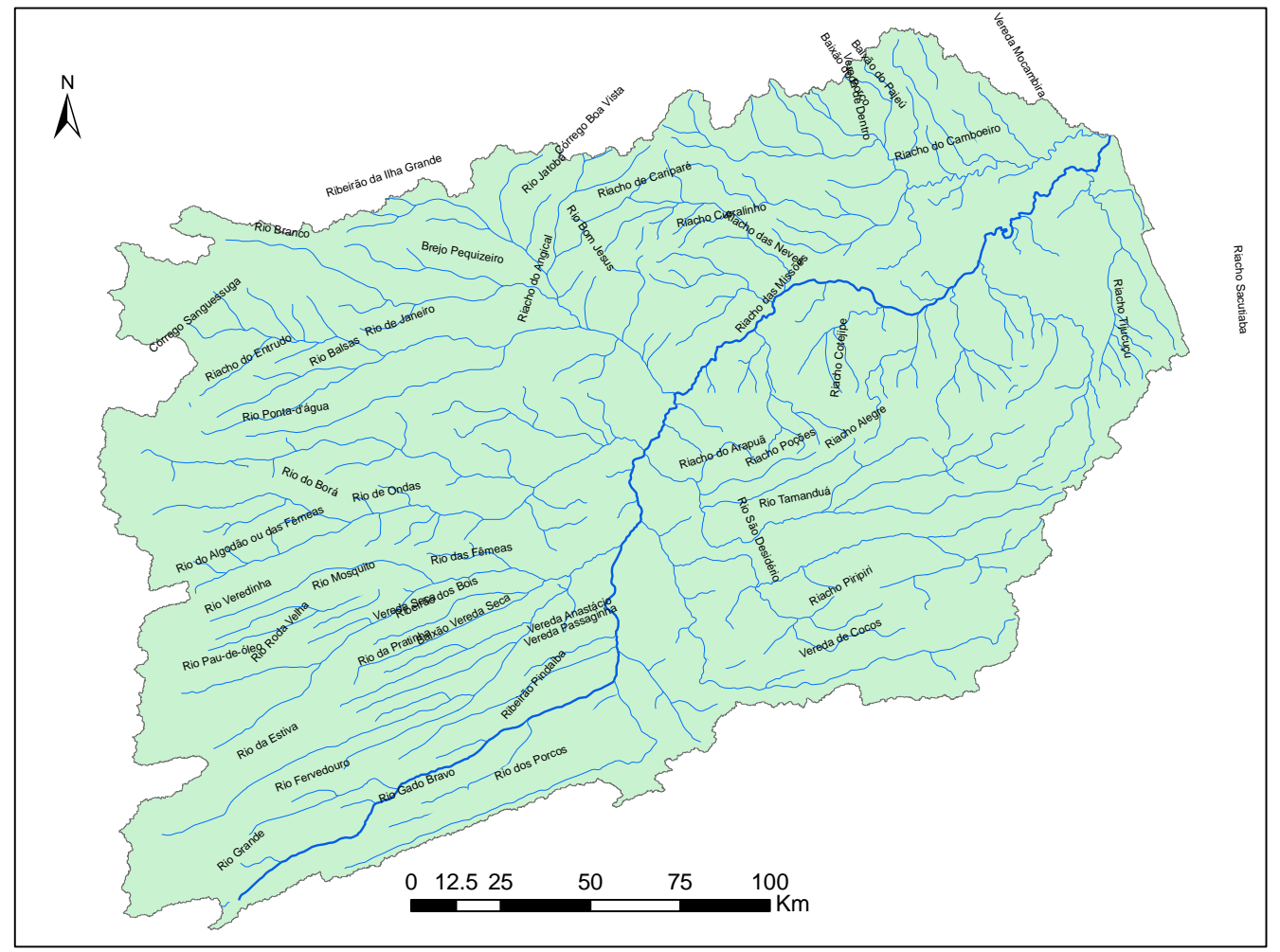

Figura 5.3 - Hidrografia da sub-bacia do Rio Grande (ANA, 2010).

\subsection{2 - Topografia}

De acordo com dados do projeto SRTM (em inglês, Shuttle Radar Topography Mission) (Miranda, 2005), as altitudes da área de estudo variam de 396 a 1048 metros, o modelo digital de elevação, com resolução horizontal de 90 metros e resolução vertical de 1 metro, é apresentado na figura 5.4 e na figura 5.5 são apresentadas as curvas de nível com espaçamento vertical de 50 metros.

De modo geral, a área da bacia é plana, com predomínio de declividades muito baixas e baixas, com a ocorrência de declividades maiores restritas às áreas onde o relevo é de escarpas serranas ou degraus estruturais e rebordos erosivos. Na figura 5.6 é apresentado o mapa de declividades da área de estudo. 


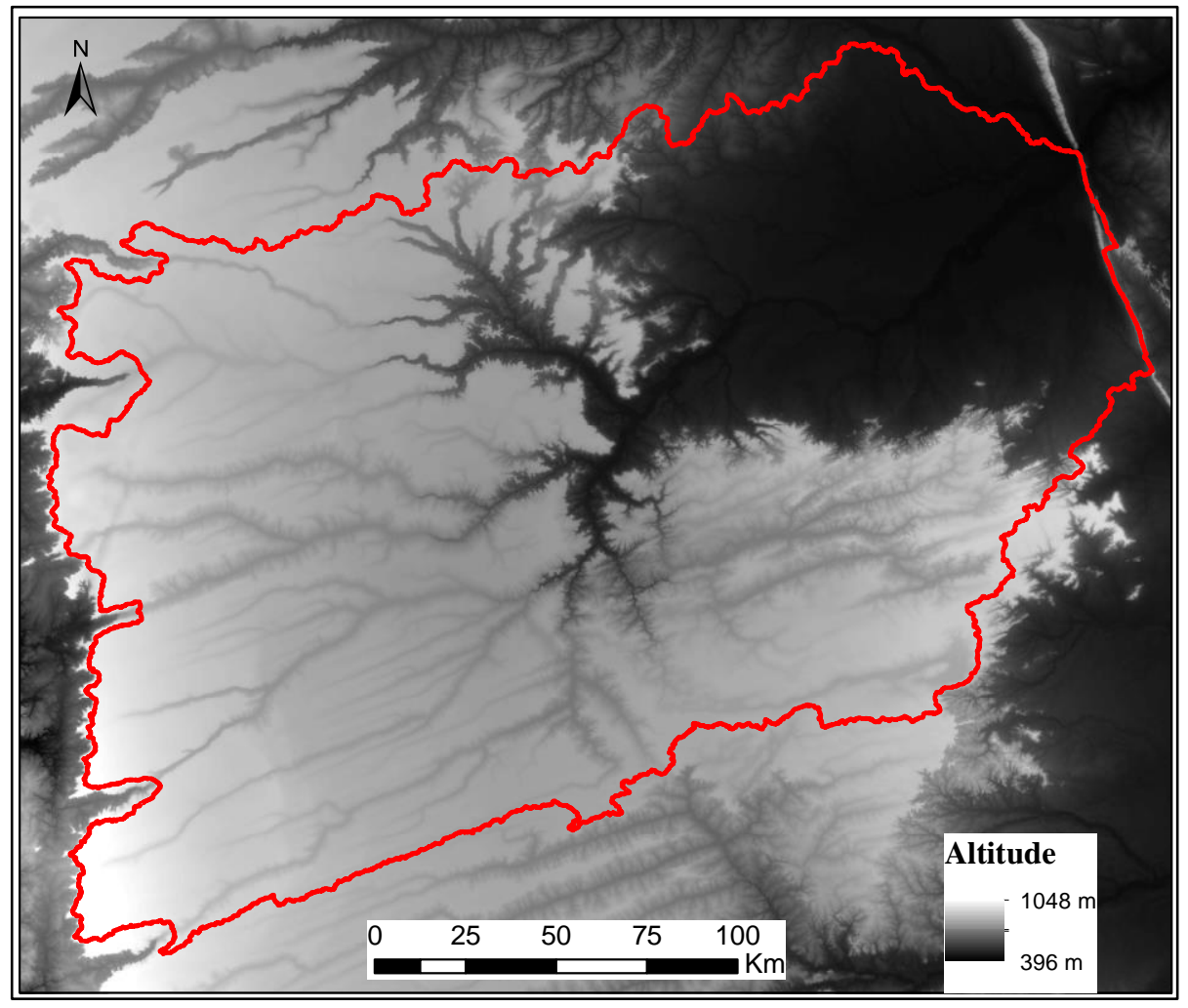

Figura 5.4 - Modelo digital de elevação da sub-bacia do Rio Grande (Miranda, 2005).

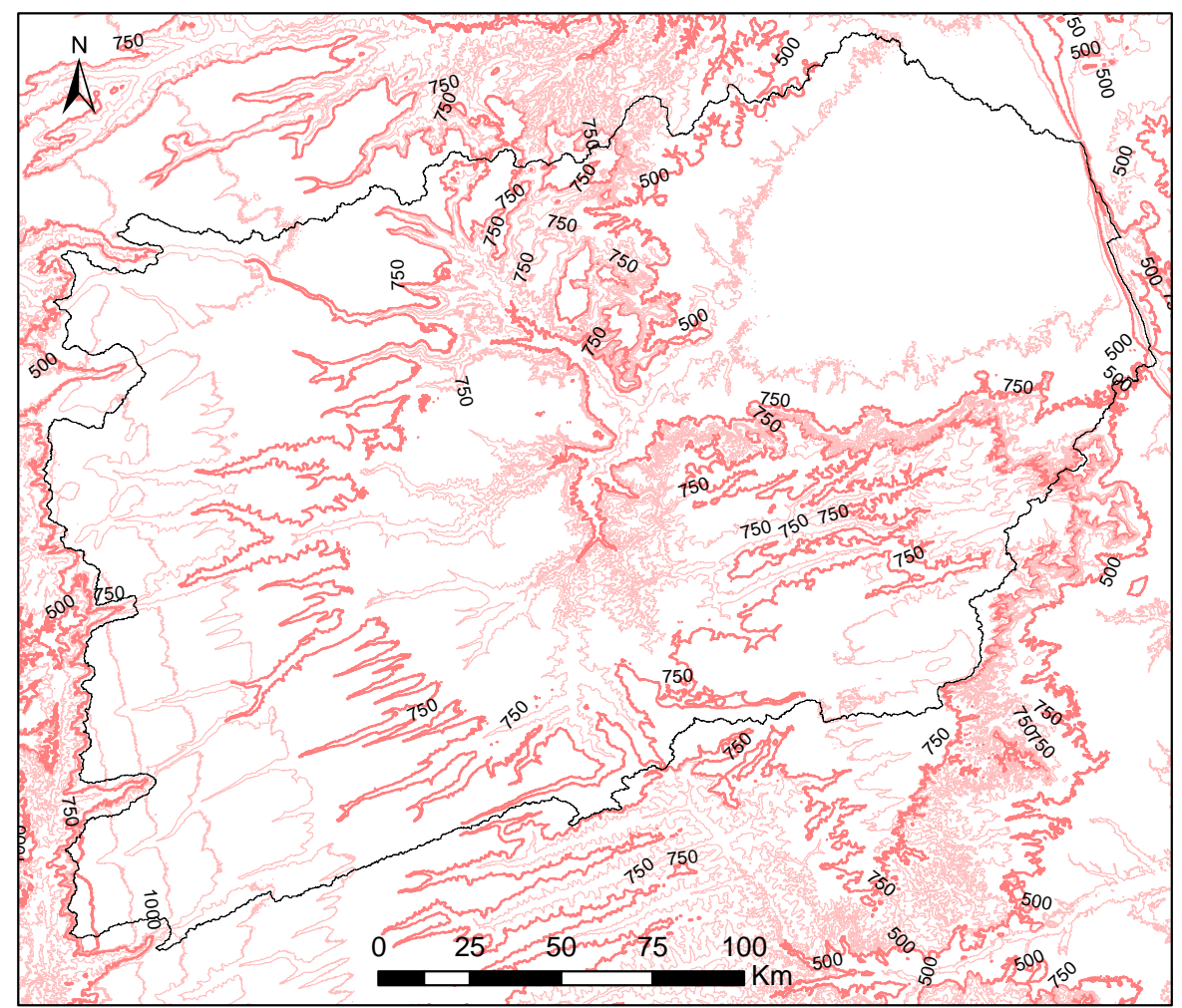

Figura 5.5 - Curvas de nível com espaçamento vertical de 50 metros da sub-bacia do Rio Grande, obtido a partir do MDE. 


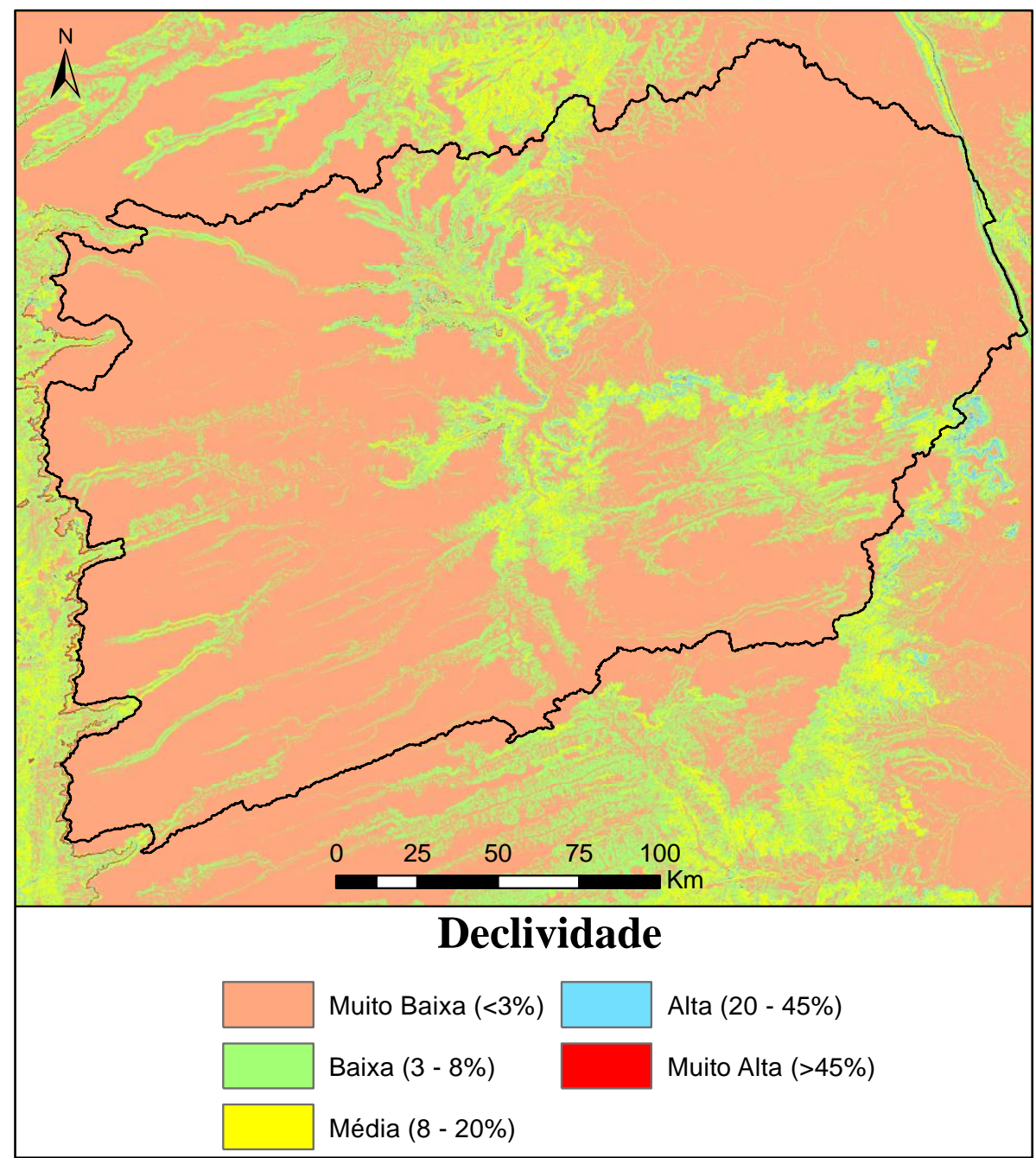

Figura 5.6 - Mapa de declividades da sub-bacia do Rio Grande obtida a partir do MDE.

O relevo da bacia se caracteriza pela amplitude altimétrica, com predomínio de chapadas e platôs na parte oeste da bacia e ocorrência de superfícies aplainadas e conservadas na parte nordeste, com destaque para os vales encaixados seguidos de planícies fluviais em meio às chapadas e platôs, havendo também o relevo de escarpas serranas separando os dois patamares de altitude da bacia. A figura 5.7 apresenta o relevo da área de estudo. 


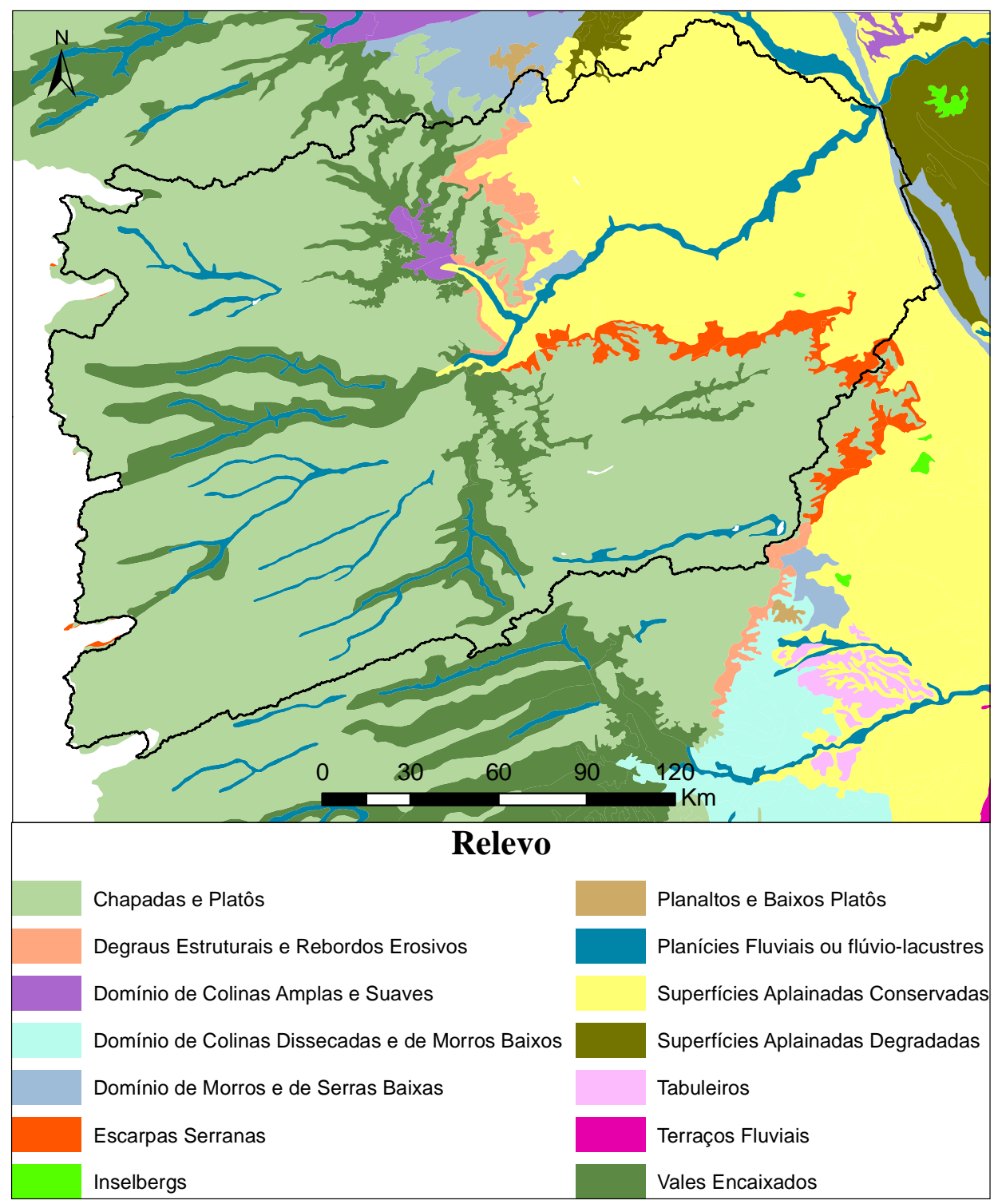

Figura 5.7 - Relevo da sub-bacia do Rio Grande ( INEMA, 2014).

\subsection{3 - Geologia e Hidrogeologia}

Na figura 5.8 é apresentado o mapa das unidades geológicas da bacia, onde se verifica que a maior parte da área está sobre o grupo Urucuia, que é dominado por sedimentos cenozóicos e mesozóicos de pouco a moderadamente consolidados associados a profundas e extensas bacias continentais, onde há o predomínio de sedimentos arenosos de deposição continental, lacustre, fluvial ou eólico, que formaram arenitos com alta porosidade.

A segunda maior unidade geológica na bacia são as coberturas detrito-lateríticas ferruginosas, que são depósitos cenozóicos provenientes de processos de lateritização em 
rochas de composições diversas sem a presença de crosta, a litologia é formada de laterita e aglomerados, esta unidade geológica tem alta porosidade.

Na bacia é observado a ocorrência de falhas contracionais, lineamentos estruturais e zonas de cisalhamento nas unidades geológicas Canabravinha, Serra da Mamona, Riachão das Neves e Sítio novo. A tabela 5.2 apresenta as características das unidades geológicas presentes na bacia.

Tabela 5.2 - Caracterização geológica da Bacia (INEMA, 2014).

\begin{tabular}{|c|c|c|c|}
\hline Unidade geológica & Domínio & Textura & Porosidade \\
\hline Canabravinha & $\begin{array}{c}\text { Sequências sedimentares } \\
\text { proterozóicas dobradas, } \\
\text { metamorfizadas em baixo grau } \\
\text { a médio grau. }\end{array}$ & $\begin{array}{l}\text { Argilo-síltico- } \\
\quad \text { arenoso }\end{array}$ & $\begin{array}{l}\text { Variável ( } 0- \\
\quad>30 \%\end{array}$ \\
\hline $\begin{array}{l}\text { Coberturas detrito- } \\
\text { lateríticas } \\
\text { ferruginosas }\end{array}$ & $\begin{array}{l}\text { Coberturas cenozóicas detrito- } \\
\text { lateríticas. }\end{array}$ & $\begin{array}{l}\text { Variável na } \\
\text { vertical }\end{array}$ & Alta $(>30 \%)$ \\
\hline $\begin{array}{l}\text { Depósitos } \\
\text { aluvionares }\end{array}$ & $\begin{array}{c}\text { Sedimentos cenozóicos } \\
\text { inconsolidados ou pouco } \\
\text { consolidados, depositados em } \\
\text { meio aquoso. }\end{array}$ & Não se aplica & Alta $(>30 \%)$ \\
\hline $\begin{array}{l}\text { Depósitos } \\
\text { aluvionares } \\
\text { antigos }\end{array}$ & $\begin{array}{c}\text { Sedimentos cenozóicos } \\
\text { inconsolidados ou pouco } \\
\text { consolidados, depositados em } \\
\text { meio aquoso. }\end{array}$ & Não se aplica & Alta $(>30 \%)$ \\
\hline Paraopeba & $\begin{array}{l}\text { Sequências sedimentares } \\
\text { proterozóicas dobradas, } \\
\text { metamorfizadas em baixo grau } \\
\text { a médio grau. }\end{array}$ & - & $\begin{array}{l}\text { Variável ( } 0 \text { - } \\
\quad>30 \%\end{array}$ \\
\hline Riachão das Neves & $\begin{array}{c}\text { Sequências sedimentares } \\
\text { proterozóicas dobradas, } \\
\text { metamorfizadas em baixo grau } \\
\text { a médio grau. }\end{array}$ & - & $\begin{array}{l}\text { Variável ( } 0- \\
\quad>30 \%\end{array}$ \\
\hline São Desidério & $\begin{array}{c}\text { Sequências sedimentares } \\
\text { proterozóicas dobradas, } \\
\text { metamorfizadas em baixo grau } \\
\text { a médio grau. }\end{array}$ & - & $\begin{array}{l}\text { Variável ( } 0- \\
\quad>30 \%\end{array}$ \\
\hline Serra da Mamona & $\begin{array}{c}\text { Sequências sedimentares } \\
\text { proterozóicas dobradas, } \\
\text { metamorfizadas em baixo grau } \\
\text { a médio grau. }\end{array}$ & Argilo-siltoso & Baixa $(0-15 \%)$ \\
\hline $\begin{array}{l}\text { Sete Lagoas - } \\
\text { fácies } 1\end{array}$ & $\begin{array}{l}\text { Sequências sedimentares } \\
\text { proterozóicas dobradas, } \\
\text { metamorfizadas em baixo grau } \\
\text { a médio grau. }\end{array}$ & Argilo-siltoso & Baixa $(0-15 \%)$ \\
\hline Sítio Novo & $\begin{array}{l}\text { Sequências sedimentares } \\
\text { proterozóicas dobradas, }\end{array}$ & Arenoso & Alta $(>30 \%)$ \\
\hline
\end{tabular}




\begin{tabular}{cccc}
\hline Unidade geológica & Domínio & Textura & Porosidade \\
\hline & $\begin{array}{c}\text { metamorfizadas em baixo grau } \\
\text { a médio grau. }\end{array}$ & & \\
& $\begin{array}{c}\text { Sedimentos cenozóicos e } \\
\text { mesozóicos pouco a }\end{array}$ & & \\
Urucuia & $\begin{array}{c}\text { moderadamente consolidadas } \\
\text { associados a profundas e } \\
\text { extensas bacias continentais. }\end{array}$ & argilo-siltoso a & Alta $(>30 \%)$ \\
\end{tabular}

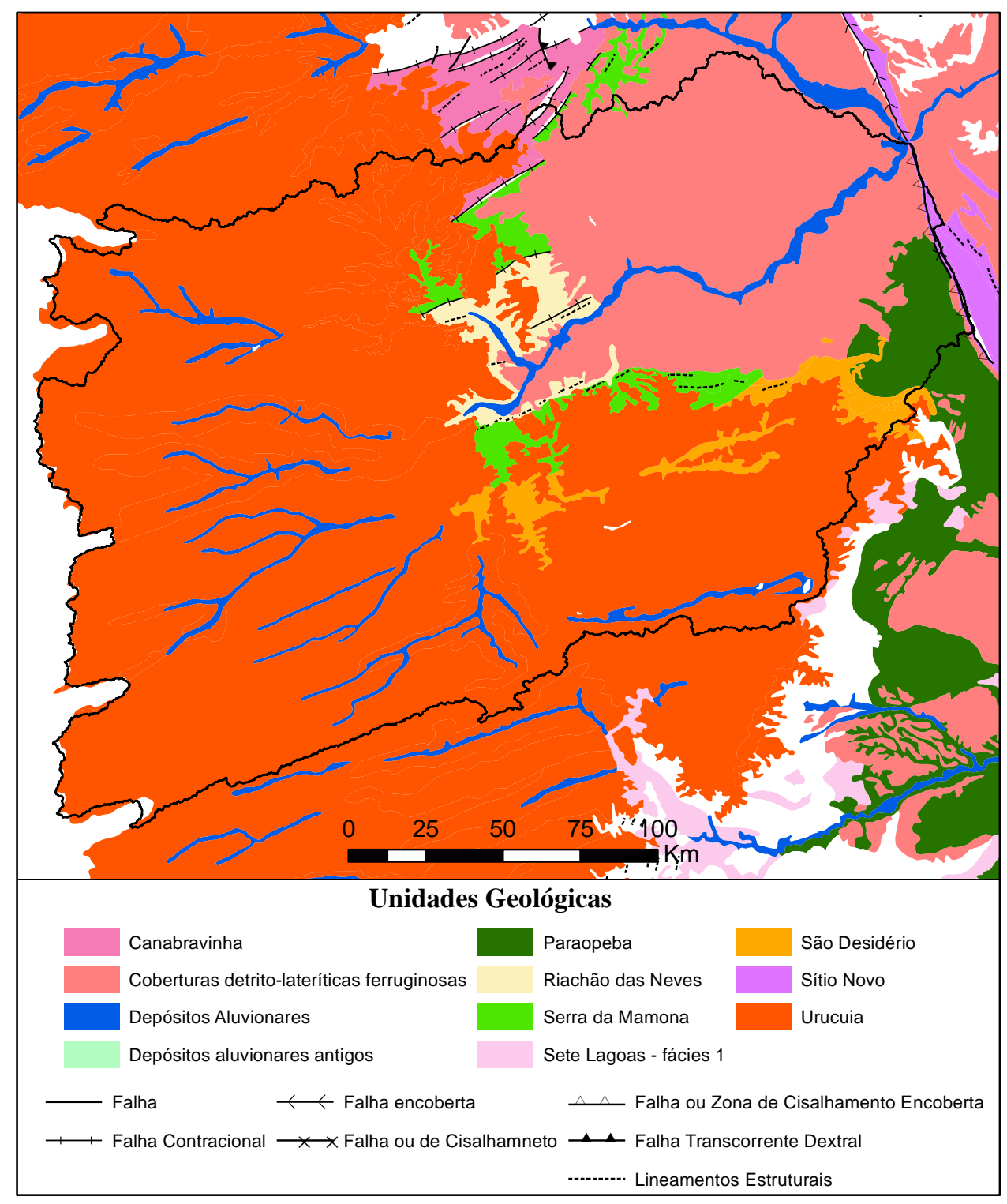

Figura 5.8 - Mapa geológico da sub-bacia do Rio Grande ( INEMA, 2014).

A maior parte da área da bacia está sob domínio hidrogeológico das bacias sedimentares e inserida no aquífero Urucuia Central, que é um aquífero granular de alta porosidade o que é o responsável pela baixa densidade de drenagem da região (Maia et al., 2009). No limite 
oeste de sua área efetiva, o sistema aquífero Urucuia exibe um eixo longitudinal divisor do fluxo subterrâneo, que separa o sentido do fluxo regional do sistema para leste e para oeste (Gaspar, 2006). A presença desta estrutura, confere ao sistema aquífero uma assimetria entre as bacias hidrográfica e hidrogeológica. Assim sendo, esta bacia de estudo comporta duas bacias hidrogeológicas que constituem um mesmo sistema aquífero. A bacia hidrogeológica leste, com fluxo no sentido O-E, contribui com fluxo de base para a alimentação da rede de drenagem pertencente à bacia hidrográfica do São Francisco, enquanto que a bacia hidrogeológica oeste, com sentido E-O, contribui para o fluxo de base da bacia do rio Tocantins, esta área é exibida hachurada na figura 4.9 (CPRM, 2012). A parte da bacia onde há divergência entre o divisor de águas superficial e subterrâneo tem uma área total de 1085 quilômetros, o que corresponde a 2,3\% da área.

Além do sistema aquífero Urucuia, há a ocorrência de domínio de calcários entre as bacias sedimentares e as coberturas lateríticas, é nesta região onde há mais poços perfurados. De acordo com dados do INEMA relativos a 2002, na área da bacia há um total de 202 poços, responsáveis por uma vazão de $2520 \mathrm{~m} 3 / \mathrm{h}$ (INEMA, 2014). Na figura 5.9 é apresentado o mapa hidrogeológico e a distribuição dos poços levantados pelo INEMA.

A expansão da ocupação do solo provocada pelo crescimento da agricultura na sub-bacia do Rio Grande, implicou no aumento do uso da água para irrigação, o que colocou a região em situação de vulnerabilidade quanto a conflitos entre usuários da água (ANA, 2004).

Em virtude da baixa densidade de drenagem e a crescente demanda de água para o suprimento das sedes de fazendas, vilarejos e projetos de irrigação, tem ocorrido um incremento na explotação da água subterrânea. Entre 2003 e 2006, as vazões subterrâneas outorgadas nos municípios de toda mesorregião do Oeste Baiano aumentou de $4.510 \mathrm{~m}^{3} / \mathrm{h}$ para $14.340 \mathrm{~m}^{3} / \mathrm{h}$, com o município de Luís Eduardo Magalhães sendo responsável por $\left(5.079 \mathrm{~m}^{3} / \mathrm{h}\right)$, seguido de São Desidério $\left(3.394 \mathrm{~m}^{3} / \mathrm{h}\right)$ e Barreiras $\left(2.311 \mathrm{~m}^{3} / \mathrm{h}\right)(\mathrm{Gaspar}$, 2006), estes municípios todos inseridos na área deste estudo. 


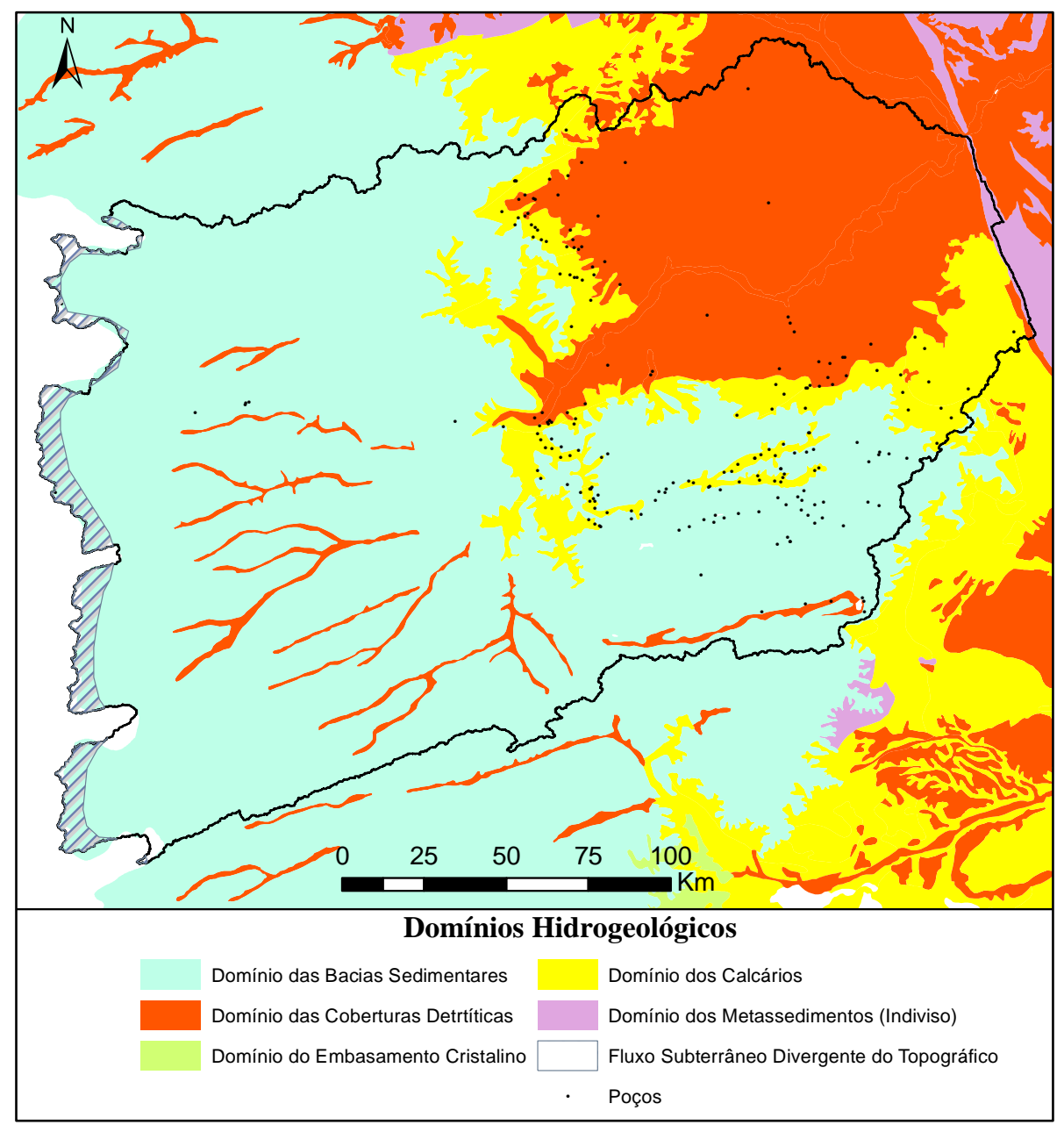

Figura 5.9 - Mapa hidrogeológico da sub-bacia do Rio Grande (INEMA, 2014).

\subsection{4 - Clima}

O clima na bacia do Rio Grande, conforme o critério de classificação de Thornthwaite disponibilizado pelo IBGE, (2000), se divide em 2 tipos de clima sub-úmido, no oeste da bacia, com índices pluviométricos que podem chegar a $1.700 \mathrm{~mm}$ por ano e semiárido, na parte oriental, este último não faz parte da área de estudo, conforme figura 5.10.

O regime pluviométrico na bacia é caracterizado por dois períodos bem distintos: o chuvoso, que se estende de outubro a abril, com maiores índices no mês de dezembro; e o seco, que se estende de maio a setembro, com estiagem crítica de julho a setembro (Moreira e Silva, 2010). 


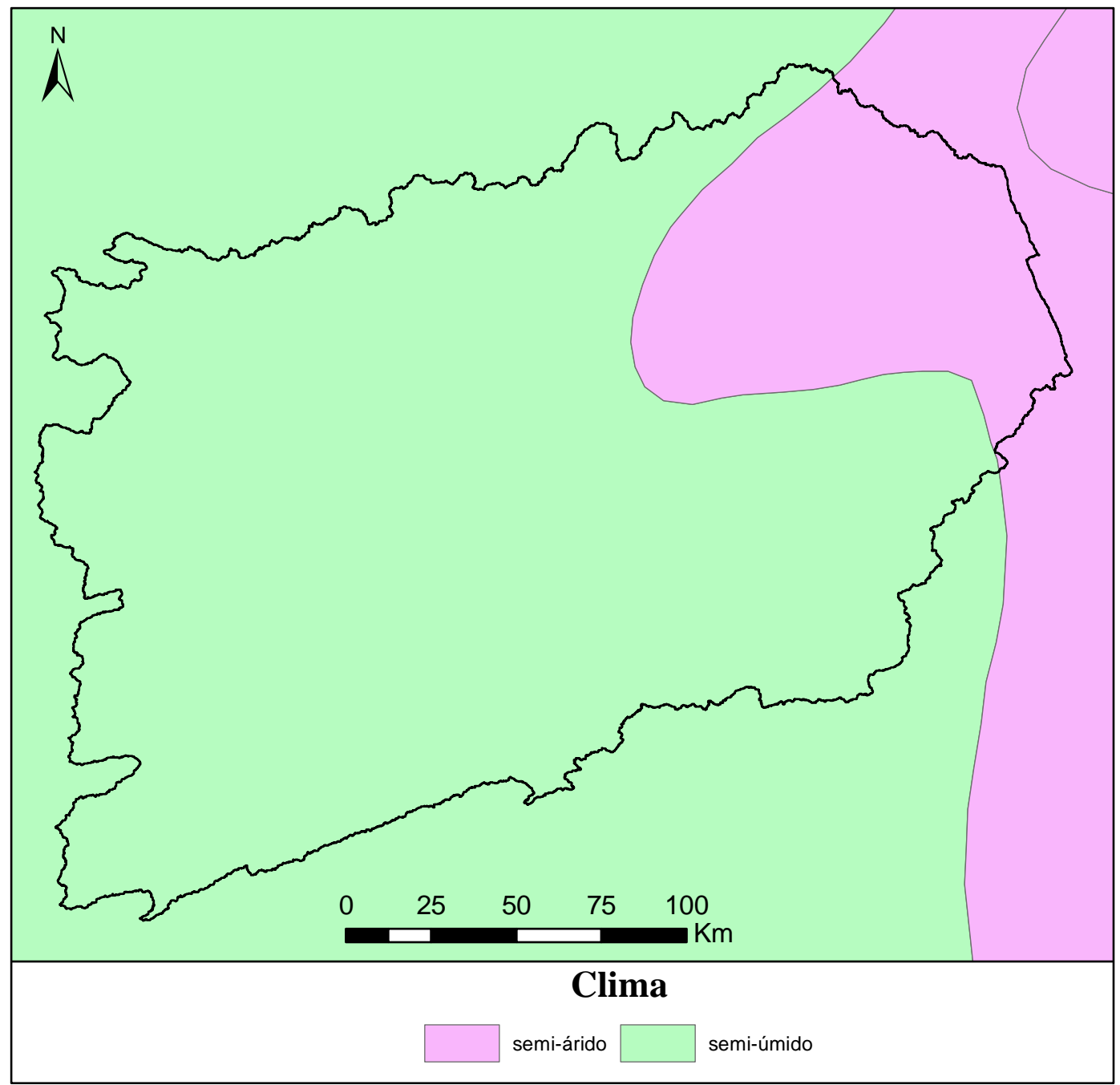

Figura 5.10 - Clima da sub-bacia do Rio Grande (IBGE, 2000).

\subsection{5 - Vegetação}

Na bacia do Rio Grande há predominância da vegetação nativa de cerrado (savana). Na área mais central há a ocorrência de transição entre o bioma cerrado e a caatinga (floresta decidual e semi-decidual), que é observada em alguns pontos da bacia (MMA, 2010), a vegetação é apresentada na figura 5.11. 


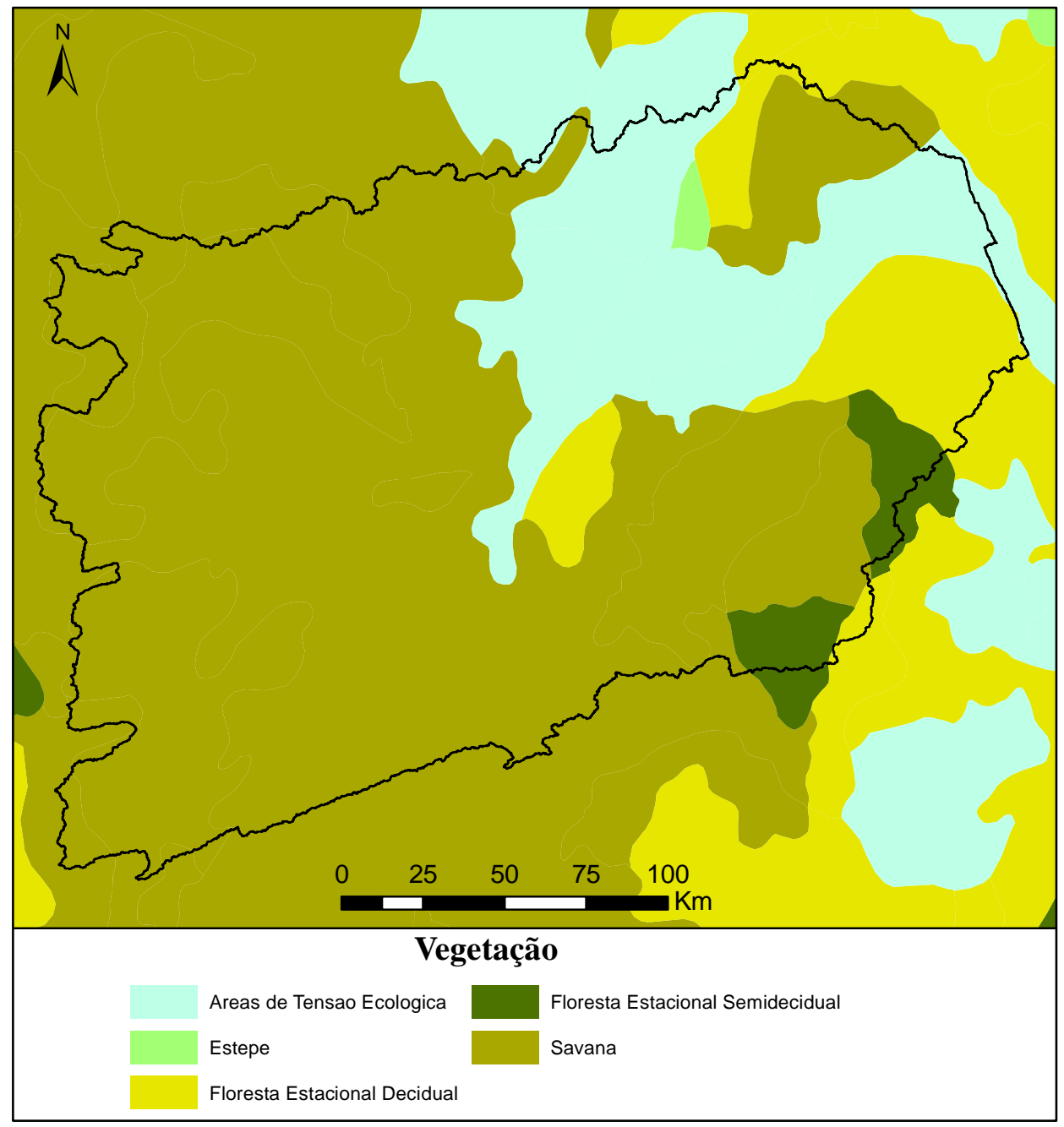

Figura 5.11 - Vegetação da sub-bacia do Rio Grande (IBGE, 2000).

\subsection{6 - Solos}

Os solos predominantes na região são os Latossolos Vemelho-Amarelo distróficos, que se caracterizam por serem associados a relevos planos, suavemente ondulados ou ondulados. Ocorrem em ambientes bem drenados, sendo muito profundos e uniformes em características de cor, textura e estrutura em profundidade. São solos com que apresentam limitações químicas por conta dos baixos níveis de nutrientes. São muito utilizados para agropecuária apresentando limitações de ordem química em profundidade ao desenvolvimento do sistema radicular. O relevo plano ou suavemente ondulado favorece a mecanização agrícola. Por serem profundos e porosos ou muito porosos, apresentam condições adequadas para um bom desenvolvimento radicular em profundidade (Embrapa, 2016). 
Há também grande ocorrência de Neossolos Quartzarênicos que são solos minerais, derivados de sedimentos arenoquartzosos, são profundos a muito profundos, com textura areia ou areia franca ao longo de pelo menos $150 \mathrm{~cm}$ de profundidade ou até o contato lítico. São excessivamente drenados, com menos de $4 \%$ de minerais primários facilmente intemperizáveis e pouco desenvolvidos devido à baixa atuação dos processos pedogenéticos e pela resistência do material de origem ao intemperismo (Embrapa, 2016).

Os Argilossolos Vermelho-Amarelo são solos que apresentam horizonte de acumulação de argila, $\mathrm{B}$ textural $(\mathrm{Bt})$, com cores vermelho-amareladas devido à presença da mistura dos óxidos de ferro hematita e goethita. São solos profundos e muito profundos; bem estruturados e bem drenados.

Os Neossolos Litólicos compreendem solos rasos, onde geralmente a soma dos horizontes sobre a rocha não ultrapassa $50 \mathrm{~cm}$, estando associados normalmente a relevos de maior decliviade.

O Mapa de Solos da área de estudo foi obtido junto ao Instituto do Meio Ambiente e Recursos Hídricos da Bahia - INEMA e está disponibilizado para download em: http://www.inema.ba.gov.br/download/460/. Este mapa de Solos foi disponibilizado na escala 1:250.000 compatível com a resolução do MDE utilizado. O mapa de solos foi rasterizado e sua resolução espacial foi compatibilizada à do MDE, ou seja, 90 metros. Na figura 5.12 é apresentado o mapa de solos da área de estudo 


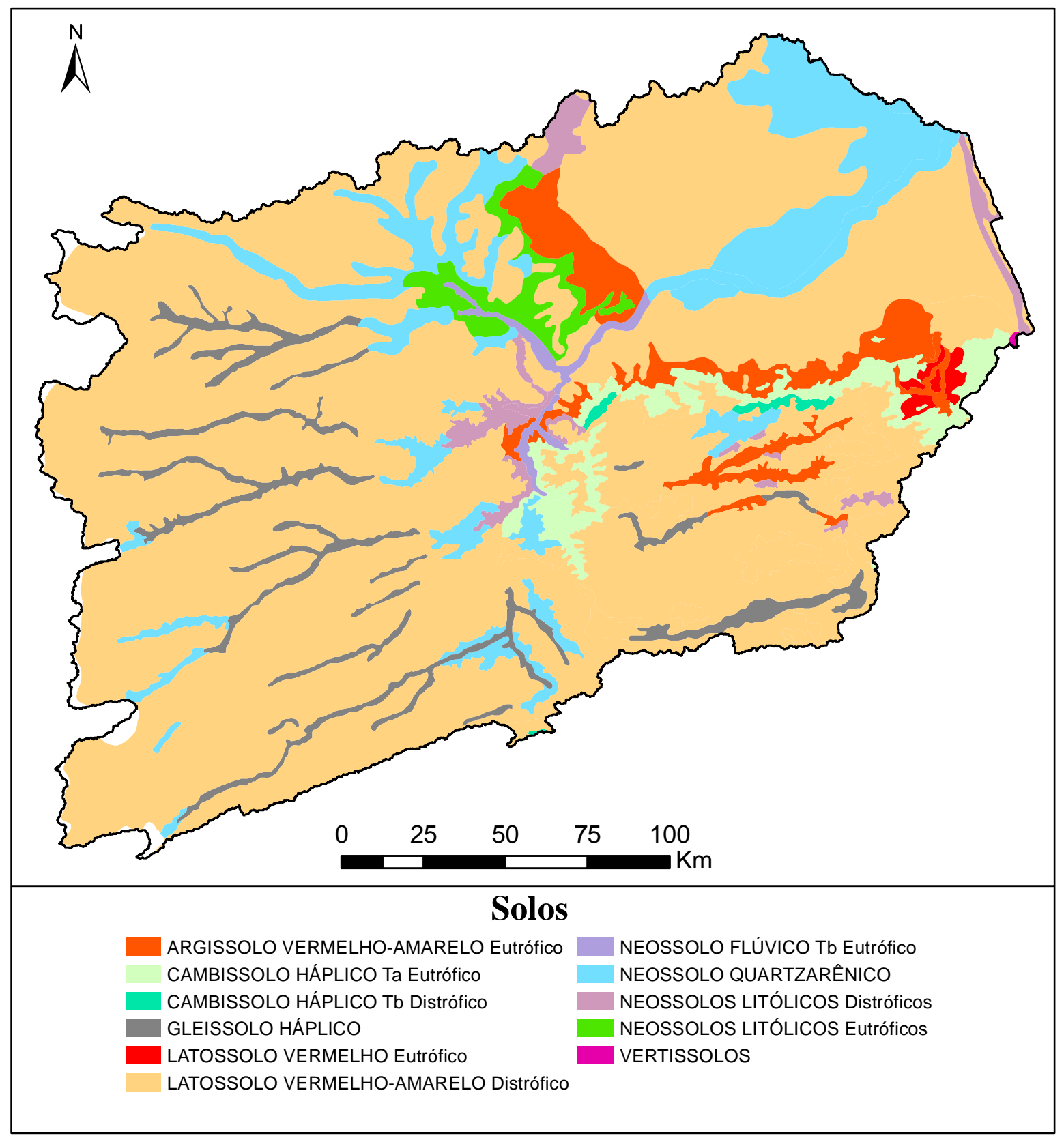

Figura 5.12 - Mapa de solos da área de estudo (INEMA, 2014).

\subsection{7 - Cobertura e uso do solo}

Os mapas de cobertura e uso do solo foram obtidos dos estudos realizados por Sano et al.(2011) que realizaram a análise temporal da ocupação do Oeste Baiano usando imagens do satélite LandSat, as imagens foram processadas por meio da técnica de segmentação de imagens por crescimento de regiões, usando o aplicativo SPRING 4.0 (Câmara et al. 1996), com os valores de limiar e similaridade iguais a 15. A identificação de classes de cobertura do solo foi realizada sobrepondo-se a composição colorida das imagens Landsat 
com o arquivo vetorial de segmentação em uma escala de visualização de aproximadamente 1:50.000. As seguintes classes espectrais foram consideradas na interpretação de imagens: culturas agrícolas, pastagens cultivadas, reflorestamento e vegetação natural. O estudo foi realizado para todos os municípios do Oeste Baiano, sendo que na área da bacia estudada não há a ocorrência de reflorestamento sendo verificada somente as três primeiras classes.

Nas figuras 5.13, 5.14 e 5.15 são apresentados os mapas de cobertura e uso do solo da bacia para os anos de 1980, 1990 e 2000 respectivamente. No estudo de Sano et al.(2011) foi apresentado o mapa de cobertura uso de solo de 2005 que poderia ter sido utilizado neste estudo, no entanto não foi observada alteração significativa na cobertura do solo da bacia do Rio Grande, que conforme já apresentado no item 5.1 é justificado pela crescimento da produção agrícola por consequência do aumento das tecnologias de produção em detrimento do aumento da área plantada.

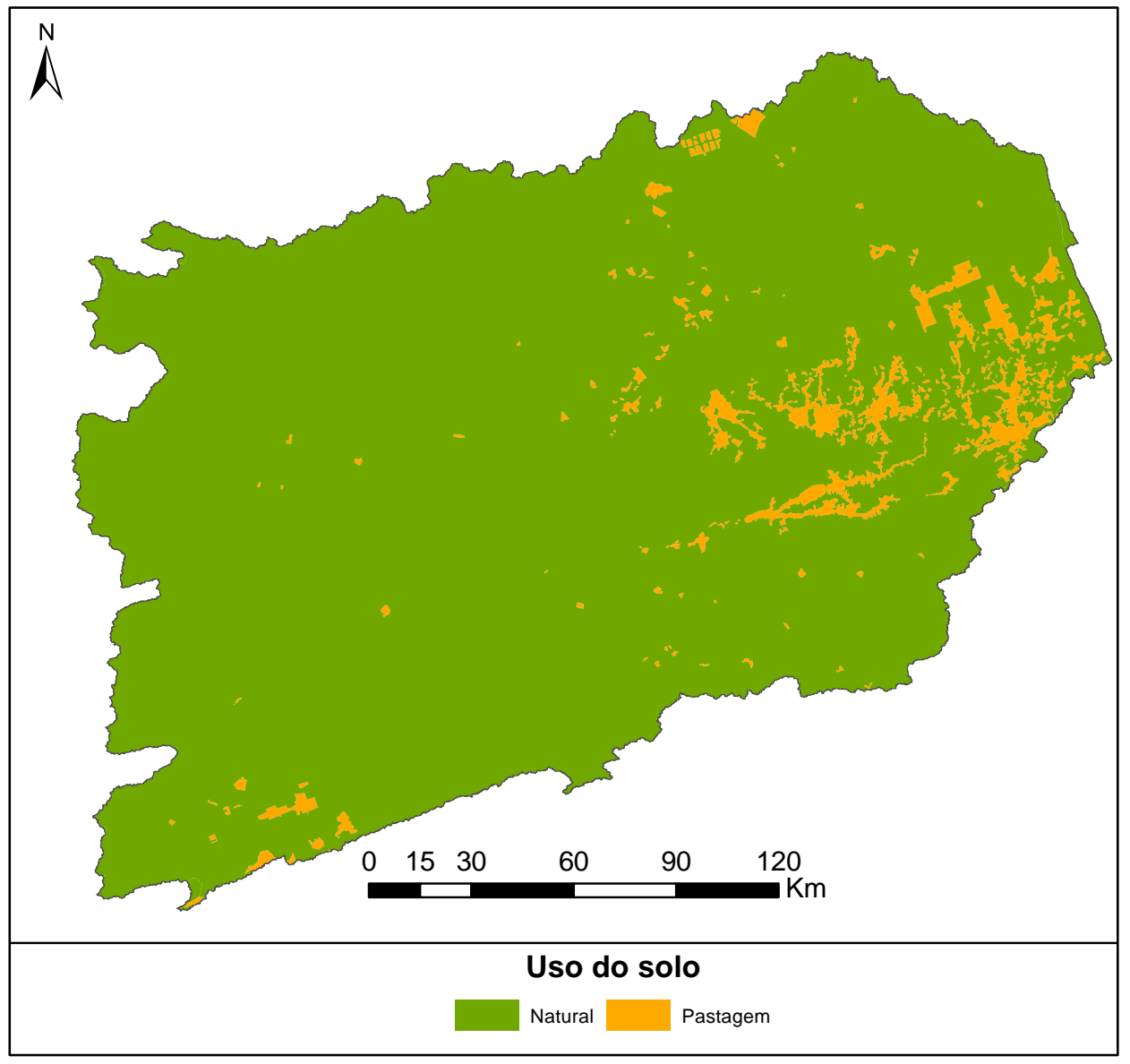

Figura 5.13 - Mapa de cobertura e uso do solo da Bacia do Rio Grande em 1980 (Sano et. al, 2011). 


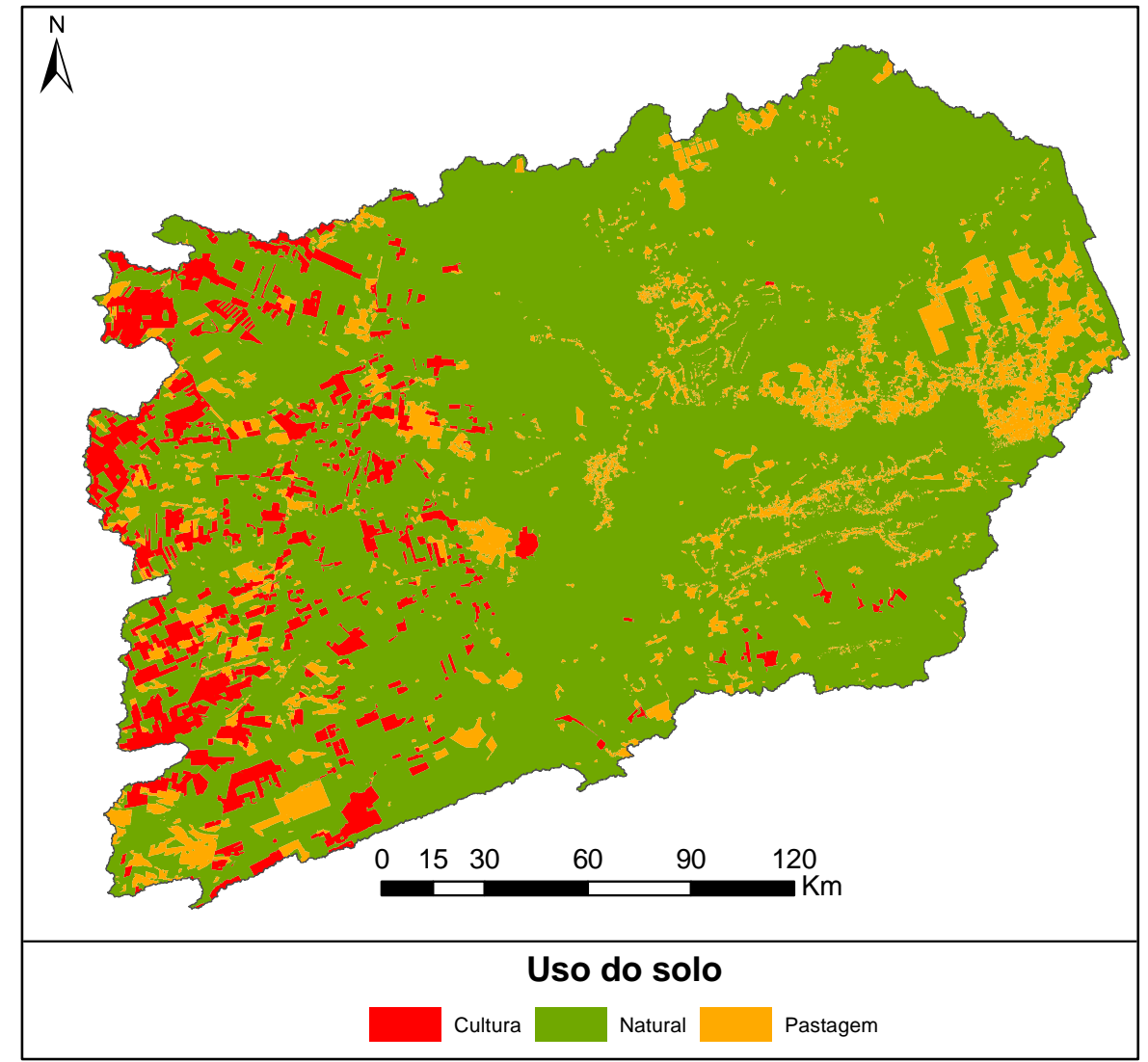

Figura 5.14 - Mapa de cobertura e uso do solo da Bacia do Rio Grande em 1990 (Sano et. al, 2011).

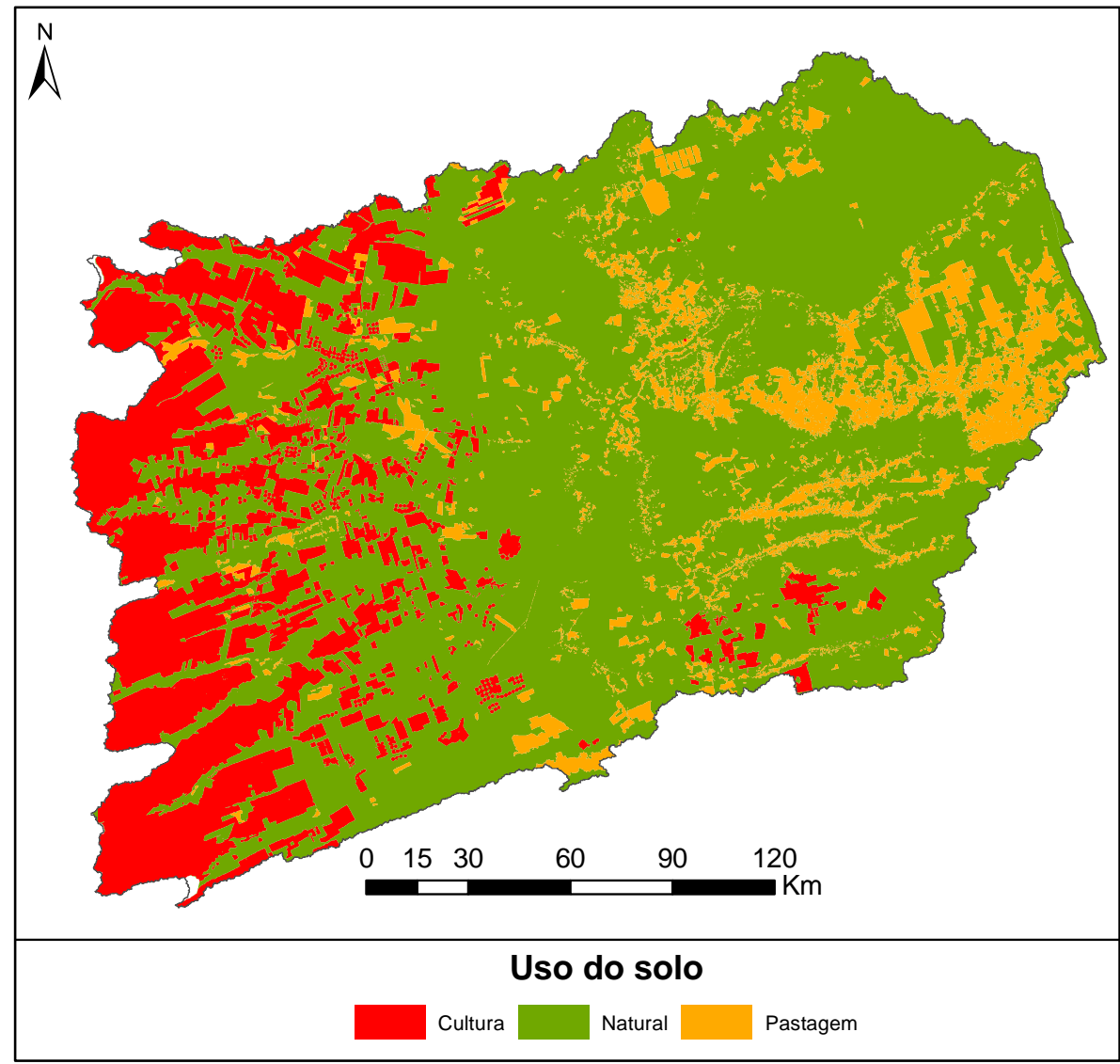

Figura 5.15 - Mapa de cobertura e uso do solo da Bacia do Rio Grande em 2000 (Sano et. al, 2011). 
Observa-se um padrão espacial da expansão agrícola na bacia que tem sua expansão ocorrendo principalmente ao longo das linhas de cumeeira do relevo, onde estão localizadas as estradas principais para o escoamento da produção. A porção oeste é a mais ocupada devido à maior precipitação e onde se observa uma topografia plana que favorece a implementação da agricultura mecanizada.

A tabela 5.3 e a figura 5.16 apresentam um resumo da evolução da cobertura e uso do solo na bacia, onde se apresentam as áreas ocupadas por cada classe nos anos de 1980, 1990 e 2000.

Tabela 5.3 - Resumo da evolução da cobertura e uso do solo na Bacia do Rio Grande.

\begin{tabular}{ccccccc}
\hline \multirow{2}{*}{ Ano } & \multicolumn{2}{c}{ Natural } & \multicolumn{2}{c}{ Cultura } & \multicolumn{2}{c}{ Pastagem } \\
& $\mathrm{Km}^{2}$ & $\%$ & $\mathrm{Km}^{2}$ & $\%$ & $\mathrm{Km}^{2}$ & $\%$ \\
\hline 1980 & 44.834 & $95,9 \%$ & 0 & $0,0 \%$ & 1.900 & $4,1 \%$ \\
1990 & 38.362 & $82,1 \%$ & 3.849 & $8,2 \%$ & 4.523 & $9,7 \%$ \\
2000 & 32.046 & $68,6 \%$ & 9.796 & $21,0 \%$ & 4.892 & $10,5 \%$ \\
\hline
\end{tabular}

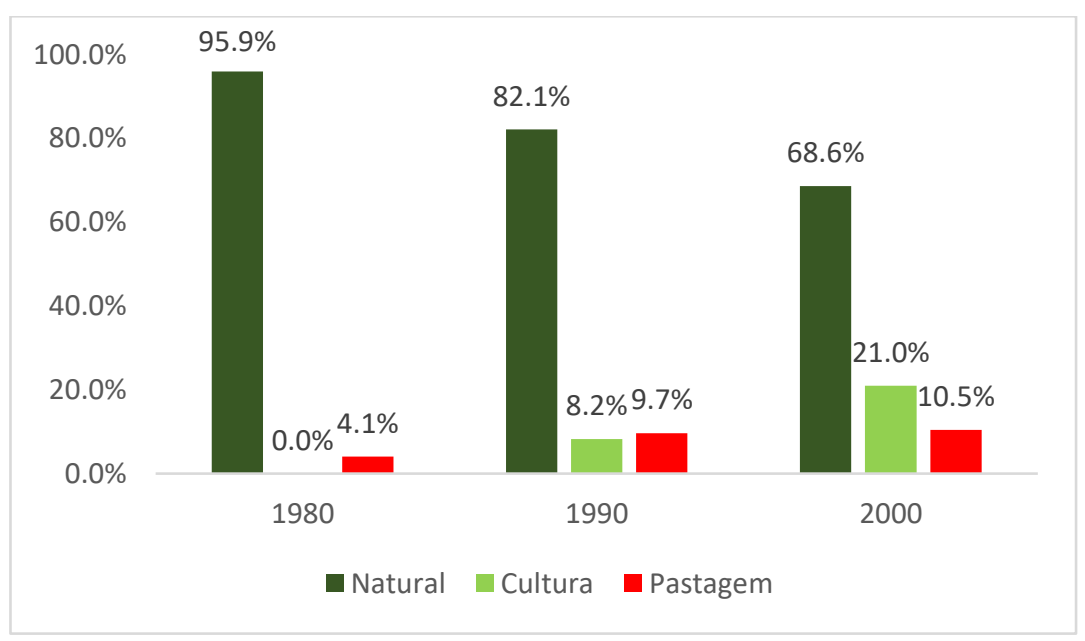

Figura 5.16 - Evolução do uso do solo na Bacia do Rio Grande.

\section{2 - DADOS HIDROMETEOROLÓGICOS}

Os dados hidrometereológicos foram obtidos junto à Agência Nacional de Águas - ANA, por meio da plataforma de compartilhamento Hidroweb. Os dados hidrometeorológicos necessários para a aplicação do modelo MGB-IPH são:

- Séries de dados de vazões de rios em postos fluviométricos; 
- Séries de dados de precipitação em postos pluviométricos;

- Séries de dados de variáveis climáticas (temperatura, umidade relativa, velocidade do vento, insolação, pressão atmosférica).

\subsection{1 - Precipitação}

Foram utilizados dados de precipitação de 29 postos pluviométricos operadas pela ANA, no interior e em áreas próximas à bacia de estudo, as precipitações médias anuais variam de 836 a $1393 \mathrm{~mm}$. A lista dos postos pluviométricos e suas respectivas vazões médias anuais são apresentados na tabela 5.4, enquanto que na figura 5.17 tem-se a disponibilidade temporal dos dados, destacando os anos em que houveram falhas nas observações e/ou nos registros. A figura 5.18 apresenta a disposição espacial das estações pluviométricas.

Tabela 5.4 - Estações pluviométricas utilizadas no estudo

\begin{tabular}{|c|c|}
\hline Código da Estação pluviométrica & Vazão média anual (mm) \\
\hline 1143010 - Boqueirão & 862,8 \\
\hline 1144005 - Fazenda Macambira & 894,7 \\
\hline 1144014 - São Sebastião & 960,0 \\
\hline 1144027 - Ibipetuba & 890,1 \\
\hline 1145001 - Formosa do Rio Preto & 967,4 \\
\hline 1145004 - Fazenda Bom Jardim & 1074,1 \\
\hline 1145013 - Ponte Serafim - Montante & 1136,8 \\
\hline 1145014 - Nova Vida - Montante & 974,5 \\
\hline 1145019 - Caripare & 955,5 \\
\hline 1145020 - Fazenda Triunfo & 908,8 \\
\hline 1243019 - Serra Dourada (Faz. Muritiba) & 973,9 \\
\hline 1244011 - Barreiras & 993,1 \\
\hline 1244019 - Fazenda Coqueiro & 1067,6 \\
\hline 1244020 - Cera & 1030,3 \\
\hline 1244021 - Brejo Novo & 1072,7 \\
\hline 1245004 - Fazenda Redenção & 1011,2 \\
\hline 1245005 - Derocal & 956,3 \\
\hline 1245007 - Sítio Grande & 1039,3 \\
\hline 1245014 - Fazenda Joha & 1110,7 \\
\hline
\end{tabular}




\begin{tabular}{cc}
\hline Código da Estação pluviométrica & Vazão média anual (mm) \\
\hline 1245015 - Roda Velha & 1107,6 \\
1245016 - Cabeceira Grande & 892,7 \\
1245017 - Limoeiro & 1238,9 \\
1343008 - Porto Novo & 815,0 \\
1344002 - Mocambo & 960,4 \\
1344014 - Correntina & 944,2 \\
1344017 - Santa Maria da Vitória & 944,6 \\
1344025 - Sítio Januário & 1045,2 \\
1345002 - Casa Real & 1072,4 \\
1346007 - Fazenda Prainha (faz.Antas) & 1378,1
\end{tabular}

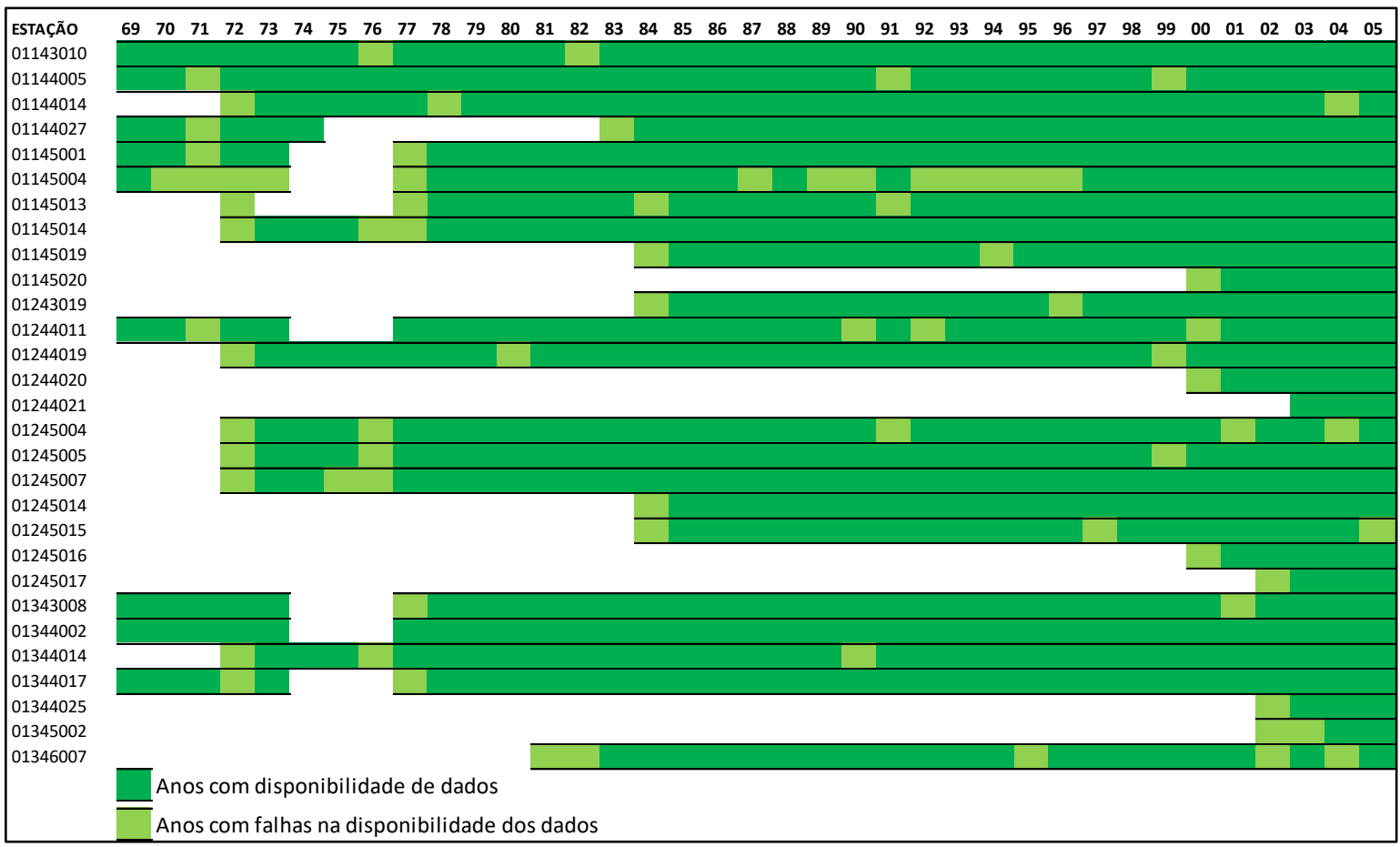

Figura 5.17 - Disponibilidade de dados de chuvas observados na área de estudo. 


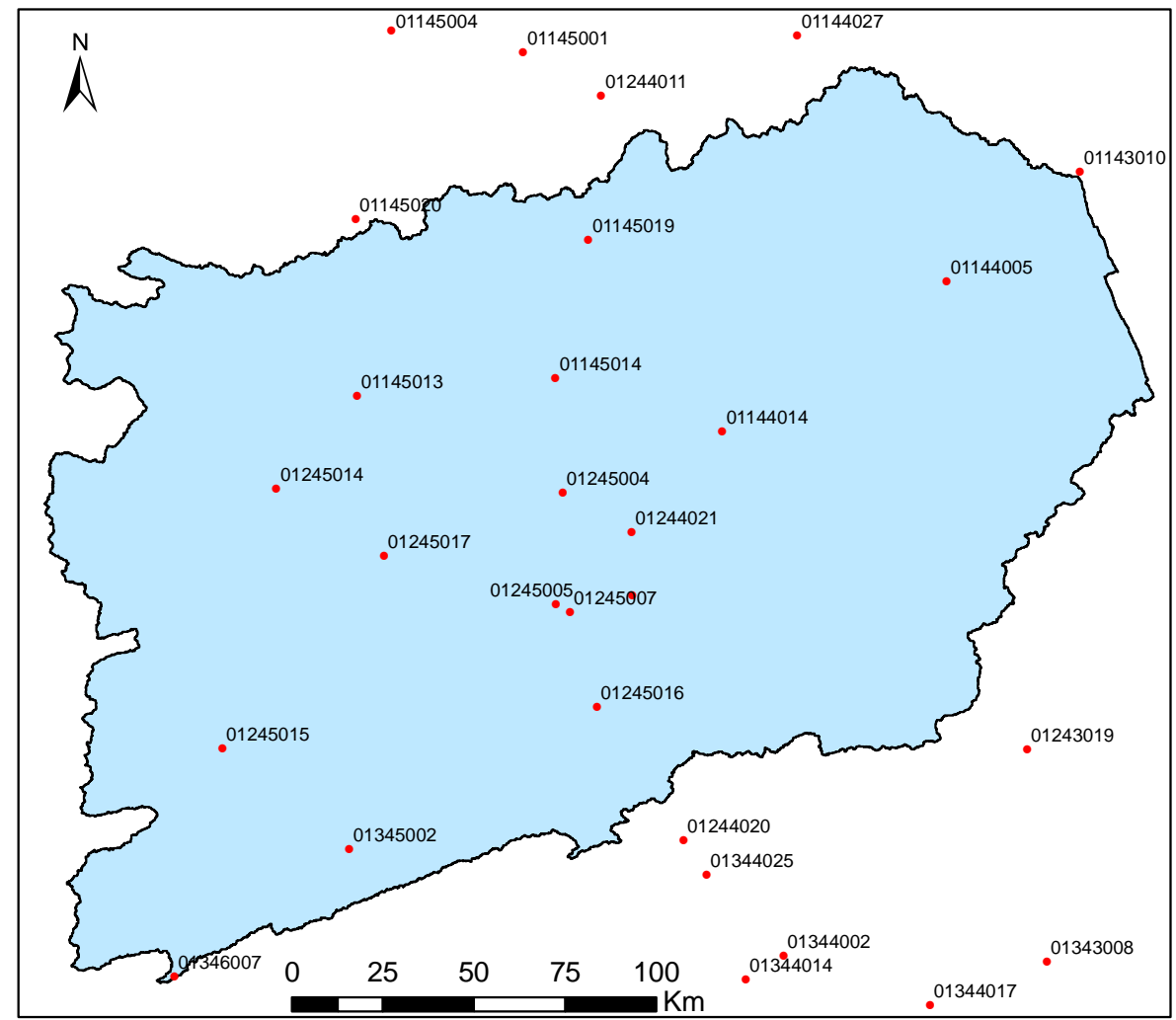

Figura 5.18 - Disposição espacial dos postos pluviométricos utilizados no estudo.

Pode-se verificar que as chuvas são mais abundantes na parte oeste da área de estudo, o que é reforçado pela figura 5.19 que apresenta as variações das precipitações anuais observadas de cada estação, e permite uma visão geral das precipitações sobre a área de estudo.

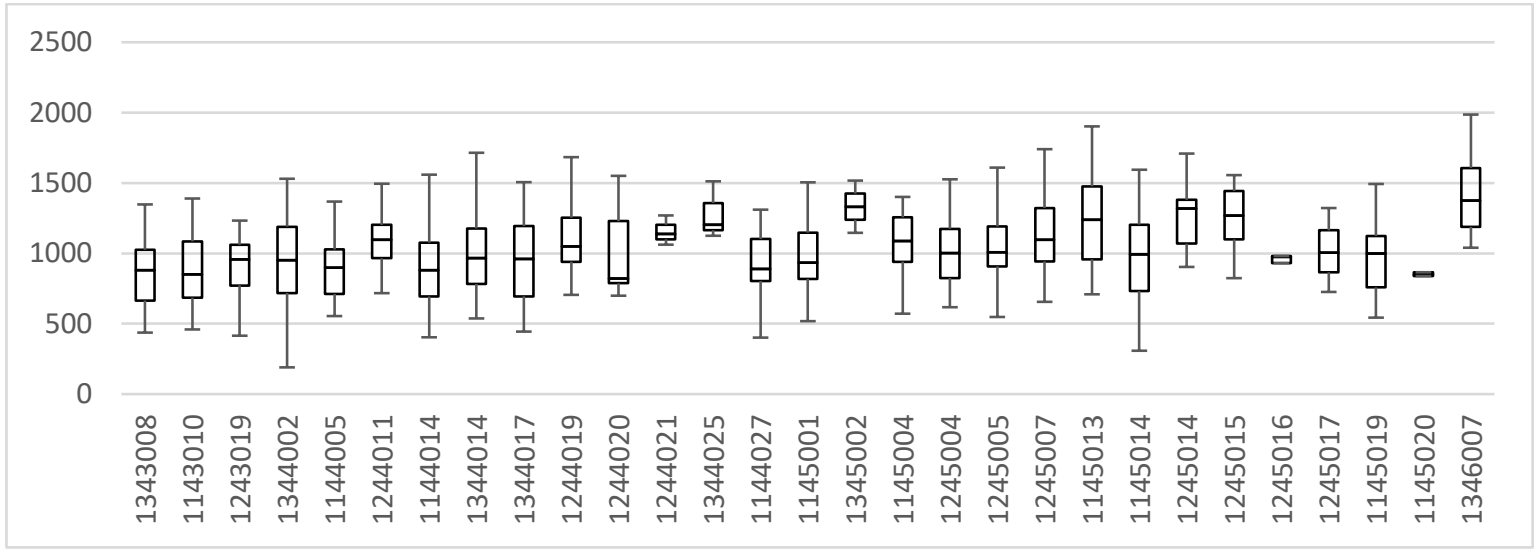

Figura 5.19 - Variações das precipitações anuais dos postos pluviométricos usados neste estudo (1969- 2005).

Quanto às precipitações mensais, os meses mais chuvosos são novembro, dezembro e janeiro, que correspondem a 54\% das chuvas anuais, enquanto que os meses mais secos 
são os meses de junho, junho e agosto, a figura 5.20 apresenta as médias mensais dos postos pluviométricos.

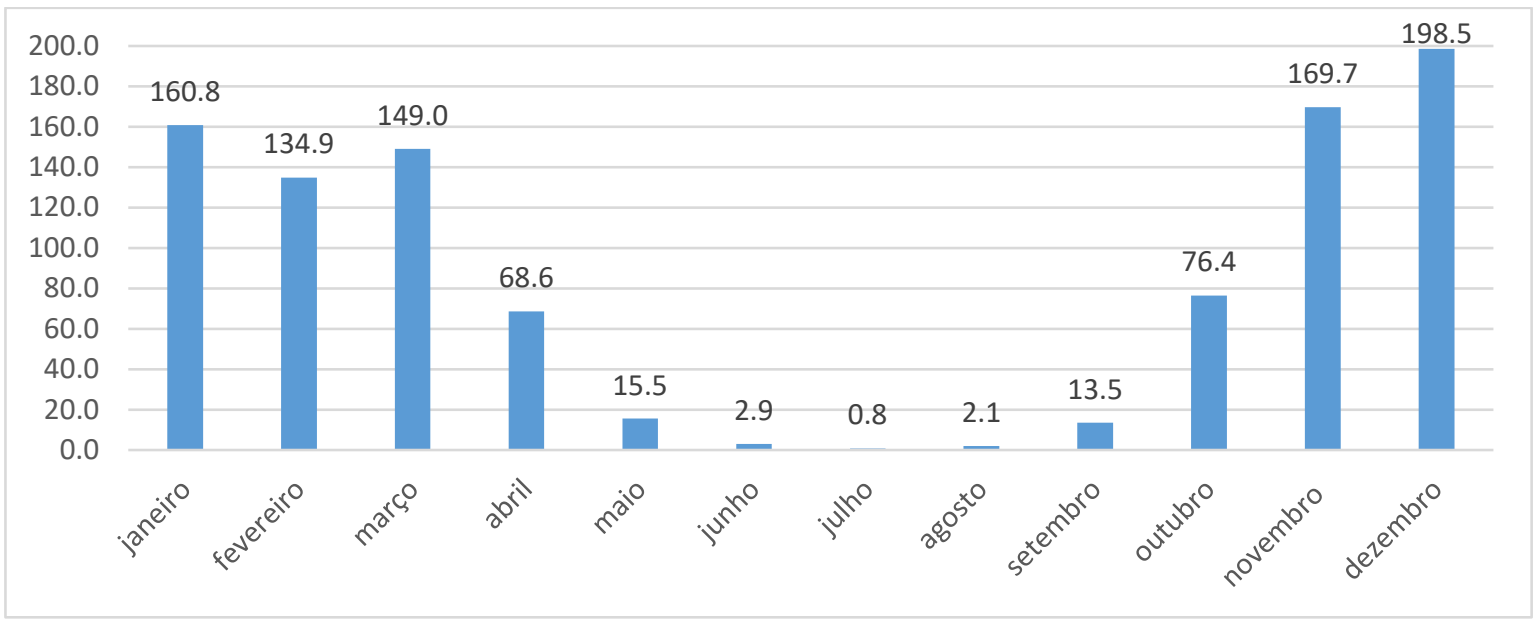

Figura 5.20 - Precipitações médias mensais dos postos pluviométricos utilizados neste estudo (1969-2005).

\subsection{2 - Vazão}

Na bacia de estudos há 17 postos fluviométricas em operação pela ANA, a lista dos estações e suas respectivas áreas de drenagem são apresentadas na tabela 5.5, a disponibilidade temporal dos dados de vazão em cada posto fluviométrico é apresentado na figura 5.21 e a sua disposição espacial na bacia é apresentada na figura 5.22, na figura .

Tabela 5.5 - Estações fluviométricas da área de estudo.

\begin{tabular}{cc}
\hline Código da estação fluviométrica & Área de drenagem $\left(\mathrm{Km}^{2}\right)$ \\
\hline 46400000 - Casa Real & 940,4 \\
46415000 - Sìtio Grande & $4.981,7$ \\
46420000 - Roda Velha de Baixo & 537,4 \\
46455000 - Derocal & $6.370,3$ \\
46490000 - Fazenda Coqueiro & $4.465,7$ \\
46520000 - Rio de Pedras & $1.486,7$ \\
46530000 - Limoeiro & $1.927,3$ \\
46543000 - Fazenda Redenção & $5.442,4$ \\
46550000 - Barreiras & $18.999,3$ \\
46555000 - Brejo Novo & $2.431,1$ \\
46570000 - Ponte Serafim - Montante & $2.742,2$
\end{tabular}




\begin{tabular}{cc}
\hline Código da estação fluviométrica & Área de drenagem $\left(\mathrm{Km}^{2}\right)$ \\
\hline 46590000 - Nova Vida - Montante & $7.530,8$ \\
46610000 - São Sebastião & $33.278,6$ \\
46650000 - Taguá & $36.194,4$ \\
46675000 - Fazenda Macambira & $39.936,4$ \\
46784000 - Savana & 680,5 \\
46902000 - Boqueirão & $46.734,3$ \\
\hline
\end{tabular}

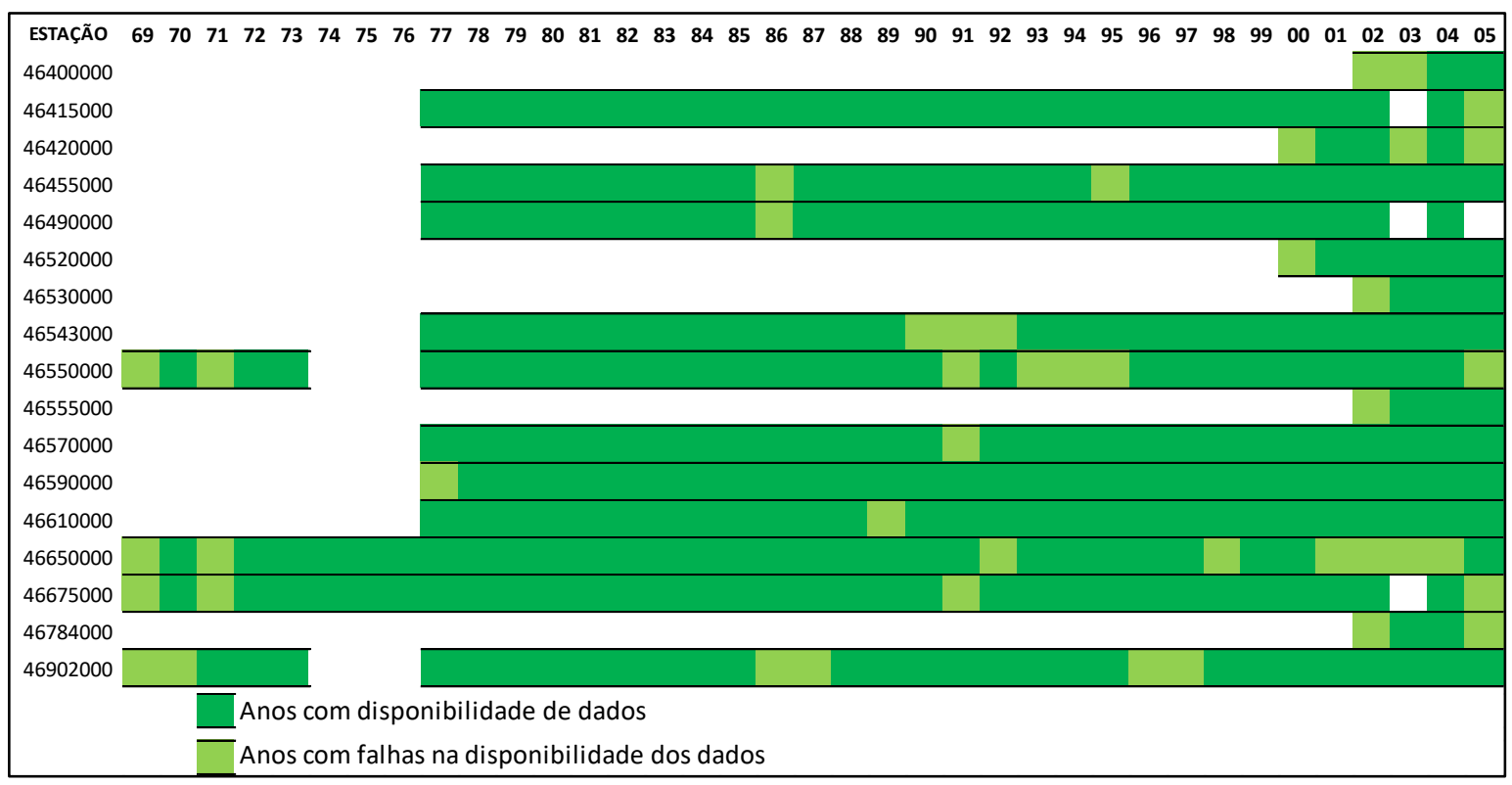

Figura 5.21 - Disponibilidade temporal dos dados de vazão dos postos fluviométricos operadas pela ANA (1969-2005) 


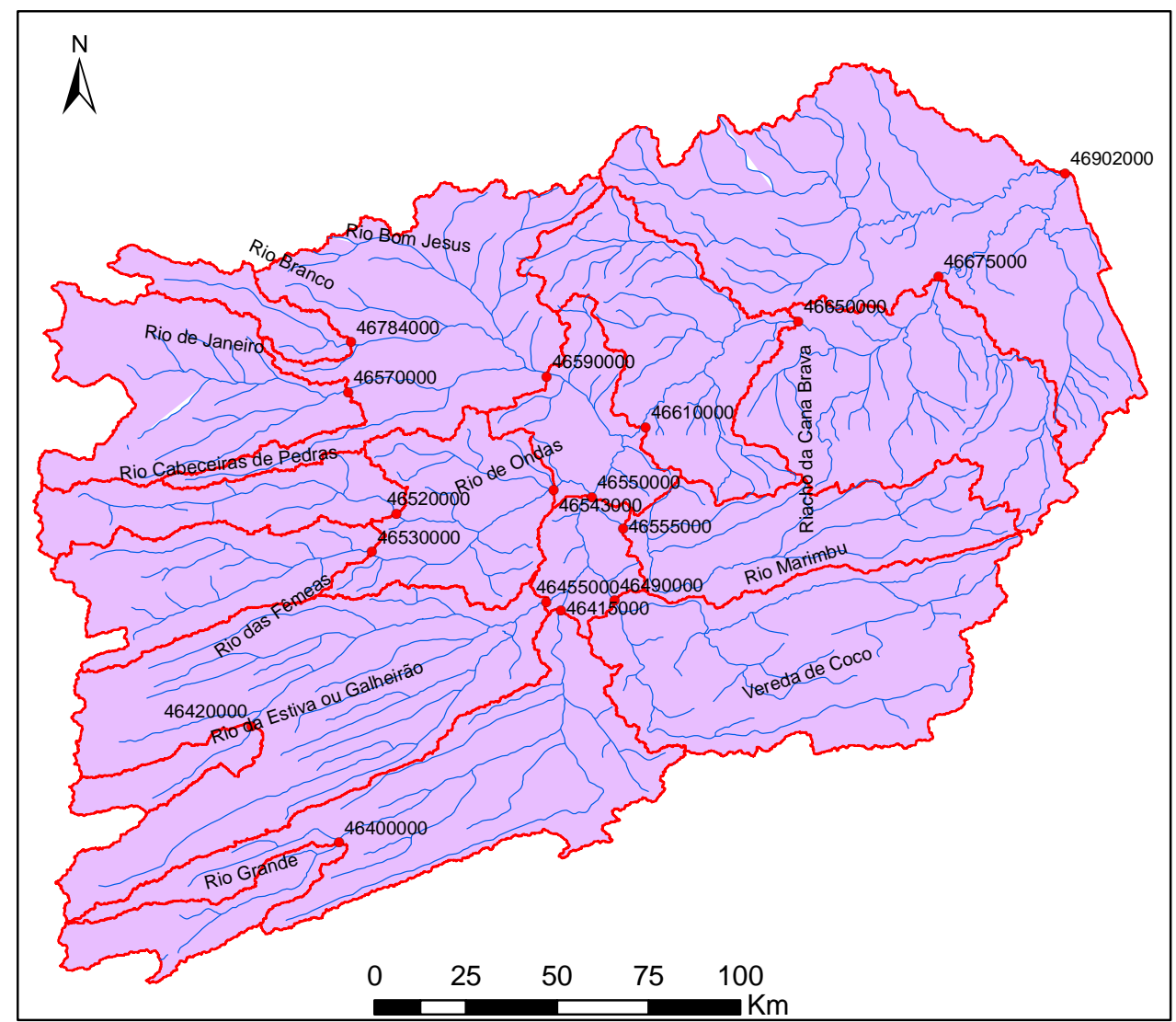

Figura 5.22 - Localização das estações fluviométricas e suas respectivas áreas de drenagem.

\subsection{3 - Dados climáticos}

Quanto aos dados climáticos, foram utilizadas 5 estações meteorológicas operadas pelo Instituto Nacional de Meteorologia - INMET e disponibilizados pela ANA via plataforma Hidroweb, conforme apresentado na tabela 5.6, que estão dispostos conforme indicado na figura 5.23.

Tabela 5.6 - Estações meteorológicas.

\begin{tabular}{c}
\hline Código - Estação Meteorológica \\
\hline 01143005 - Santa Rita de Cássia \\
01144008 - Barra \\
01246003 - Taguatinga \\
01244010 - Barreiras \\
01343018 - Bom Jesus da Lapa \\
\hline
\end{tabular}


Os dados climáticos que são solicitados pelo MGB-IPH são temperatura média diária, umidade relativa do ar, velocidade do vento, pressão atmosférica e horas de insolação, nem todas as estações meteorológicas usadas neste trabalho contam com todos esses dados, e para os dias em que não há dados disponíveis são utilizadas as médias mensais históricas, que fazem parte da base de dados internas do próprio modelo,

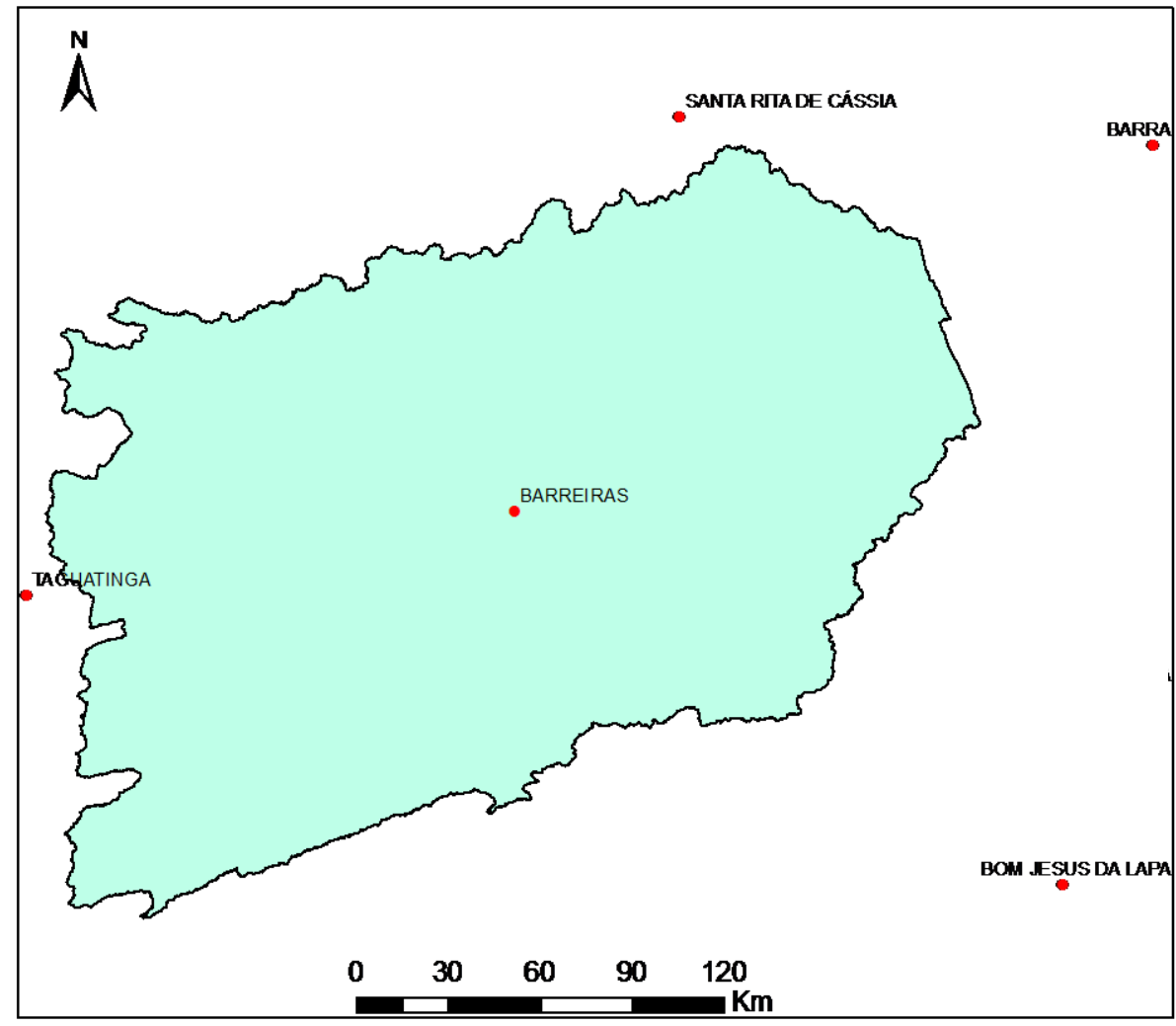

Figura 5.23 - Localização das estações meteorológicas.

As temperaturas médias diárias registradas pelas estações com esses dados apresentaram valores mínimos entre 17,1 e $19,0^{\circ} \mathrm{C}$, enquanto os valores máximos ficam entre 30,5 a $34,1^{\circ} \mathrm{C}$ e as médias entre 24,4 e $26,3^{\circ} \mathrm{C}$, sendo que a estação de Barreiras foi a que apresentou maior amplitude. Quanto às médias mensais, o mês de julho tem os menores valores enquanto os maiores são registrados em outubro, a figura 5.24 apresenta a variação dos dados das temperaturas médias diárias e na figura 5.25 são apresentadas as temperaturas médias mensais.

A umidade relativa do ar das estações tem média variando de 49,2 a 61,0\%, sendo que as estações meteorológicas localizadas mais ao norte tiveram valores menores que as demais, a estação de Barra, que também é a estação mais oriental, tem a menor média. Os meses mais secos são agosto e setembro, enquanto que os meses mais úmidos são entre dezembro 
e março, dependendo da localização da estação meteorológica. As figuras 5.26 e 5.27 apresentam as respectivamente a variação dos dados de umidade relativa e as médias mensais para cada estação.

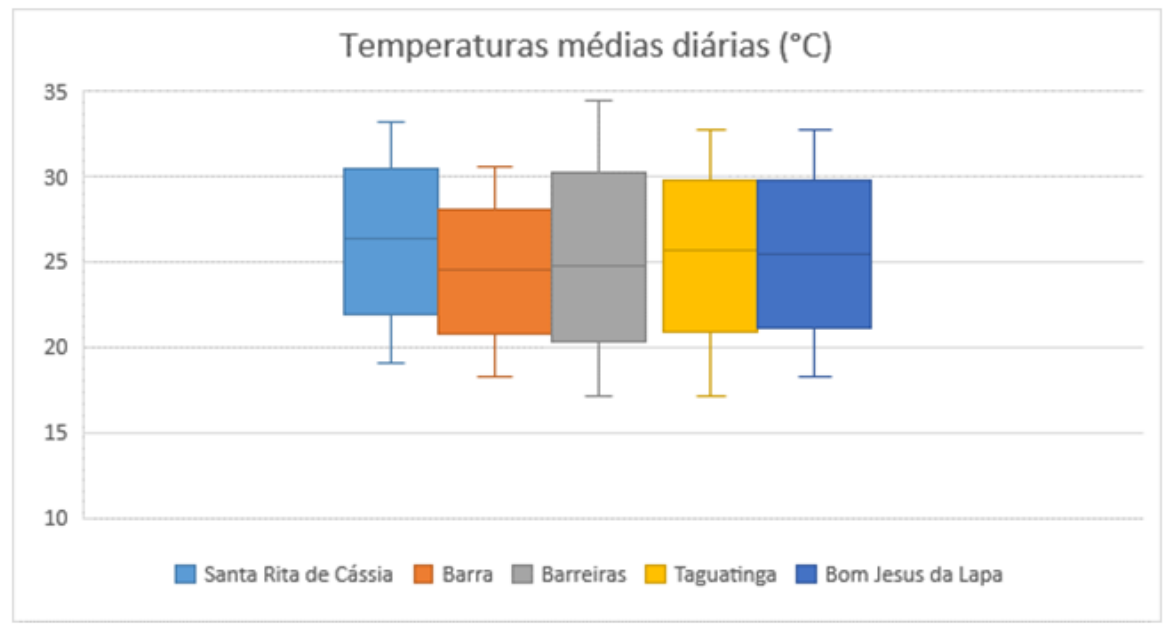

Figura 5.24 - Variação das temperaturas médias diárias do período entre 1969-2005.

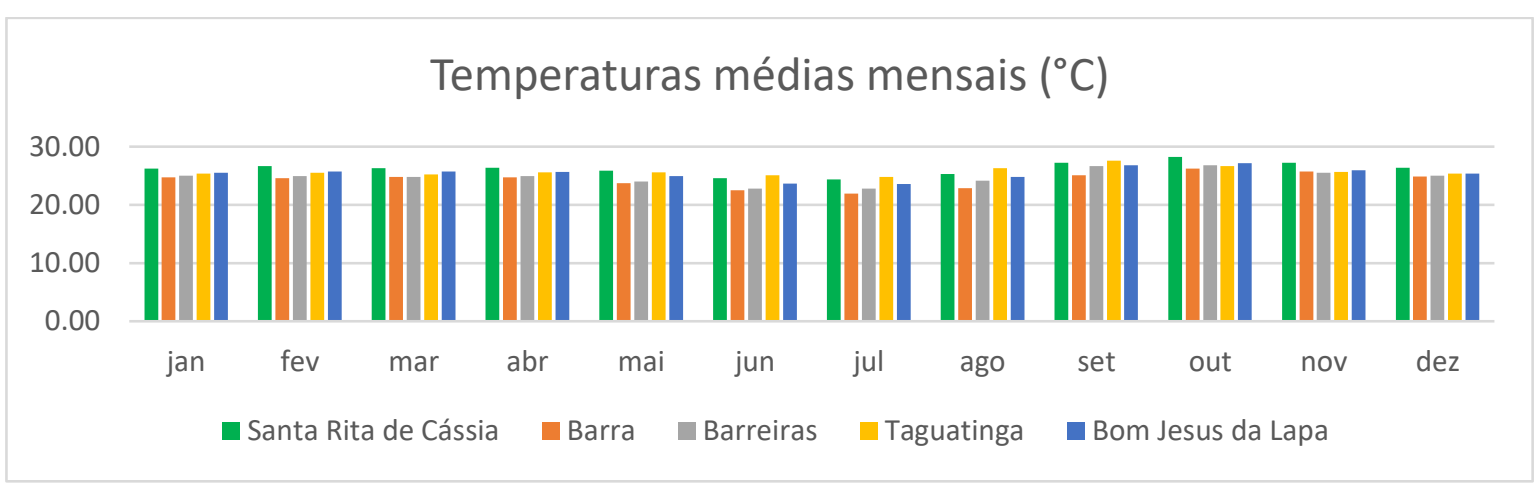

Figura 5.25 - Variação das temperaturas médias mensais do período entre 1969-2005.

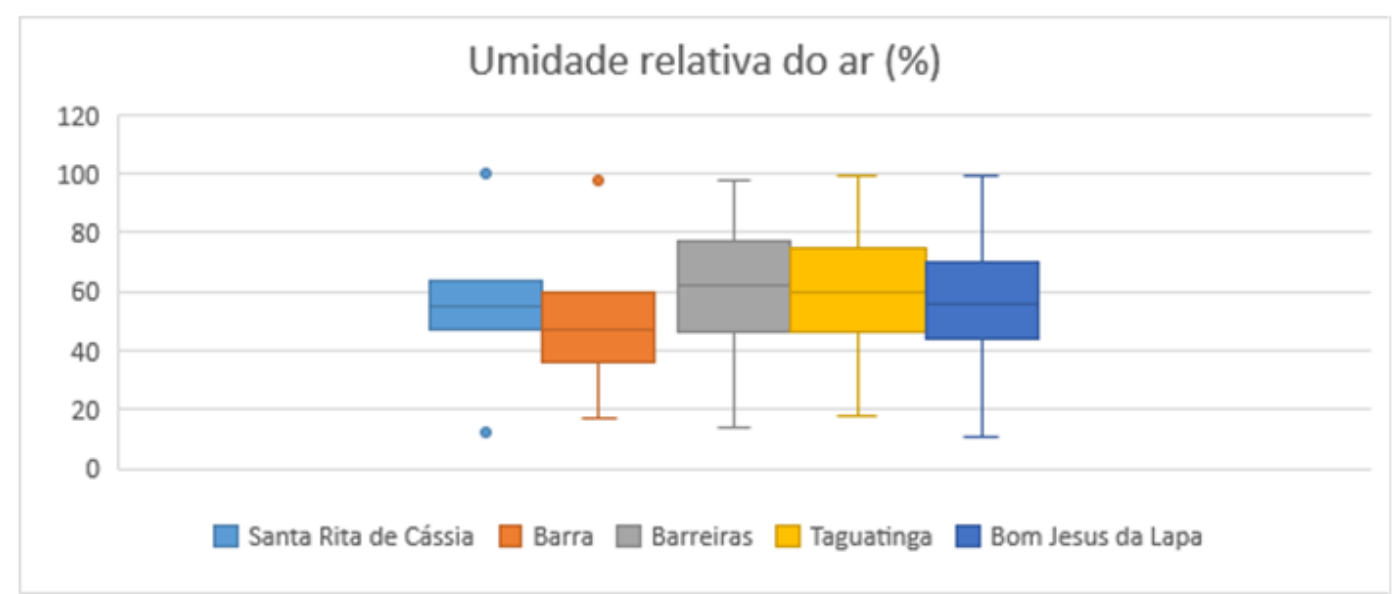

Figura 5.26 - Variação da umidade relativa do ar na área de estudo entre 1969-2005. 


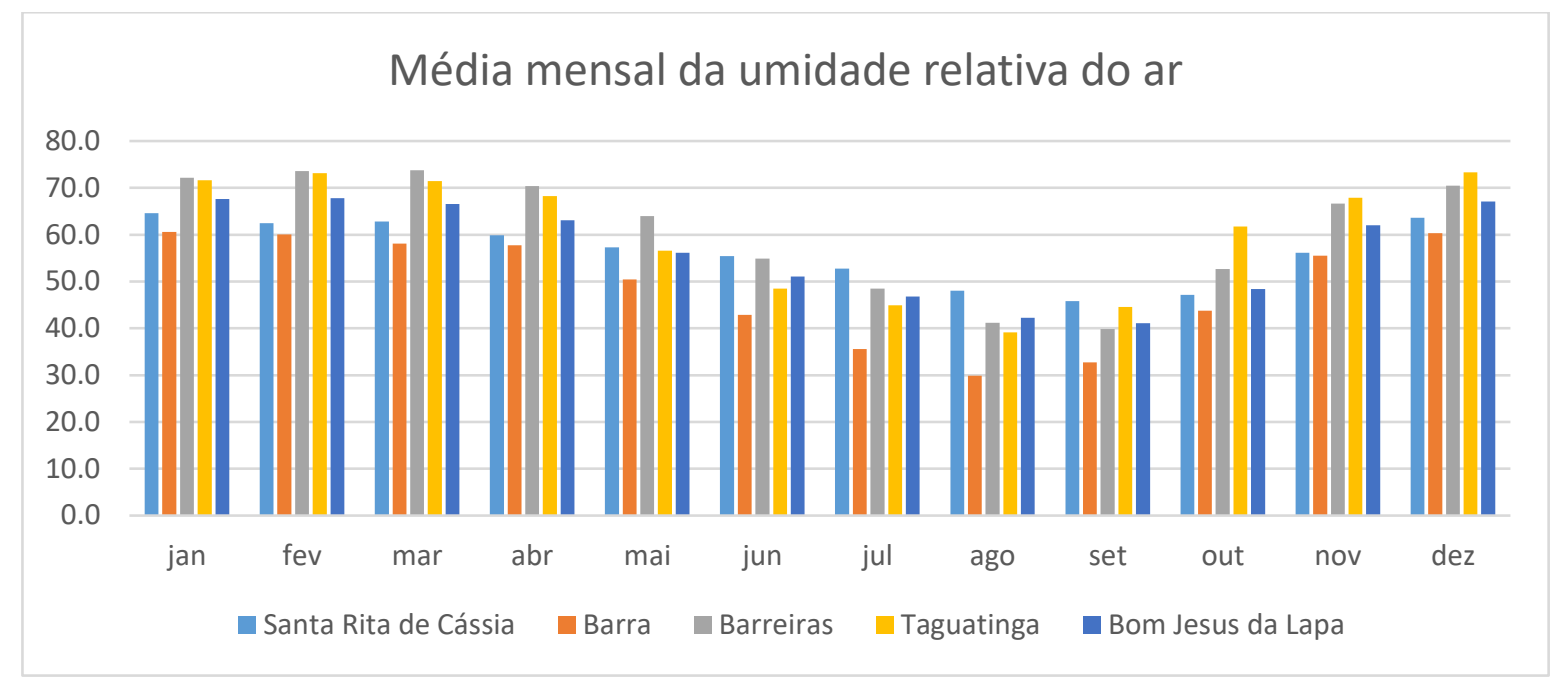

Figura 5.27 - Variação mensal da umidade relativa do ar no período entre 1969-2005.

Os dados de velocidade do vento são escassos nas estações meteorológicas utilizadas neste trabalho, apenas a estação de Taguatinga possui esses dados, ainda assim com muitas falhas, com dados disponíveis em somente $27 \%$ do período estudado, com velocidade do vento diária média de 1,6 m/s, as maiores velocidades ocorrem entre os meses de junho e setembro, nas demais estações é considerado que a velocidade média mensal é de 1,2 $\mathrm{m} / \mathrm{s}$. A figura 5.28 apresenta a variação mensal média da velocidade do vento.

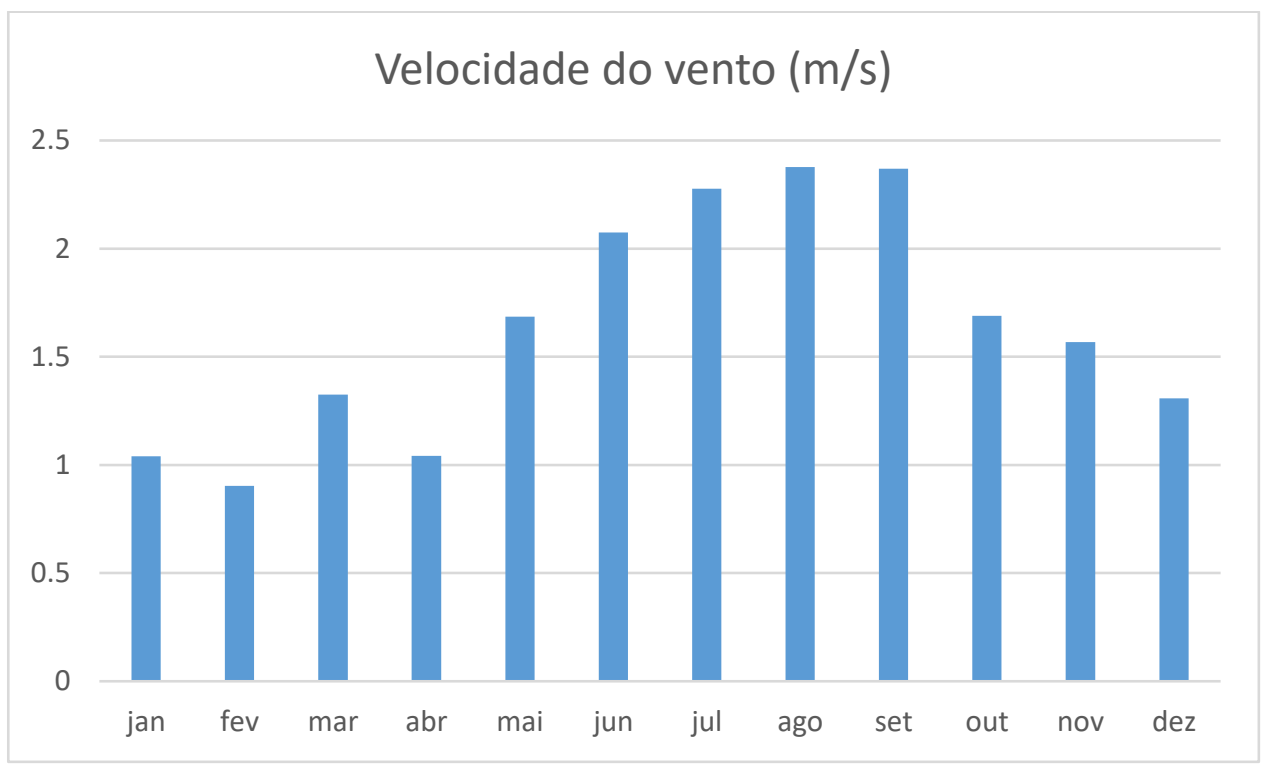

Figura 5.28 - Variação mensal média da velocidade do vento no período entre 1969-2005.

As pressões atmosféricas médias variam de 945,4 e 964,6 kPa, com valores máximos entre 959,7 e 972,8 kPa e mínimo entre 936,7 e 955,6 kPa, a estação de Taguatinga é a que 
registra as menores pressões atmosféricas, enquanto que na estação de Santa Rita de Cássia é que tem os maiores valores. A figura 5.29 apresenta a distribuição dos dados de pressão atmosférica em cada estação meteorológica.

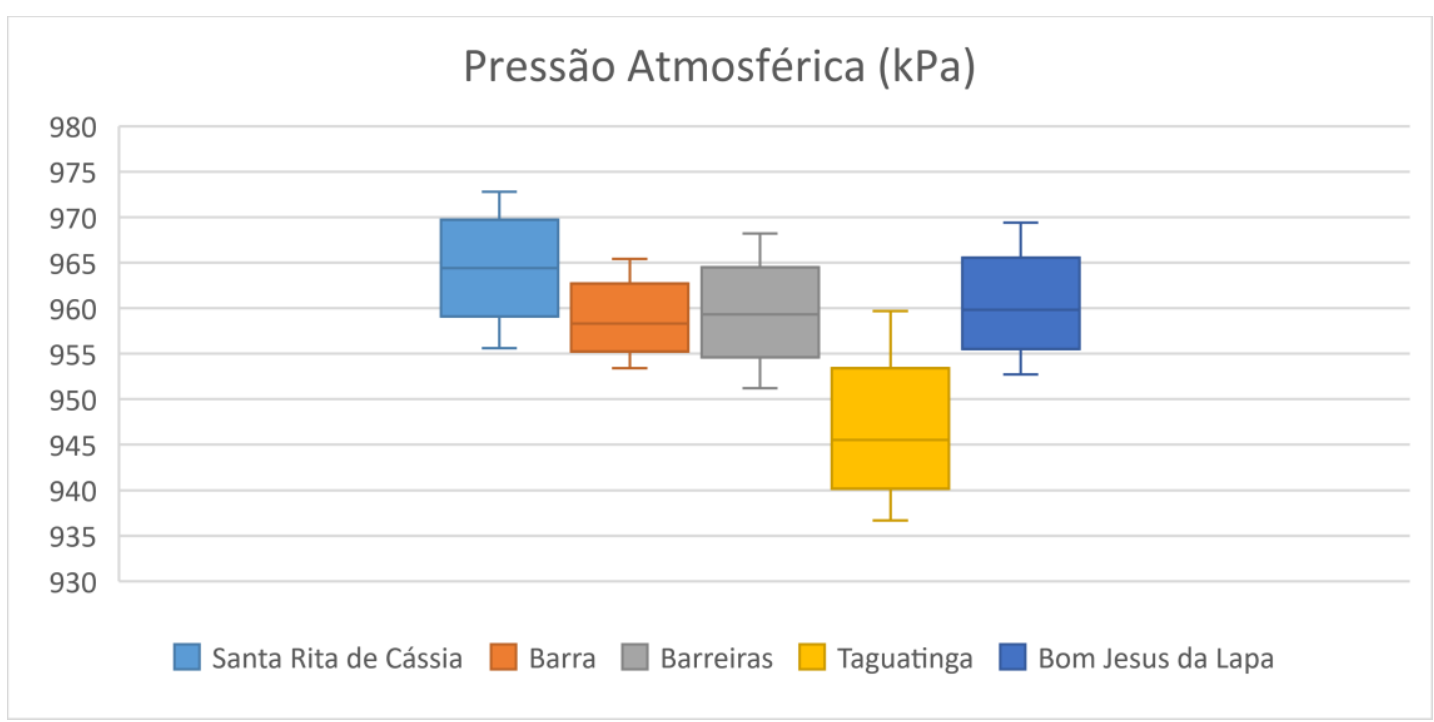

Figura 5.29 - Variação da pressão atmosférica no período entre 1969-2005.

Os dados de insolação demonstram que os meses de julho e agosto são os de maiores valores e fevereiro o menor. A média varia de 6,3 a 8,3 horas de insolação por dia, e os valores máximos a 12,7 horas. A figura 5.30 apresenta a distribuição dos dados em cada estação meteorológica e na figura 5.31 são apresentadas as variações mensais.

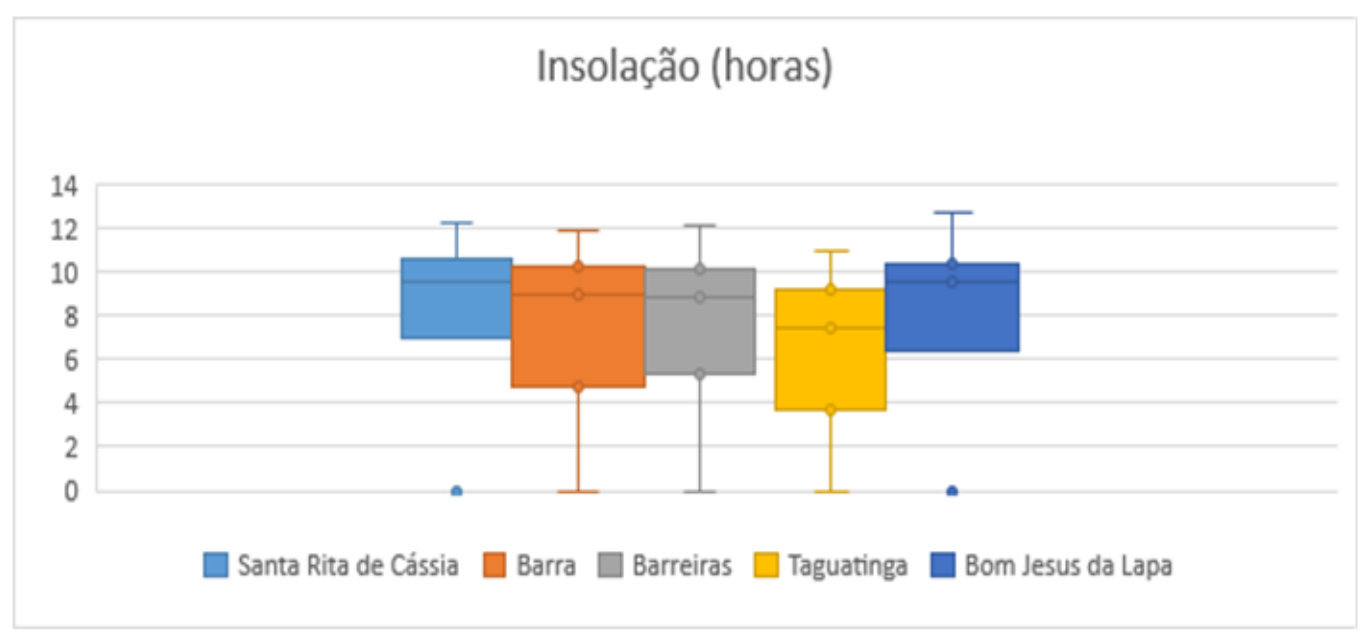

Figura 5.30 - Variação das horas de insolação diárias entre o período de 1969-2005. 


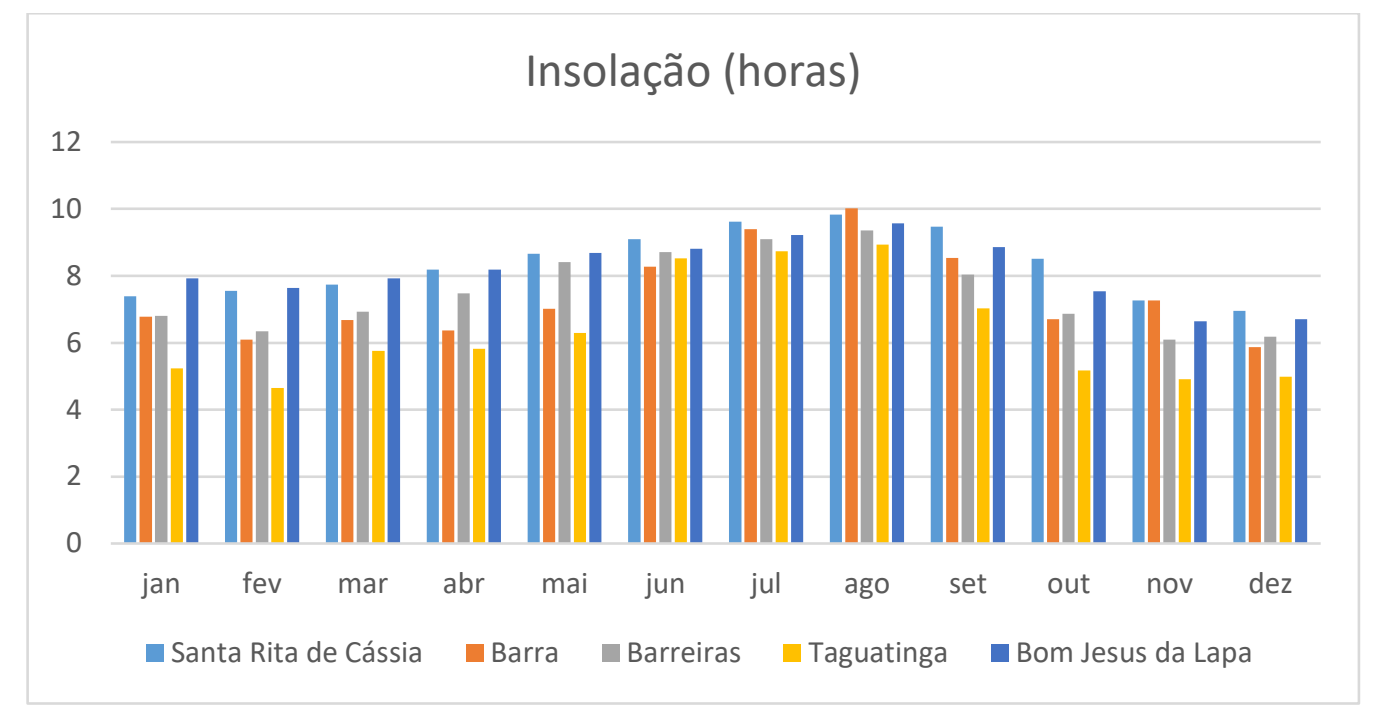

Figura 5.31 - Variação mensal das horas de insolação diária no período entre 1969-2005. 


\section{6 - RESULTADOS}

A área de estudo, como já citado, contém 17 postos fluviométricos, dos quais 11 foram utilizados para a calibração do modelo e foram utilizados para análise das mudanças de vazão por conta das mudanças na cobertura e uso do solo. A seguir serão apresentadas as análises dessas mudanças para as bacias a montante do posto fluviométrico Nova VidaMontante -46590000 e do posto Boqueirão - 46902000 .

A bacia a montante do posto Nova Vida-Montante foi escolhida por ter sido uma das subbacias onde houve uma das maiores mudanças na cobertura e uso do solo durante o período estudado e por ser representativa em relação às bacias a oeste da área de estudo, que é a região onde há maior atividade agrícola. A bacia a montante do posto Boqueirão, por sua vez representa toda a área de estudo.

\section{1 - BACIA A MONTANTE DO POSTO FLUVIOMÉTRICO NOVA VIDA- MONTANTE}

O Posto fluviométrico Nova Vida-Montante fica localizado no Rio Branco e abrange parte dos municípios de Barreiras, Luís Eduardo Magalhães e Riachão das Neves, esta bacia tem uma área de 7.530,8 km². É uma bacia que em 1980 era quase completamente coberta por vegetação natural, com apenas $0,01 \%$ coberta por pastagens e sem a ocorrência de culturas agrícolas. No segundo período de análise, referente à cobertura em 1990 a área com cobertura natural passou para $79,1 \%$, enquanto cultura agrícola passou para $15,8 \%$ e $5,1 \%$ coberta por pastagem, a expansão da agricultura chegou a 40,7\% em 2000. A figura 6.1 apresenta a evolução da cobertura e uso do solo para esta bacia. 


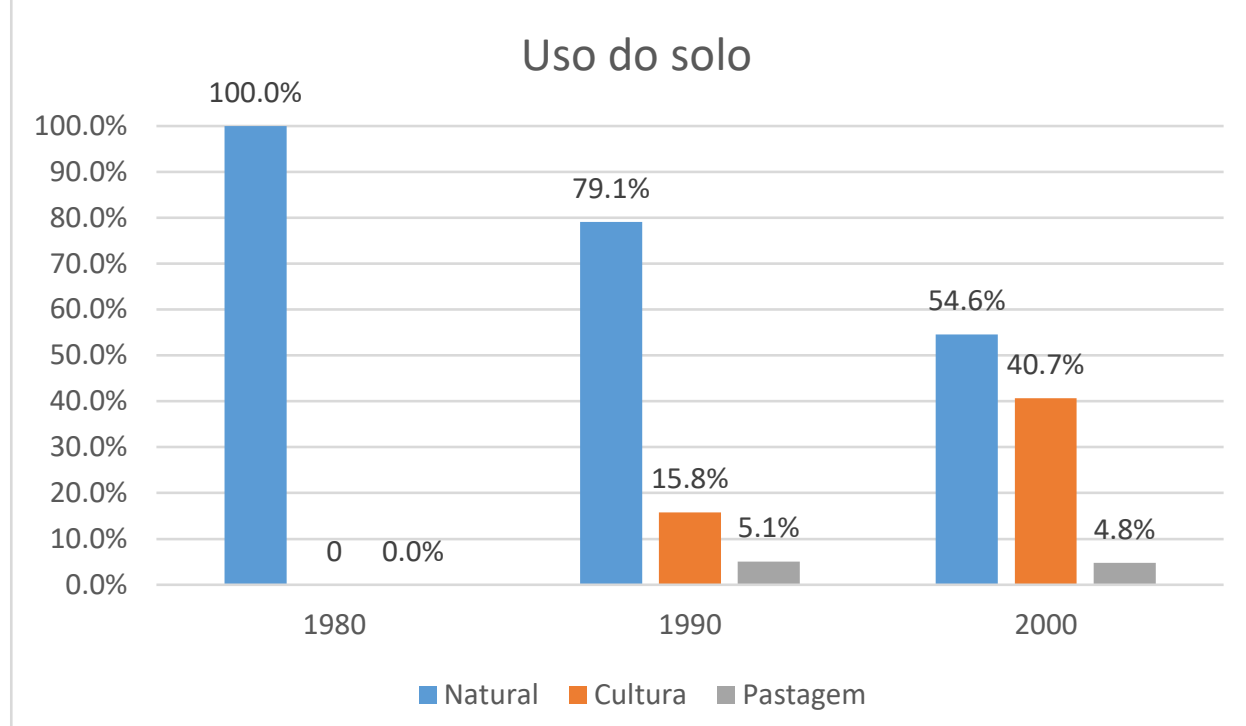

Figura 6.1 - Evolução da cobertura e uso do solo da Bacia a montante do posto fluviométrico Nova Vida -Montante.

\subsection{1 - Calibração do modelo na bacia a montante do posto Nova Vida-Montante}

Para a avaliação das alterações nas vazões em decorrência das mudanças na cobertura e uso do solo, foi realizada a calibração do modelo para situação de cobertura do solo para os períodos P1(1969-1985), P2 (1986-1995) e P3(1996-2005). O desempenho do modelo para cada calibração, considerando as vazões mensais, para cada período são apresentadas na tabela 6.1, onde também são indicados os valores das funções objetivo obtidos nos demais períodos.

Tabela 6.1 - Desempenho do modelo nos períodos calibrado e nos demais períodos na bacia a montante do posto Nova Vida-Montante

\begin{tabular}{ccccc}
\hline & & 1980 & 1990 & 2000 \\
\hline \multirow{2}{*}{ P1 } & $\mathrm{R}^{2}$ & $0,81-0,88^{*}$ & $0,72-0,79$ & $0,65-0,73$ \\
& $\mathrm{R}^{2} \log$ & $0,74-0,84^{*}$ & $0,66-0,76$ & $0,62-0,71$ \\
& $\Delta \mathrm{V}$ & $0,02-0,03^{*}$ & $0,06-0,07$ & $0,08-0,09$ \\
\hline \multirow{2}{*}{$\mathrm{P} 2$} & $\mathrm{R}^{2}$ & $0,84-0,91$ & $0,85-0,89^{*}$ & $0,75-0,84$ \\
& $\mathrm{R}^{2} \log$ & $0,77-0,88$ & $0,84-0,89^{*}$ & $0,75-0,87$ \\
& $\Delta \mathrm{V}$ & $-0,04-0,01$ & $0,01-0,05^{*}$ & $0,03-0,07$ \\
\hline & $\mathrm{R}^{2}$ & $0,75-0,77$ & $0,78-0,80$ & $0,82-0,83^{*}$ \\
$\mathrm{P3}$ & $\mathrm{R}^{2} \log$ & $0,57-0,61$ & $0,75-0,77$ & $0,84-0,85^{*}$ \\
& $\Delta \mathrm{V}$ & $-0,07--0,06$ & $-0,05--0,04$ & $-0,02--0,01^{*}$ \\
\hline
\end{tabular}

* Período calibrado 
Observa-se que o modelo apresentou bons ajustes às calibrações, conforme indicado pelos valores das funções objetivo, no entanto, nos períodos em que não foi realizada a calibração, observa-se que houve dificuldade em representar as vazões mínimas. Nas figuras 6.2. 6.3 e 6.4 são apresentados os 30 melhores hidrogramas para o posto e é possível verificar as diferenças de ajuste entre os períodos calibrados e os demais. Incialmente estas diferenças poderiam ser atribuídas às diferenças na cobertura do solo em cada período, no entanto é necessária a realização de testes estatísticos para confirmar se realmente se trata de mudança real ou apenas de uma variação decorrente das incertezas inerentes ao processo de modelagem, os testes para esta confirmação são apresentados a seguir. 


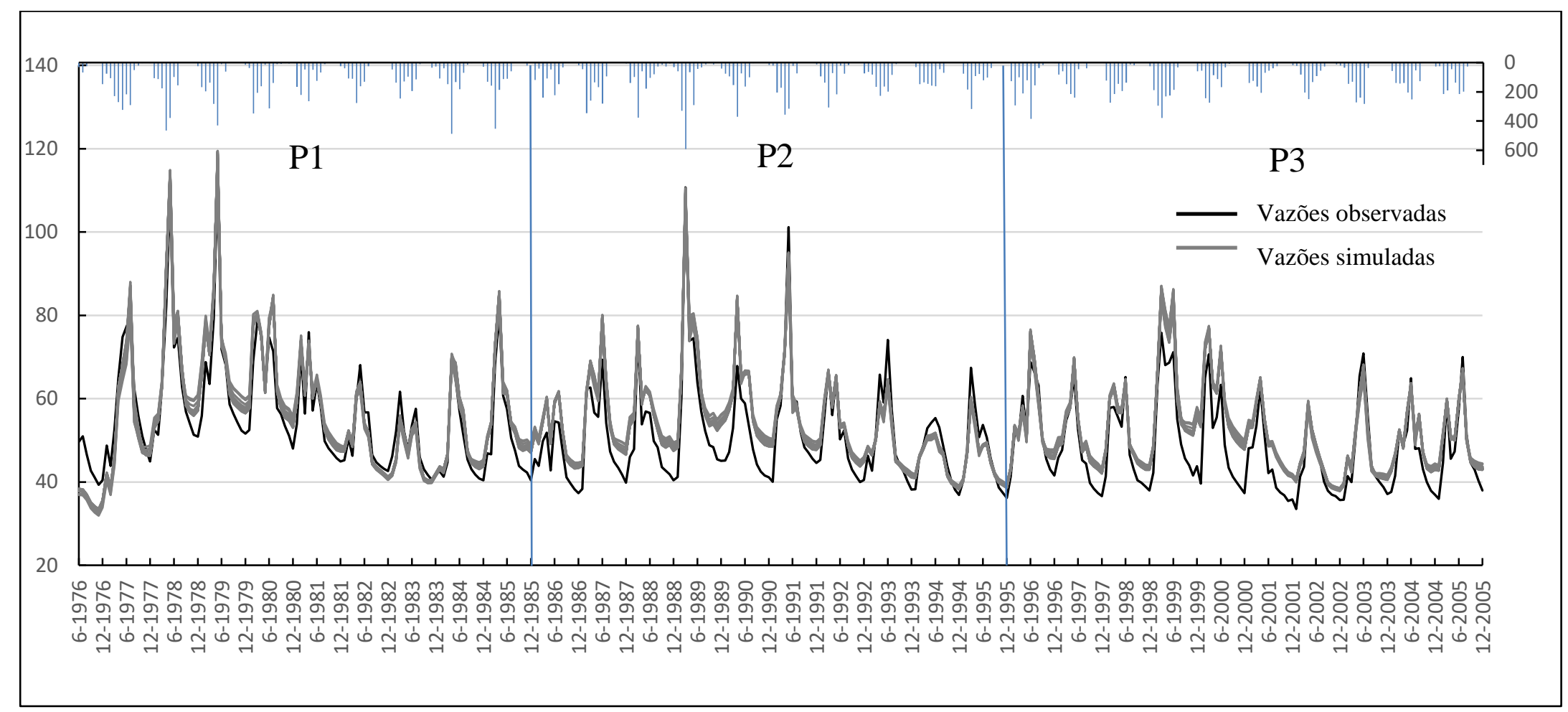

Figura 6.2 - Conjunto dos 30 melhores hidrogramas do posto Nova Vida-Montante - calibração no período entre junho de 1976 e 1985. 


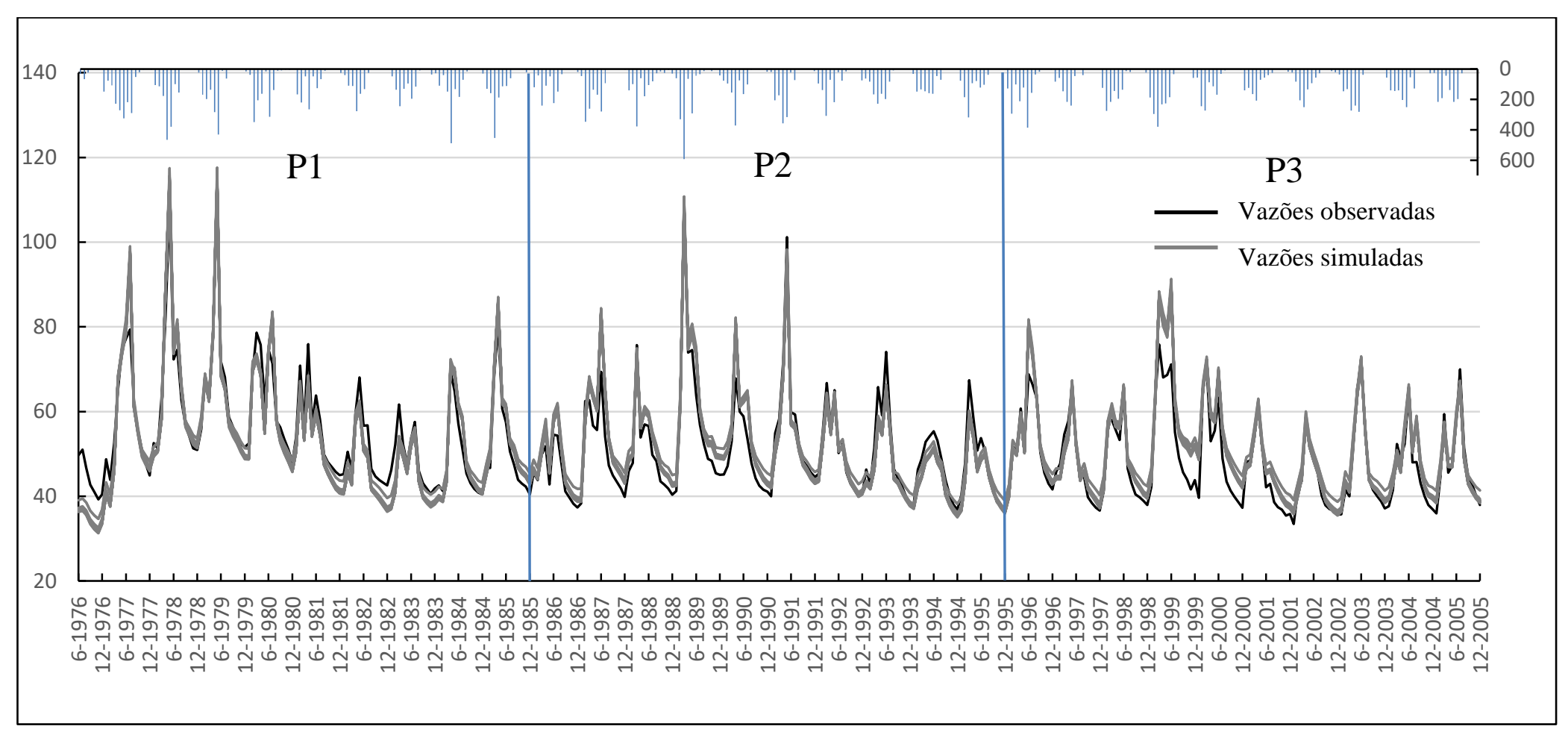

Figura 6.3 - Conjunto dos 30 melhores hidrogramas do posto Nova Vida-Montante - calibração no período entre junho de 1986 e 1995. 


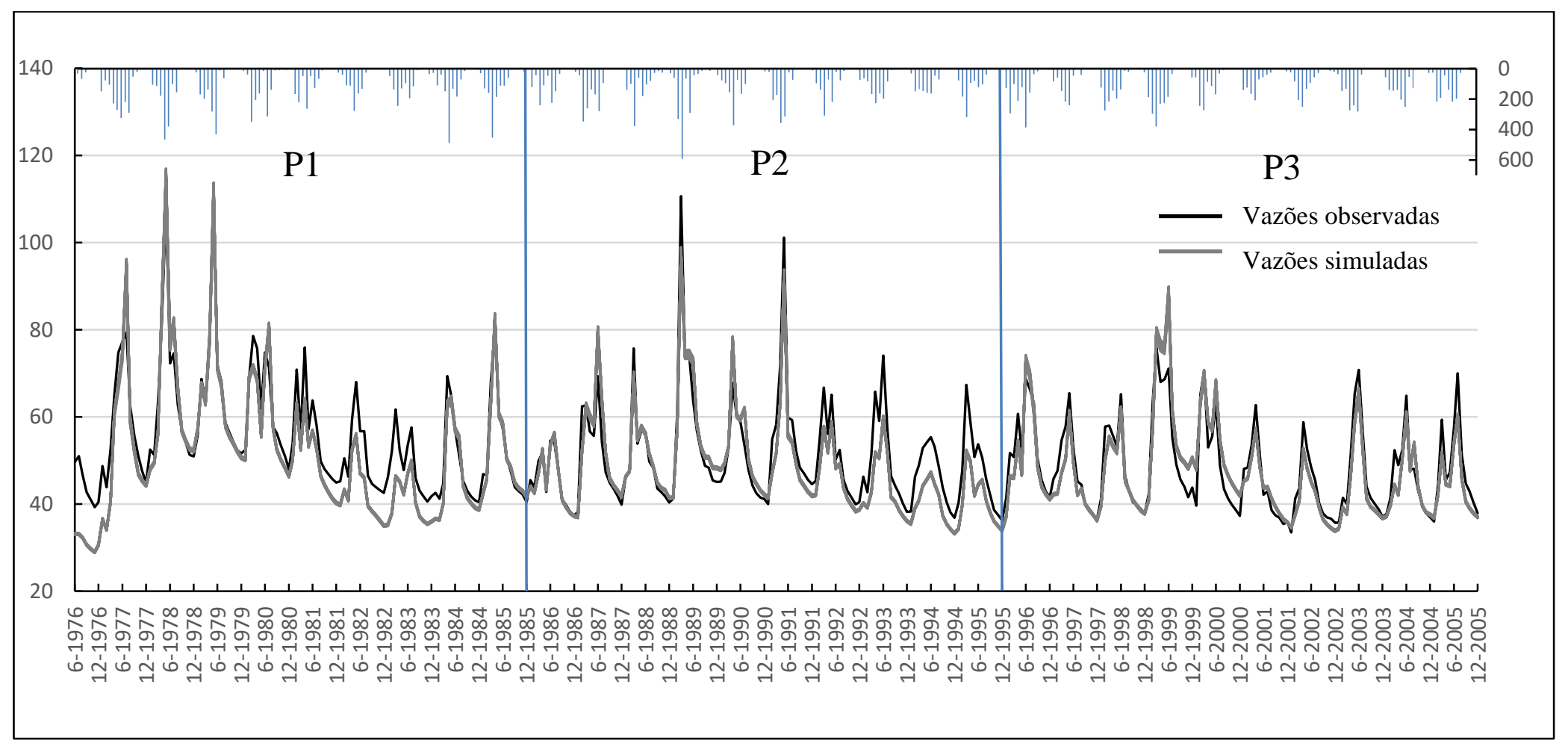

Figura 6.4 - Conjunto dos 30 melhores hidrogramas do posto Nova Vida-Montante - calibração no período entre junho de 1996 e 2005. 


\subsection{2 - Comparação entre as vazões simuladas e as vazões observadas no posto Nova}

Vida - Montante

Tendo em vista as incertezas na estimativa dos parâmetros, a avaliação das mudanças no regime de vazões causadas pelas mudanças na cobertura e uso do solo é realizada pela análise de 30 séries de vazões simuladas, geradas pelos melhores conjuntos de parâmetros obtidos na calibração do período de referência P1.

Considerando as vazões mensais, os resíduos das simulações com a calibração do primeiro período foram em média -0,018 no período P1 e -0,073 e -0,094 nos períodos P2 e P3 respectivamente. Os valores negativos indicam que a vazão sofreu redução por conta das mudanças no uso do solo. A figura 6.5 apresenta os resíduos obtidos em cada período, considerando a calibração realizada no primeiro período como simulação de controle.

\section{Resíduos das vazões no posto Nova Vida-Montante - Mensal}

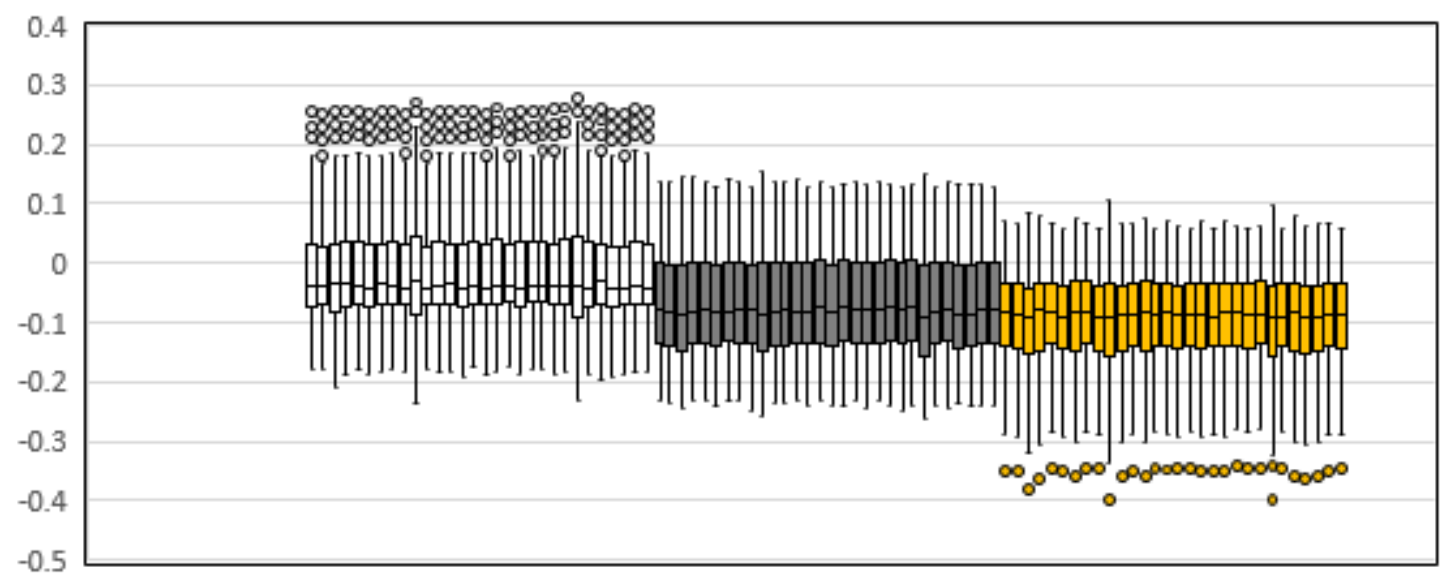

Figura 6.5 - Resíduos das vazões mensais simuladas com os parâmetros obtidos na calibração do primeiro período $-\mathrm{P} 1$.

O teste de Mann-Whitney confirmou, com significância de 5\%, que os resíduos dos períodos P2 e P3 são estatisticamente diferentes dos resíduos do P1, o que indica que houveram mudanças nas vazões e, considerando que as condições climáticas são as mesmas, estas mudanças são por conta das mudanças na cobertura e uso do solo. Como apresentado no item 4.1.1, o teste também foi realizado com os resíduos do mesmo período e foi constatado que dentro do mesmo período não há mudanças, o que confirma a capacidade do modelo em detectar que os as mudanças na cobertura e uso do solo causaram mudanças nas vazões mensais do Rio Branco. 
Na tabela 6.2 são apresentados os valores das medianas e dos percentis de 10 e $90 \%$ dos resíduos obtidos em cada período, também são apresentadas as mesmas estatísticas dos valores de $\mathrm{p}$, que foram obtidos do teste de Mann-Whitney e que representam como os resíduos de cada período são mais semelhantes ou mais diferentes que os resíduos do período de referência. Quanto maior o valor de p, mais semelhantes são as amostras, de forma que se este valor for superior a 0,05 , já não se pode afirmar com significância de $5 \%$, que as duas amostras são diferentes.

Tabela 6.2 - Valores das medianas e dos percentis de 10 e $90 \%$ dos resíduos e dos valores de p das vazões mensais no posto Nova Vida-Montante.

\begin{tabular}{ccccccc}
\hline & & & & P2 & & P3 \\
\hline & mediana & $\begin{array}{c}\text { percentis } \\
(10-90 \%)\end{array}$ & mediana & $\begin{array}{c}\text { percentis } \\
(10-90 \%)\end{array}$ & mediana & $\begin{array}{c}\text { percentis } \\
(10-90 \%)\end{array}$ \\
\hline Resíduos & $-0,039$ & $-0,113-0,112$ & $-0,080$ & $-0,179-0,051$ & $-0,087$ & $-0,200-0,011$ \\
p & & & $1,7 \times 10^{-5}$ & $(0,97-3,1) \times 10^{-5}$ & $1,1 \times 10^{-8}$ & $(0,45-2,9) \times 10^{-8}$ \\
\hline
\end{tabular}

Observa-se no período P1 que a mediana dos resíduos das vazões mensais é próxima a zero e oscila igualmente, em torno de $11 \%$ maior ou menor que a vazão observada. No período P2, os resíduos são menores que em P1 e os valores de p confirmam a diferença entre os dois períodos e no período P3 os resíduos são ainda menores, indicando maior efeito das mudanças no uso do solo sobre as vazões mensais.

Embora as diferenças entre os valores dos resíduos dos períodos P2 e P3 não seja tão acentuada, os valores de p demonstram que essa diferença se torna mais consistente no período P3, quando as alterações no uso do solo foram mais intensas. A grande variabilidade dos valores de p revela a importância de estar se considerando as incertezas paramétricas com a utilização de vários conjuntos de parâmetros para realizar a análise dos efeitos das mudanças na cobertura e uso do solo sobre o regime de vazões.

Em relação às vazões médias anuais, os resíduos das simulações com a calibração do primeiro período foram em média - 0,029 no período calibrado, no período P2 o valor médio dos resíduos foi - 0,063 e - 0,083 no período P3, os valores são ligeiramente menores que os verificados em relação às médias mensais. A figura 6.6 apresenta os resíduos obtidos em cada período, considerando a calibração realizada no primeiro período como simulação de controle. 


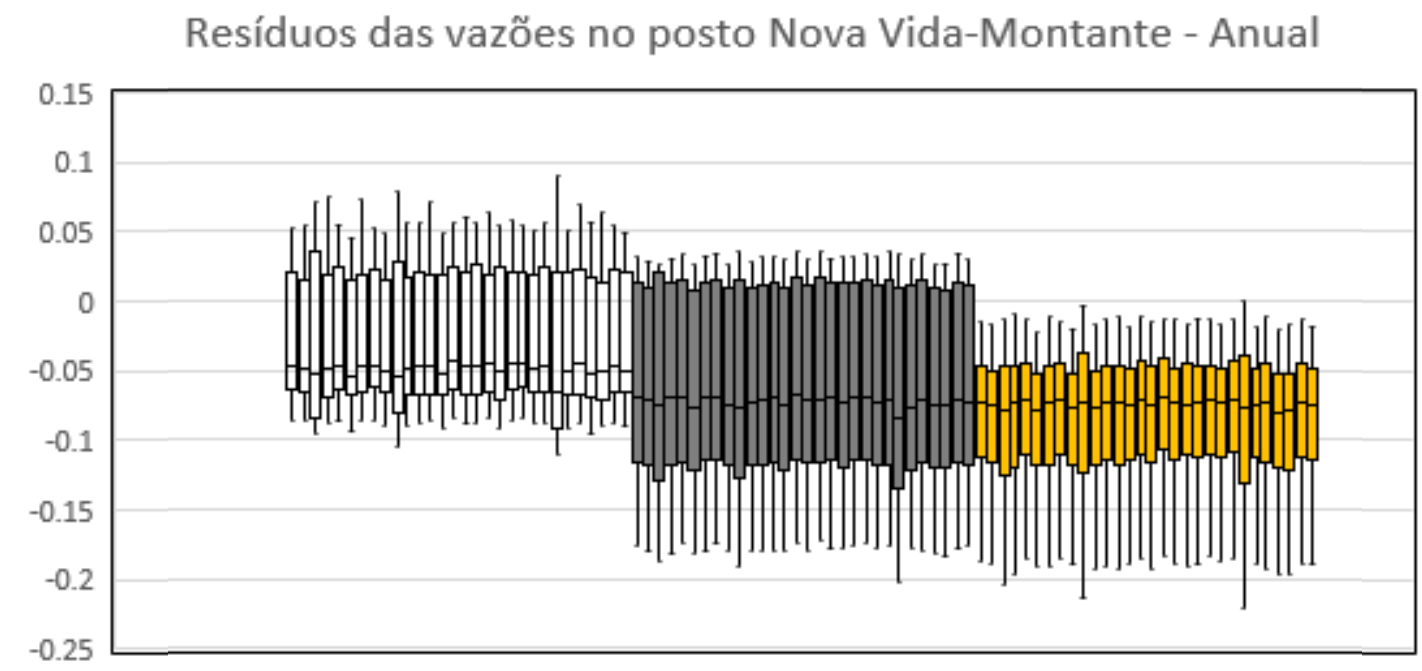

Figura 6.6 - Resíduos das médias anuais das vazões simuladas com os parâmetros obtidos na calibração do primeiro período-P1.

Observa-se que as variações dos resíduos dos 3 períodos se superpõem, o que não permite descartar a hipótese de que as variações observadas são apenas decorrentes das incertezas do modelo, portanto, não é possível afirmar que as variações das vazões ocorreram por conta das mudanças no uso da terra. Os testes estatísticos realizados para todos os períodos indicaram que não houve mudança significativa nas vazões $(p \geq 0,05)$. A tabela 6.3 apresenta as medianas e os percentis (10 e 90 \%) dos resíduos das vazões médias anuais e dos valores de $\mathrm{p}$ obtidos do teste de Mann-Whitney.

Tabela 6.3 - Valores das medianas e dos percentis de 10 e 90\% dos resíduos e dos valores de p das vazões médias anuais no posto Nova Vida-Montante.

\begin{tabular}{ccccccc}
\hline & \multicolumn{2}{c}{ P1 } & & P2 & & P3 \\
\hline & mediana & $\begin{array}{c}\text { percentis } \\
(10-90 \%)\end{array}$ & mediana & $\begin{array}{c}\text { percentis } \\
(10-90 \%)\end{array}$ & mediana & $\begin{array}{c}\text { percentis } \\
(10-90 \%)\end{array}$ \\
\hline Resíduos & $-0,048$ & $-0,087-0,054$ & $-0,076$ & $-0,144-0,028$ & $-0,073$ & $-0,164--0,019$ \\
$\mathrm{p}$ & & & 0,28 & $0,28-0,32$ & 0,15 & $0,13-0,18$ \\
\hline
\end{tabular}

Os resíduos das vazões mínimas anuais, para o período de calibração foi em média -0,06 e apresentou uma variação maior que a dos demais períodos com valor mínimo de $-0,28$ e máximo de 0,18 , enquanto os demais períodos tiveram valores médios menores -0,16 e 0,17 respectivamente para P1 e P2. A figura 6.7 apresenta os resíduos das vazões mínimas de todas as simulações em todos os períodos baseados na calibração com condições de uso do solo de 1980. 


\section{Resíduos das vazões mínimas no posto Nova Vida-Montante}

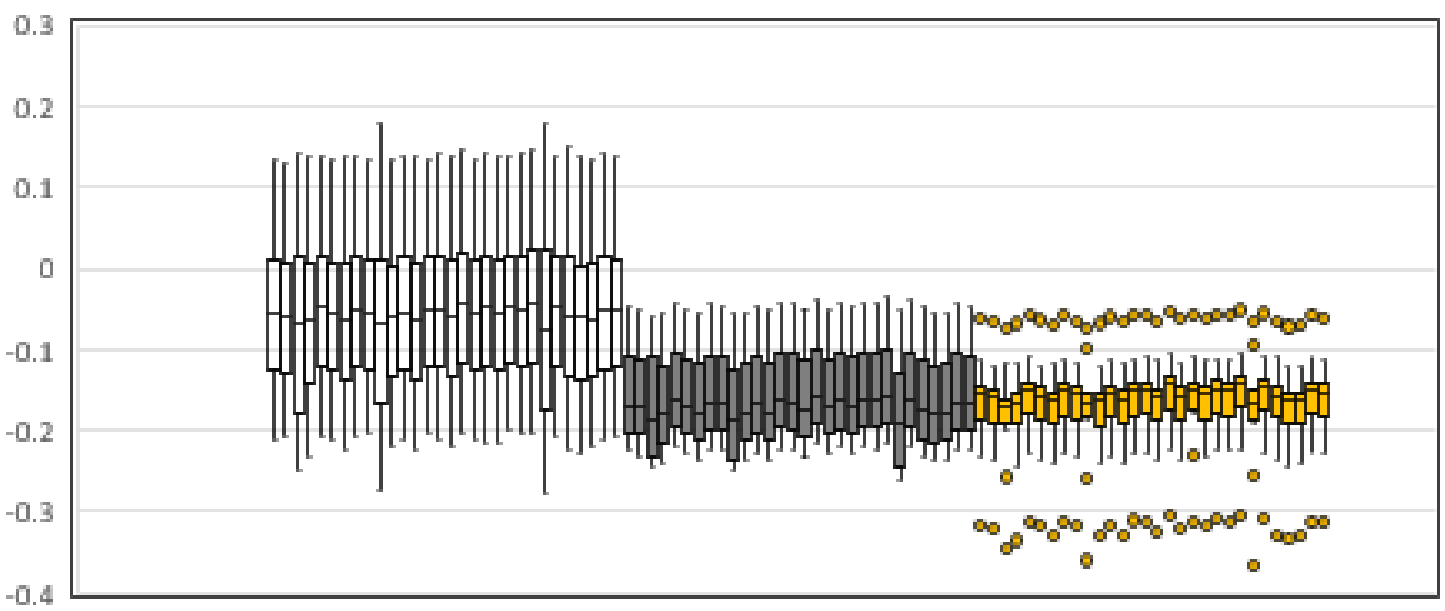

Figura 6.7 - Resíduos das vazões mínimas simuladas com os parâmetros obtidos na calibração do primeiro período-P1

Os resíduos com valores negativos indicam que as vazões mínimas diminuíram em consequência das mudanças do uso do solo na bacia, no entanto a grande variação nos resíduos do período de referência implicaram que em 4 das 30 simulações o teste estatístico não indicou alterações das vazões para o período P2 e no período P3 uma das simulações apresentou resultado semelhante $(p \geq 0,05)$. A tabela 6.4 apresenta as medianas e os percentis (10 e 90\%) dos valores dos resíduos e dos valores de p obtidos pelo teste de Mann-Whitney.

Tabela 6.4 - Valores das medianas e dos percentis de 10 e $90 \%$ dos resíduos e dos valores de p das vazões mínimas no posto Nova Vida-Montante.

\begin{tabular}{ccccccc}
\hline & & P1 & & P2 & & P3 \\
\hline & mediana & $\begin{array}{c}\text { percentis } \\
(10-90 \%)\end{array}$ & mediana & $\begin{array}{c}\text { percentis } \\
(10-90 \%)\end{array}$ & mediana & $\begin{array}{c}\text { percentis } \\
(10-90 \%)\end{array}$ \\
\hline Resíduos & $-0,05$ & $-0,20-0,133$ & $-0,170$ & $-0,226--0,067$ & $-0,158$ & $-0,263--0,093$ \\
$\mathrm{p}$ & & & 0,035 & $0,035-0,054$ & 0,028 & $0,028-0,035$ \\
\hline
\end{tabular}

Observa-se que no período $\mathrm{P} 2$, o valor de p do percentil de $90 \%$ é um pouco superior ao limiar de aceitabilidade da ocorrência de mudanças nas vazões mínimas, o que pode ser atribuído à variabilidade dos resíduos das vazões mínimas no período P1, que faz com que alguns elementos da amostra referência se confundam com os da amostra comparada. Embora a distribuição dos resíduos do período de referência seja aproximadamente simétrica em torno de zero, a diferença entre os percentis de 10 e $90 \%$ é a maior dos 3 períodos analisados, o que causou este efeito até no período P3 em que uma das 
comparações, entre as 30, não constatou mudanças, mas nesse período o percentil de $90 \%$ dos valores de $\mathrm{p}$ ainda aponta que as mudanças nas vazões mínimas são estatísticamente significativas.

A variabilidade dos valores dos resíduos e os diferentes valores de p obtidos do no teste de Mann-Whitney em cada análise reforçam a importância de se considerar as incertezas do modelo para evitar se chegue a conclusões equivocadas sobre os efeitos das mudanças na cobertura e uso do solo sobre o regime de vazões.

Analisando as variações das vazões médias mensais, anuais e mínimas da bacia a montante do posto Nova Vida-Montante, verifica-se que houve redução das vazões em consequência das mudanças ocorridas na cobertura e uso do solo, com excessão das vazões médias anuais que não apresentaram cofirmação estatística. Trata-se de uma resultado divergente dos apresentados em bacias experimentais, onde a substituição das florestas por pasatagens e culturas agrícolas causam o aumentos das vazões (Bosch e Hewlett, 1982), no entanto é um resultado semelhante ao obtido por Caram (2010) na bacia do Rio Piracicaba em São Paulo, onde a vegetação natural também era o cerrado.

Cabe ressaltar, que a análise realizada neste trabalho parte da premissa de que as diferenças entre as vazões simuladas o observadas nos períodos posteriores às alterações no uso do solo, considerando-se as mesmas condições hidrometeorológicas, são causadas pelas mudanças na cobertura e uso do solo, no entanto, há a possibilidade de essas mudanças também ter sido causadas pelo aumento do consumo de água pela irrigação das culturas agrícolas, que tem aumentado com o passar dos anos, como apresentado no item 5.1.3.

\subsection{3- Comparação dos parâmetros da bacia a montante do posto Nova Vida- Montante}

A comparação dos parâmetros obtidos em cada calibração foi realizada para detectar mudanças na hidrologia da bacia em complemento à comparação dos resíduos entre as vazões observadas e simuladas. As figuras 6.8 e 6.9 apresentam a variabilidade dos parâmetros para cada URH em cada período de calibração e os valores de referência recomendados nos manuais do modelo. 


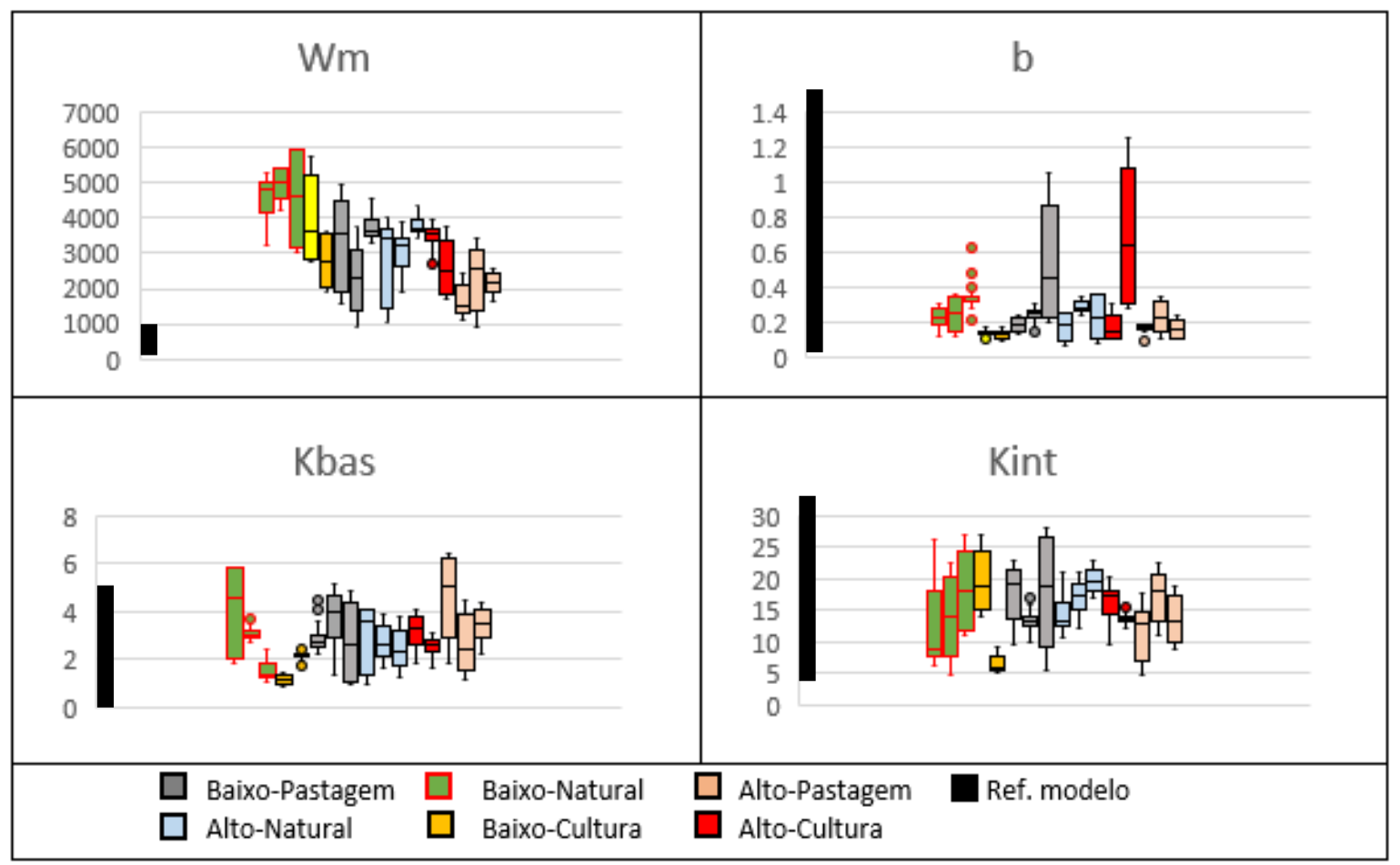

Figura 6.8 - Variabilidade de parâmetros Wm, b, Kbas e Kint obtidos nas calibrações de P1, P2 e P3, que se apresentam agrupados em cada URH.

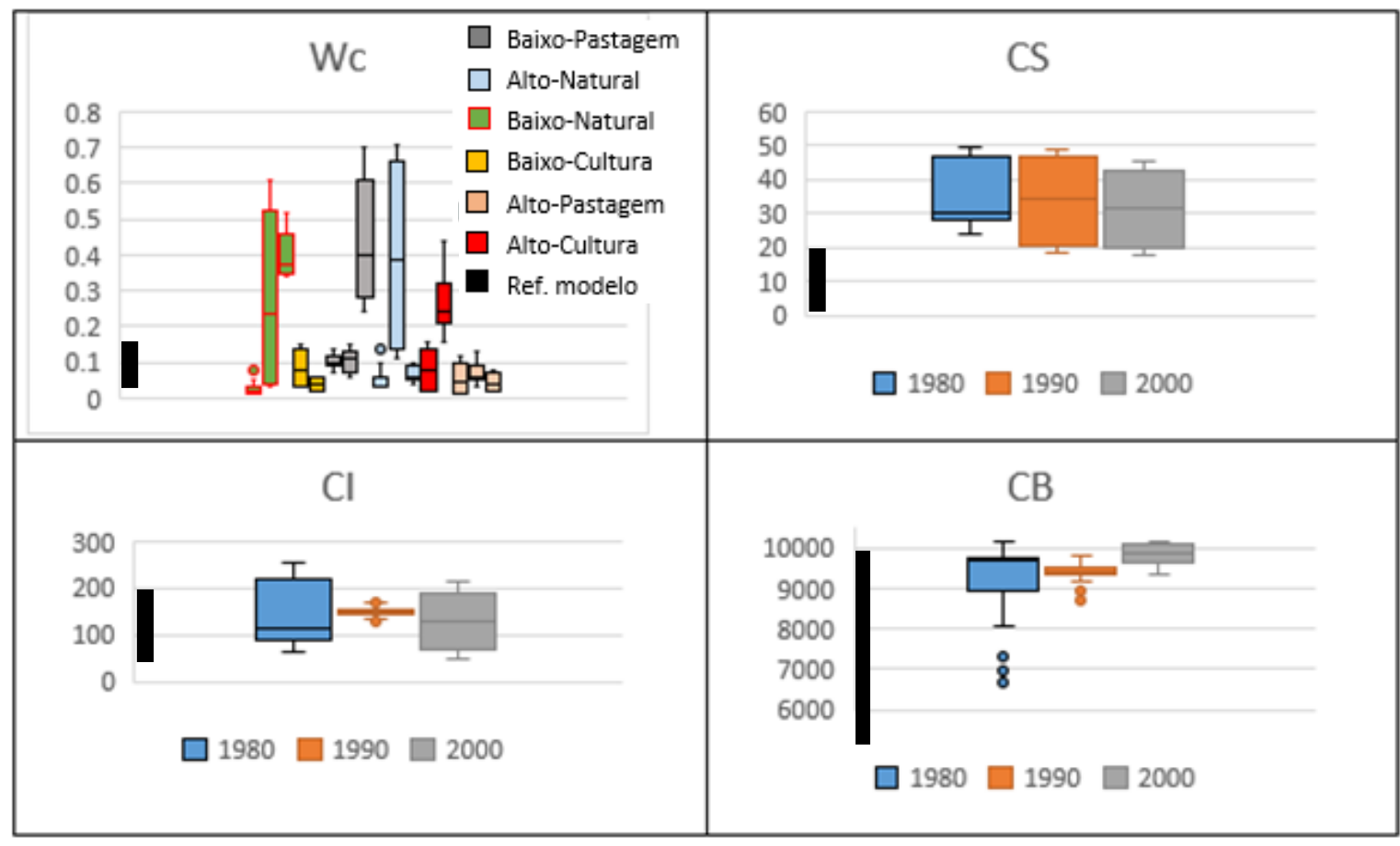

Figura 6.9 - Variabilidade de parâmetros Wc, CS, CI e CB obtidos nas calibrações de P1, P2 e P3, que se apresentam agrupados em cada URH.

O parâmetro referente à capacidade máxima de armazenamento da água do solo $\mathrm{Wm}$, apresentou valores bem superiores à faixa padrão recomendada no manual do modelo, que 
é de 50 a $1000 \mathrm{~mm}$, esta situação em parte é justificável pelas características físicas da região, que possuem solos muito profundos e de alta condutividade (Moreira e Silva, 2010), também merecendo destaque os parâmetros referentes aos tempos de retardo da bacia, CS, CI e CB. Valores para esses parâmetros, com ordem de grandeza diferentes das recomendadas pelo modelo, foram obtidos para diversas sub-bacias da Bacia do Rio São Francisco conforme apresentado no estudo de Silva (2005).

$\mathrm{Na}$ tabela 6.5 apresenta os resultados do teste de Mann-Whitney comparando os parâmetros obtidos na calibração de cada período. Na tabela, o sinal “+” indica que foi detectada mudança dos valores dos parâmetros, o sinal “_” indica que não se pode afirmar que houve mudança. Na coluna P1-P1, é apresentada a comparação dos parâmetros do mesmo período e o símbolo + indica que houve um resultado falso positivo para detecção de mudança.

Tabela 6.5 - Resultados do teste de Mann-Whitney para a comparação dos parâmetros obtidos na calibração de cada período na bacia a montante do posto Nova Vida-Montante.

\begin{tabular}{|c|c|c|c|c|}
\hline URH & Parâmetro & P1-P1 & $\mathrm{P} 1-\mathrm{P} 2$ & P1-P3 \\
\hline \multirow{5}{*}{ Alto Natural } & $\mathrm{Wm}$ & - & + & + \\
\hline & $\mathrm{b}$ & + & + & + \\
\hline & Kbas & - & + & + \\
\hline & Kint & - & + & + \\
\hline & $\mathrm{Wc}$ & - & + & - \\
\hline \multirow{5}{*}{ Alto-Pastagem } & $\mathrm{Wm}$ & + & + & + \\
\hline & $\mathrm{b}$ & - & - & + \\
\hline & Kbas & - & - & + \\
\hline & Kint & - & + & + \\
\hline & $\mathrm{Wc}$ & - & - & + \\
\hline \multirow{5}{*}{ Baixo-Natural } & $\mathrm{Wm}$ & - & - & + \\
\hline & $\mathrm{b}$ & + & + & + \\
\hline & Kbas & - & + & - \\
\hline & Kint & + & + & + \\
\hline & $\mathrm{Wc}$ & - & + & - \\
\hline \multirow{8}{*}{ Baixo-Pastagem } & $\mathrm{Wm}$ & + & - & - \\
\hline & $\mathrm{b}$ & - & + & - \\
\hline & Kbas & - & + & - \\
\hline & Kint & - & + & + \\
\hline & $\mathrm{Wc}$ & - & - & - \\
\hline & $\mathrm{CS}$ & + & + & + \\
\hline & CI & - & - & + \\
\hline & $\mathrm{CB}$ & - & + & + \\
\hline
\end{tabular}


Na comparação dos valores dos parâmetros obtidos pelas calibrações de cada período, por conta da grande variabilidade, os resultados do teste estatístico não apresentaram um padrão suficiente para se chegar a uma conclusão sobre se as mudanças dos valores dos parâmetros são devidas às mudanças no uso do solo. O teste foi realizado comparando os conjuntos de parâmetros de cada período e também foi realizada a comparação entre os parâmetros de uma mesma calibração, que na tabela 6.6 corresponde à coluna de P1-P1, o sinal "+" apresentado nesta coluna indica que foi detectada mudança no valor do parâmetro, tendo em vista que os valores analisados nesta coluna são do mesmo período, esses valores indicam que as considerações devem ser tomadas com cautela, sob o risco da ocorrência de falsos-positivos para a detecção de mudanças. Esta dificuldade em detectar mudanças dos parâmetros devidas às mudanças na cobertura e uso do solo também foi encontrada por Gebrehiowt et al. (2013) que utilizaram esta mesma metodologia com o modelo HBV na bacia do Rio Nilo Azul na Etiópia.

As mudanças nos valores dos parâmetros são mais acentuadas que as mudanças das vazões, como pode-se ver na comparação dos hidrogramas, o que se deve à complexidade das inter-relações entre os parâmetros, que permite que diferentes conjuntos de parâmetros associados a diferentes estruturas de modelo apresentem respostas equivalentes, o que caracteriza o conceito de equifinalidade (Beven e Freer, 2001).

\subsection{4 - Comparação entre as simulações com diferentes conjuntos de parâmetros da bacia a montante do posto Nova Vida-Montante}

Como visto acima, a comparação entre os valores de cada parâmetro é muito complexa e de difícil compreensão, por isso mais interessante do que as diferenças nos valores dos parâmetros individuais, são as implicações das mudanças das respostas da bacia a diferentes conjuntos de parâmetros combinados (Seibert et al., 2010). Para comparar as respostas da bacia aos diferentes conjuntos de parâmetros foi realizada a comparação entre as vazões simuladas com diferentes conjuntos de parâmetros.

A figura 6.10 apresenta os hidrogramas de todas simulações superpostas, onde se pode observar que as vazões simuldas com os parâmetros do período P3 são menores que as com parâmetros do período P2, que são menores que as vazões simuladas com parâmetros do período P1, o que é um indicativo que as mudanças na cobertura e uso do solo causaram a redução das vazões. 
A análise dos resíduos das vazões mensais entre as simulações, com conjuntos de parâmetros obtidos de diferentes calibrações, confirma que os parâmetros obtidos nos períodos com alteração da cobertura e uso do solo geram vazões menores que dos parâmetros obtidos no período de referência. Na comparação entre as vazões mensais obtidas com parâmetros do período P1 e P2, os resíduos foram em média 0,10, entre os períodos $\mathrm{P} 1$ e P3 os valores dos resíduos foram em média 0,15 e entre os períodos P2 e P3, a diferença foi menor e os valores foram em média 0,05. A tabela 6.6 apresenta os valores das medianas e dos percentis de 10 e $90 \%$ dos resíduos das simulações obtidas com parâmetros calibrados em cada período.

Tabela 6.6 - Comparação dos resíduos entre as simulações obtidas com parâmetros calibrados nos períodos P1, P2 e P3.

\begin{tabular}{ccccc}
\hline & Comparação & mediana & percentil 10\% & percentil 90\% \\
\hline \multirow{2}{*}{ Vazões } & P1-P2 & 0,052 & $-0,016$ & 0,114 \\
mensais & P1-P3 & 0,112 & 0,038 & 0,161 \\
& P2-P3 & 0,056 & 0,014 & 0,097 \\
\hline Vazões & P1-P2 & 0,044 & $-0,002$ & 0,097 \\
médias & P1-P3 & 0,110 & 0,063 & 0,154 \\
anuais & P2-P3 & 0,067 & 0,020 & 0,109 \\
\hline \multirow{2}{*}{ Vazões } & P1-P2 & 0,010 & 0,041 & 0,149 \\
mínimas & P1-P3 & 0,150 & 0,128 & 0,176 \\
& P2-P3 & 0,050 & 0,011 & 0,094 \\
\hline
\end{tabular}

Os resíduos das vazões mensais e vazões anuais obtidos com parâmetros calibrados nos períodos P1 e P2 não satisfizeram as condições para se considerar que houve mudança significativa, pois, a mediana dos resíduos foi menor que $10 \%$ e os percentis de 10 e $90 \%$ não apresentaram o mesmo sinal, nas demais comparações foi constatada que houve mudanças. As maiores diferenças foram entre os períodos P1 e P3, o que era esperado já que são os períodos mais afastados entre si e quando as alterações na cobertura e uso do solo são maiores. 


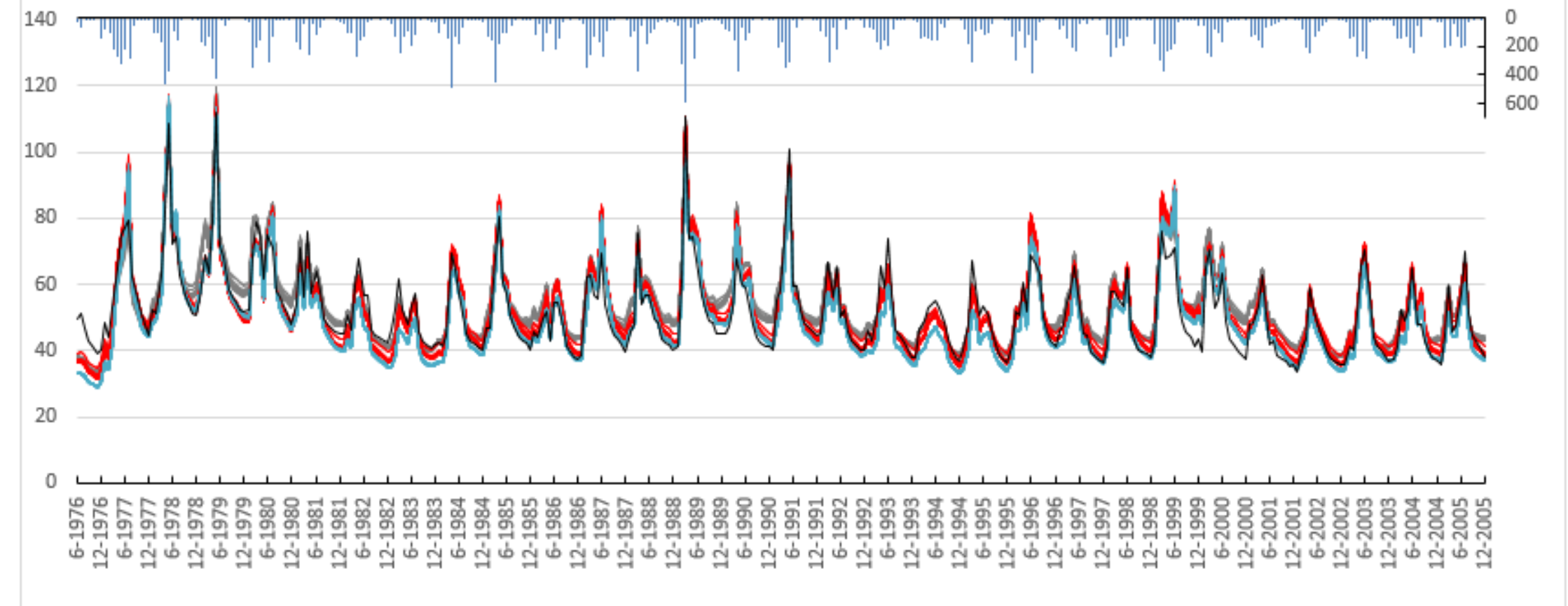

Figura 6.10 - Hidrogramas obtidos com parâmetros dos períodos P1, P2 e P3 no posto Nova Vida-Montante. 


\section{2- BACIA A MONTANTE DO POSTO FLUVIOMÉTRICO BOQUEIRÃO}

O posto fluviométrico Boqueirão é localizado no Rio Grande e é o principal posto da área de estudo pois suas vazões representam o conjunto de toda a área de estudo, a bacia tem uma área de 46.734,3 km². Em 1980 a bacia tinha 95,9\% de sua área coberta com vegetação natural de cerrado e transição do cerrado para a caatinga e ainda não haviam sido implantadas culturas agrícolas. Em 1990 a área de cobertura natural passou para $82,1 \% ; 9,7 \%$ coberta por pastagens e 8,2\% de culturas agrícolas. Em 2000 a área ocupada por vegetação natural era de $68,6 \%$. A figura 6.11 apresenta a evolução da cobertura e uso do solo da bacia durante o período do estudo.

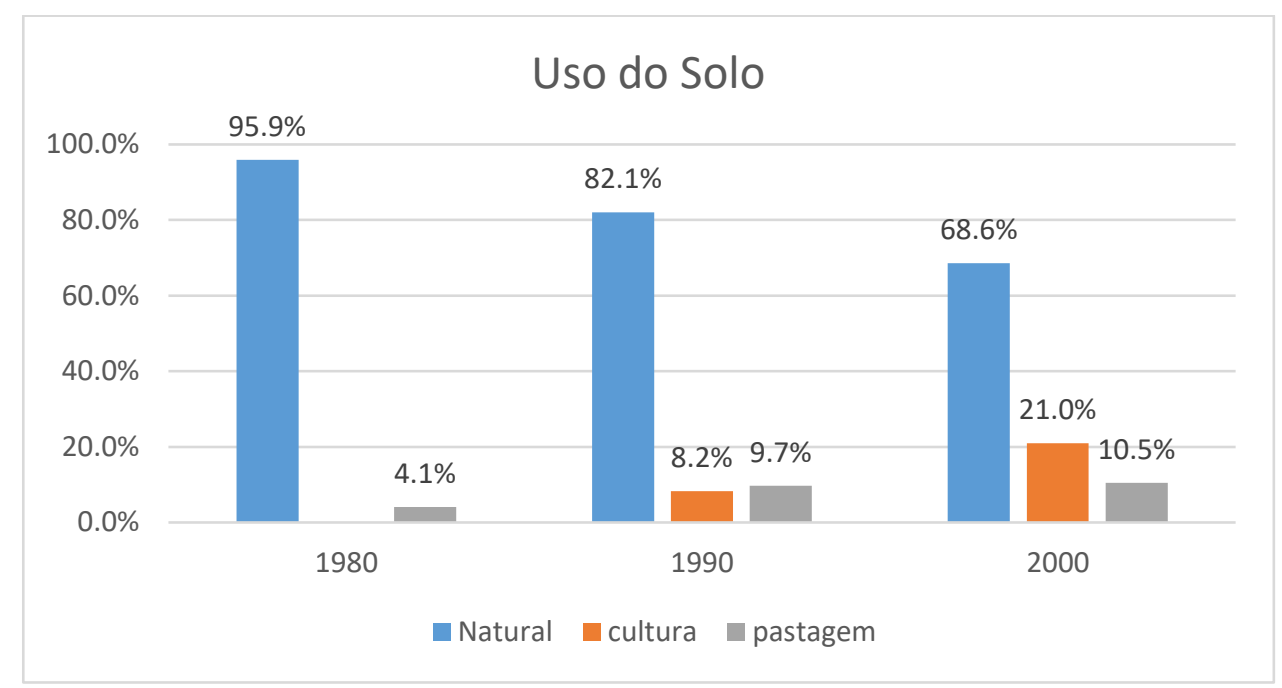

Figura 6.11 - Evolução da cobertura e uso do solo da Bacia a montante do posto fluviométrico Boqueirão.

\subsection{1 - Calibração do modelo na bacia a montante do posto Boqueirão}

A calibração do modelo para os diferentes períodos obteve bons valores para as funções objetivos, confirmando a capacidade do modelo em representar as vazões da região. Considerando as vazões mensais, nos períodos calibrados, os coeficientes de eficiência de Nash-Sutcliffe das vazões e do logaritmo das vazões foram superiores 0,7 , sofrendo algum decaimento para os demais períodos, especialmente nas vazões mais baixas. A tabela 6.7 apresenta o desempenho do modelo para cada período e para cada calibração. Nas figuras 
6.12, 6.13 e 6.14 são apresentados os 30 melhores hidrogramas de cada calibração para o período de estudo.

Pode-se observar pela figura 6.12 que nos períodos posteriores à calibração, quando ocorreram as mudanças no uso do solo, as vazões simuladas se afastam das observadas, indicando que as vazões sofreram redução, pois como as precipitações e o clima da bacia são os mesmos, essa diferença não deveria ser tão grande se não tivesse ocorrido mudanças no uso solo.

Tabela 6.7 - Desempenho do modelo nos períodos calibrados e nos demais períodos da bacia a montante do posto Boqueirão

\begin{tabular}{ccccc}
\hline & & 1980 & 1990 & 2000 \\
\hline \multirow{2}{*}{$\mathrm{P} 1$} & $\mathrm{R}^{2}$ & $0,82-0,84^{*}$ & $0,80-083$ & $0,72-0,76$ \\
& $\mathrm{R}^{2} \log$ & $0,79-0,81^{*}$ & $0,75-0,80$ & $0,67-0,72$ \\
& $\Delta \mathrm{V}$ & $-0,02--0,01^{*}$ & $0,06-0,07$ & $0,09-0,11$ \\
\hline & $\mathrm{R}^{2}$ & $0,56-0,69$ & $0,79-0,87^{*}$ & $0,84-0,90$ \\
& $\mathrm{R}^{2} \log$ & $0,30-0,57$ & $0,78-0,88^{*}$ & $0,84-0,90$ \\
& $\Delta \mathrm{V}$ & $-0,16--0,12$ & $-0,08--0,05^{*}$ & $-0,05--0,01$ \\
\hline & $\mathrm{R}^{2}$ & $0,71-0,74$ & $0,83-0,86$ & $0,88-0,89^{*}$ \\
& $\mathrm{R}^{2} \log$ & $0,50-0,55$ & $0,85-0,88$ & $0,89-0,90^{*}$ \\
& $\Delta \mathrm{V}$ & $-0,12--0,11$ & $-0,06--0,04$ & $-0,02--0,01^{*}$ \\
\hline
\end{tabular}

* Período calibrado 


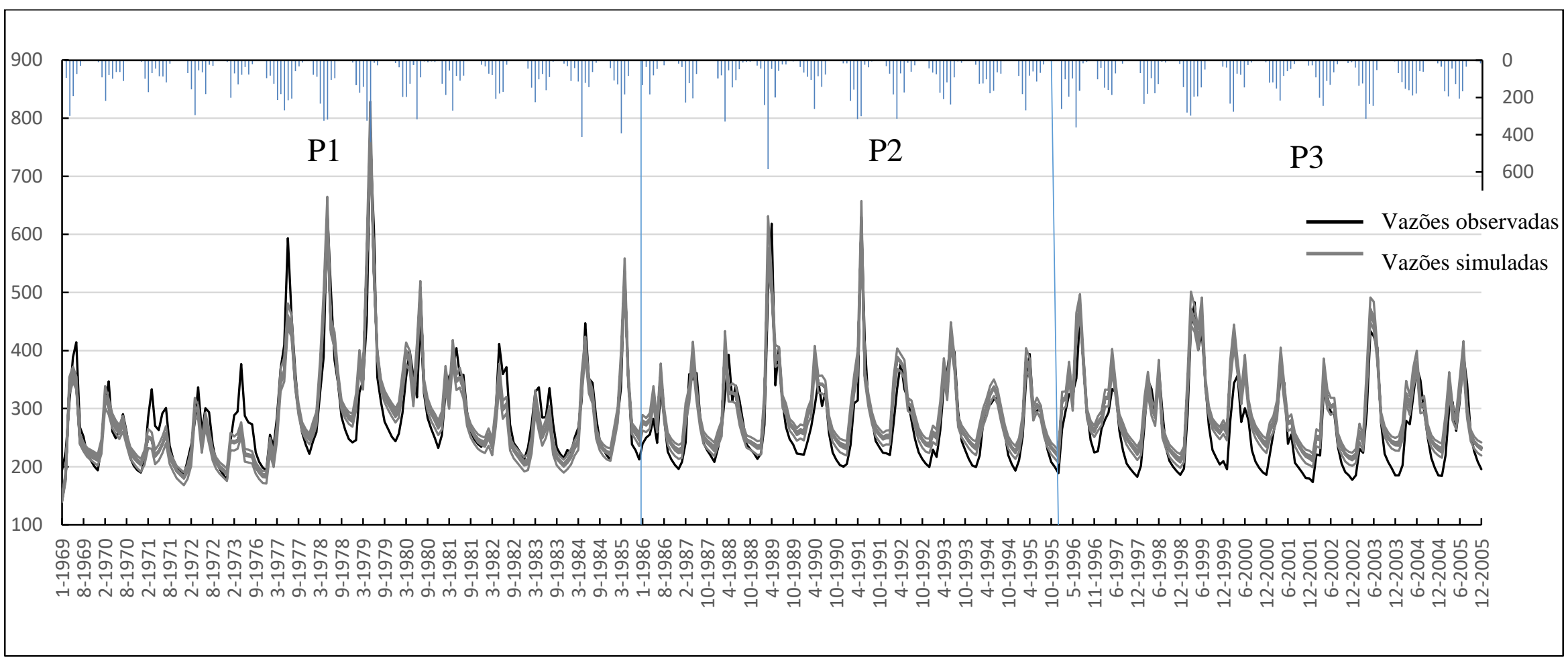

Figura 6.12 - Conjunto dos 30 melhores hidrogramas do posto Boqueirão obtidos com os parâmetros do período P1 


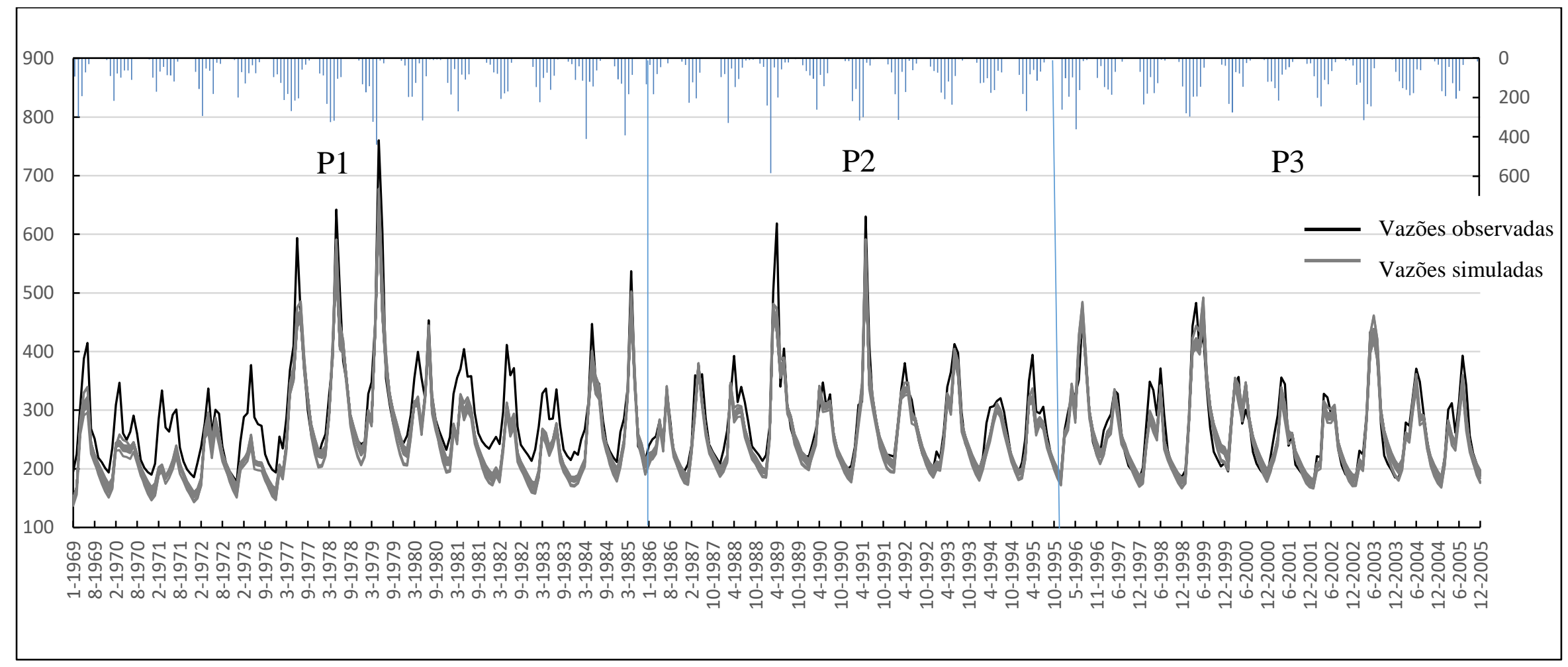

Figura 6.13 - Conjunto dos 30 melhores hidrogramas do posto Boqueirão obtidos com parâmetros do período P2 


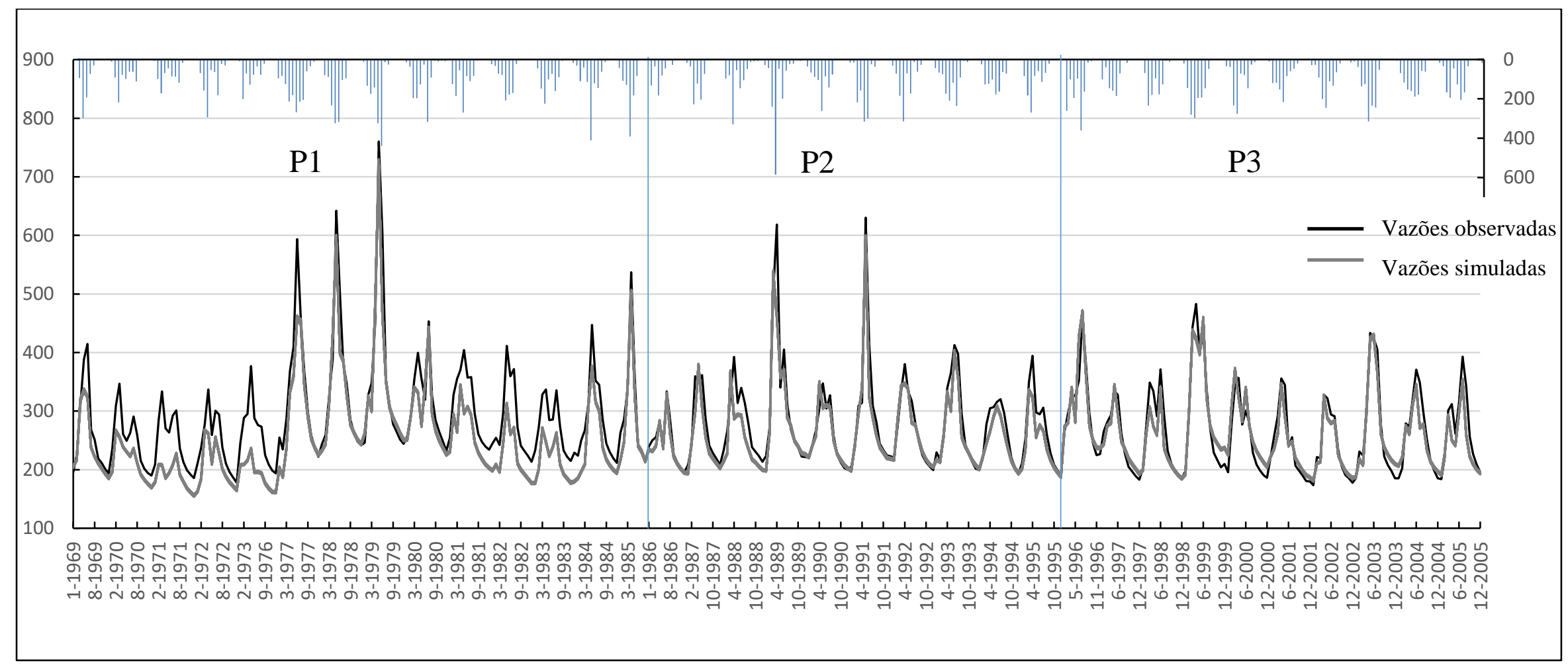

Figura 6.14 - Conjunto dos 30 melhores hidrogramas do posto Boqueirão obtidos com parâmetros do período P3 


\subsection{2 - Comparação entre as vazões simuladas e as vazões observadas no posto}

Boqueirão

Os residuos do período P1 foram em média 0,03 , no perído P2 -0,08 e no período P3 -0,12. Os valores negativos dos resíduos dos períodos posteriores às mudanças no uso do solo são um indicador de que as vazões diminuíram, o teste de Mann-Whitney indicou que há mudanças significativas entre um período e outro, no entanto o teste também apontou mudanças até mesmo dentro do período $\mathrm{P} 1$, o que se trata de uma falsa detecção de mudança. A figura 6.15 apresenta os resíduos obtidos em cada um dos períodos.

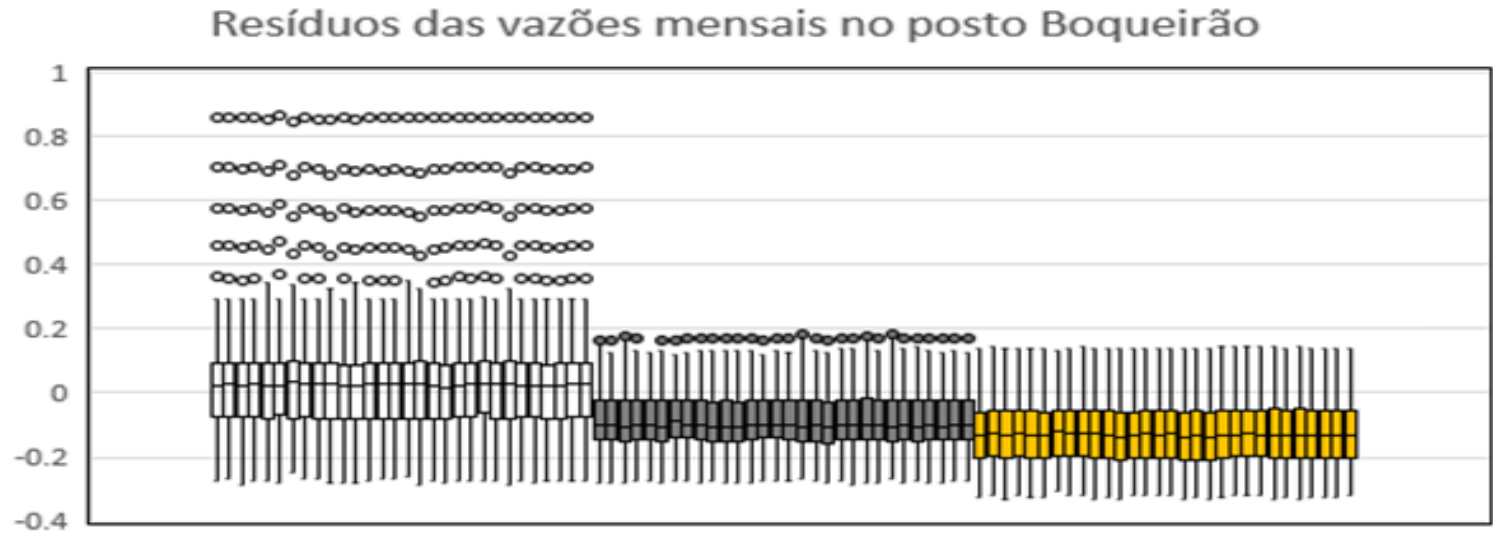

Figura 6.15 - Resíduos das vazões mensais obtidas com parâmetros do período P1.

No período P1 houveram muitos pontos atípicos, o que pode ser a razão pela qual o teste de Mann-Whitney detectou uma falsa mudança, como apresentado na tabela 6.8. As vazões mensais simuladas para o período P2 indicam que houve uma redução média de $6,0 \%$ e do período P3, uma redução de $8,2 \%$ das vazões mensais por conta da mudança no uso do solo, são valores equivalentes aos valores da bacia a montante do posto Nova VidaMontante, mas naquela bacia, as houve uma redução de cobertura natural de $20 \%$ do período P1 para P2, enquanto que na bacia do posto Boqueirão essa redução foi de $13 \%$. Esses valores devem ser considerados com cuidado uma vez que o modelo indicou falsas mudanças no mesmo período.

Na tabela 6.8 são apresentados os valores das medianas e dos percentis de 10 e $90 \%$ dos resíduos entre as vazões observadas e simuladas com parâmetros do período de referência P1 e os valores de p obtidos do teste de Mann-Whitney. 
Tabela 6.8 - Valores das medianas e dos percentis de 10 e $90 \%$ dos resíduos e dos valores de p das vazões mensais no posto Boqueirão.

\begin{tabular}{ccccccc}
\hline & & P1 & \multicolumn{2}{c}{ P2 } & P3 \\
\hline & mediana & $\begin{array}{c}\text { percentis } \\
(10-90 \%)\end{array}$ & mediana & $\begin{array}{c}\text { percentis } \\
(10-90 \%)\end{array}$ & mediana & $\begin{array}{c}\text { percentis } \\
(10-90 \%)\end{array}$ \\
\hline Resíduos & 0,026 & $-0,128-0,173$ & $-0,102$ & $-0,179-0,048$ & $-0,130$ & $-0,254-0,021$ \\
$\mathrm{p}$ & & & $2,0 \times 10^{-13}$ & $(1,3-4,4) \times 10^{-13}$ & $5,1 \times 10^{-19}$ & $(0,3-10) \times 10^{-19}$ \\
\hline
\end{tabular}

Observa-se que os valores dos resíduos apresentam grande variação, especialmente no período P1, que é decorrente das incertezas do modelo e dos parâmetros, uma variabilidade tão acentuada que não permite distinguir se as diferenças dos resíduos entre um período são causadas pelas alterações na cobertura e uso do solo ou pelas incertezas do modelo.

Como descrito no item 4.1.1, é realizado o teste de Mann-Whitney com os resíduos do período de referência, que é divido em duas sub-amostras que são tratadas como amostras diferentes. Na análise das vazões mensais, os valores de p que foram obtidos tem mediana de $7 \times 10^{-4}$, que embora seja um valor que caracteriza que as duas sub-amostras, com significância de 5\%, não podem ser consideradas como sendo da mesma população, observa-se que os valores de $\mathrm{p}$ tem ordem de grandeza bem diferentes entre si. De todo modo, como já descrito acima, a grande variabilidade dos resíduos das vazões mensais no período de referência não permite confirmar que as mudanças foram causadas pelas alterações no uso do solo e reforçam ainda mais a importância de se levar em consideração as incertezas do modelo nesse tipo de análise.

Em relação às vazões anuais, os resíduos do período P1 apresentaram uma variação maior que as dos demais, mas bem menores que os resíduos das vazões mensais. Os resíduos de cada período estão bem estratificados, com pouca sobreposição entre seus valores, demonstrando que houveram mudanças nas vazões em decorrências das mudanças na cobertura e uso do solo.

No período P1 o valor médio dos resíduos foi 0,16 , enquanto que nos períodos P2 e P3 foi $-0,07$ e -0,11 respectivamente. O teste de Mann-Whitney confirmou essas diferenças de um período para outro, e ao contrário do que ocorreu com as vazões mensais, não foi verificado a ocorrência de falsa detecção de mudança no período de referência. Na tabela 6.9 são apresentados as medianas e os percentis de10 e 90\% dos valores dos resíduos das vazões anuais e dos valores de $\mathrm{p}$ do teste de Mann-Whitney. 
A figura 6.16 apresenta os resíduos das vazões anuais, onde pode-se observar a uniformidade do comportamento de cada período e visualizar as mudanças confirmadas pelo teste estatístico com significância de 5\%.

\section{Resíduos das vazões anuais no posto Boqueirão}

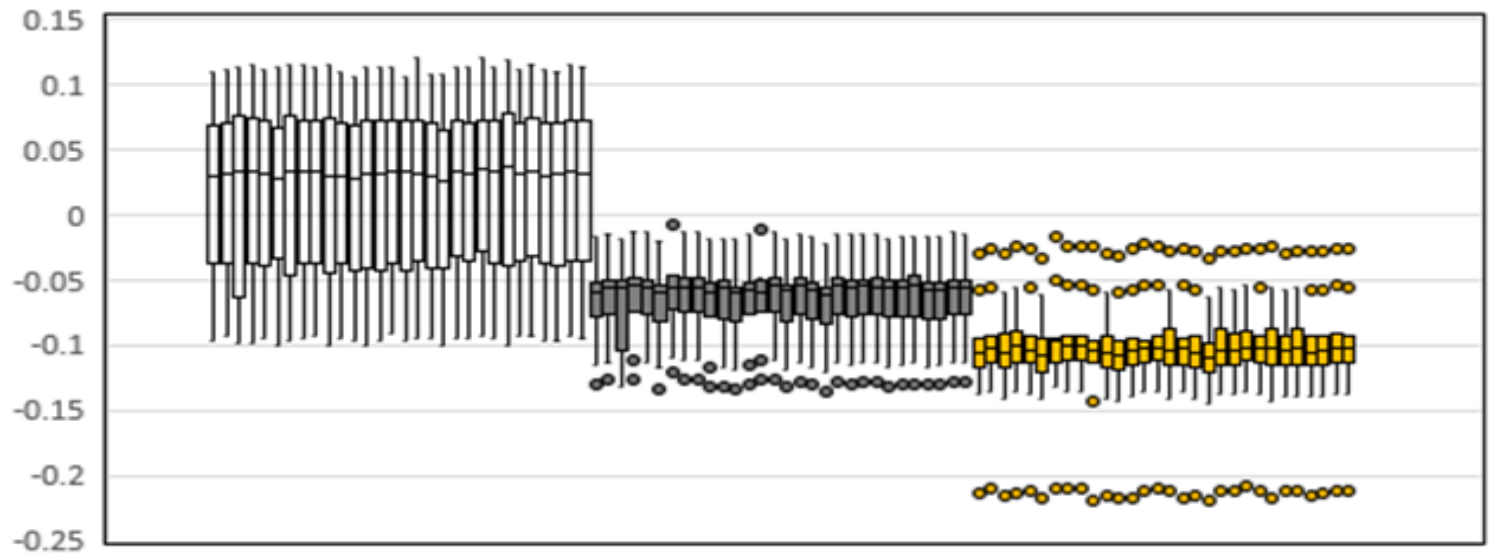

Figura 6.16 - Resíduos das vazões médias anuais com parâmetros obtidos na calibração do período P1.

Tabela 6.9 - Valores das medianas e dos percentis de 10 e 90\% dos resíduos e dos valores de p das vazões médias anuais no posto Boqueirão

\begin{tabular}{ccccccc}
\hline & \multicolumn{2}{c}{ P1 } & \multicolumn{2}{c}{$\mathrm{P} 2$} & \multicolumn{2}{c}{$\mathrm{P} 3$} \\
\hline & mediana & $\begin{array}{c}\text { percentis } \\
(10-90 \%)\end{array}$ & mediana & $\begin{array}{c}\text { percentis } \\
(10-90 \%)\end{array}$ & mediana & $\begin{array}{c}\text { percentis } \\
(10-90 \%)\end{array}$ \\
\hline Resíduos & 0,032 & $-0,094-0,104$ & $-0,056$ & $-0,127--0,018$ & $-0,105$ & $-0,210--0,031$ \\
$\mathrm{p}$ & & & 0,026 & $0,026-0,041$ & 0,002 & $0,001-0,002$ \\
\hline
\end{tabular}

A redução de $13 \%$ da vegetação natural no período $\mathrm{P} 2$ em relação a $\mathrm{P} 1$ causaram uma redução na vazão anual média de $6,2 \%$ e a redução de $27 \%$ da vegetação natural causou uma redução média de 9,6\% na vazão média anual no período $\mathrm{P} 3$.

Para as vazões mínimas, os resíduos apresentaram características semelhantes às vazões anuais, com uma variação maior no período P1 e bem estratificados nos períodos seguintes, sendo bem visível a diferença de patamares desses valores. No período P1 o valor médio dos resíduos foi de $-0,05$ e nos períodos P2 e P3 os valores foram -0,17 e 0,24, mais uma vez indicando que a substituição da cobertura natural por pastagens e culturas agrícolas causou a redução nas vazões.

O teste de Mann-Whitney confirmou que houveram mudanças entre os diferentes períodos e não apresentou falsas detecções no período de referência, na tabela 6.10 são apresentados 
os valores das medianas e dos percentis de 10 e $90 \%$ dos resíduos e dos valores de $\mathrm{p}$ obtidos do teste de Mann-Whitney. A figura 6.17 apresenta os resíduos obtidos em cada um dos períodos. As vazões simuladas indicam que houve uma redução de 14,2\% e 19,5\% nas vazões mínimas nos períodos $\mathrm{P} 2$ e $\mathrm{P} 3$ respectivamente.

Tabela 6.10 - Valores das medianas e dos percentis de 10 e $90 \%$ dos resíduos e dos valores de p das vazões mínimas no posto Boqueirão.

\begin{tabular}{ccccccc}
\hline & \multicolumn{2}{c}{ P1 } & \multicolumn{2}{c}{ P2 } & \multicolumn{2}{c}{ P3 } \\
\hline & mediana & $\begin{array}{c}\text { percentis } \\
(10-90 \%)\end{array}$ & mediana & $\begin{array}{c}\text { percentis } \\
(10-90 \%)\end{array}$ & mediana & $\begin{array}{c}\text { percentis } \\
(10-90 \%)\end{array}$ \\
\hline Resíduos & $-0,040$ & $-0,190-0,053$ & $-0,178$ & $-0,208--0,104$ & $-0,238$ & $-0,304--0,161$ \\
p & & & 0,009 & $0,007-0,012$ & $6,3 \times 10^{-4}$ & $(6,3-6,4) \times 10^{-4}$ \\
\hline
\end{tabular}

\section{Resíduos das vazões mínimas no posto Boqueirão}

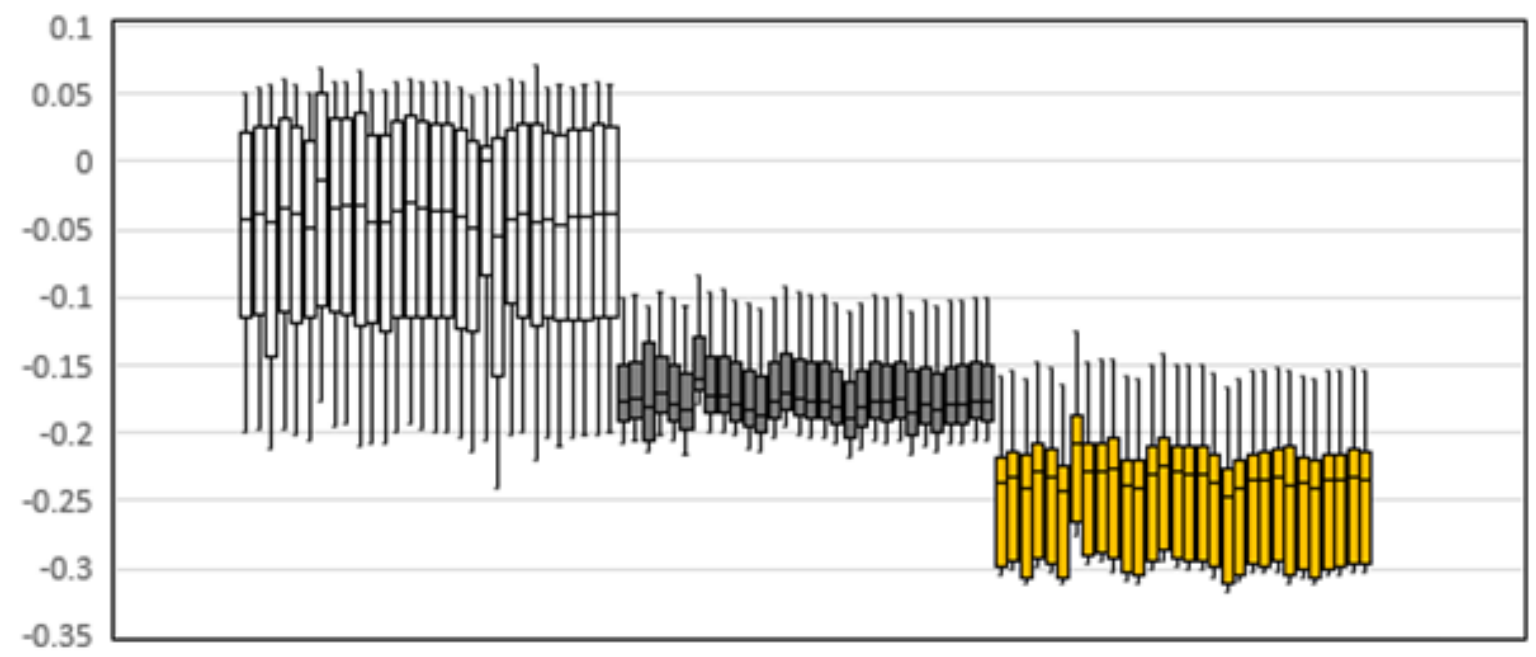

Figura 6.17 - Resíduos das vazões mínimas simulas com parâmetros obtidos no período P1.

\subsection{3 - Comparação dos parâmetros obtidos em diferentes calibrações na bacia do Rio}

\section{Grande}

Para detectar mudanças na hidrologia da bacia a montante do posto Boqueirão, foram comparados os parâmetros obtidos nas calibrações com as condições de cobertura e uso do solo de cada período de estudo. A variabilidade dos parâmetros obtidos em cada período para cada URH é apresentada na figura 6.18. Na figura, os parâmetros obtidos em cada período são apresentados em sequência e agrupados por tipo de URH. 


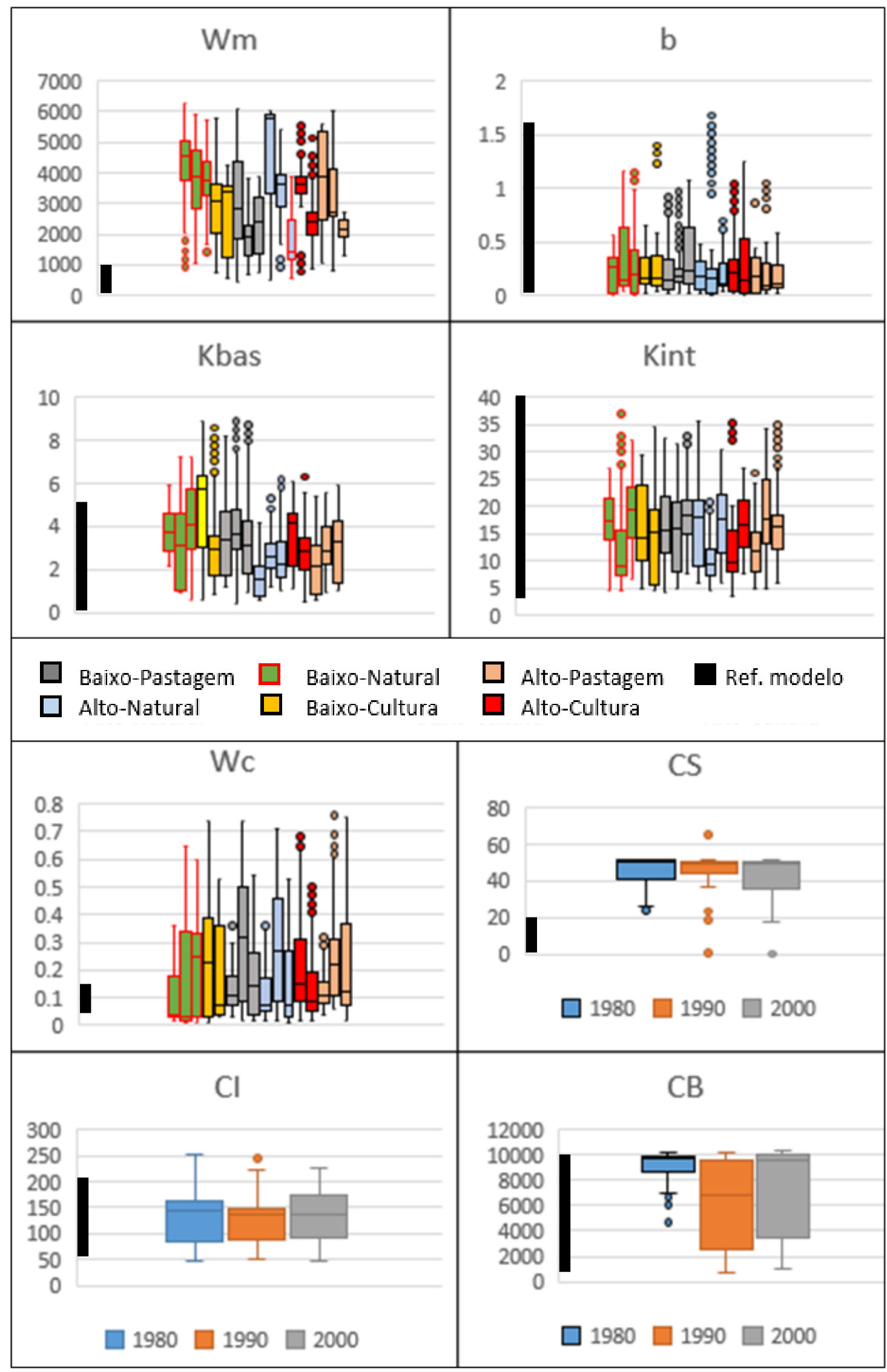

Figura 6.18 - Variação dos parâmetros obtidos em cada calibração 
A variabilidade dos parâmetros desta bacia é maior que a verificada na bacia a montante do posto fluviométrico Nova Vida-Montante porque essa bacia engloba os parâmetros de outras 10 bacias que foram calibradas a montante.

Na tabela 6.11 é apresentado o resultado o teste de Mann-Whitney para a comparação dos parâmetros em cada período. O símbolo“+”" indica que foi detectada mudança dos valores dos parâmetros, o símbolo “-” indica que não se pode afirmar que houve mudança. Na coluna P1-P1, é apresentado a comparação dos parâmetros do mesmo período e o símbolo “+” indica que houve um resultado falso positivo para detecção de mudança.

Tabela 6.11 - Resultados do teste de Mann-Whitney para a comparação dos parâmetros obtidos na calibração de cada período.

\begin{tabular}{|c|c|c|c|c|}
\hline URH & Parâmetro & P1-P1 & P1-P2 & P1-P3 \\
\hline \multirow{5}{*}{ Alto Natural } & $\mathrm{Wm}$ & - & + & - \\
\hline & $\mathrm{b}$ & + & - & + \\
\hline & Kbas & - & + & + \\
\hline & Kint & + & + & - \\
\hline & $\mathrm{Wc}$ & + & + & + \\
\hline \multirow{5}{*}{ Alto-Pastagem } & $\mathrm{Wm}$ & - & + & + \\
\hline & $\mathrm{b}$ & - & + & + \\
\hline & Kbas & + & + & + \\
\hline & Kint & - & + & + \\
\hline & $\mathrm{Wc}$ & - & + & + \\
\hline \multirow{5}{*}{ Baixo-Natural } & $\mathrm{Wm}$ & - & + & + \\
\hline & $\mathrm{b}$ & - & + & - \\
\hline & Kbas & - & + & + \\
\hline & Kint & - & + & + \\
\hline & $\mathrm{Wc}$ & + & - & + \\
\hline \multirow{8}{*}{ Baixo-Pastagem } & $\mathrm{Wm}$ & - & - & + \\
\hline & $\mathrm{b}$ & - & - & + \\
\hline & Kbas & - & - & + \\
\hline & Kint & - & - & + \\
\hline & $\mathrm{Wc}$ & - & + & + \\
\hline & $\mathrm{CS}$ & - & + & + \\
\hline & CI & - & - & - \\
\hline & $\mathrm{CB}$ & - & + & + \\
\hline
\end{tabular}

Os resultados do teste estatísticos da bacia do Rio Grande foram um pouco mais concisos que os testes na bacia do Rio Branco, apresentando menos ocorrências de falsos positivos e maior detecção de mudanças no período P3 do que no período P2, o que era de se esperar por ter havido maior mudança no uso do solo. De toda forma, assim como na bacia do Rio Branco, a detecção das mudanças nos parâmetros em virtude das mudanças de uso no solo 
na bacia ainda é de difícil análise por conta de toda a complexidade existente nas interrelações dos parâmetros.

\subsection{4 - Comparação entre as vazões simuladas com diferentes conjuntos de Parâmetros na bacia a montante do posto Boqueirão}

Como já citado anteriormente, é mais interessante analisar as respostas da bacia a diferentes conjuntos de parâmetros do que os valores dos parâmetros em si. Desta forma, na figura 6.19 são apresentados os hidrogramas obtidos pela calibração do modelo em cada um dos períodos de estudo. Pode-se notar que as vazões geradas com os parâmetros do período P1 são maiores que as dos demais, por outro lado, para as vazões mínimas as vazões obtidas com parâmetros do período P2 são menores que as do período P3. Na tabela 6.12 são apresentados os valores das medianas e dos percentis de 10 e $90 \%$ dos resíduos obtidos entre as vazões simuladas com diferentes conjuntos de parâmetros.

Tabela 6.12 - Comparação dos resíduos entre as simulações obtidas com parâmetros calibrados nos períodos P1, P2 e P3 na bacia a montante do posto Boqueirão.

\begin{tabular}{ccccc}
\hline & Comparação & mediana & percentil 10\% & percentil 90\% \\
\hline \multirow{2}{*}{ Vazões } & P1-P2 & 0,124 & 0,028 & 0,221 \\
mensais & P1-P3 & 0,127 & 0,072 & 0,172 \\
& P2-P3 & $-0,001$ & $-0,067$ & 0,064 \\
\hline Vazões & P1-P2 & 0,124 & 0,067 & 0,168 \\
médias & P1-P3 & 0,124 & 0,078 & 0,154 \\
anuais & P2-P3 & $-0,002$ & $-0,033$ & 0,034 \\
\hline \multirow{2}{*}{ Vazões } & P1-P2 & 0,194 & 0,145 & 0,250 \\
mínimas & P1-P3 & 0,161 & 0,138 & 0,180 \\
& P2-P3 & $-0,038$ & $-0,090$ & $-0,001$ \\
\hline
\end{tabular}




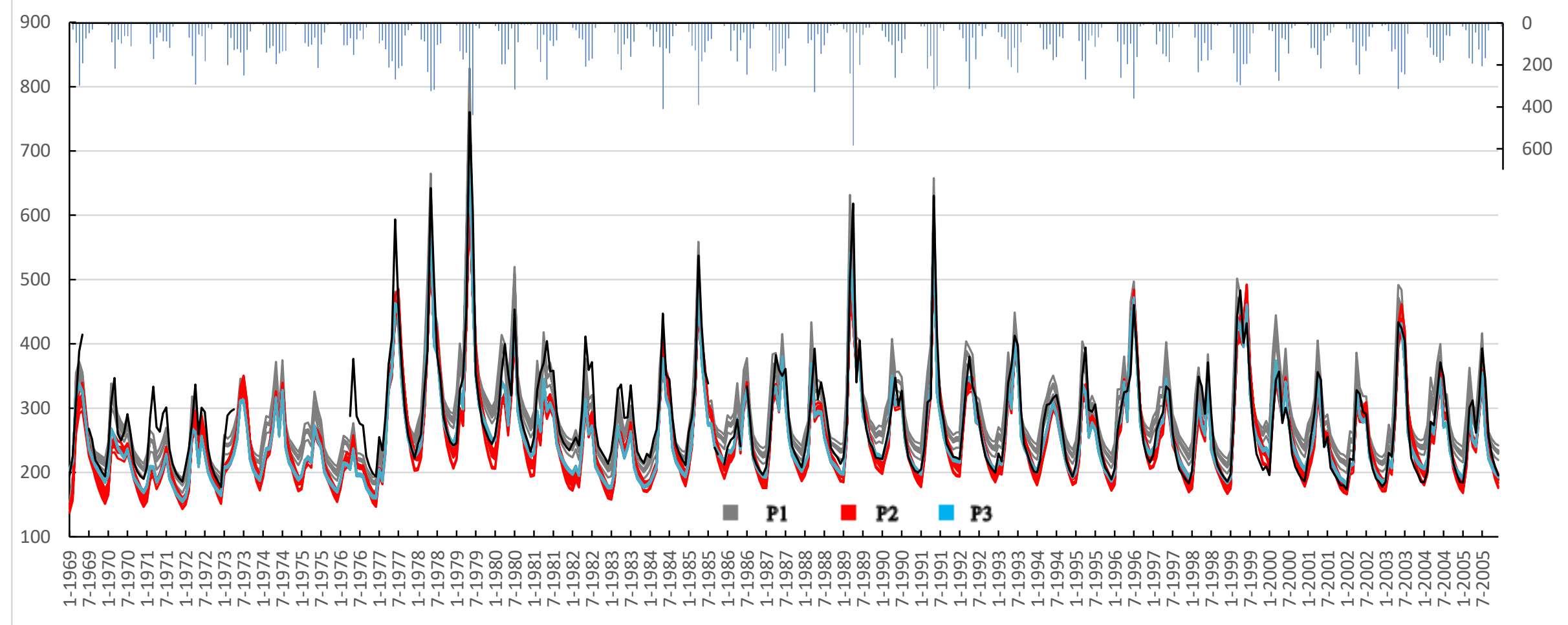

Figura 6.19 - Hidrogramas obtidos com parâmetros dos períodos P1, P2 e P3 no posto Boqueirão 
Em todas as comparações entre simulações, os parâmetros obtidos do período P1 produziram vazões maiores que os demais, reforçando a constatação de que a alteração na cobertura e uso do solo da área de estudo causou a redução das vazões. Na comparação entre as simulações com parâmetros dos períodos P2 e P3 as diferenças entre as vazões mensais e anuais não foram consideradas significativas, já que não atenderam às condições apresentadas no item 4.1.3, de valor de mediana superior a $10 \%$ ou percentis de 10 e $90 \%$ com o mesmo sinal; se montrando significativas apenas para a comparação das vazões mínimas.

Em todas as análises, foram detectadas mudanças nas vazões causadas pelas mudanças na cobertura e uso do solo. Assim como na bacia a montante do posto Nova Vida-Montante, na bacia do posto Boqueirão, a substituição da cobertura natural por pastagens e culturas agrícolas causou a redução das vazões, situação que diverge dos estudos realizados em bacias experimentais, no entanto, deve-se ter em mente que a maior parte desses estudos foram realizados em florestas que são diferentes do cerrado brasileiro.

Nos estudos experimentais, o aumento das vazões após a remoção da vegetação florestal, é justificado pela maior evapotranspiração dessa vegetação, que após a sua remoção, deixa mais água disponível para o escoamento. Esta conclusão parte do princípio que em florestas a evapotranspiração é maior que em pastagens e culturas agrícolas, no entanto, no caso do cerrado brasileiro, o estudo realizado por Silva (2003), com medições in loco, fez a comparação da evapotranspiração do cerrado com pastagens e verificou, que na maior parte do ano, as pastagens apresentam maior evapotranspiração que o cerrado, sendo que a evapotranspiração do cerrado só é maior que a da pastagem nos períodos com menor disponibilidade hídrica. 


\section{7 - CONCLUSÃO E RECOMENDAÇÕES}

O modelo MGB-IPH se mostrou eficiente em reproduzir os hidrogramas da área de estudo, apresentando bons ajustes em todas as calibrações realizadas, com as maiores deficiências sendo observadas nos períodos de estiagem.

A consideração das incertezas na detecção das alterações das vazões causadas por alterações na cobertura e uso do solo se mostrou de grande importância, permitindo que os resultados obtidos fossem avaliados quanto à sua representatividade e grau de confiança. A negligência quanto às incertezas envolvidas no processo de modelagem poderia induzir à consideração de que variações decorrentes da modelagem fossem tratadas como mudanças na vazão causadas por alterações na cobertura e uso do solo.

Também se mostrou importante a avaliação de mais de uma variável hidrológica, neste trabalho foram analisadas as vazões mensais, anuais e mínimas. Aliada à consideração das incertezas, a avaliação de mais de uma variável reforça os resultados.

Quanto às mudanças das vazões causadas pelas mudanças no uso do solo, foi constatado que a remoção da cobertura natural por pastagens e culturas agrícolas provocou reduções das vazões nas bacias analisadas. A aplicação da metodologia se mostrou eficiente na detecção das mudanças, no entanto a quantificação dessas mudanças não se mostrou conclusiva, uma vez que as mudanças detectadas nas vazões não apresentaram linearidade com as mudanças na cobertura do solo, sendo que na bacia a montante do posto Boqueirão as vazões do último período, em que houve maior mudança no uso do solo, apresentaram alterações equivalentes às do período intermediário.

Os parâmetros obtidos nas calibrações de cada período apresentaram grande variação em seus valores, quer entre as diferentes bacias quer entre as unidades de resposta hidrológicas, a quantidade elevada de parâmetros calibrados e essa grande variabilidade tornou complexa a detecção de mudanças na hidrologia das bacias estudadas, os testes estatísticos realizados para constatar as mudanças nos parâmetros apresentaram resultados diversos. Durante as calibrações do modelo não foi realizada uma análise de sensibilidade sistematizada dos parâmetros, mas apenas consultas às análises de sensibilidade realizadas em outras regiões, para trabalhos futuros nessa área, visando reduzir a variabilidade dos parâmetros calibrados, recomenda-se que seja realizada uma análise de sensibilidade sistematizada e consistente. 
A comparação das respostas da bacia a diferentes conjuntos de parâmetros confirmou que ocorreram reduções nas vazões, causadas pelas mudanças no uso do solo em todas as variáveis hidrológicas analisadas.

O fluxo de água subterrânea das bacias analisadas tem um papel importante na manutenção das vazões durantes os meses de estiagem e são nesses períodos que o ajuste do modelo se mostrou menos eficiente, dessa forma, recomenda-se que em trabalhos futuros seja dada maior ênfase aos fluxos subterrâneos e também às retiradas de água para irrigação de culturas agrícolas e seus impactos nas vazões dos rios. 


\section{REFERÊNCIAS BIBLIOGRÁFICAS}

Abbott, M.B., Bathurst, J., Cunge, J.A., O’Connell, P.E., Rasmusses, J. (1986) An introduction to the European Hydrological System - Système Hydrologique Européen, 'SHE' - 1: Structure of a Physically-Based, Distributed Modelling System. Journal of Hydrology, 87, 45-59.

Allen, R.G., Pereira, L.S., Raes, D. e Smith, M. (1998). "Crop evapotranspiration Guidelines for computing crop water requirements". FAO Irrigation and drainage paper 56, FAO, Roma, Itália. 15p.

ANA - Agência Nacional de Águas. (2004). Plano Decenal de Recursos Hídricos da Bacia Hidrográfica do Rio São Francisco - PBHSF (2004-2013) - Resumo Executivo. Brasília, DF, 150p.

ANA - Agência Nacional de Águas (2010). "Hidroweb - Sistema de Informações Hidrológicas”. Disponível em : http://hidroweb.ana.gov.br/

Andréassian, V. (2004). "Waters and forests: from historical controversy to scientific debate". Journal of Hydrology, 291, 1-27.

Balakrishnan, S., Roy, A., Ierapetritou, M., Flach, G., Georgopoulos, P. (2003). "Uncertainty Reduction and Characterization for Complex Environmental Fate and Transport Models: An Empirical Bayesian Framework Incorporating the Stochastic Response Surface Method”. Water Resources Research, 38 (12), 1-8.

Batista, M.S. (2006). “Análise de Incerteza no Escoamento Simulado com o Modelo Distribuído Navmo". Dissertação de Mestrado, Universidade Federal de Campina Grande, Campina Grande, PB, 133p.

Bayer, D.M. e Collischonn, W. (2013). “Análise de Sensibilidade do Modelo MGB-IPH a Mudanças de uso da Terra”. Revista Brasileira de Recursos Hídricos, 18(3), 165179.

Bayer, D.M. (2014). "Efeitos das Mudanças de Uso da Terra no Regime Hidrológico de Bacias de Grande Escala”. Tese de Doutorado, Universidade Federal do Rio Grande do Sul, Instituto de Pesquisas Hidráulicas, Porto Alegre, RS, 172p. 
Bertoni, J., Lombardi Neto, F. (1993). “Conservação do Solo”. Ícone, São Paulo, 355p.

Best, A., Zhang, L., McMahon, T., Western, A. e Vertessy, R. (2003). “A critical review of paired catchment studies with reference to seasonal flows and climatic variability”. Cooperative Research Centre for Catchment Hydrology Thecnical Report 25/03, CSIRO Land and Water, Camberra, Austrália. 56p.

Beven, K. (1993). "Prophecy, reality and uncertainty in distributed hydrological modelling”. Advances in Water Resources, 16, 41-51.

Beven, K. (2011). Rainfall-Runoff Modelling: The Primer. John Wiley \& Sons, West Sussex, Reino Unido. 457p.

Beven, K., Kirkby, M. J. (1979). "A physically based, variable contributing area model of basin hydrology". Hydrological Sciences-Bulletin-des Sciences Hydrologiques, 24, 4369.

Beven, K. e Binley, A. (1992). "The future os distributed models: model calibration and uncertainty prediction”. Hydrological Processes, 6, 279-298.

Beven, K., Freer, J. (2001). "Equifinality, data assimilation, and uncertainty estimation in mechanistic modelling of complex environmental systems using the GLUE methodology". Journal of Hydrology, 249, 11-29.

Borah, D.K., Bera, M. (2004) "Watersehd-scale hydrologic and nonpoint-source pollution models: Review of applications". Transactions of the ASABE. American Society of Agricultural Engineers, 47(3), 789-803.

Bosh, J.M. e Hewlett, J.D. (1982). "A review of catchment experiments to determine the effect of vegetation changes on water yield and evapotranspiration". Journal of Hydrology, 55, 3-23.

Brown, A.E., Zhang, L., McMahon, T.A., Western, A.W. e Vertessy, R.A. (2005). “A review of paired catchment studies for determining changes in water yield resulting from alterations in vegetation". Journal of Hydrology, 310, 28-61.

Bruijnzeel, L.A. (1990). "Hydrology of moist tropical forests and effects of conversion: A state of knowledge review". IAHS, IHP-UNESCO, ITC, VUA, Amsterdam, Holanda. $172 \mathrm{p}$. 
Bruijnzeel, L.A. e Critchley, W.R.S. (1994). "Environmental impacts of logging moist tropical forest". IHP Humid Tropics Programme series n 7. UNESCO, Amsterdam, Holanda. 52p.

Brutsaert, W. (2005). Hydrology: An Introduction. Cambridge University Press, New York, 616p

Bultot, F., Dupriez, G.L. e Gellens, D. (1990). "Simulation of land use changes and impacts on the water balance - A case study for Belgium". Journal of Hydrology, 114, 327-348.

Calder, I.R. (1998). "Water-resource and land-use issues". SWIM Paper 3. International Water Management Institute, Colombo, Sri Lanka, 33p.

Caram, R.O. (2010). "Mudanças no Uso e Cobetura do Solo e Resposta Hidrológica da Bacia do Rio Piracicaba”. Tese de Doutorado, Universidade de São Paulo, Escola Superior de Agricultura "Luiz de Queiroz", Piracicaba, SP, 140p.

Carneiro, M.A.C., Souza, E.D., Reis, E.F., Pereira, H.S., Azevedo, W.R. (2009). "Atributos físicos, químicos e biológicos de solo de cerrado sob diferentes sistemas de uso e manejo". Revista Brasileira de Ciência do Solo, 33, 147-157.

Coe, M.T. (2000). "Modeling terrestrial hydrological systems at the continental scale: Testing the accuracy of an atmospheric GCM". Journal of Climate, 13, 686-704.

Collischonn, W. (2001). "Simulação Hidrológica de Grandes Bacias". Tese de Doutorado, Universidade Federal do Rio Grande do Sul, Instituto de Pesquisas Hidráulicas, Porto Alegre, RS, 270p.

Collischonn, W., Allasia, D., Silva, B.C. e Tucci, C.E.M. (2007). "The MGB-IPH model for large-scale rainfall-runoff modelling”. Hydrological Sciences Journal, 52(5), 878-895.

Collischonn, W., Buarque, D.C., Paiva, R.C.D., Fan, F.M. e Kayser, R. (2010-1). Manual introdutório para aplicação do modelo MGB-IPH. Manual 01/05. IPH-UFRGS, Porto Alegre, RS, 7p.

Collischonn, W., Buarque, D.C., Paiva, R.C.D., Fan, F.M. e Kayser, R. (2010-2). Manual de discretização de Bacias para aplicação do modelo MGB-IPH. Manual 02/05. IPHUFRGS, Porto Alegre, RS, 51p. 
Collischon, W. e Tucci, C.E.M. (2003). "Ajuste Multiobjetivo dos Parâmetros de um Modelo Hidrológico”. Revista Brasileira de Recursos Hídricos, 8(3), 27-39.

Crawford, N.H. e Linley JR, R.K. (1966). Digital simulation in hydrology: Stanford Watershed Model IV. Departament of Civil Engineering, Stanford University, Stanford, CA, Tech. Rep. N. 39.

CPRM - Serviço Geológico do Brasil. (2012). Relatório diagnóstico: Sistema Aquífero Urucuia - Bacia sedimentar Sanfranciscana. v10. CPRM, Belo Horizonte, MG, 43p.

Devi, G.K., Ganasri, B.P., Dwarakish, G.S. (2015). "A Review of Hydrological Model.” In: Singh, A. K. (ed.) International Conference on Water Resources, Coastal and Ocean (ICWRCOE 2015). Aquatic Procedia, 1001-1007.

DHI. (2012). Danish Hydraulic Institute, "MIKE SHE User Manual". Hørsholm, Dinamarca. Disponível em: http://dssplanning.dhigroup.com/links/MIKE_SHE_Printed_V1.pdf.

Doll, P., Berkhoff, K., Bormann, H., Fohrer, N., Gerten, D., Hagemann, S. e Krol, M. (2008). "Advances and visions in large-scale hydrological modelling: findings from the 11th Workshop on Large-Scale Hydrological Modelling". Advances in Geosciences, 18, 51-61.

Dooge, J.C.I. (1959). “A general theory of the unit hydrograph.” Journal of Geophysical Research., 64 (2), 241-256.

Dunne, T., Black, R.D. (1970) "Partial area contributions to storm runoff in a small New England watershed”. Water Resources Research, 6(5), 1296-1311.

Duan, Q.Y., Gupta, V.K., Sorooshian, S. (1993) "Shuffled complex evolution approach for effective and efficient global minimization". Journal of Optimization Theory and Applications, 76(3), 501-521.

Eckhardt, K., Haverkamp, S., Fohrer,N. e Frede, H.G. ( 2002). "SWAT-G, a version of SWAT99.2 modified for application to low mountain range catchments". Physics and Chemistry of the Earth, 27, 641-644.

Eckhardt, K., Breuer, L. e Frede, H. (2003). "Parameter uncertainty and the significance of simulated land use change effects”. Journal of Hydrology, 273, 164-176. 
Fan, F.M., Buarque, D.C., Collischonn, W., Paiva, R.C.D., e Kayser, R. (2010). Manual do prepro-mgb para aplicação do modelo MGB-IPH. Manual 04/05. IPH-UFRGS, Porto Alegre, RS, 19p

Fan, F.M. (2011). Acoplamento entre Modelos Hidrológicos e Sistemas de informação Geográfica: Integração do Modelo MGB-IPH. Monografia de Graduação em Engenharia Ambiental, Universidade Federal do Rio Grande do Sul, Instituto de Pesquisas Hidráulicas e Escola de Engenharia, Porto Alegre, RS, 179p.

Flores, P.M. (2011). Análise Multitemporal do Avanço da Fronteira Agrícola no Município de Barreiras - BA (1988 - 2008). Dissertação de Mestrado, Universidade de Brasília, Departamento de Geografia, Brasília, DF, 99p.

Gaspar, M.T.P. (2006). Sistema Aquífero Urucuia: Caracterização Regional e Proposta de Gestão. Tese de Doutorado, Instituto de Geociências, Brasília, DF, 204p.

Gebrehiwot, S. G., Seibert, J., Gardenas, A.I., Mellander, P. Bishop, K. (2013). "Hydrological Change Detection Using Modeling: Half a Century of Runoff from Four Rivers in the Blue Nile Basin”. Water Resources Research, 49, 3842-3851.

Gupta, H.V., Sorooshian, S. e Yapo, P.O. (1998). "Toward inproved calibration of hydrologic models: Multiple and noncommensurable measures of information". Water Resources Research, 34(4), 751-763.

Hernandez, M., Miller, S.N., Goddrich, D.C., Goff, B.F., Kepner, W.G., Edmonds, C.M. e Jones, K.B. (2000). "Modeling runoff response to land cover and rainfall spatial variability in semi-arid watersheds." Environmental Monitoring and Assessment, 64, 285-298.

Hibbert, A.R. (1967). "Forest treatment effects on water yield." In: Sopper, W.E. e Lull, H.W. (eds.) Forest Hydrology, Proceedings of a National Science Foudation Advanced Science Seminar. Pergamon Press, Oxford, E.U.A, 527-543.

Hornbeck, J.W, Adams, M.B, Corbett, E.S, Verry, E.S e Lynch, J.A. (1993). "Long-term impacts of forest treatments on water yield: a summary for northeastern USA." Journal of Hydrology, 150, 323-344. 
Hundecha, Y. e Bárdossy, A. (2004). "Modeling of the effect of land use changes on tje runoff generation of a river basin through parameter regionalization of a watershed model." Journal of Hydrology, 292, 281-295.

Hunke, P., Roller, R., Zeilhofer, P., Schöder, B. e Mueller, E.N. (2015). "Soil changes under different land-uses in the Cerrado of Matogrosso, Brazil." Geoderma Regional, 4, 31-43.

Hydrologic Engineering Center - HEC (1968). "'HEC-1 flood hydrograph package, user's manual.' U.S. Army Corps of Engineers.

IBGE. Instituto Brasileiro de Geografia e Estatística. (2014). "Produção Agrícola Municipal”. Rio de Janeiro: IBGE, Disponível em: http://www.ibge.gov.br/home/estatistica/economia/pam/2013/default_temp_perm_xl s.shtm. Acesso em: 10 jun. 2015.

INEMA. Instituto do Meio Ambiente e Recursos Hídricos. (2014). Plano Estadual de Recursos Hídricos da Bahia. Disponível em: http://www.inema.ba.gov.br/download.

Kavvas, M.L., Chen, Z.Q., Tan, L., Soong, A. (1998). “A regional scale land surface parameterization based on areally-averaged hydrological conservation equation."' Hydrological Sciences Jounal, 43 (4), 611-631.

Lacey, G.C. e Grayson, R.B. (1998). "Relating baseflow to catchment properties in southeastern Australia." Journal of Hydrology, 204, 231-250.

Leavesley, G.H.; Lichty, R.W.; Troutman, B.M.; Saindon, L.G. (1983) "Precipitation-Runoff Modelind System: User's Manual". Denver, Colorado (EUA). Water-Resources Investigations Report, 214 p.

Li, K.Y., Coe, M.T., Ramankutty, N. e Jong, R. (2007). "Modeling the hydrological impact of land-use change in West Africa." Journal of Hydrology, 337, 258-268.

Liang, X., Lettenmaier, D. P, Wood, E. F. e Burges, S. J. (1994). "A Simple Hydrologically Based Model of Land Surface Water and Energy Fluxes for GSMs”, Journal of Geophysical Research, 99(D7), 14415-14428.

Lighthill, M.J., Whitham, G.B. (1955). “On kinematic waves: Flood movement in long rivers." Proceedings of the Royal Society of Mathematical, Physical and Engineering Sciences, 229, 281-316. 
Lopes, J.E.G.; Braga Jr., B.P.F.; Conejo, J.G.L. (1981) "Simulação hidrológica: Aplicações de um modelo simplificado". In: Anais do III Simpósio Brasileiro de Recursos Hídricos, v.2, 42-62, Fortaleza.

Lopes, J.E.G. (1999) “Soil Moisture Accounting Procedure - Modelo SMAP”. Disponível em: http://pha.poli.usp.br/LeArq.aspx?id_arq=3596. Acessado em 27 de julho de 2016.

Maia, P.H.P., Cruz, M.J.M. e Sampaio, M.C. (2009). “Zoneamento dos Aquífferos do Estado da Bahia”. Revista Brasileira de Ciência e Tecnologia Aquática,13(1), 45-52.

Mapa, R.B. (1995). "Effect of reforestation using Tectona grandis on infiltration and soil water retention." Forest Ecology and Management, 77, 119-125.

Markstrom, S.L., Regan, R.S., Hay, L.E., Viger, R.J., Webb, R.M.T., Payn, R.A., LaFontaine, J.H. (2015). "PRMS-IV, the precipitation-runoff modeling system, version 4”. U.S. Geological Survey Techniques and Methods. 158p. Disponível em: http://dx.doi.org/10.3133/tm6B7.

McCulloch, J.S.G. e Robinson, M. (1993). "History of forest hydrology." Journal of Hydrology, 150, 189-216.

McGuinness, J.L. e Harrold, L. (1971). "Reforestation influences on small waterched streamflow." Water Resources Research, 7(4), 845-852.

Menke, A.B., Carvalho Júnior, O.A., Gomes, R.A.T., Martins, E.S., Oliveira, S.N. (2009). "Análise das Mudanças do Uso Agrícola da Terra a Partir de Dados de Sensoriamento Remoto Multitemporal no Município de Luis Eduardo Magalhães. ” Sociedade e Natureza, 21 (3), 315-326.

Metcalf and Eddy, Inc., (1971). “Storm water management model, Vol. 1-Final report.', EPA, Washington D.C., Estados Unidos.

Miranda, E. E. de; (Coord.). Brasil em Relevo. Campinas: Embrapa Monitoramento por Satélite, 2005. Disponível em: http://www.relevobr.cnpm.embrapa.br.

Moradkhani, H., Sorooshian, S., 2008. "General review of rainfall-runoff modeling: model calibration, data assimilation, and uncertainty analysis”. In: Sorooshian, S. et al., (eds.) Hydrological Modeling and the Water Cycle. Springer Berlin Heidelberg, Berlin, Alemanha. 1-24. 
Moreira, M.C. e Silva, D.D. (2010). Atlas Hidrológico da Bacia Hidrográfica do Rio Grande. Editora Gazeta Santa Cruz, Santa Cruz do Sul, Brasil, 80p.

Nash, J. E. (1957). "The form of the instantaneous unit hydrograph." Hydrological Sciences Bulletin. 3, 114-121.

Neitsch, S.L., Arnold, J.C., Kiniry, J.R. e Williams, J.R. (2011). "Soil and water assessment tool. Theoretical Documentation. Version 2009.” Texas Water Resources Institute Technical Report No 406, Texas A\&M University, Texas, E.U.A., 647p.

Niehoff, D., Fritsch, U. e Bronstert, A. (2002). "Land-use impacts on storm-runoff generation: scenarios of land-use change and simulation of hydrological response in a meso-scale catchment in SW-Germany." Journal of Hydrology, 267, 80-93.

Niu, J., Sivakumar, B. (2014). "Study of runoff response to land use change in the East River basin in South China". Stochastic Environmental Research and Risk Assessment, 28, 857- 865 .

NRCS, Natural Resources Conservation Service. Chapter 7: Hydrologic Soil Groups. In: National Engineering Handbook: Part 630, Hydrology. 2009. Disponível em: <http://directives.sc.egov.usda.gov/>. Acesso em: 25 de outubro de 2014.

Pimentel, M.L., Souza, T.C.L., Távora, G.S.G., Turetta, A.P.D. (2011) “ Mudanças de Uso da Terra e Expansão da Agricultura do Oeste da Bahia. " Boletim de Pesquisa e Desenvolvimento/ Emprapa Solos, Rio de Janeiro, 27p.

Rodriguez, D.A. Tomasella, J. Linhares, C. (2010). "Is the forest conversion to pasture affecting the hydrological response of Amazonian catchments? Signals in the JiParaná Basin.” Hydrological Processes, 24, 1254-1269.

Robinson, M., Gannon, B. e Schuch, M. (1991). “A comparison of the hydrology of moorland under natural conditions, agricultural use and forestry." Hydrological Sciences Journal, 36(6), 565-577.

Rossman, L.A. e Huber, W.C. (2016). National Risk Management Laboratory, "Storm Water Management Model Reference Manual Volume I - Hydrology (Revised)”. Cincinnati, Ohio (EUA).

Sahin, V. e Hall, M.J. (1996). "The Effects of Afforestation and Deforestation on Water Yields." Journal of Hydrology, 178, 293-309. 
Sano, E.E., Santos, C.C.M., Silva, E.M. e Chaves, J.M. (2011). "Fronteira Agrícola do Oeste Baiano: Considerações Sobre os Aspectos Temporais e Ambientais". Geociências, 30(3), 479-489.

Sarmento, L.R. (2010). Análise de Incertezas e Avaliação dos Fatores Influentes no Desempenho de Modelos de Simulação de Bacias Hidrográficas. Tese de Doutorado, Universidade de Brasília, Departamento de Engenharia Civil e Ambiental, Brasília, DF, 241p.

Sartori, A., Lombardi Neto, F., Genovez, A.M. (2005). “Classificação Hidrológica de Solos Brasileiros para a Estimativa da Chuva Excedente com o Método do Serviço de Conservação do Solo dos Estados Unidos Parte 1: Classificação”. Revista Brasileria de Recursos Hídricos, 10 (4), 5-18.

Seibert, J., McDonnell, J.J. (2010). "Land-Cover Impacts on Streamflow: A ChangeDetection Modelling Approach that Incorporates Parameter Uncertainty". Hydrological Sciences Journal, 55 (3), 316-332.

Sharma, M.L., Barron, R.J.W. e Williamson, D.R. (1987). "Soil Water Dynamics of Lateritic Catchments as Affected by Forest Clearing for Pasture." Journal of Hydrology, 94, 29-46.

Shukla, J. e Mintz, Y. (1982). "Influence of Land-Surface Evapotranspiration on the Earth's Climate.” Science, 215(4539), 1498-1501.

Shuttleworth, W.J. (1993). "Evaporation.” In: Handbook of Hydrology, McGraw-Hill, New York, E.U.A., 4.1-4.53.

Silva, L.B. (2003). “Disponibilidade de Água para as Plantas e Evapotranspiração em um Cerrado Denso, um Cerrado Strictu Sensu e uma Pastagem Plantada". Dissertação de Mestrado, Universidade de Brasília, Instituto de Ciências Biológicas, Brasília, DF, 42p.

Silva, B.C., Collischonn, W., Tucci, C.E.M. (2004). "Simulação da Bacia do Rio São Francisco Através do Modelo Hidrológico MGB-IPH”. In: VII Simpósio de Recursos Hídricos do Nordeste, São Luis.

Singh, V.P. Woolhiser, D.A. (2002) Mathematical Modeling of Watershed Hydrology, Journal of Hydrologic Engineering, 7, 270-292. 
Sorooshian, S., Hsu, K., Coppola, E., Tomassetti, B., Verdecchia, M., Visconti, G. (2008) Hydrological Modelling and the Water Cycle. Springer Berlin Heidelberg. Berlin, Alemanha. 291p.

Tang, Q., Oki, T. e Kanae, S. (2006). "A distributed biosphere hydrological model (DBHM) for large river basin.” Annual Journal of Hydraulic Engineering, 50, 37-42.

Tatsch, J.D. (2011). Controle do Uso da Terra no Clima e no Regime Hidrológico da Bacia do Rio Mogi-Guaçu, SP. Tese de Doutorado, Universidade de São Paulo, Instituto de Astronomia, Geofísica e Ciências Atmosféricas, São Paulo, SP, 88p.

Trimble, S.W., Weirich, F.H. e Hoag, B.L. (1987). "Reforestation and the reduction of water yield on the Southern Piedmont since circa 1940”. Water Resources Research, 23(3), 425-437.

Tucci, C.E.M (1998). Modelos Hidrológicos. Universidade/UFRGS/Associação Brasileira de Recursos Hídricos, Porto Alegre, 669p.

Tucci, C.E.M. e Clarke, R.T. (1997). "Impacto das mudanças da cobertura vegetal no escoamento: Revisão.” Revista Brasileira de Recursos Hídricos, 2(1), 135-152.

US Army Corps of Engineers. Hydrologic Engineering Center. (2013) "Hydrologic Modeling System HEC-HMS - User's Manual Version 4.0”. Disponível em http://www.hec.usace.army.mil/software/hec-hms/documentation/HEC-

HMS_Users_Manual_4.0.pdf.

Van Griensven, A., Meixner, T., Grunwald, S., Bishop, T., Diluzio, M. e Srinivasan, R. (2006). "A Global Sensitivity Analisys Tool for the Parameters of Multivariable Catchment Models". Journal of Hydrology. 94, 10-23.

Vrugt, J.A., Braak, C. J., Clark, M., Hyman, J. e Robinson, B. (2008). “Treatment of Input Uncertainty in Hydrologic Modeling: Doing Hydrology Backward with Markov Chain Monte Carlo Simulation”. Water Resources Research. 44, 1-15.

Wheater, H., (2008) "Modelling Hydrological Processes in Arid and Semi-Arid Areas - $\quad$ An Introduction.” In: Sharma, K. D., Sorooshian, S. and Wheater, H. (eds.) Hydrological Modelling in Arid and Semi-Arid Areas. Cambridge University Press, New York. 139. 
White, R., Engelen, G. (2000). "High-resolution integrated modeling of the spatial dynamics of urban and regional systems". Computers, Environment and Urban Systems, 24, 383-400.

Wijesekaraa, G.N., Gupta,A., Valeoc C., Hasbanid J.G. e Marceau D.J. (2012). “Assessing the impact of future land-use changes on hydrological processes in the Elbow River watershed in southern Alberta, Canada". Journal of Hydrology, 412, 220-232.

Woolhiser, D.A., Smith, R.E., Goodrich, D.C. (1990) "KINEROS: A kinematic runoff and erosion model: Documentation and user manual". Rep. No. ARS-77, USDA, Washington, D.C.

Xavier, L.N.R. (2002). Análise da Incerteza Causada pela Representação da Precipitação no Modelo Topmodel. Dissertação de Mestrado, Universidade Federal do Rio de Janeiro, Instituto Alberto Luiz Coimbra de Pós-Graduação e Pesquisa de Engenharia, Rio de Janeiro, RJ, 124p.

Yapo, P.O., Gupta, H.V. e Sorooshian, S. (1998), "Multi-objective global optimization for hydrologic models". Journal of Hydrology, 204, 83-97.

Zhang, L., Dawes, W.R. e Walker, G.R. (1999). "Predicting the effect of vegetation changes on catchment average water balance". Cooperative Research Centre for Catchment Hydrology Thecnical Report 99/12, CSIRO Land and Water, Camberra, Austrália, 42p.

Zhang, L., Dawes, W.R. e Walker, G.R. (2001). "Response of mean annual evapotranspiration to vegetation changes at catchment scale." Water Resources Research, 37(3), 701-708. 